\title{
POTENCIAL DE ADAPTAÇÃO DOS MUNICÍPIOS PAULISTAS AOS EFEITOS DAS MUDANÇAS \\ CLIMÁTICAS: Aplicação do Índice de Adaptação Urbana no Estado de São Paulo
}




\section{EDUARDO ALVES NEDER}

POTENCIAL DE ADAPTAÇÃO DOS MUNICÍPIOS PAULISTAS AOS EFEITOS DAS MUDANÇAS CLIMÁTICAS: Aplicação do Índice de Adaptação Urbana no Estado de São Paulo.

Dissertação apresentada ao Programa de PósGraduação Ambiente, Saúde e Sustentabilidade, da Faculdade de Saúde Pública, da Universidade de São Paulo, para a obtenção do título de Mestre em Ciências.

Orientador: Prof. Dr. Arlindo Philippi Junior

Coorientadora: Profa. Dra. Gabriela Marques Di Giulio

Versão Revisada

\section{São Paulo}


É expressamente proibida a comercialização deste documento, tanto na sua forma impressa como eletrônica. Sua reprodução, total ou parcial, é permitida exclusivamente para fins acadêmicos e científicos, desde que na reprodução figure a identificação do autor, título, instituição e ano da dissertação.

Catalogação da Publicação

Serviço de Documentação

Faculdade de Saúde Pública da Universidade de São Paulo

Neder, Eduardo Alves

POTENCIAL DE ADAPTAÇÃO DOS MUNICÍPIOS PAULISTAS AOS EFEITOS DAS MUDANÇAS CLIMÁTICAS: Aplicação do Índice de Adaptação Urbana no Estado de São Paulo, Arlindo Phillipi Jr e Gabriela Marques Di Giulio - São Paulo - 2019.

$178 f$.

Dissertacão (Mestrado) - Universidade de São Paulo, 2019 
NEDER, Eduardo Alves, POTENCIAL DE ADAPTAÇÃO DOS MUNICÍPIOS PAULISTAS AOS EFEITOS DAS MUDANÇAS CLIMÁTICAS: Aplicação do Índice de Adaptação Urbana no Estado de São Paulo - Faculdade de Saúde Pública da Universidade de São Paulo, São Paulo, 2019. 
Janus

Universidade de São Paulo

\section{ATA DE DEFESA}

Aluno: 6139 - $8635701-2$ / Página 1 de 1

Ata de defesa de Dissertação do(a) Senhor(a) Eduardo Alves Neder no Programa: Mestrado Profissional Ambiente, Saúde $\epsilon$ Sustentabilidade, do(a) Faculdade de Saúde Pública da Universidade de São Paulo.

Aos 12 dias do mês de junho de 2019, no(a) realizou-se a Defesa da Dissertação do(a) Senhor(a) Eduardo Alves Neder, apresentada para a obtenção do título de Mestre intitulada:

"POTENCIAL DE ADAPTAÇÃO DOS MUNICÍPIOS PAULISTAS AOS EFEITOS DAS MUDANÇAS CLIMÁTICAS: Aplicação do Índice de Adaptação Urbana no Estado de São Paulo"

Após declarada aberta a sessão, o(a) Sr(a) Presidente passa a palavra ao candidato para exposição e a seguir aos examinadores para as devidas arguições que se desenvolvem nos termos regimentais. Em seguida, a Comissão Julgadora proclama o resultado:

$\begin{array}{llll}\text { Nome dos Participantes da Banca } & \text { Função } & \text { Sigla da CPG Resultado } \\ \text { Arlindo Philippi Junior } & \text { Presidente } & \text { FSP - USP } \\ \text { Tadeu Fabricio Malheiros } & \text { Titular } & \text { EESC - USP } \\ \text { Ivan Carlos Maglio } & \text { Titular } & \text { Externo } \\ \text { Edmilson Dias de Freitas } & \text { Suplente } & \text { IAG - USP }\end{array}$

Resultado Final: ARROVIAO

Eu, Carlos Alberto da Silva Santos 1 a lavei a presente ata, que assino juntamente com os(as) Senhores(as). Săo Pàulo, aos 12 dias do mês de junho de 2019 .

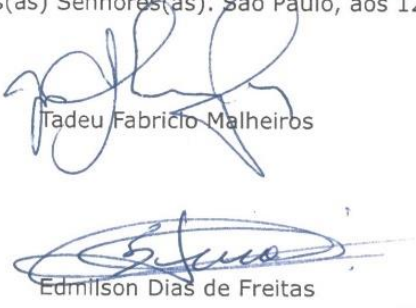

Arlindo Phitippi Junior Presidente da Comissã Julgadora

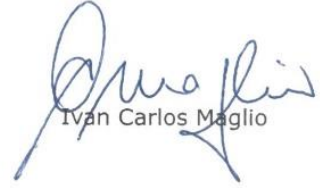

* Obs: Se o candidato for reprovado por algum dos membros, o pkeenchimgnto do parecer é obrigatório. 


\section{AGRADECIMENTOS}

Agradeço a todos que contribuíram direta ou indiretamente para a elaboração desta dissertação, incluindo as empresas onde trabalhei ao longo deste período, que compreenderam a importância deste processo para o meu crescimento pessoal e profissional.

Ao meu orientador Prof. Dr. Arlindo Philippi Jr. pelas importantes reuniões e conversas que tivemos ao longo deste período e por suas colaborações certeiras para o bom andamento e evolução da minha pesquisa.

À minha coorientadora Prof. Dra. Gabriela Marques Di Giulio por toda atenção dispendida e incentivo no desenvolvimento (e alterações) de minha pesquisa, resultando em um processo mais instigante e um produto final que acredito ser de grande valia para a evolução do tema no âmbito local.

Aos grupos de pesquisa "Saúde - vulnerabilidades e adaptação no contexto da saúde ambiental" e "Cidades, Vulnerabilidades e Mudanças Climáticas: uma abordagem integrada e interdisciplinar para análise de ações e de capacidade adaptativa (CiAdapta)" pela possibilidade de participação e trocas realizadas, em especial ao Prof. Dr. Roger Torres, pelas importantes trocas ao longo deste processo.

À amiga Rita de Cássia Ogera, grande incentivadora desde o início de minha vida profissional e que vem me acompanhando desde então.

Ao Dr. Ivan Carlos Maglio pelo exemplo pessoal e profissional, cuja atuação nas áreas ambiental e de planejamento influenciou o rumo das minhas atividades profissionais.

Aos Prof. Dr. Tercio Ambrizzi, Prof. Dr. Tadeu Fabricio Malheiros, Prof. Dr. Edmilson Dias de Freitas pela honra de terem aceitado o convite para participar de minha banca de avaliação.

Aos colegas de mestrado e à toda equipe da Faculdade de Saúde Pública da USP que foram uma importante parte desse processo.

À minha família pelo incentivo e compreensão, em especial à minha esposa Maíra pelas conversas e aprendizados, essenciais para que eu superasse dificuldades técnicas e aflições pessoais ao longo da elaboração da minha dissertação. 


\section{RESUMO}

NEDER, E. A. POTENCIAL DE ADAPTAÇÃO dOS MUNICÍPIOS PAULISTAS AOS EFEITOS DAS MUDANÇAS CLIMÁTICAS: Aplicação do Índice de Adaptação Urbana no Estado de São Paulo.

2019. 178 f. Dissertação (Mestrado) - Faculdade de Saúde Pública, Universidade de São Paulo, São Paulo, 2019.

Pesquisadores apontam que a ação antrópica é responsável pelo aquecimento de aproximadamente $1^{\circ} \mathrm{C}$ na temperatura do planeta e que, se esse ritmo for mantido, a meta do Acordo de Paris de restringir o aquecimento global em $1,5^{\circ} \mathrm{C}$ deverá ser ultrapassada por volta do ano de 2040. Os impactos deste aquecimento afetarão com maior intensidade populações social, ambiental e economicamente mais vulneráveis, trazendo especiais desafios para as cidades, que concentrarão $66 \%$ da população mundial até a metade do século. No Brasil, alguns fatores dificultam a ampliação da capacidade de adaptação dos governos locais aos efeitos das mudanças climáticas. Dentre estes fatores, destacam-se uma taxa de urbanização acima da média mundial, a desigualdade social, a maneira que as cidades foram planejadas e o baixo domínio da questão climática pelos gestores públicos. Para superar estes problemas, diversos instrumentos de planejamento poderiam ser implantados ou aprimorados, entretanto, muitos municípios necessitam de auxílio para sua tomada de decisão. Nesse sentido, o Índice de Adaptação Urbana (UAI) propõe uma sistematização de indicadores, que verifica a existência ou não de instrumentos de desenvolvimento urbano e de políticas públicas, vinculados às temáticas de habitação, mobilidade urbana, agricultura sustentável, gestão ambiental e resposta aos impactos climáticos que visam a ampliação do potencial adaptativo municipal. Este projeto discute os resultados da aplicação do UAI nos 645 municípios do Estado de São Paulo, fornecendo um diagnóstico do potencial adaptativo dos municípios paulistas. A correlação desses resultados com as características socioambientais de cada região poderá ser utilizada para subsidiar um planejamento local e regional mais adaptado aos efeitos das mudanças climáticas.

Palavras-chave: Adaptação, Governos Locais, Índice de Adaptação Urbana, Estado de São Paulo. 


\section{ABSTRACT}

\section{NEDER, E. A. ADAPTIVE POTENTIAL OF SÃO PAULO'S MUNICIPALITIES TO CLIMATE CHANGE}

EFFECTS: Application of the Urban Adaptation Index in the State of São Paulo. 2019. 178p.

Dissertação (Mestrado) - Faculdade de Saúde Pública, Universidade de São Paulo, São Paulo, 2019.

Researchers indicate that anthropic action is responsible for the warming of approximately $1^{\circ} \mathrm{C}$ in the planet's temperature and that, if this pace is maintained, the goal of the Paris Agreement to restrict global warming by $1.5^{\circ} \mathrm{C}$ should be exceeded by the year 2040. The impacts of this warming will affect with greater intensity social, environmental and economically more vulnerable populations, bringing special challenges to cities, which will concentrate $66 \%$ of the world's population by the middle of the century. In Brazil, some factors make it difficult for local governments to increase their capacity to adapt to the effects of climate change. Among these factors, there is a rate of urbanization above the world average, social inequality, the way cities have been planned, and the low level of climate issues by public administrators. In order to overcome these problems, several planning instruments could be implemented or improved, however, many municipalities need assistance for their decision-making. In this sense, the Urban Adaptation Index (UAI) proposes a systematization of indicators, which verifies the existence or not of urban development and public policy instruments, linked to the themes of housing, urban mobility, sustainable agriculture, environmental management and response to climate impacts that aim to increase the municipal adaptive potential. This project discusses the results of the application of UAI in the 645 municipalities of the State of São Paulo, providing a diagnosis on the adaptive potential of these cities. The correlation of the results with the socio-environmental characteristics of each region can be used to support local and regional planning more adapted to the effects of climate change.

Keywords: Adaptation, Local Governments, Urban Adaptation Index, State of São Paulo. 


\section{LISTA DE SIGLAS E ABREVIATURAS}

AAE - Avaliação Ambiental Estratégica

AGEMCAMP - Agência Metropolitana de Campinas

AIA - Avaliação de Impacto Ambiental

AbE - Adaptação Baseada em Ecossistemas

APP - Área de Preservação Permanente

AR - Relatório de Avaliação (Assessment Report)

COP - Conferência das Partes

GEE - Gases de Efeito Estufa

GT - Grupo de Trabalho

IDH - Índice de Desenvolvimento Humano

IPCC - Painel Intergovernamental de Mudanças Climáticas (Intergovenmental Panel on Climate Change)

MAPA - Ministério da Agricultura, Pecuária e Abastecimento

MC - Mudanças Climáticas

MMA - Ministério do Meio Ambiente

MMP - Macrometrópole Paulista

NDC - Contribuições Nacionalmente Determinadas

ODS - Objetivos do Desenvolvimento Sustentável

PD - Plano Diretor

PEMC - Política Estadual de Mudanças Climáticas (São Paulo)

PIB - Produto Interno Bruto

PNA - Plano Nacional de Adaptação

PNMC - Política Nacional sobre a Mudança do Clima

PROCLIMA - Programa Estadual de Mudanças Climáticas do Estado de São Paulo

PROZONESP - Programa Estadual de Proteção à Camada de Ozônio

RL - Reserva Legal

RQA - Relatório de Qualidade Ambiental

SIG - Sistema de Informações Geográficas

SMA/ CPLA - Secretaria de Meio Ambiente / Coordenadoria de Planejamento Ambiental SSA - Secretaria de Agricultura e Abastecimento

TI - Terra Indígena

UC - Unidade de Conservação

UNFCCC - Convenção das Nações Unidas sobre Mudanças Climáticas (Framework Convention on Climate Change)

ZA - Zoneamento Ambiental 


\section{LISTA DE ILUSTRAÇÕES}

Figura 1 - Curva do aquecimento global frente ao período pré-industrial ................................. 29

Figura 2 - Exemplos de Adaptação e Adaptação Transformacional............................................. 34

Figura 3 - Evolução da densidade populacional dos municípios paulistas e sua projeção para os

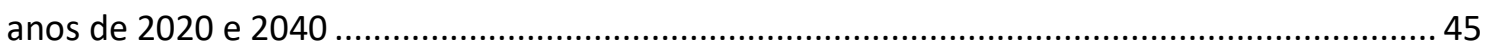

Figura 4 - Remanescentes vegetais do Estado de São Paulo - 2008/2009................................ 46

Figura 5 - Evolução das emissões de $\mathrm{CO}_{2}$ no estado de São Paulo (milhões de toneladas) ......... 48

Figura 6 - Evolução do percentual de população residente em áreas urbanas ........................... 52

Figura 7 - Percentual da população urbana por município no Estado de São Paulo ................... 53

Figura 8 - Correlações das Mudanças Climáticas com a Saúde................................................ 55

Figura 9 - Proporção de municípios com aglomerados subnormais no Brasil em 2017 ............. 58

Figura 10 - Percentual de municípios brasileiros com Plano Diretor - 2005/2015 ...................... 64

Figura 11 - Projeto de Water Square "De Urbanisten" - Roterdã .......................................... 73

Figura 12 - Carta Geotécnica Regional de Aptidão à Urbanização - Síntese do Grande ABC ..... 77

Figura 13 - Interação dos componentes urbano-ambientais da Matriz PEIR .............................. 86

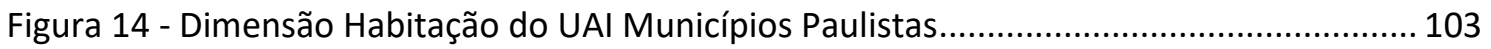

Figura 15 - Densidade Demográfica do Estado de São Paulo - 2017 .......................................... 104

Figura 16 - Dimensão Mobilidade Urbana do UAI Municípios Paulistas.................................... 108

Figura 17 - Distribuição dos Estabelecimentos Agropecuários do Estado de São Paulo - 2017109

Figura 18 - Dimensão Agricultura Sustentável do UAI Municípios Paulistas ............................ 112

Figura 19 - Dimensão Gestão Ambiental do UAI Municípios Paulistas ..................................... 115

Figura 20 - Percentual de cobertura vegetal nativa por município - 2008/2009....................... 116

Figura 21 - Taxa de mortalidade por doenças relacionadas ao saneamento ambiental

inadequado (DRSAI) no Estado de São Paulo em 2016 ....................................................... 117

Figura 22 - Taxa de mortalidade de idosos por doenças do aparelho respiratório no Estado de

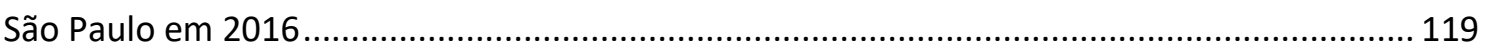

Figura 23 - Dimensão Resposta aos Impactos Climáticos do UAI Municípios Paulistas ............ 121

Figura 24 - Acidentes relacionados a fenômenos Geológicos (A), Hidrológicos(B),

Meteorológicos (C) e Climatológicos (D) entre 1997 e 2016

Figura 25 - Distribuição dos municípios com mapeamento de Áreas de Risco (A), Planos

Municipais de Redução de Risco (B), Setorização de Ricos Alto e Muito Alto (c) e Carta de

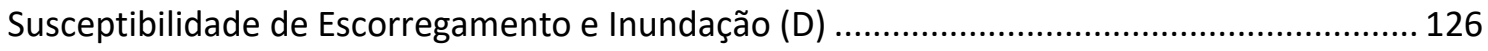

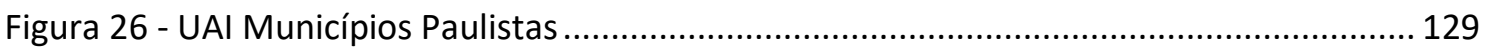

Figura 27 - Regiões Geográficas Intermediárias do Estado de São Paulo - IBGE ....................... 130

Figura 28 - Aglomerações Urbanas e Regiões Metropolitanas do Estado de São Paulo - 2018131

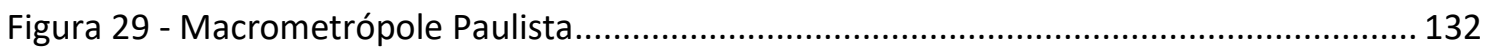

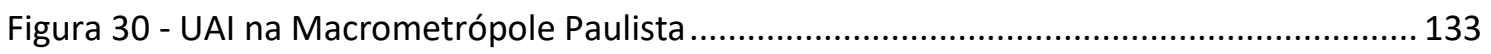

Figura 31 - Distribuição da Riqueza por Município em 2014 ..................................................... 134 


\section{LISTA DE GRÁFICOS}

Gráfico 1 - Número de municípios com instrumentos da Dimensão de Habitação 105

Gráfico 2 - Número de municípios com instrumentos da Dimensão de Mobilidade Urbana... 107

Gráfico 3 - Número de municípios com instrumentos da Dimensão Agricultura Sustentável 110

Gráfico 4 - Número de municípios com instrumentos da Dimensão de Gestão Ambiental ..... 114

Gráfico 5 - Número de municípios com instrumentos da Dimensão de Resposta aos Impactos

Climáticos

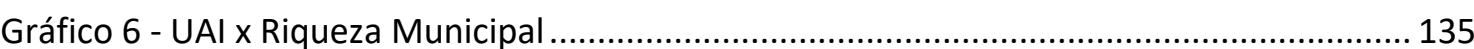

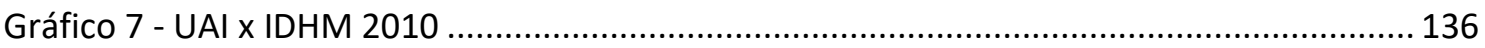

\section{LISTA DE QUADROS}

Quadro 1 - Dimensões e indicadores do UAI 20

Quadro 2 - Riscos e medidas de adaptação para as Américas Central e do Sul .......................... 32

Quadro 3 - Exemplos de medidas de adaptação por tipo de abordagem ................................... 35

Quadro 4 - Estratégias de Adaptação no Planejamento Urbano ................................................. 71

Quadro 5 - Medidas para a ampliação da resiliência em âmbito local ........................................ 79

Quadro 6 - Indicadores de Habitação frente às Diretrizes Setoriais do PNA ................................ 93

Quadro 7 - Indicadores de Mobilidade Urbana frente às Diretrizes Setoriais do PNA ................ 94

Quadro 8 - Indicadores de Agricultura Sustentável frente às Diretrizes Setoriais do PNA......... 95

Quadro 9 - Indicadores de Gestão Ambiental frente às Diretrizes Setoriais do PNA .................. 97

Quadro 10 - Indicadores de Resposta aos Impactos Climáticos frente às Diretrizes Setoriais do

PNA.

\section{LISTA DE TABELAS}

Tabela 1- Exemplos de adaptação em diferentes regiões 32

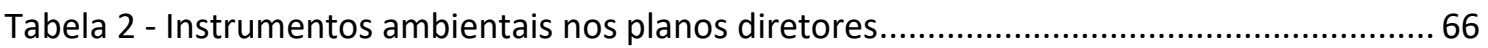

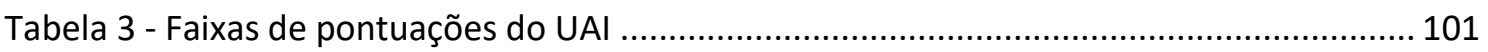

Tabela 4 - Distribuição dos municípios paulistas por faixas do UAI .......................................... 128 


\section{Sumário}

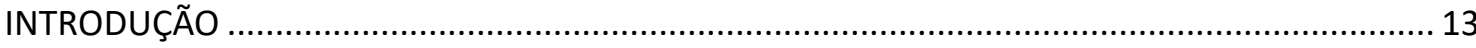

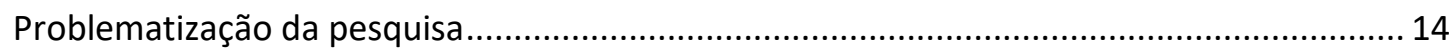

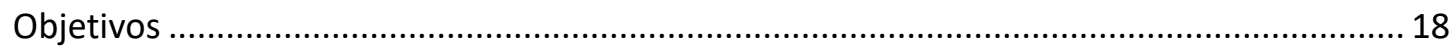

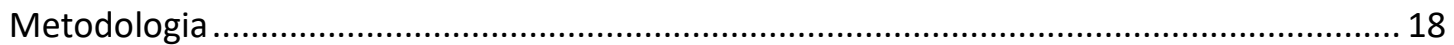

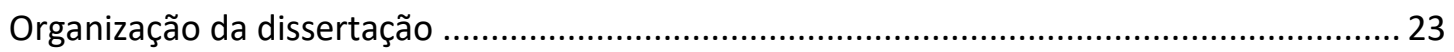

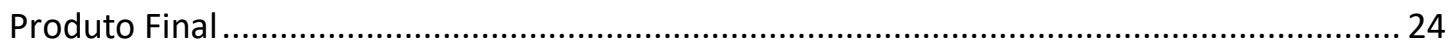

1 MITIGAÇÃO E ADAPTAÇÃO ÀS MUDANÇAS CLIMÁTICAS: DO GLOBAL AO LOCAL .............. 25

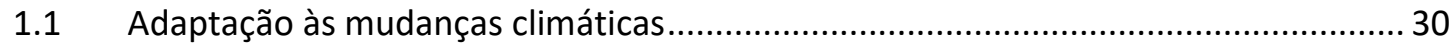

1.2 Mudanças climáticas no contexto brasileiro .............................................................. 38

1.2.1 Impactos na Região Sudeste do Brasil.................................................................. 41

1.2.2 Evolução do tema no Estado de São Paulo .............................................................. 43

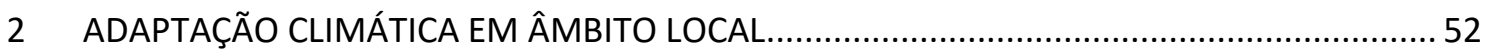

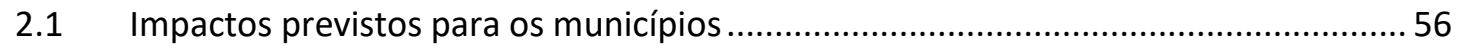

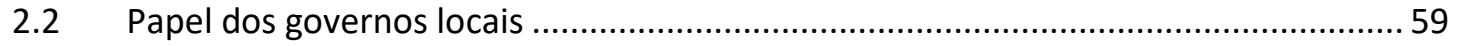

2.3 Planejamento urbano e a necessidade da sustentabilidade ambiental ......................61 61

2.4 Intervenções urbanas e políticas públicas adaptativas................................................ 69

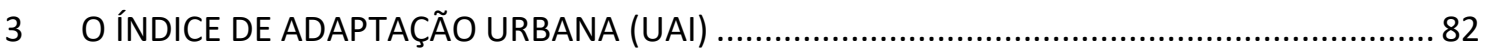

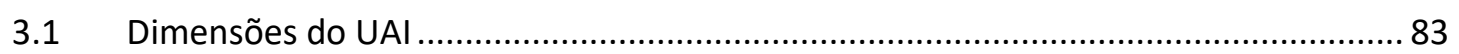

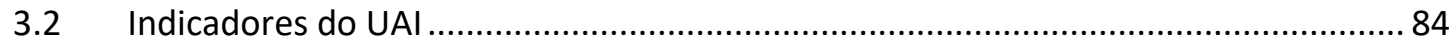

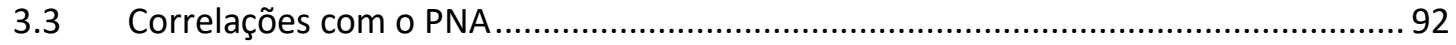

4 APLIAÇÃO DO UAI NOS MUNICÍPIOS PAULISTAS PARA O ANO DE 2017 .......................... 101

4.1 Dimensão de Habitação .............................................................................................. 102

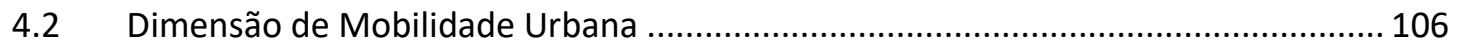

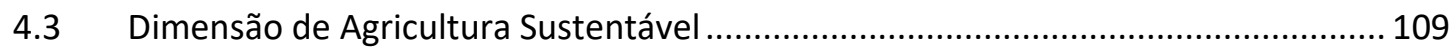

4.4 Dimensão de Gestão Ambiental......................................................................... 113

4.5 Dimensão de Resposta aos Impactos Climáticos ....................................................... 119

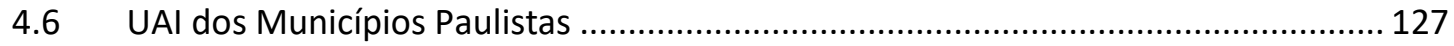

5 CONCLUSÕES

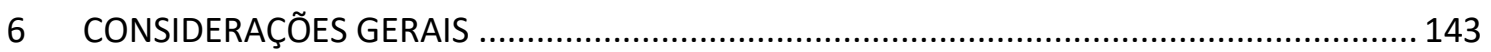

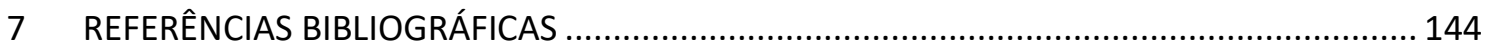

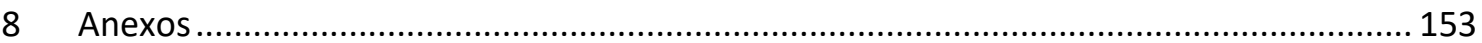

8.1 Resultados dos Indicadores UAI Municípios Paulistas ............................................. 153 


\section{INTRODUÇÃO}

A ocorrência cada vez mais constante de eventos climáticos extremos como enchentes, secas prolongadas, ondas de calor, tufões e tornados, é observada em diversas partes do planeta. A publicação do Relatório Especial sobre Gestão dos Riscos de Eventos Extremos e Desastres para o Avanço da Adaptação às Mudanças Climáticas pelo IPCC no ano de 2012 (FIELD et al., 2012) teve um importante papel ao reforçar as ligações entre o aumento da frequência, intensidade, distribuição espacial, duração e temporalidade desses tipos de acontecimentos com as mudanças climáticas.

Mesmo com a existência de movimentos de negacionistas do aquecimento global, motivados por convicção ou por conveniência, a agenda climática está cada vez mais presente na pauta dos governos nacionais. Segundo o IPCC (2018) as atividades humanas já causaram o aumento de aproximadamente $1{ }^{\circ} \mathrm{C}$ na temperatura global frente às médias observadas no período pré-industrial e, se esse ritmo de aumento for mantido, o aquecimento da terra deverá atingir o nível de $1,5^{\circ} \mathrm{C}$ entre os anos de 2030 e 2052 . Como um agravante, segundo este mesmo documento, o aquecimento poderá ser maior em regiões ou épocas diferentes, inclusive, atingindo níveis duas ou três vezes maiores no Ártico (IPCC, 2018).

O Acordo de Paris passou a vigorar em 2016 e tem como meta restringir a ampliação da temperatura global bem abaixo dos $2^{\circ} \mathrm{C}$, tentando limitar este aumento à $1,5^{\circ} \mathrm{C}$ acima dos níveis pré-industriais. Ainda que as previsões indiquem que os efeitos do aumento da temperatura global em $1,5^{\circ} \mathrm{C}$ serão menos catastróficos do que em temperaturas maiores, ele já ocasionará impactos como a ocorrência de precipitações extremas e a ampliação da frequência e intensidade de dias e noites quentes. Além disso, é prevista a ocorrência de mais enchentes e ciclones tropicais relacionados a fortes precipitações, assim como a ampliação de eventos de secas e déficits de precipitação em algumas regiões (IPCC, 2018).

Pesquisadores confirmam que as atividades antrópicas têm alterado o clima do planeta de uma maneira a ampliar os riscos em cidades. Os efeitos sobre essas áreas deverão ser mais devastadores, apresentando especial correlação com a produção de ilhas de calor, redução da qualidade do ar e a aceleração do escoamento superficial das águas pluviais (MONZONI et al., 2009; NOBRE et al., 2011; PACHAURI; MEYER, 2014; ROSENZWEIG et al., 2015; RIBEIRO; SANTOS, 2016; HOEGH-GULDBERG et al., 2018). Segundo a Nova Agenda Urbana do Habitat III, a forma que as cidades são planejadas e geridas causam impactos diretos sobre a sua sustentabilidade e resiliência, e as características dos centros urbanos podem torná-los, e seus habitantes, mais vulneráveis aos impactos adversos das mudanças climáticas (ONU, 2016).

Dessa forma, as cidades deverão se preparar para enfrentar uma maior frequência de eventos climáticos extremos e situações de calamidade pública, afetando especialmente a 
saúde e segurança das populações que não têm acesso a serviços e infraestruturas essenciais (FIELD et al., 2014). Estas situações exigirão ações específicas dos governos locais com vistas a ampliar a capacidade de adaptação de sua população, forçando os tomadores de decisão a aplicar medidas diretas e indiretas que reduzam a vulnerabilidade socioambiental e climática dos habitantes (ROSENZWEIG et al., 2015; CONINCK et al., 2018).

A presente dissertação foi elaborada no âmbito do Programa de Mestrado de Profissional em Ambiente, Saúde e Sustentabilidade da Faculdade de Saúde Pública da Universidade de São Paulo. Considera-se que a característica multidisciplinar dos efeitos das mudanças climáticas no nível local possibilitou uma análise que abrangesse as diferentes interfaces entre as temáticas propostas pelo Programa. O desenvolvimento deste trabalho se deu através do envolvimento do autor com dois grupos de pesquisa vinculados ao Núcleo de Apoio à Pesquisa - Mudanças Climáticas da Universidade de São Paulo, os Subprojetos "Saúde - vulnerabilidades e adaptação no contexto da saúde ambiental" e "Cidades, Vulnerabilidades e Mudanças Climáticas: uma abordagem integrada e interdisciplinar para análise de ações e de capacidade adaptativa (CiAdapta)". Espera-se que os resultados obtidos auxiliem a continuação das pesquisas em andamento, principalmente no tocante aos desafios do planejamento local frente às alterações climáticas e as suas relações com a qualidade de vida da sociedade.

\section{Problematização da pesquisa}

Apesar da importância das cidades na agenda da sustentabilidade neste século 21, ainda faltam no Brasil elementos mandatórios para a ação dos municípios para a redução das suas emissões de Gases de Efeito Estufa (GEE) e para a implantação de medidas de adaptação. A Política Nacional de Mudanças Climáticas (PNMC)(BRASIL, 2009), em vigência desde 2009, tem como uma de suas diretrizes o "estímulo e o apoio à participação dos governos federal, estadual, distrital e municipal, assim como do setor produtivo, do meio acadêmico e da sociedade civil organizada, no desenvolvimento e na execução de políticas, planos, programas e ações relacionados à mudança do clima" (BRASIL, 2009), contudo, não há nenhuma obrigação para que estes entes federativos realizem tais medidas.

Frente à temática da mitigação que apresenta marcos importantes desde a década dos anos 1990, a adaptação só recebeu o mesmo grau de importância nas discussões internacionais durante a COP16, em 2010, com a negociação do acordo de Cancun (RODRIGUES FILHO et al., 2016; UNFCCC, 2019a). No Brasil, o Plano Nacional de Adaptação à Mudança do Clima (PNA) só foi aprovado em 2016 (BRASIL - MMA, 2016a), apresentando 11 (onze) estratégias setoriais e temáticas a serem aplicadas para a promoção da capacidade de adaptação dos entes federativos e para a redução dos riscos 
relacionados à mudanças climáticas, ainda enfrentando dificuldades para a sua incorporação, especialmente nos centros urbanos (DI GIULIO et al., 2016).

A adaptação é o conjunto de ações que a sociedade pode realizar para minimizar os impactos, ou se aproveitar dos benefícios, relacionados às condições climáticas atuais ou previstas para o futuro. A capacidade adaptativa de um sistema está relacionada ao quanto ele está preparado para lidar com os efeitos das alterações climática, podendo ser ampliada ou reduzida através de ações individuais ou por políticas públicas. Caso este sistema consiga absorver estas alterações e manter o seu funcionamento original, ele será considerado como um sistema resiliente (THE WORD BANK, 2011; IPCC, 2014).

Compreendendo o importante papel que as cidades possuem no enfrentamento das mudanças climáticas, seja na implementação de medidas de adaptação como na mitigação das emissões de gases de efeito estufa (ROSENZWEIG et al., 2015), um dos objetivos da estratégia de cidades do PNA é o fornecimento de subsídios para que os governos locais considerem a questão climática durante a formulação de suas políticas de planejamento e desenvolvimento urbano. Esta ação é fundamental uma vez que as cidades enfrentam obstáculos técnicos e financeiros que dificultam a elaboração de instrumentos específicos como estratégias ou planos de adaptação (MARGULIS, 2017).

Uma vasta literatura se debruça sobre as dificuldades e barreiras que as cidades e os governos locais ainda encontram para avançar na agenda climática. Parte desses desafios está relacionada às dificuldades dos governos locais em utilizar e acessar informações sobre as mudanças climáticas e a capacidade das cidades em se adaptar. As incertezas e controvérsias dos efeitos das mudanças climáticas, as diferentes percepções de risco frente a estes impactos, o uso da linguagem técnica e o distanciamento entre os pesquisadores e os tomadores de decisão são barreiras a serem ultrapassadas para a ampliação da capacidade adaptativa em nível local(DI GIULIO et al., 2016). Além disso, são poucos os municípios com potencial para obtenção de crédito no mercado internacional, e, dessa forma, a maioria dos municípios do mundo dependem de recursos próprios ou de repasses de outras esferas de governo (federal ou estadual) para viabilizar projetos em respostas aos impactos das mudanças climáticas, dificultado a sustentação desses projetos a longo prazo e a ampliação da escala de suas ações (ICLEI, 2016). Esta situação é ainda mais grave em municípios de pequeno porte onde adaptação climática entra como mais uma temática em uma complexa agenda de prioridades, competindo com outras temáticas urgentes como a saúde, segurança e educação (MARGULIS, 2017).

Dentre as diferentes abordagens para a adaptação às mudanças climáticas, dois tipos se destacam; uma marcada por um comprometimento mais específico do poder público com a questão, a Abordagem Dedicada (Dedicated Approach), e uma abordagem mais indireta e abrangente, na qual os resultados não se relacionam somente com a temática da adaptação, sendo denominada como Abordagem Transversal (Mainstreaming Approach) (UITTENBROEK et al., 2013, 2014). Um exemplo de Abordagem Dedicada para 
municípios é a elaboração de estratégias ou políticas específicas focadas em mudanças climáticas, incluindo as de mitigação e as mais centradas na adaptação, o que exige do município vontade política, recursos, objetivos e uma distribuição formal de responsabilidades para que as metas propostas sejam alcançadas (UITTENBROEK et al., 2013).

$\mathrm{Na}$ outra direção, pode-se adotar a Abordagem Transversal, a qual permite que os tomadores de decisão incluam medidas de resposta aos efeitos das mudanças climáticas através em outras políticas e processos, podendo influenciar na redução da vulnerabilidade de locais e populações aos efeitos das mudanças climáticas, inclusive para situações onde o discurso climático não tem a força necessária ou quando as mudanças climáticas são percebidas como um problema menor(DI GIULIO; et al., 2017; RUNHAAR et al., 2017; DI GIULIO; BEDRAN-MARTINS; VASCONCELLOS; RIBEIRO, 2017)

Uma vez que os efeitos das mudanças climáticas serão maiores sobre populações social, ambiental e economicamente mais vulneráveis (THE WORD BANK, 2011; FIELD et al., 2014; HOEGH-GULDBERG et al., 2018), existem diferentes maneiras de se enfrentar os impactos climáticos e ampliar a capacidade de adaptação de sistemas. Uma opção é a atuação focada nos impactos previstos, aplicando medidas para a antecipação, identificação e resposta aos riscos. Este conjunto de medidas são relacionadas com a capacidade específica de atuação frente às alterações climáticas. Por outro lado, como a redução da situação de vulnerabilidade socioambiental de uma comunidade também reduz os riscos a que ela está submetida, a capacidade genérica surge como uma segunda opção de atuação, sendo composta pelos fatores sociais, econômicos e políticos que ampliam ou reduzem a vulnerabilidade de uma determinada população(DI GIULIO et al., 2016).

Levando em consideração que menos de $1 \%$ dos municípios brasileiros possuem iniciativas climáticas (MARGULIS, 2017), das quais a maioria ainda tem como foco exclusivo a mitigação, é preciso investigar se os municípios estão criando outros instrumentos ou aplicando intervenções que os auxiliem a ampliar suas capacidades adaptativas. Neste sentido, e com os objetivos de sistematizar estas ações e incentivar as atuações de outros municípios, foi elaborado, em conjunto com pesquisadores do Protejo CiAdapta $^{1}$, o Índice de Adaptação Urbana (Urban Adaptation Index - UAI). Este índice agrega informações sobre a existência ou não de instrumentos de desenvolvimento urbano

\footnotetext{
${ }^{1}$ O projeto "Cidades, Vulnerabilidade e Mudanças Climáticas: uma abordagem integrada e interdisciplinar para análise de ações e de capacidade adaptativa" - CiAdapta é coordenado pela Profa. Gabriela Marques Di Giulio (FSP-USP), financiado pelo CNPq (Proc. 446032/2015-8) e conta com a participação de uma rede de pesquisadores de oito universidades públicas (USP, Unifei, Unicamp, UFAM, UFRGS, UFRN, UFES, UFPR) e University of Michigan. O projeto envolve um estudo sobre como grandes cidades brasileiras vêm incorporando a questão climática em suas agendas e políticas públicas e que fatores influenciam em suas capacidades adaptativas. Link do projeto: https://ciadapta.webnode.com/
} 
e políticas públicas que auxiliariam a ampliação do potencial adaptativo municipal no contexto brasileiro. Para sua elaboração, foram consideradas dimensões que contemplam proposições e intervenções relacionadas à capacidade adaptativa genérica do município em ampliar o seu potencial de adaptação, podendo resultar em benefícios indiretos frente aos impactos das mudanças climáticas. Nesse sentido, e em consonância com a literatura analisada, quatro dimensões foram definidas: Habitação, Mobilidade Urbana, Agricultura Sustentável e Gestão Ambiental do território. Complementarmente, buscou-se integrar ao índice uma dimensão que considera proposições e intervenções mais ajustadas à capacidade específica do município, atuando na minimização dos impactos diretos dos eventos climáticos (DI GIULIO et al., 2016). Assim, a quinta dimensão integrada ao índice refere-se à Resposta aos Impactos Climáticos.

A definição destas 05 (cinco) dimensões foi ajustada durante o processo de busca indicadores e fontes de informações confiáveis sobre os municípios brasileiros. Para tanto, os pesquisadores do projeto CiAdapta selecionaram 26 (vinte e seis) indicadores derivados do Relatório Perfil dos Municípios Brasileiros, lançado pelo Instituto Brasileiro de Geografia e Estatística - IBGE, em 2017 (IBGE, 2018a), com o foco em informações que demonstrassem o potencial institucional dos municípios para se adaptar às mudanças do clima. Esses indicadores foram posteriormente correlacionados e validados com as diretrizes propostas pelo Plano Nacional de Adaptação(BRASIL - MMA, 2016a), informações que são apresentadas nos Quadros 6 a 10 do Item 3.3 deste documento.

Nesta dissertação, a partir da elaboração do UAI, propõe-se sua aplicação para os 645 municípios do Estado de São Paulo, com o objetivo de obter um retrato da situação atual dos municípios do estado mais rico e populoso da federação quanto à estrutura institucional e legal vigente e sensível à capacidade de adaptação às mudanças do clima. As análises realizadas e a apresentação gráfica dos resultados obtidos, inclusive para cada uma das dimensões que compõem o UAI, fornecem um diagnóstico e indicações de setores onde os municípios e governos regionais poderão concentrar os seus esforços para a ampliação do potencial adaptativo local.

Espera-se que este índice funcione como uma ferramenta para subsidiar a criação de políticas públicas e a alocação de esforços, seja na esfera regional ou local, auxiliando na preparação dos municípios para os efeitos das mudanças climáticas. Entretanto, ressaltase que a seleção das ações a serem realizadas pelos municípios deverão ser precedidas de uma análise dos instrumentos mais adequados para as demandas e características de cada região, de modo a permitir um desenvolvimento mais sustentável e que traga maior qualidade de vida para seus habitantes. 


\section{Objetivos}

Os objetivos desta dissertação foram definidos da seguinte forma:

Objetivo Geral: $\quad$ Avaliar o potencial adaptativo institucional dos municípios paulistas frente aos efeitos das mudanças climáticas.

Objetivo Específico 01: Identificar, por meio de revisão de literatura, os principais impactos das mudanças climáticas nos centros urbanos e os fatores que influenciam a capacidade adaptativa dos municípios.

Objetivo Específico 02: Aplicar o Índice de Adaptação Urbana aos municípios do Estado de São Paulo.

Objetivo Específico 03: Avaliar os resultados obtidos considerando a sua distribuição espacial e outras características socioambientais dos municípios paulistas.

\section{Metodologia}

A abordagem utilizada para a realização desta pesquisa possui um caráter exploratório(GIL, 2002), uma vez que buscou-se verificar diferentes aspectos relacionados à temática da adaptação climática em âmbito local. A metodologia de pesquisa de métodos mistos discutida por CRESWELL (2007) também apresenta correlações com o processo de elaboração desta dissertação, ao propor a união de métodos quantitativos e qualitativos em um mesmo estudo. Dentre as estratégias da pesquisa de métodos mistos, foi selecionada a estratégia exploratória sequencial, onde parte-se da realização de um levantamento inicial de informações de referência através da coleta e análise de dados qualitativos, seguida por uma análise quantitativa de dados e a posterior integração dessas informações durante a análise dos resultados(CRESWELL, 2007).

Por meio de uma pesquisa bibliográfica e documental abrangendo instrumentos jurídicos, políticas de estado e trabalhos técnicos e acadêmicos, foi avaliado o estado da arte da temática das mudanças climáticas no mundo, no Brasil e no estado de São Paulo. Devido à recente ampliação do protagonismo da adaptação climática, foram levantadas informações específicas que ajudaram a compreender qual o entendimento desta temática pela academia e organismos internacionais, além do seu papel como estratégia de enfrentamento aos impactos climáticos. O conjunto de documentos consultados possibilitou ainda a obtenção dos subsídios teóricos necessários para a correlação entre os temas de interesse da pesquisa (mudanças climáticas, cidades e adaptação), auxiliando 
na avaliação dos impactos a que os governos locais estarão submetidos e o seu papel como principais atores para o fornecimento de respostas às alterações climáticas.

Para compreender como a adaptação tem sido considerada na esfera municipal, foi realizada uma busca por trabalhos científicos sobre a aplicação de medidas de adaptação por governos locais de diferentes cidades ao redor do mundo. Para isso, realizou-se uma busca nas bases de dados Web of Science e Scopus por meio da seleção das palavraschave: Mudança Climática, Urbano, Política, Adaptação, Planejamento e Cidades ou Cidade (formato da pesquisa e termos em inglês: "climate change" and urban and policy and adaptation and planning and (city or cities)).

Considerando o planejamento urbano como um importante instrumento que relaciona os diversos setores presentes em âmbito local, os resultados obtidos nas pesquisas foram analisados, sendo selecionados aqueles que tratavam de experiências de aplicação de medidas de adaptação por meio do planejamento urbano em cidades. Complementarmente, de modo a obter as produções mais recentes sobre o tema, os termos Adaptação Climática, Mudança Climática e Planejamento urbano (termos utilizados em inglês: climate adaptation, climate change e urban planning) foram inseridos no sistema de busca de artigos do Google Scholar, que apresenta as novas produções na temática de interesse, das quais, as mais relevantes foram consideradas para análise.

A partir da análise desta pesquisa bibliográfica, as principais medidas observadas nos estudos analisadas foram organizadas entre as temáticas Habitação e Planejamento Urbano, Mobilidade, Produção de Alimento, Gestão Ambiental e Resposta aos Impactos Climáticos. Ainda que esta relação de medidas não tenha como intuito esgotar as possibilidades de atuação em âmbito municipal ou de servir como um check list para a atuação de governos municipais, ela ajudou na análise dos indicadores aplicados nesta dissertação.

Para o cálculo do Índice de Adaptação Urbana (UAI) dos municípios do estado de São Paulo, tendo como objetivo avaliar o potencial dos municípios em se adaptar aos efeitos das mudanças climáticas, foi aplicada a metodologia elaborada pelo autor e outros pesquisadores no âmbito do Projeto CiAdapta.

A seleção dos indicadores que compuseram o UAI teve como base a publicação Perfil dos Municípios Brasileiros de 2017 - Munic 2017, elaborada pelo Instituto Brasileiro de Geografia e Estatística - IBGE (IBGE, 2018a). Em sua 15 edição, a pesquisa Munic apresentou o levantamento realizado 5570 municípios brasileiros ao longo do ano de 2017 abrangendo informações sobre a gestão e estrutura dos municípios a partir de questionários aplicados às administrações municipais. Com o auxílio dos pesquisadores do IBGE, cada município indicou os responsáveis pela coleta e sistematização das informações junto aos diversos setores. Por fim, os resultados foram validados pelas 
diferentes Unidades Estaduais do IBGE, com o apoio da Coordenação de População e Indicadores Sociais, até a sua consolidação no documento avaliado (IBGE, 2018a).

A decisão de que a composição do UAI tivesse como base as informações do Munic levou em consideração a expertise e reconhecimento do IBGE, a abrangência e disponibilidade dos dados apresentados, além do seu potencial de atualização periódica, o que permitirá avaliar a evolução do UAI de um determinado município períodos diferentes.

A seleção dos indicadores que compuseram o UAI teve como pano de fundo impactos previstos em âmbito municipal e as potenciais medidas de adaptação que podem ser incentivadas pelos governos locais. Além disso, foram selecionados indicadores que avaliassem a existência ou a ausência de instrumentos de gestão que, se aplicados levando em consideração a questão climática, podem ampliar a capacidade adaptativa municipal.

Dessa forma, o UAI é composto por 26 indicadores distribuídos em 05 (cinco), denominadas: Habitação, Mobilidade Urbana, Agricultura Sustentável, Gestão Ambiental e Resposta aos Impactos Climáticos. As dimensões e indicadores que compõe o UAI são apresentados no Quadro 1, a seguir.

Quadro 1 - Dimensões e indicadores do UAI

Dimensões Indicadores

1. Existe Plano Municipal de Habitação?

Habitação 2. Existe Conselho Municipal de Habitação?

3. Existe Fundo Municipal de Habitação?

4. Existe Plano Municipal de Transporte?

5. Existe Transporte coletivo por ônibus intramunicipal?

Mobilidade

6. Existe Transporte coletivo por ônibus intermunicipal?

Urbana

7. Existe Ciclovia no município?

8. Existe Bicicletário no município?

9. A prefeitura desenvolve programa ou ação de estímulo à agricultura orgânica?

10. A prefeitura desenvolve programa ou ação de estímulo à agricultura Agricultura familiar?

Sustentável 11. A prefeitura desenvolve programa ou ação de estímulo à Produção de hortas comunitárias?

12. A prefeitura desenvolve programa ou ação de prevenção contra problemas climáticos para o setor? 


\begin{tabular}{|c|c|}
\hline Dimensões & Indicadores \\
\hline & $\begin{array}{l}\text { 13. A prefeitura desenvolve programa ou ação para estímulo ao } \\
\text { associativismo (associação de produtores, cooperativas etc.)? }\end{array}$ \\
\hline \multirow{8}{*}{$\begin{array}{c}\text { Gestão } \\
\text { Ambiental }\end{array}$} & $\begin{array}{l}\text { 14. O município possui Fundo Municipal de Meio Ambiente ou } \\
\text { similar? }\end{array}$ \\
\hline & $\begin{array}{l}\text { 15. Existe legislação ou instrumento de gestão ambiental no município } \\
\text { que contemple saneamento básico (mesmo que na Lei Orgânica, } \\
\text { Plano Diretor, Código Ambiental etc.)? }\end{array}$ \\
\hline & $\begin{array}{l}\text { 16. Existe legislação ou instrumento de gestão ambiental no município } \\
\text { que contemple área e/ou zona de proteção ou controle ambiental } \\
\text { (mesmo que na Lei Orgânica, Plano Diretor, Código Ambiental } \\
\text { etc.)? }\end{array}$ \\
\hline & $\begin{array}{l}\text { 17. Existe legislação ou instrumento de gestão ambiental no município } \\
\text { que contemple poluição do ar (mesmo que na Lei Orgânica, Plano } \\
\text { Diretor, Código Ambiental etc.)? }\end{array}$ \\
\hline & $\begin{array}{l}\text { 18. Existe legislação ou instrumento de gestão ambiental no município } \\
\text { que contemple proteção à biodiversidade (mesmo que na Lei } \\
\text { Orgânica, Plano Diretor, Código Ambiental etc.)? }\end{array}$ \\
\hline & $\begin{array}{l}\text { 19. Existe legislação ou instrumento de gestão ambiental no município } \\
\text { que contemple adaptação e mitigação de mudança do clima (mesmo } \\
\text { que na Lei Orgânica, Plano Diretor, Código Ambiental etc.)? }\end{array}$ \\
\hline & $\begin{array}{l}\text { 20. O município possui Plano de Gestão Integrada de Resíduos Sólidos, } \\
\text { nos termos da Política Nacional de Resíduos Sólidos? }\end{array}$ \\
\hline & 21. O município paga diretamente por serviços ambientais - PSA? \\
\hline
\end{tabular}

22. O município possui como instrumento de planejamento Lei de Uso e Ocupação do Solo que contemple a prevenção de enchentes ou inundações graduais, ou enxurradas ou inundações bruscas?

23. O município possui como instrumento de planejamento Lei de Uso

Resposta aos Impactos Climáticos e Ocupação do Solo que contemple a prevenção de escorregamentos ou deslizamentos de encostas?

24. O município possui como instrumento de planejamento Plano Municipal de Redução de Riscos?

25. O município possui como instrumento de planejamento Carta geotécnica de aptidão à urbanização?

26. Em relação à gestão de riscos e resposta a desastres, existe no município Coordenação Municipal de Defesa Civil (COMDECs)?

Fonte: Elaborado pelo autor 
Visando validar os indicadores selecionados no UAI, realizou-se uma comparação desses indicadores com o Plano Nacional de Adaptação aprovado em 2016 (BRASIL - MMA, 2016a). Para tal, foi verificada a existência de diretrizes que apresentassem correlações com os instrumentos selecionados.

Uma vez tabuladas as respostas para cada indicador dos 645 municípios paulistas em uma planilha Office Excel, a existência de instrumentos/políticas foi pontuada como "1" e a sua ausência como "0". Além disso, a inexistência da informação municipal para um indicador, com base no relatório do MUNIC 2017 (IBGE, 2018a), foi tratada como ausência do instrumento, também recebendo a pontuação " 0 ", medida que possibilitou a comparação entre os diferentes municípios do Estado.

Em posse das pontuações de cada indicador, realizou-se a média dos resultados obtidos em cada uma das 5 (cinco) dimensões selecionadas, fornecendo resultados setoriais para os municípios avaliados. Finalmente, o UAI de cada município paulista foi obtido pela média dos resultados de cada uma das 5 dimensões que o compõe, variando de zero (0), para os municípios com o menor potencial em se adaptar a um (1), para os municípios que apresentam o maior potencial de adaptação.

É importante ressaltar que a existência de um instrumento e sua pontuação como "1" no cálculo do UAI não significa que este instrumento contém as medidas de adaptação necessárias para aquele município ou que ele tem sido efetivamente aplicado. A proposta do UAI considera que a existência do instrumento é a condição inicial para que, quando o município decidir ampliar a sua resiliência, ele tenha os meios para que isso seja realizado.

Após o cálculo das pontuações do UAI para cada município paulista e suas dimensões, os índices obtidos foram inseridos em um Sistema de Informações Geográficas (SIG), por meio do programa QGIS. A alimentação deste sistema com outras informações obtidas em bases de dados secundárias e relatórios técnicos permitiu a realização de correlações espacializadas entre os resultados obtidos e a sua comparação com as características socioambientais de cada área, possibilitando um aprofundamento na leitura do território.

Visando facilitar a utilização e o entendimento dos resultados do índice, foram definidas cinco faixas de pontuação relacionadas a uma escala de cores semafórica, variando do verde escuro (melhor resultado) ao vermelho escuro (pior resultado), permitindo a comparação visual entre os diferentes municípios e de um mesmo município nas diferentes dimensões.

Além dessa análise espacializada, foram realizadas correlações do UAI com diferentes índices através da função de correlação linear de Pearson (CORREA, 2003) através da função CORREL disponível no programa Office Excel. O Coeficiente de Correção Linear de Pearson (r) relaciona duas matrizes de valores retornando uma correlação entre eles, 
através da seguinte fórmula, onde (n) é o número de observações, $\left(\mathrm{x}_{\mathrm{i}}\right)$ é a variável independente e $\left(\mathrm{y}_{\mathrm{i}}\right)$ é a variável dependente:

$$
\begin{gathered}
r=\frac{n \sum_{x_{i} y \cdot}-\left(\sum x_{i}\right)\left(y_{i}\right)}{\sqrt{\left[n \sum x_{i}^{2}-\left(\Sigma_{x_{i}}\right)^{2}\right] *\left[n \Sigma_{y_{i}^{2}}-\left(\Sigma_{y_{i}}\right)^{2}\right]}} \\
\text { Fonte: (CORREA, 2003) }
\end{gathered}
$$

Dessa forma, para cada um dos 645 municípios paulistas, foi avaliada a correlação entre os resultados do UAI com o Índice de Desenvolvimento Humano Municipal (IDHM) e o Nível de Riqueza dos municípios paulistas, proposto pelo Índice Paulista de Responsabilidade Social (IPRS).

\section{Organização da dissertação}

Para além dessa introdução, esta dissertação foi organizada em seis capítulos. No primeiro são apresentadas as bases teóricas das pesquisas e negociações climáticas internacionais até o Acordo de Paris, os conceitos fundamentais para a compreensão da adaptação às mudanças climáticas e a evolução da temática no Brasil e do Estado de São Paulo.

No segundo capítulo é avaliado o papel dos governos municipais na adaptação climática, os principais impactos a que os municípios estão submetidos e as medidas de adaptação que podem ser aplicadas em âmbito local, com foco em instrumentos de desenvolvimento urbano e políticas públicas.

No terceiro capítulo, são apresentadas as bases do Índice de Adaptação Urbana produzido no âmbito do Projeto CiAdapta e suas correlações com o Plano Nacional de Adaptação

O quarto capítulo apresenta o UAI calculado para os 645 municípios do Estado de São Paulo, as análises sobre os resultados obtidos e uma discussão sobre as potencialidades e restrições da aplicação desta ferramenta por municípios e órgãos estaduais.

No quinto capítulo são apresentadas as conclusões da dissertação sobre a aplicação do UAI aos municípios paulistas, seguido pelo capítulo final, que apresenta as considerações gerais da dissertação. 


\section{Produto Final}

Como essa dissertação foi elaborada no âmbito de um mestrado profissional, buscou-se trazer contribuições para a discussão atual sobre mudanças climáticas, adaptação e governos locais, numa perspectiva de compreender as sinergias existentes entre instrumentos e intervenções aplicadas pelos municípios e a adaptação climática, visando a promoção de cidades mais saudáveis e sustentáveis. Como produto final da dissertação, será disponibilizado o Índice de Adaptação Urbana (UAI) aplicado aos municípios do Estado de São Paulo, o qual poderá ser utilizado como um produto técnico de referência ou uma ferramenta que sirva de subsídio para ações de planejamento que visem ampliar a capacidade adaptativa dos municípios paulistas. A escolha de uma base de dados oficial e de atualização periódica, possibilitará ainda que os municípios acompanhem a evolução de seu potencial adaptativo, auxiliando as futuras tomadas de decisão. Esta análise ainda poderá ser realizada regionalmente ou para o estado como um todo, fornecendo elementos para a criação ou adequação de políticas públicas setoriais. 


\section{MITIGAÇÃO E ADAPTAÇÃO ÀS MUDANÇAS CLIMÁTICAS: DO GLOBAL AO LOCAL}

Uma das principais instituições que organiza as bases científicas para a criação de políticas relacionadas às mudanças climáticas é o Painel Intergovernamental sobre a Mudança do Clima - IPCC (Intergomernmental Panel on Climate Change). O IPCC foi criado em 1988 e produz regularmente relatórios sobre as mais recentes descobertas sobre as mudanças climáticas, seus impactos, riscos futuros e opções de adaptação e mitigação. Para isso, o IPCC conta com a participação de diversos pesquisadores e revisores que avaliam as publicações mais consistentes sobre as temáticas abordadas no naquele momento. Atualmente, o IPCC é organizado em três diferentes grupos de trabalho, o WGI que avalia as bases científicas das mudanças climáticas, o WGII que abrange os impactos, a adaptação e a vulnerabilidade, e o WGIII que avalia as medidas de mitigação necessárias para reverter o avanço da mudança do clima. Adicionalmente, o IPCC conta com uma força tarefa para a definição de metodologias para o cálculo e informação de emissões a serem utilizadas nos inventários nacionais de gases de efeito estufa (IPCC, 2013).

O primeiro relatório de avaliação (AR1) foi elaborado pelo IPCC em 1990, apresentando a importância global da temática das mudanças climáticas e da cooperação internacional frente ao tema. O AR1 foi decisivo para a formalização da Convenção Quadro das Nações Unidas sobre Mudança do Clima (UNFCCC, em inglês) na Eco-92 (Conferência das Nações Unidas sobre Meio Ambiente e Desenvolvimento) realizada no Rio de Janeiro em 1992, onde foram definidos compromissos e obrigações a todos os países participantes (Partes). A partir do ano de 1995 a UNFCCC passou a realizar as Conferências das Partes (COP) com periodicidade anual (IPCC, 2019).

O segundo relatório do IPCC (AR2), elaborado em 1995, forneceu a base teórica aos países na adoção do Protocolo de Quioto. O Protocolo de Quioto foi adotado formalmente em 1997 durante a terceira Conferência das Partes (COP 3) definindo que os países desenvolvidos (denominados de Anexo I) deveriam implantar políticas e medidas para a reduzir suas emissões de Gases de Efeito Estufa (GEE).

No ano de 2001 foi publicado o terceiro relatório do IPCC (AR3) tendo como foco a avaliação dos impactos das mudanças climáticas e ressaltando a necessidade da aplicação de medidas de adaptação. Além disso, foi criado, no âmbito do Protocolo de Quioto, o Fundo de Adaptação (Adaptatiom Fund) com o objetivo de auxiliar os países a se adaptar aos efeitos das mudanças climáticas(IPCC, 2019; RODRIGUES FILHO et al., 2016; UNFCCC, 2019a, 2019b). Outros marcos importantes para a temática da adaptação ocorreram em 2003, durante a COP-09, onde foram demandados trabalhos sobre os impactos das mudanças do clima, vulnerabilidade e adaptação. Essas temáticas compuseram ainda o Plano de Trabalho de Nairobi, estabelecido na COP-11 em 2005 e 
nomeado, no ano seguinte, em homenagem à capital do Quênia durante a COP12(CARVALHO et al., 2014; RODRIGUES FILHO et al., 2016).

O protocolo de Quioto passou a vigorar em 16 de fevereiro de 2005, tendo como primeiro período do compromisso de 2008 a 2012, visando uma redução em média de 5,2\% frente às emissões de 1990. Em 2007, o quarto relatório (AR4) foi elaborado fornecendo os elementos para a ação pós Protocolo de Quioto. Neste mesmo ano, na COP 13, as Partes entraram em um acordo sobre o Bali Road Map, que estabeleceu um plano de ação com as medidas a serem adotadas para a vigência do primeiro período do Protocolo de Quioto e as negociações para um segundo período do protocolo, após 2012 (RODRIGUES FILHO et al., 2016; ONU, 2018; IPCC, 2019; UNFCCC, 2019b, 2019a).

Na COP 15, em 2009, foi discutido o Acordo de Copenhague, o qual não foi aprovado por unanimidade, mas que serviu como base para negociações futuras. No âmbito deste acordo, ainda que tenha sido discutido se o aquecimento do globo deveria ser fixado em $1,5^{\circ} \mathrm{C}$ acima dos níveis pré-industriais para que as consequências do aquecimento global fossem menores, definiu-se que o aquecimento deveria ser restringido em até $2^{\circ} \mathrm{C}$ (UNFCCC, 2019a).

A COP16, em 2010, foi marcada pela negociação do Acordo de Cancun onde definiu-se a criação do Fundo Verde para o Clima (Green Climate Fund) e do Quadro de Adaptação de Cancun (Cancun Adaptation Framework), sendo a primeira vez que a temática da adaptação recebeu o mesmo grau de importância da mitigação em uma Conferência das Partes (RODRIGUES FILHO et al., 2016; UNFCCC, 2019a).

Em 2012 o primeiro período de compromisso do protocolo de Quioto se encerrou. Como não houve consenso na criação de um novo acordo, foi criado um segundo período de compromisso através do Doha Amendment, se estendendo até 31 de dezembro de 2020, onde deveriam ser reduzidas, em pelo menos, 18\% das emissões relativas a 1990 (FIELD et al., 2014; RODRIGUES FILHO et al., 2016; ONU, 2018; UNFCCC, 2019b, 2019a).

O $5^{\circ}$ Relatório de Avaliação - AR5, último publicado pelo IPCC (PACHAURI; MEYER, 2014), considerou não haver mais dúvidas quanto à responsabilidade das atividades antrópicas frente às mudanças do clima nas últimas décadas, principalmente quanto às alterações da atmosfera em âmbito regional e às variações da temperatura dos oceanos(HOEGH-GULDBERG et al., 2018). O AR5, finalizado no ano de 2014, serviu como base para as negociações realizadas durante a COP-21 (Conferência das Partes realizada em Paris em dezembro de 2015) que culminou na assinatura do "Acordo de Paris", um novo pacto a ser implementado após 2020 que compreende tanto a mitigação como a adaptação, tendo como objetivos (UNFCCC, 2015, 2019a; ONU, 2018; IPCC, 2019): 
“(a) Manter o aumento da temperatura média global bem abaixo dos 2

${ }^{\circ} \mathrm{C}$ acima dos níveis pré-industriais e buscar esforços para limitar o aumento da temperatura a $1,5{ }^{\circ} \mathrm{C}$ acima dos níveis pré-industriais, reconhecendo que isso reduziria significativamente os riscos e impactos das mudanças climáticas;

(b) Aumentar a capacidade de adaptar-se aos impactos adversos das mudanças climáticas e fomentar a resiliência ao clima $e \quad o$ desenvolvimento de baixas emissões de gases de efeito estufa, de uma forma que não ameace a produção de alimentos;

(c) Promover fluxos financeiros consistentes com um caminho de baixas emissões de gases de efeito estufa e de desenvolvimento resiliente ao clima."

(UNFCCC, 2015 - Tradução Centro de Informação das Nações Unidas para o Brasil - UNIC Rio)

Para que este limite de aquecimento seja respeitado, os países deverão atender as metas de redução de emissões por eles apresentadas através das NDC (Nationally Determined Contribution). Estas metas devem ainda ser atualizadas a cada 5 anos, sendo acompanhadas de informações transparentes que apresentem as situações a que os países estão submetidos.

Entretanto, mesmo com o atendimento das metas do Acordo de Paris, a população mundial ainda estará submetida a uma ampliação média de temperatura de 1,5 a $2^{\circ} \mathrm{C}$, sendo necessário atuar na adaptação aos efeitos que ocorrerão. Dessa forma, o Acordo estabeleceu dentre as suas metas a ampliação da capacidade adaptativa, o fortalecimento da resiliência e a redução das vulnerabilidades às mudanças climáticas dos países de modo a contribuir com o desenvolvimento sustentável e fornecer uma resposta adequada aos efeitos da meta de ampliação de temperatura acordada. Além disso, os países signatários devem fortalecer a cooperação no âmbito do Quadro de Adaptação de Cancun (Cancun Adaptation Framework) quanto ao compartilhamento de informações, fortalecimento de arranjos institucionais, ampliação do conhecimento científico sobre o tema, ampliação da eficácia e durabilidade de medidas de adaptação, além da proposição de que os países desenvolvidos auxiliem os países em desenvolvimento em se adaptar (UNFCCC, 2015, 2019a).

Outro importante marco ocorrido no ano de 2015 foi a adoção do Marco de Sendai para a Redução de Riscos de Desastres. Reforçado pelo Acordo de Paris, este marco prevê a complementação das ações previstas pelo Marco de Hyogo (2005 - 2015) com quatro 
ações prioritárias a serem realizadas entre os anos de 2015 e 2030: conhecer os riscos de desastre; fortalecer a governança para o gerenciamento desses riscos; realizar investimentos para a ampliação da resiliência; e, aprimorar o planejamento para a ação frente a estes riscos, melhorando a dinâmica para a recuperação, reabilitação e reconstrução de áreas atingidas(ONU, 2015a).

Atualmente os pesquisadores do IPCC estão trabalhando no sexto relatório de avaliação (AR6), inclusive com a publicação de relatórios especiais intermediários, o qual deve ser finalizado em 2022 (IPCC, 2019). Em outubro de 2018, o IPCC publicou um relatório especial sobre os impactos do aquecimento global acima de $1,5^{\circ} \mathrm{C}$ previstos no Acordo de Paris, o SR1.5 (IPCC, 2018). Segundo este relatório, a adaptação e a mitigação já estão sendo colocados em prática e os riscos futuros previstos deverão ser reduzidos pela ampliação e aceleração da aplicação de medidas de mitigação de longo alcance, multinível e trans-setorial, aplicadas em conjunto com medidas de adaptação incrementais e transformacionais, em um processo constante de ajustamento. Avaliando cenários do aquecimento global de $1,5^{\circ} \mathrm{C}$ e do aquecimento entre os 1,5 a $2^{\circ} \mathrm{C}$, o relatório informa haver alta confiabilidade no aumento das temperaturas médias na maioria dos continentes e áreas oceânicas, e de calores extremos em regiões habitadas, sendo que o número de dias quentes deverá aumentar na maioria das regiões, especialmente nos trópicos. É avaliada como média confiabilidade a ocorrência do aumento da ocorrência de chuvas extremas em diversas regiões e da probabilidade de secas e déficits de precipitação em algumas regiões, entretanto, estas situações apresentaram projeções piores para o caso do aquecimento atingir $2^{\circ} \mathrm{C}$ (IPCC, 2018).

O SR1.5 afirma ainda que já são observados impactos sobre diversos ecossistemas terrestres e oceânicos e sobre os serviços que eles fornecem à humanidade. As projeções demostram que o nível do mar deverá continuar a elevar até o ano de 2100 , mesmo se o aquecimento da terra for limitado aos $1,5^{\circ} \mathrm{C}$. No caso do aquecimento atingir os $2^{\circ} \mathrm{C}$, é prevista uma elevação adicional do nível do mar em 0,1 metro, o que significaria um impacto em mais 10 milhões de habitantes (caso nenhuma ação adicional de adaptação seja tomada). A perda de biodiversidade terrestre também deverá ser menor no aquecimento de $1,5^{\circ} \mathrm{C}$ em relação ao aquecimento de $2^{\circ} \mathrm{C}$, porém, em ambos os casos, há a possibilidade de perda de espécies e extinção. É previsto que o percentual de perda de insetos e plantas dobre entre os dois cenários e que a perda de biodiversidade relacionada à ocorrência de incêndios florestais e disseminação de espécies invasoras seja maior com o aquecimento de $2^{\circ} \mathrm{C}$ (IPCC, 2018).

A partir do legado dos Objetivos de Desenvolvimento do Milênio (2000) foi publicada pela ONU em 2015 a Agenda 2030 composta por 17 Objetivos do Desenvolvimento Sustentável (ODS) e 169 metas que estimularão a ação de todos os países até o ano de 2030(ONU, 2015b). De acordo com HOEGH-GULDBERG et al., (2018), as mudanças climáticas já afetaram profundamente os ecossistemas, a saúde humana e a agricultura, dificultando o atendimento de algumas das metas propostas. O relatório afirma que, se 
mantida a ampliação da temperatura global em $1,5^{\circ} \mathrm{C}$, será mais fácil de atingir os ODS, entretanto, o aquecimento de $2^{\circ} \mathrm{C}$ ou mais reduzirá as chances de atendimentos dos objetivos de erradicação da pobreza e fome, disponibilização de água, redução de desigualdades e proteção de ecossistemas (HOEGH-GULDBERG et al., 2018).

Segundo ALLEN et al. (2018), até o ano de 2017 a ação humana já havia causado a ampliação na temperatura global em $1^{\circ} \mathrm{C}$ em relação ao período pré-industrial, e, se esta média de aquecimento for mantida, a meta de $1,5^{\circ} \mathrm{C}$ deverá ser atingida por volta de 2040(ALLEN et al., 2018). O relatório ressalta, entretanto, que estas informações retratam uma média das temperaturas globais, dessa forma, muitas regiões já convivem com temperaturas acima deste limite. A Figura 1 apresenta a evolução do aquecimento observado frente à temperatura pré-industrial e as previsões para os próximos anos. No modelo proposto, para o atendimento da meta de restringir o aquecimento a $1,5^{\circ} \mathrm{C}$, as reduções de emissões devem iniciar imediatamente e as emissões de $\mathrm{CO}_{2}$ devem ser zeradas até o ano de 2055. Observa-se, porém, que mesmo com o atendimento dessas metas, por alguns períodos as temperaturas médias globais deverão ultrapassar a faixa $\operatorname{dos} 1,5^{\circ} \mathrm{C}$.

Figura 1 - Curva do aquecimento global frente ao período pré-industrial

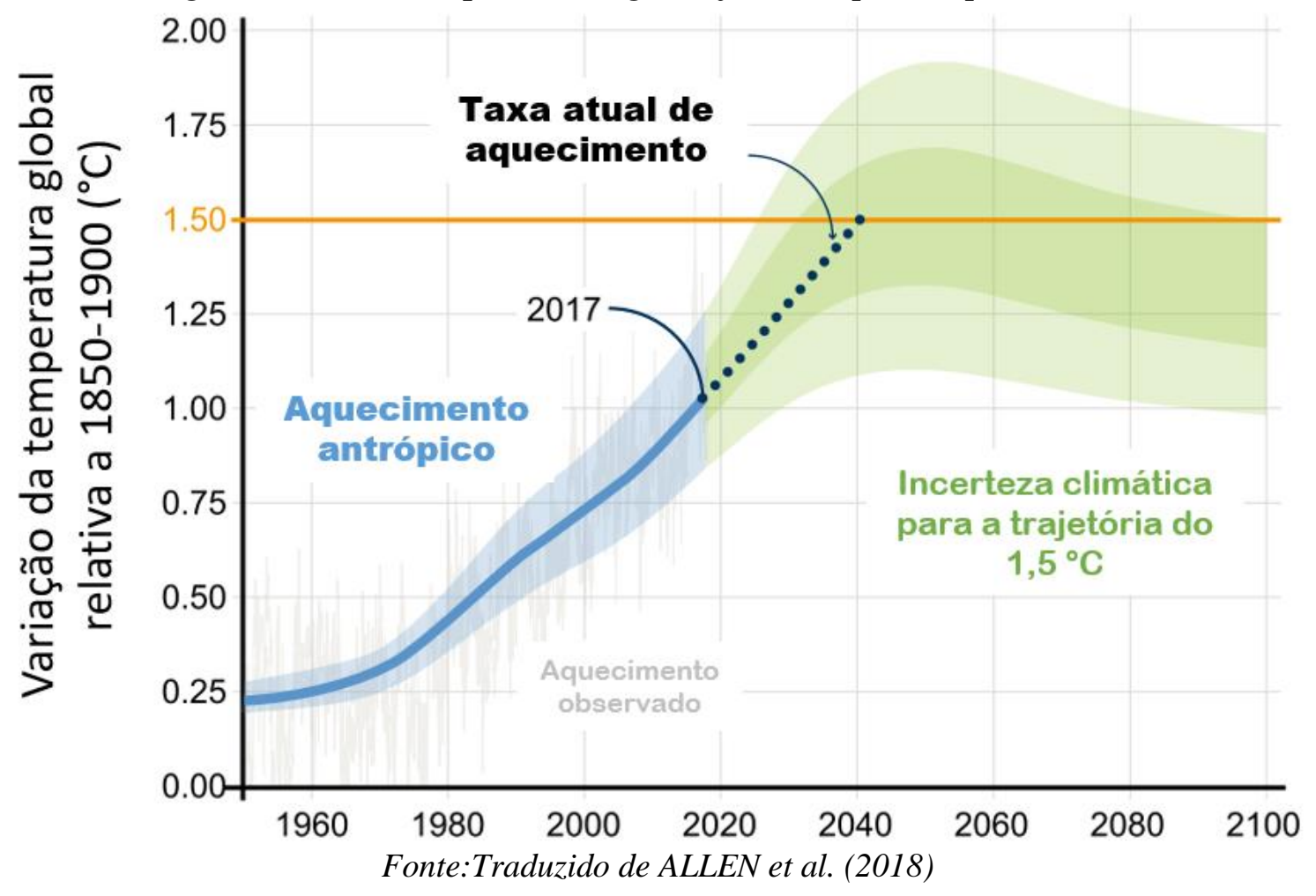

Após a publicação do Relatório Especial sobre os efeitos da ampliação da temperatura global em $1,5^{\circ} \mathrm{C}$, dezoito autores do SR1,5 se juntaram para elaborar um sumário para tomadores de decisão, avaliando as consequências desta ampliação da temperatura para o ambiente urbano(BAZAZ et al., 2018). Este relatório afirma que exceder o limite de 
aquecimento de $1,5^{\circ} \mathrm{C}$, mesmo que temporariamente, irá levar a humanidade a um cenário de incertezas, para o qual possuímos pouco conhecimento científico e nenhuma experiência de governança ou institucional. Além disso, este aquecimento submeterá diversos sistemas naturais e humanos para além de seus limites de adaptação. Os principais impactos previstos seriam o aumento de mortes e doenças, a ampliação de populações expostas à riscos climáticas e à extrema pobreza, ampliação da escassez de recursos hídricos, redução da segurança alimentar e a perda de biodiversidade (BAZAZ et al., 2018).

\subsection{Adaptação às mudanças climáticas}

De acordo com Petit et al. (1999, apud RODRIGUES FILHO et al., 2016) o ritmo dos aquecimentos e resfriamentos do planeta entre diferentes ciclo glaciares e interglaciares ocorre de maneira distinta. Enquanto o aquecimento da terra em $10^{\circ} \mathrm{C}$ pode ocorrer em um período de 10 mil anos, seriam necessários 30 a 50 mil anos para o resfriamento desta mesma temperatura. Dessa forma, mesmo com todos os esforços e comprometimento dos países em reduzir as suas emissões de gases causadores do efeito estufa e manter o aquecimento dentro das metas estabelecidas pelo Acordo de Paris, ainda sofreremos os efeitos do aquecimento que a humanidade já causou no planeta, o que exigirá a aplicação de medidas de adaptação aos efeitos das mudanças climáticas (FIELD et al., 2012; RODRIGUES FILHO et al., 2016).

Adaptação é entendida como o processo de se preparar e se ajustar às condições climáticas atuais ou esperadas e seus efeitos, sejam elas negativas, com a minimização de seus impactos, como as positivos, aproveitando as oportunidades que se apresentam(THE WORD BANK, 2011; IPCC, 2014). A adaptação tem como objetivo reduzir a vulnerabilidade e a exposição de sistemas aos efeitos nocivos das mudanças climáticas(ALLEN et al., 2018), ocorrendo de maneira distinta nos sistemas naturais e humanos.

$\mathrm{Na}$ adaptação em sistemas naturais, a atuação humana poderá facilitar o ajuste dessas áreas às novas condições climáticas, de modo que elas mantenham a prestação de serviços ambientais, como a produção de água e a manutenção da biodiversidade, entre outros. Já em sistemas humanos, a adaptação tem como objetivo reduzir ou evitar os impactos a serem sentidos pelas pessoas e animais domesticados, além de potencializar as oportunidades como a criação de novas culturas mais adequadas às novas condições climáticas(IPCC, 2014).

A capacidade de sistemas, instituições e comunidades em se ajustar frente aos danos potenciais, responder às consequências ou aproveitar das oportunidades é denominada de capacidade adaptativa (IPCC, 2014). A capacidade adaptativa possui, entretanto, uma 
característica dinâmica, uma vez que é influenciada por decisões realizadas no passado e suas relações com riscos incertos previstos para o futuro(DI GIULIO et al., 2016). Giddens (2010, apud. ANDRADE, 2017) relaciona a capacidade adaptativa com o conceito de resiliência, sendo ambos o inverso de vulnerabilidade. De acordo com IPCC (2014), resiliência é a capacidade dos sistemas social, econômico e ambiental de enfrentar um evento adverso ou uma tendência de alteração e fornecer uma resposta ou se reorganizar de modo que a sua função, identidade e estrutura original sejam mantidas, bem como, as suas capacidades de adaptação, de aprendizado ou de transformação (IPCC, 2014). Tanto a resiliência como a capacidade adaptativa de um sistema podem ser construídas ou aprimoradas a partir do conhecimento dos riscos a que o sistema está submetido e do seu grau de vulnerabilidade (ANDRADE, 2017).

Por fim, vulnerabilidade é definida pela predisposição de um sistema ser afetado adversamente, estando relacionada à sensibilidade ou suscetibilidade de um meio a danos e à sua falta de capacidade em lidar com as alterações ou de se adaptar (IPCC, 2014). A vulnerabilidade é afetada ainda pela exposição de um sistema ou comunidade a eventos adversos, assim, uma ampliação da exposição ou da sensibilidade a eventos adversos, ou a redução capacidade de adaptação de um sistema, resultarão na ampliação de sua vulnerabilidade (IPCC, 2007).

Segundo AMBRIZZI e ARAUJO (2014), o aquecimento projetado para a América do Sul deverá variar entre $1^{\circ}$ e $4^{\circ} \mathrm{C}$ em cenários de baixas emissões de GEE, e de $2^{\circ}$ a $6^{\circ} \mathrm{C} \mathrm{em}$ cenários de emissões maiores. Em todos os modelos analisados pelos autores foi observada a preponderância de climas mais quentes. Já as previsões de alteração da intensidade e frequência das precipitações variaram entre as regiões analisadas e modelos utilizados(AMBRIZZI; ARAUJO, 2014).

No ano de 2014, o IPCC publicou o relatório resumo para tomadores de decisão sobre os impactos, vulnerabilidade e adaptação às mudanças climáticas (FIELD et al., 2014). Este documento foi realizado pelo Grupo de Trabalho II como contribuição para a realização do Quinto Relatório de Avaliação do IPCC - WGII AR5. A partir da análise de diversos estudos, os autores apresentaram os impactos e medidas de adaptação por regiões. $\mathrm{O}$ Quadro 2 apresenta os principais impactos previstos para as Américas do Sul e Central e suas perspectivas de adaptação, e a Tabela 1 destaca alguns exemplos de adaptação que vêm sendo implantados ao redor do globo.

Conforme pode ser observado, os níveis aquecimento serão determinantes para a intensidade dos riscos a que os habitantes do planeta estarão submetidos e, consequentemente, para o dimensionamento das medidas de adaptação necessárias. No caso das Américas do Sul e Central, os principais risco estão relacionados à disponibilidade de água e a ocorrência de cheiras e deslizamentos; diminuição da produção de alimentos; e, a propagação de doenças transmitidas por vetores (FIELD et al., 2014; PACHAURI; MEYER, 2014). 
Quadro 2 - Riscos e medidas de adaptação para as Américas Central e do Sul

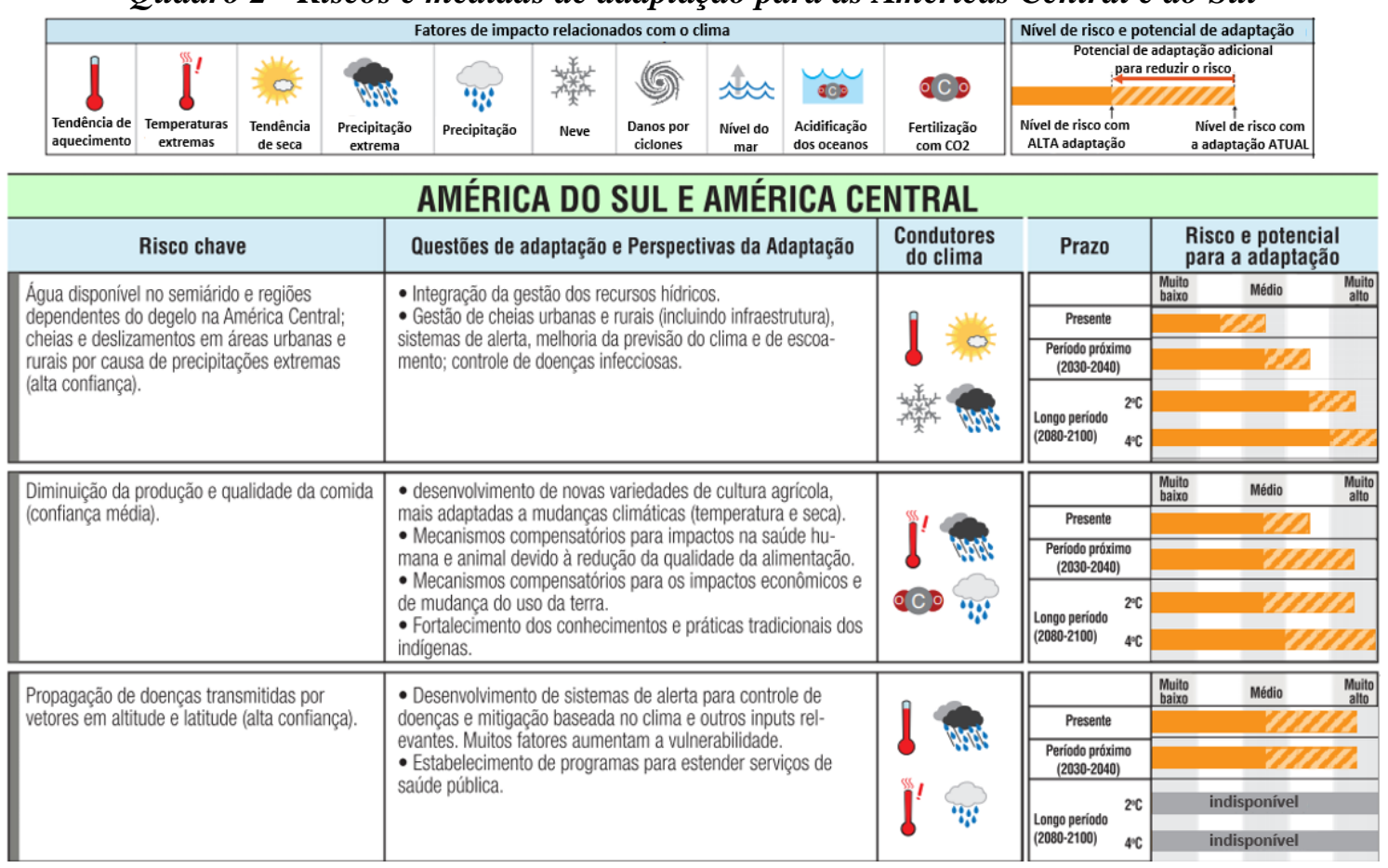

Fonte: Adaptado de (PACHAURI; MEYER, 2014) e (FIELD et al., 2014)

Tabela 1- Exemplos de adaptação em diferentes regiões

\begin{tabular}{|c|c|c|c|c|c|c|c|c|}
\hline & $\begin{array}{l}\text { Gestão de } \\
\text { Risco de } \\
\text { Desastres }\end{array}$ & $\begin{array}{c}\text { Ajuste nas } \\
\text { Tecnologias e } \\
\text { Infraestruturas }\end{array}$ & $\begin{array}{l}\text { Abordagens } \\
\text { Baseadas em } \\
\text { Ecossistemas }\end{array}$ & \begin{tabular}{|c|} 
Medidas de \\
Saúde Pública e \\
Diversificação \\
de Formas de \\
Sustento \\
\end{tabular} & $\begin{array}{l}\text { Medidas de } \\
\text { Adaptação } \\
\text { Climática ao } \\
\text { Planejamento } \\
\text { Subnacional }\end{array}$ & $\begin{array}{c}\text { Gestão } \\
\text { Integrada de } \\
\text { Recursos } \\
\text { Hídricos }\end{array}$ & $\begin{array}{c}\text { Consideração } \\
\text { da Elevação do } \\
\text { Nível do Mar }\end{array}$ & $\begin{array}{l}\text { Adaptação } \\
\text { Baseada na } \\
\text { Comunidade }\end{array}$ \\
\hline África & $x$ & $x$ & $x$ & $x$ & - & - & - & - \\
\hline Europa & $x$ & - & - & - & $x$ & $\mathrm{x}$ & $x$ & - \\
\hline Ásia & - & - & $x$ & - & $x$ & $x$ & - & - \\
\hline Australásia & - & - & - & - & - & $x$ & $x$ & - \\
\hline $\begin{array}{c}\text { América do } \\
\text { Norte }\end{array}$ & - & $\mathrm{x}$ & - & - & $x$ & - & - & - \\
\hline América Latina & - & - & $x$ & $x$ & - & $x$ & - & - \\
\hline Ártico & - & $x$ & - & - & - & - & - & - \\
\hline $\begin{array}{l}\text { Pequenas } \\
\text { Ilhas }\end{array}$ & - & - & - & - & - & - & - & $x$ \\
\hline
\end{tabular}

Fonte: Adaptado de IPCC 2014 - WG II - AR5 (FIELD et al., 2014)

O IPCC (2018) afirma que existem sinergias entre o desenvolvimento sustentável e medidas de adaptação que reduzam a vulnerabilidade de sistemas humanos e naturais. Isso se dá por estas medidas atuarem nas questões da segurança hídrica e alimentar, na redução de riscos de desastres, na melhoria das condições de saúde da população e na manutenção dos serviços ecossistêmicos. Entretanto, o documento sugere que as medidas adotadas também incluam a atenção à pobreza e ao desenvolvimento sustentável, de modo a reduzir a possibilidade de má adaptação (maladaptation - políticas ou medidas de 
adaptação que ao serem implantadas aumentam a vulnerabilidade do sistema ou de determinados grupos sociais (DI GIULIO et al., 2016)). Além disso, afirma que as medidas de adaptação e mitigação podem ser aplicadas de maneira combinada e de forma participativa para que ocorram transformações mais rápidas nos meios urbanos e rurais, as quais serão mais eficazes se os governos nacionais apoiarem os governos locais e regionais em sua elaboração e implantação (IPCC, 2018).

As abordagens de adaptação podem ser separadas entre a adoção de medidas que visem a redução da vulnerabilidade de um sistema e pela adoção de medidas incrementais ou transformacionais(FIELD et al., 2014; CONINCK et al., 2018). FIELD et al. (2014) afirmam que a adaptação deve ter como foco principal a redução da vulnerabilidade e da exposição das pessoas às mudanças climáticas previstas, levando em consideração as conexões entre as características socioeconômicas locais, a busca pelo desenvolvimento sustentável e os efeitos das mudanças climáticas. A partir disso, podem ser aplicadas medidas adaptativas incrementais que visam ajustar as atividades realizadas atualmente para uma nova realidade, sem alterar, porém, a suas estruturas de funcionamento; ou medidas transformacionais, as quais são marcadas por uma alteração profunda e de longo prazo na sociedade, influenciando o seu desenvolvimento e causando mudanças significativas em suas estruturas e funções(BAZAZ et al., 2018; CONINCK et al., 2018).

Estudos demonstram que as medidas incrementais não deverão ser suficientes para reduzir os impactos das mudanças climáticas em algumas regiões, sendo necessária a implantação de medidas transformacionais, como por exemplo a alteração das vocações econômicas de comunidades (CONINCK et al., 2018). Para BAZAZ et al. (2018), a adoção de medidas de adaptação aos efeitos do aquecimento global exige ações em âmbito nacional e local, devendo variar conforme as características de cada região. Dessa forma, a adaptação transformacional não será necessária em todas as localidades. Por outro lado, para os casos onde a sua implantação for necessária, a viabilização ainda deverá superar diversas barreiras, entre elas as financeiras, relacionadas aos custos envolvidos em sua implementação. A Figura 2 apresenta as diferenças entre adaptação e a adaptação transformacional. 
Figura 2 - Exemplos de Adaptação e Adaptação Transformacional

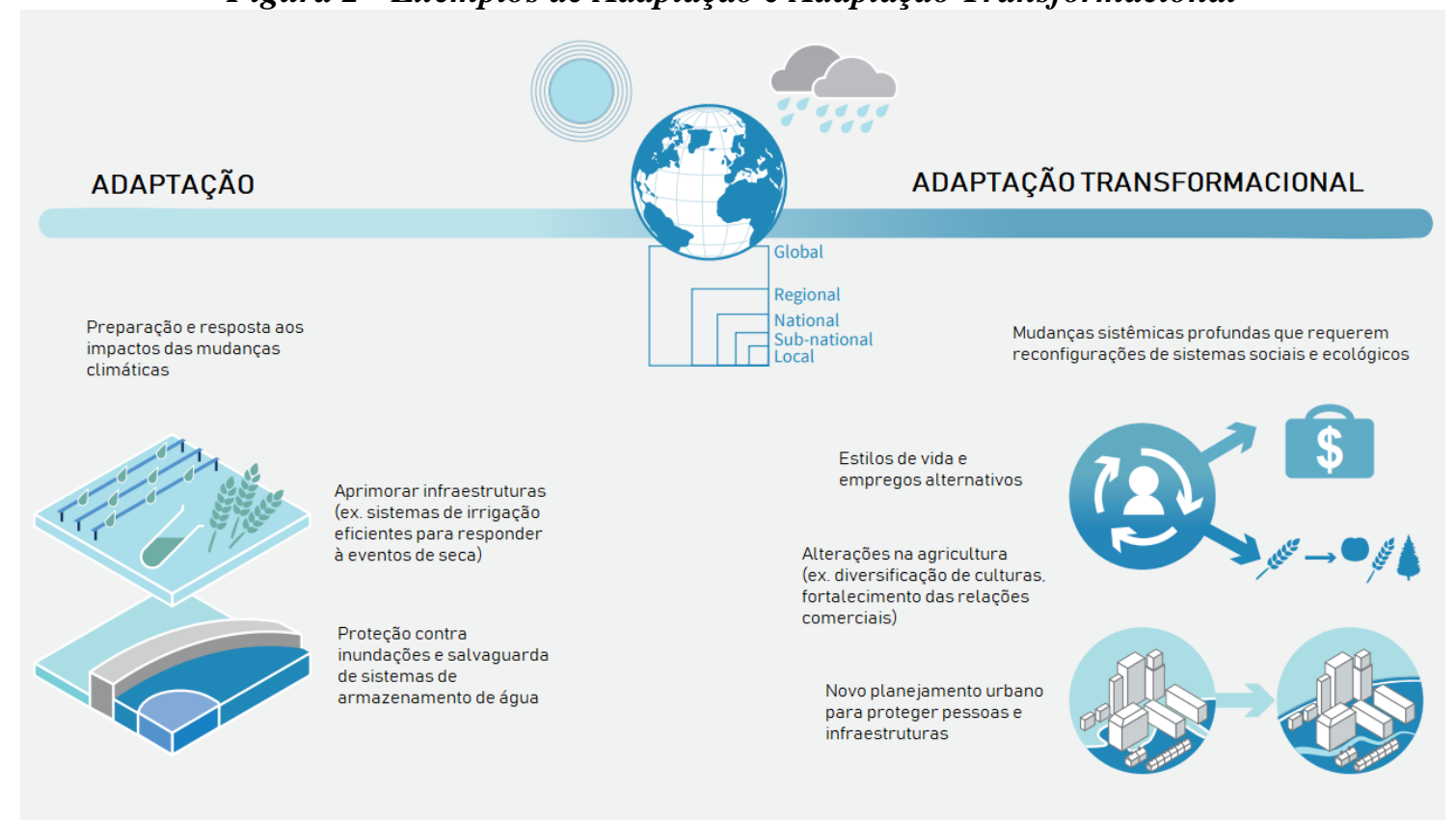

Fonte: adaptado de BAZAZ et al. (2018)

O Quadro 3, elaborado por PACHAURI e MEYER (2014) com informações de FIELD et al. (2014), apresenta diferentes medidas de adaptação organizadas conforme as abordagens de redução de vulnerabilidades, medidas incrementais e medidas transformacionais, as quais, segundo os autores, devem ser aplicadas simultaneamente(FIELD et al., 2014; PACHAURI; MEYER, 2014). 


\section{Quadro 3 - Exemplos de medidas de adaptação por tipo de abordagem}

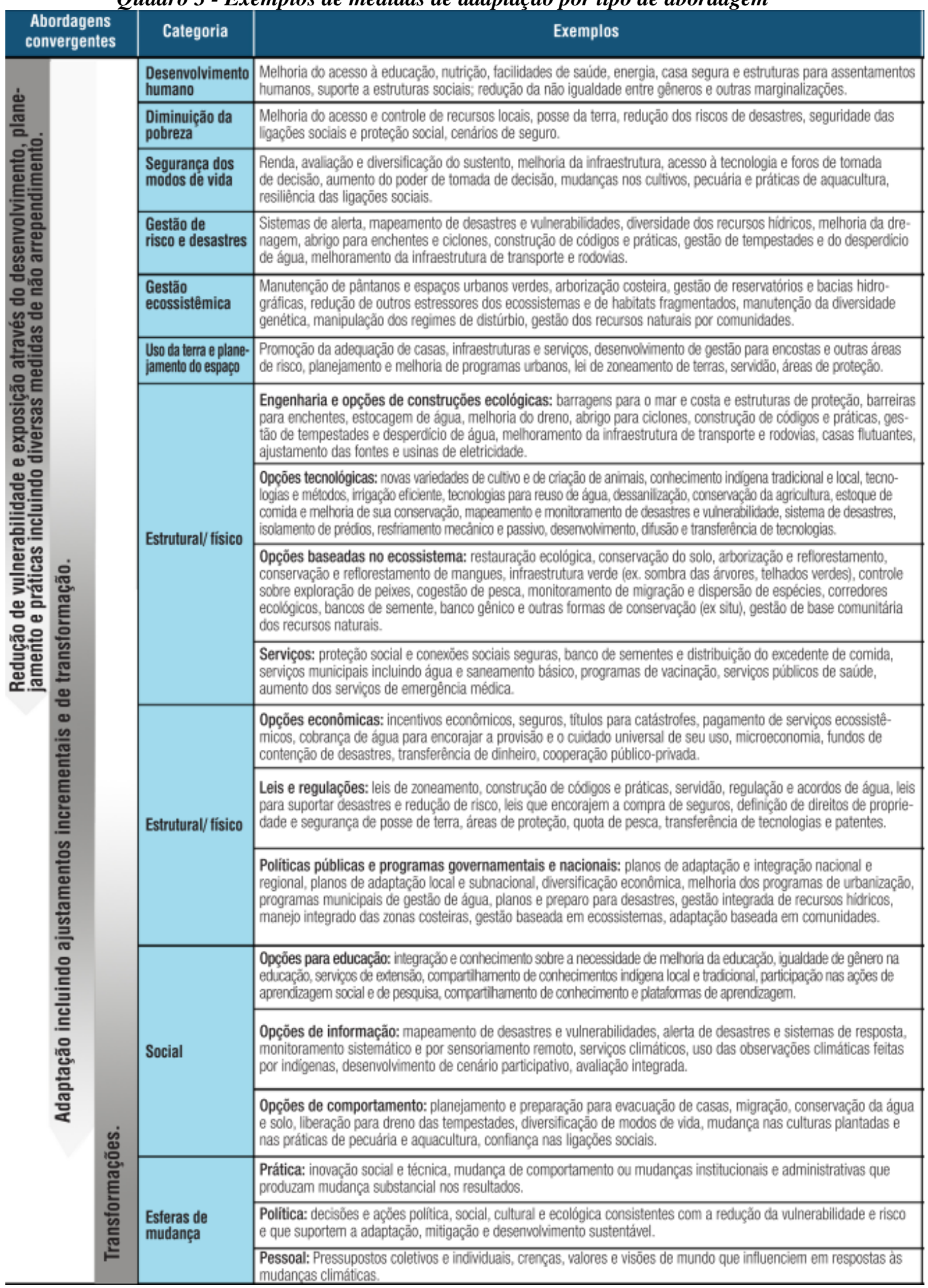

Fonte: Reproduzido de FIELD et al., 2014 e PACHAURI; MEYER, 2014 - Tradução Iniciativa

Verde 
Avaliando os desafios causados pelas mudanças climáticas para as cidades, Uittenbroek et al. (2014) apresentam duas abordagens para a aplicação da adaptação climática, a Abordagem Transversal (Mainstreaming Approach) e a Abordagem Dedicada (Dedicated Approach). A Abordagem Transversal para a adaptação às mudanças climáticas é um comprometimento político indireto, mas mais pragmático, para a ampliação da capacidade adaptativa de um município. Neste caso, a adaptação climática seria integrada a políticas e instrumentos existentes, mantendo as rotinas e estruturas administrativas inalteradas. Ainda que a falta de ferramentas e estruturas específicas possa dificultar algumas respostas, essa perspectiva é mais prática, permitindo a atuação do poder municipal frente aos efeitos das mudanças climáticas por meio da definição de sinergias entre as ações que já seriam realizadas, com medidas de adaptação, sem a alocação explícita de recursos para estes fins. Em contraponto, a Abordagem Dedicada se baseia no comprometimento político explicito com o tema, possibilitando outras oportunidades como pressões políticas e o suporte de estruturas organizacionais específicas, podendo, porém, enfrentar dificuldades para a implantação, uma vez que muitas vezes elas não são entendidas como prioritárias pela sociedade (UITTENBROEK et al., 2014).

O Guia de Adaptação para entes Federativos (MARGULIS, 2017) avaliou 12 guias de adaptação e suas metodologias, definindo 07 (sete) aspectos fundamentais para a sua viabilização: a identificação do problema; as alternativas de adaptação; avaliação da viabilidade econômica e política das ações; avaliação das limitações da administração para implementação das medidas; a "transversalização" das medidas nos diferentes setores da administração; a implementação e monitoramento das medidas propostas; e, a comunicação e o envolvimento das partes interessadas (MARGULIS, 2017). No Guia, o autor apresenta a abordagem transversal como a incorporação das medidas adaptativas pelos diferentes setores da administração, ação que representa um grande desafio para governos locais ao exigir a implementação de políticas e ações de maneira coordenada e integrada.

DI GIULIO, MARTINS e LEMOS (2016), ao avaliarem os desafios para um planejamento voltado à adaptação no Brasil apresentam três abordagens que relacionam capacidade adaptativa com resiliência e desenvolvimento sustentável, as Capacidades Diferenciadas, Adaptação Sustentável e Trajetórias de Adaptação(DI GIULIO et al., 2016).

Segundo as autoras, a perspectiva de Trajetórias de Adaptação trata a adaptação como um processo que, permeado pelo conceito de desenvolvimento sustentável durante a elaboração de políticas, produzirá ações de múltiplos ganhos (win-win e triple-win) promovendo um crescimento econômico e social sustentável, reduzindo as emissões de GEE e transformando positivamente o ambiente de modo a torná-lo mais adaptado. Para ALLEN et al. e BAZAZ et al. (2018), as Trajetórias de Adaptação (adaptation pathways) são as maneiras que as pessoas, comunidades e sistemas respondem frente aos impactos das mudanças climáticas. Como as mudanças climáticas são sentidas de maneiras 
distintas em cada região, a implementação das ações de adaptação deverá levar em consideração os fatores políticos, econômicos sociais e culturais das áreas afetadas, obrigando o envolvimento de diferentes atores envolvidos (BAZAZ et al., 2018), como o poder público, o setor privado, a academia e a sociedade civil organizada. Nos últimos anos o IPCC tem trabalhado como conceito de caminhos de adaptação relevantes para o aquecimento de $1,5^{\circ} \mathrm{C}\left(1.5^{\circ} \mathrm{C}\right.$-consistent pathways ou adaptation options that are $1.5^{\circ} \mathrm{C}$ relevant), para a promoção de respostas para os impactos previstos, mesmo se atendidas as metas do Acordo de Paris (CONINCK et al., 2018).

Nesse contexto das trajetórias de adaptação, onde as ações a serem aplicadas dependem dos contextos sociais, culturais, ambientais e institucionais, a Adaptação Sustentável surge como uma busca pela conexão entre a adaptação climática com a redução da pobreza e o desenvolvimento das comunidades. Neste sentido, a adaptação sustentável busca evitar a ocorrência de medidas consideradas como má adaptação, atuando de forma a reduzir os riscos e assegurar o bem-estar dos indivíduos, garantindo o equilíbrio socioambiental regional (DI GIULIO et al., 2016).

O consenso de que os efeitos das alterações climáticas serão mais prejudiciais para populações mais pobres residentes de centros urbanos, moradores de assentamentos precários e outros grupos vulneráveis (THE WORD BANK, 2011; FIELD et al., 2014; HOEGH-GULDBERG et al., 2018) ajuda a entender que, além da aplicação de medidas específicas e estruturais para a ampliação da capacidade adaptativa em uma certa região, qualquer melhoria nas condições de vida dessas populações também resultará em uma ampliação de sua capacidade de lidar com os efeitos das alterações climáticas. Essas diferentes opções de atuação para a ampliação da capacidade adaptativa são chamadas de capacidades diferenciadas, sendo compostas pelas capacidades específicas e genéricas (DI GIULIO et al., 2016).

A capacidade específica é composta por medidas que têm como objetivo a antecipação, identificação e resposta aos riscos a que uma comunidade ou região está submetida. A ampliação desta capacidade pode ser obtida com a implementação de ações governamentais, privadas ou realizadas pelo terceiro setor, que atuem diretamente na mitigação dos impactos climáticos. São exemplos de medidas relacionadas à capacidade específica a implantação de sistemas de alerta, planos de evacuação e a construção de infraestruturas adequadas às características climáticas previstas. Já a capacidade genérica é definida pelos fatores sociais, econômicos e políticos que ampliam ou reduzem a vulnerabilidade de uma determinada população. Nesse sentido, mesmo que nenhuma ação específica seja tomada para reduzir os impactos das mudanças climáticas, a simples melhoria das condições de vida dessa população, como a redução da desigualdade, acesso a sistemas de saúde, melhoria dos níveis de educação, etc. ampliará a sua capacidade de adaptação (DI GIULIO et al., 2016). 
Ainda que a capacidade genérica seja a base para o sucesso da ampliação da resiliência de uma população, a sua atuação é limitada, só podendo alavancar a capacidade adaptativa até um determinado ponto. Por outro lado, é menos eficaz a aplicação de medidas para ampliação da capacidade adaptativa de um sistema sem que sejam enfrentados os fatores que ampliam a sua vulnerabilidade. Dessa forma, esses diferentes conceitos de capacidades adaptativas devem ser aplicados de maneira clara, simultânea e integrada para que a adaptação sustentável possa ser alcançada (DI GIULIO et al., 2016). LEMOS et al. (2016) ressalta, entretanto, que a aplicação desses diferentes conceitos de capacidades adaptativas deve ser planejada de maneira específica para cada contexto, onde algumas ações podem apresentar importantes sinergias, ampliando a capacidade adaptativa de uma região, enquanto, para outra região, as mesmas medidas poderão provocar resultados desfavoráveis(LEMOS et al., 2016).

Estes conceitos também apresentam correlações com as abordagens dedicada e transversal de adaptação. Se por um lado a aplicação da abordagem dedicada deverá ampliar a capacidade específica de uma população ou um sistema se adaptar, a abordagem transversal tem tanto o potencial de influenciar a capacidade específica como a capacidade genérica para o enfrentamento e resposta aos estressores, dependendo de como as medidas adaptativas são inseridas ou consideradas pelos instrumentos de gestão municipal.

\subsection{Mudanças climáticas no contexto brasileiro}

Verifica-se um descompasso entre a institucionalização do tema das mudanças climáticas no Brasil frente à sua evolução em âmbito mundial, inclusive quanto às políticas de adaptação. Após sediar a Eco-92 (Conferência das Nações Unidas sobre Meio Ambiente e Desenvolvimento) em 1992, o Brasil só criou um ambiente para a discussão acerca das questões climáticas no ano 2000, através do Fórum Brasileiro de Mudança Climáticas (Decreto 3.515/2000 - recentemente atualizado pelo Decreto 9.082 de junho de 2017)(RODRIGUES FILHO et al., 2016). Nesta época, o IPCC finalizava os trabalhos para a publicação do AR3, marcado pelas avaliações dos impactos das mudanças climáticas e as medidas necessárias para a adaptação (IPCC, 2019; RODRIGUES FILHO et al., 2016; UNFCCC, 2019a, 2019b).

Em 2006 o país apresentou, na COP 12, a sua proposta de incentivos para a redução de emissões de desmatamento. Em 2007 foram criados a Secretaria de Mudanças Climáticas e Qualidade Ambiental (SMCQA - Decreto 6.101 - revogado pelo Decreto no 8.975, de 24/1/2017), com o objetivo de coordenar as ações do Ministério do Meio Ambiente relacionadas às questões climáticas e desenvolver políticas e estratégias relacionadas à mitigação e adaptação; e o Comitê Interministerial dobre Mudanças do Clima (CIM Decreto 6.263) com o objetivo de delinear as diretrizes da política do clima no país e 
orientar a elaboração do Plano Nacional sobre Mudança do Clima(BRASIL, 2007a, 2007b; RODRIGUES FILHO et al., 2016).

O Plano Nacional sobre Mudança do Clima foi publicado no final de 2008, tendo como objetivo identificar, planejar e coordenar as ações e medidas de mitigação e adaptação no país. Para isso, este Plano defendeu o aumento da eficiência dos diversos setores da economia, a ampliação da participação de energias renováveis na matriz energética nacional, a ampliação da participação de biocombustíveis e a redução nas taxas de desmatamento. Além disso, foi considerado o fortalecimento de ações intersetoriais para a redução de vulnerabilidades da população, a identificação dos impactos decorrentes da mudança do clima e o desenvolvimento de pesquisas que definissem estratégias para minimizar os custos da adaptação(BRASIL, 2008).

Elaborada em 2009, a Política Nacional sobre Mudança do Clima apresentou o marco legal para as ações de mitigação e adaptação do país, formalizando os compromissos voluntários assumidos durante a COP 15, ocorrida naquele mesmo ano (RODRIGUES FILHO et al., 2016). A Política Nacional sobre a Mudança do Clima (PNMC - lei $\mathrm{n}^{\circ} 12.187 / 2009$ ) foi regulamentada inicialmente pelo Decreto $\mathrm{n}^{\circ} 7.390 / 2010$, o qual foi substituído no final do ano de 2018 pelo Decreto $n^{\circ}$ 9.578(BRASIL, 2018). Mesmo não estando inserido na lista de países obrigados a reduzir suas emissões (Anexo 1 do Protocolo de Quioto, que havia passado a vigorar no ano de 2005), ficaram definidas pela PNMC, como um compromisso nacional voluntário, as ações de mitigação das emissões de GEE com o objetivo de reduzir entre $36,1 \%$ e $38,9 \%$ as emissões nacionais previstas para o ano de 2020(BRASIL, 2009), o equivalente a 1.168 milhões a 1.259 milhões de tonCO2eq (BRASIL, 2018). Para o atendimento dessas metas, a PNMC estabeleceu o desenvolvimento de planos setoriais de mitigação e adaptação nos âmbitos local, regional e nacional ${ }^{2}$.

Segundo RODRIGUES FILHO et al., (2016), a criação do Centro Nacional de Monitoramento e Alertas de Desastres Naturais (CEMADEN) em 2011 foi a primeira institucionalização da temática da adaptação no país. A criação do CEMADEN ocorreu no contexto do desastre da região Serrana do Rio de Janeiro, que resultou na morte de 947 pessoas, além de mais de 300 desaparecidos e milhares de desabrigados, tendo como finalidade promover o desenvolvimento científico e tecnológico para a prevenção e

\footnotetext{
${ }^{2}$ Conforme informações apresentadas pelo governo brasileiro na COP 24 sediada na Polônia em 2018, o Brasil antecipou o atendimento dessas metas em dois anos, tendo como principal fator de sucesso as ações no setor florestal que permitiram a redução das emissões em 1.288 milhões de toneladas de carbono no período entre agosto de 2017 a julho de 2018, sendo 564 milhões de toneladas relativas à redução do desmatamento na Amazônia, 186 milhões de toneladas à redução do desmatamento no cerrado e os demais 538 milhões de toneladas pela remoção de carbono com a criação e preservação de TIs, UCs, APPs e RL (MMA, 2018).
} 
mitigação de desastres e ampliar a confiabilidade de sistemas de alerta(CEMADEN, 2018).

O Plano Nacional de Adaptação à Mudança do Clima - PNA (BRASIL - MMA, 2016a) só foi lançado em maio de 2016 pela portaria No 150 do Ministério do Meio Ambiente, sendo elaborado pelo Grupo Executivo do Comitê Interministerial sobre Mudança do Clima (GEx-CIM) ao longo dos anos de 2013 a 2016. A sua elaboração buscou apresentar as principais vulnerabilidades e propor diretrizes a serem adotadas para a ampliação da resiliência climática no país. Como estratégia, o PNA tratou de temas e setores separadamente, sendo composto pelos setores de Agricultura, Biodiversidade e Ecossistemas, Cidades, Desastres Naturais, Indústria e Mineração, Infraestrutura (englobando as temáticas de energia, transportes e mobilidade urbana), Povos e Populações Vulneráveis, Recursos Hídricos, Saúde, Segurança Alimentar e Nutricional e Zonas Costeiras (BRASIL - MMA, 2016a).

Segundo o PNA (BRASIL - MMA, 2016b) seu objetivo é gerenciar e reduzir os riscos relacionados aos efeitos adversos das alterações climáticas, e para isso propõe a integração da gestão de risco em planos e políticas setoriais existentes. Complementarmente, o documento informa que a viabilização deste objetivo dependerá da disponibilização de metodologias e informações adequadas aos agentes responsáveis nos três níveis de governo, de modo que em até 4 (quatro) anos, todos os setores vulneráveis possuam as suas estratégias de adaptação aos riscos climáticos (BRASIL MMA, 2016b). Entretanto, os pesquisadores observam dificuldades para que um planejamento estratégico com foco na adaptação entre na agenda nacional, situação ainda mais complicada nos centros urbanos (DI GIULIO et al., 2016).

Elaborada antes da aprovação do Plano Nacional de Adaptação, a elaboração da intenção de Contribuição Nacionalmente Determinada (iNDC) brasileira para o Acordo de Paris considerou a adaptação um elemento fundamental para enfrentar as mudanças climática e seus efeitos, uma vez que contribui para a ampliação da resiliência das populações, ecossistemas, infraestrutura e sistemas de produção. Através do PNA, ainda em elaboração à época, a iNDC propôs a priorização da proteção de populações vulneráveis e a implementação um sistema de gestão do conhecimento sobre o tema. Além disso, devido à uma rápida transformação urbana, o documento afirmava que as políticas de adaptação deveriam ter como elemento fundamental o foco em áreas de risco, habitação, infraestrutura básica, especialmente nas áreas de saúde, saneamento e transporte. Outros temas que a iNDC apresentou como prioritários foram a questão da segurança hídrica e a conservação e uso sustentável da biodiversidade, apresentando como instrumentos para a aplicação dessas medidas o Plano Nacional de Segurança Hídrica, o Plano Estratégico Nacional de Áreas Protegidas e a regularização ambiental por meio da aplicação do código florestal (BRASIL-INDC, 2016). 
O Brasil ratificou a adesão ao Acordo de Paris no dia 12 de setembro 2016, confirmando as metas previstas em sua proposta de reduzir as emissões de GEE em 37\% abaixo dos níveis de 2005, em 2025 e, em 43\% abaixo dos níveis de 2005 em 2030(BRASIL-INDC, 2016). O Acordo de Paris passou a vigorar no dia 4 de novembro de 2016(UNFCCC, 2019a) e o atendimento destas metas determinadas pelo Brasil dependerá da sensibilização dos atual e futuros governos federais ${ }^{3}$ e de uma intensificação das ações de governos municipais para a redução das emissões de GEE.

Em seus compromissos, o Brasil ressalta a importância do engajamento e esforços dos governos locais para o combate das mudanças climáticas. Para atingir as metas apresentadas, foram propostos o aumento da participação de bioenergia sustentável na matriz energética nacional com a ampliação do uso do etanol e do biodiesel, a redução o desmatamento e a ampliação do reflorestamento (com o objetivo de reflorestar 12 milhões de hectares de florestas), a ampliação da utilização de energias renováveis no setor elétrico além da energia hídrica (incluindo o uso doméstico de fontes de energia não fóssil), além da aplicação e fortalecimento do Plano de Agricultura de Baixa Emissão de Carbono (Plano ABC), alterações no setor industrial, e, no setor de transporte, a promoção de medidas de eficiência e a melhoria das infraestruturas de transporte e a disponibilização de transporte público em áreas urbanas(BRASIL-INDC, 2016).

\subsubsection{Impactos na Região Sudeste do Brasil}

O relatório Impactos, Vulnerabilidades e Adaptação às Mudanças Climáticas elaborado pelo Painel Brasileiro de Mudança do Clima (ASSAD; MAGALHÃES, 2014) apresentou uma síntese dos impactos regionalizados para o contexto brasileiro. Segundo os autores, até o final do século são previstos para a região sudeste do Brasil uma elevação de 4 a $4,5^{\circ} \mathrm{C}$ na temperatura média do ar, um possível aumento de 10 a $15 \%$ na precipitação pluviométrica de outono e a possibilidade de secas no verão. Já MARGULIS (2017), no Guia de Adaptação às Mudanças Climáticas para Entes Federativos, apresentando informações do Instituto Nacional de Pesquisas Espaciais (INPE) de 2014, afirma que os cenários pessimistas para o sudeste brasileiro preveem ampliações de temperatura em até $8^{\circ} \mathrm{C}$ para o ano de 2100 , além de redução acentuada de chuvas durante o verão e intensificação de ventos para regiões com altitude de 100 (cem) metros no nível do mar (MARGULIS, 2017).

\footnotetext{
${ }^{3}$ O governo brasileiro eleito no ano de 2018 afirma não ter a agenda climática como uma de suas prioridades. Mesmo sendo anunciada antes de sua posse, o novo presidente fez questão de informar que a decisão de retirar a candidatura do Brasil para sediar a COP-25 em 2019 teve a sua participação. Ainda que justificada pelo governo da época por dificuldades orçamentárias, o novo governo já afirmou que considera o Acordo de Paris ruim para o desenvolvimento do país e que teme a perda de soberania sobre o território nacional com o seu cumprimento.
} 
Além disso, deverá ser observada uma maior frequência na ocorrência de dias quentes e uma redução de noites frias no sudeste brasileiro, assim como uma forte tendência para a ocorrência de ondas de calor. É prevista ainda a ocorrência de eventos extremos com a precipitação de grandes volumes de chuva em curtos espaços de tempo, ocasionando alagamentos e enchentes, principalmente em regiões mais adensadas e impermeabilizadas, e a ampliação de deslizamentos de encostas (ASSAD; MAGALHÃES, 2014; MARGULIS, 2017).

A ampliação da população urbana e a forma de ocupação do solo em metrópoles como as de São Paulo e Belo Horizonte deverão provocar maiores pressões sobre investimentos em programas de contenção de enchentes e remoção de residentes de áreas de risco, exigindo em um incremento de programas de defesa civil de modo a fornecer respostas para situações extremas (ASSAD; MAGALHÃES, 2014). Essas alterações ainda irão impactar diretamente o tráfego diário de milhões de pessoas no Estado de São Paulo, principalmente as populações mais pobres, o que demandará dos municípios o desenvolvimento de um sistema de transporte diversificado, inclusivo e seguro (EICHHORST, 2009).

Também ocorrerão impactos no meio agrícola paulista que deverá se adaptar aos novos padrões de temperatura do ar, altas taxas de evaporação e dias secos consecutivos, o que poderá afetar a agricultura de subsistência, a pecuária e a agroindústria. Esta situação poderá levar à escassez de alimentos, elevação de seus preços e ocasionar desabastecimento(ASSAD; MAGALHÃES, 2014; MARGULIS, 2017). É sugerida ainda a adoção de técnicas alternativas de cultivo "como as de plantio direto e consórcio com florestas, gado e agricultura, medidas necessárias para se minorar riscos climáticos futuros" (ASSAD; MAGALHÃES, 2014). De forma complementar, os autores defendem que programas de conservação da biodiversidade sejam incentivados como parte de uma estratégia de reduzir a vulnerabilidade regional a um potencial aumento do risco de insegurança alimentar.

Outro fator que deverá pressionar a segurança alimentar, além de causar impactos no fornecimento e na qualidade da água e na saúde da população, é a escassez hídrica, a qual deverá receber especial atenção para que os impactos à qualidade de vida dos habitantes da região sejam reduzidos (ASSAD; MAGALHÃES, 2014; MARGULIS, 2017). Segundo MARENGO et al. (2015), os níveis de precipitações no sul e sudeste brasileiro dependem da produção e transporte de umidade da bacia amazônica, cuja garantia possui estreita relação com a redução do desmatamento e ampliação de áreas reflorestadas. Entretanto, os autores ressaltam que eventos de escassez hídrica como os observados na Região Metropolitana de São Paulo entre os anos de 2014 e 2015 não resultam apenas das condições climáticas anormais, mas também da ineficiência do gerenciamento do abastecimento do sistema paulista, o qual precisa ser aprimorado (MARENGO et al., 2015). 
A saúde poderá ser influenciada direta ou indiretamente pela ocorrência de fenômenos climáticos, tendo como variáveis determinantes a idade, situação da saúde e condições sociais da população. $\mathrm{O}$ aumento da temperatura e a ocorrência de picos de chuvas previstos para o sudeste brasileiro podem influenciar o padrão de disseminação e dinâmica de doenças vetoriais, como a dengue e a leishmaniose, condições onde os vetores se proliferam mais rapidamente. Doenças de veiculação hídrica também podem ser agravadas durante enchentes e períodos de seca, ao afetar a qualidade e o acesso da população à água. Outros impactos na saúde são relacionados à desnutrição e implicações no desenvolvimento infantil devido à redução na disponibilidade de alimentos e pela contaminação por agrotóxicos, cujo uso é intensificado na tentativa de adaptar a produção agrícola aos impactos climáticos. Além disso, as alterações climáticas ampliam os riscos associados a doenças respiratórias e cardiovasculares, atingindo principalmente crianças menores de 5 anos e adultos com mais de 65 anos. Como efeito das fortes chuvas que serão observadas no sudeste do Brasil, agravadas pela impermeabilização e ocupação desordenada das capitais, amplia-se também o risco de deslizamentos e inundações, aumentando os índices de morbidade e mortalidade da população(ASSAD; MAGALHÃES, 2014).

Frente às previsões para a região sudeste do Brasil, o relatório do Painel Brasileiro de Mudança do Clima (ASSAD; MAGALHÃES, 2014) defende a elaboração de programas que apresentem respostas a estes impactos e que prevejam a implantação de profundas intervenções urbanas, os quais deverão ser considerados como estratégicos para a alocação dos recursos públicos pelos governantes.

\subsubsection{Evolução do tema no Estado de São Paulo}

Localizado na região sudeste do Brasil e composto por 645 municípios, o Estado de São Paulo é o mais rico e populoso do país. Sua área abrange somente 2,9\% do território brasileiro, mas é a residência para $21 \%$ da população nacional. Na economia o seus números também impressionam, em 2015, só as atividades econômicas realizadas no estado representaram 32,4\% do PIB brasileiro (SÃO PAULO (ESTADO), 2018a).

O histórico da ocupação do solo paulista resultou em uma distribuição desigual de suas infraestruturas e população, resultando na concentração de $87 \%$ da população paulista em pouco mais de um terço de seu território. Estão incluídas nestas áreas as Regiões Metropolitanas de São Paulo, de Campinas, da Baixada Santista, do Vale do Paraíba e Litoral Norte, de Sorocaba e de Ribeirão Preto, com populações que variam entre 1,6 milhões a 20,7 milhões de habitantes. Existem também grandes concentrações populacionais e de serviços nas aglomerações urbanas e nos centros regionais de Barretos, Botucatu, Catanduva, Franca, Jaú, Marília, Ourinhos e Presidente Prudente, formado por 
municípios que funcionam como polos regionais de desenvolvimento (SÃO PAULO (ESTADO), 2018a).

A concentração populacional em certas regiões do estado teve estreita relação com a evolução e distribuição das atividades econômicas e infraestruturas existentes. Inicialmente, as indústrias paulistas se concentraram ao longo das linhas férreas, situação que foi alterada com a ampliação da malha rodoviária no estado, funcionando como novos eixos de indução da concentração populacional. Entretanto, a distribuição destas atividades não foi homogênea ao redor de todas as rodovias. A proximidade aos mercados consumidores e às infraestruturas de importação e exportação foram preponderantes para que a maior concentração de atividades ocorresse próximo à metrópole paulistana e ao porto de Santos. A Figura 3 demonstra este processo de concentração da população ao redor do que é conhecido como a Macrometrópole Paulista (MMP), definida como uma rede de cidades com intensas articulações funcionais estabelecidas nos arredores da Região Metropolitana de São Paulo, e as previsões de ampliação desta concentração para os próximos anos(SÃO PAULO (ESTADO), 2018a). 
Figura 3 - Evolução da densidade populacional dos municípios paulistas e sua projeção para
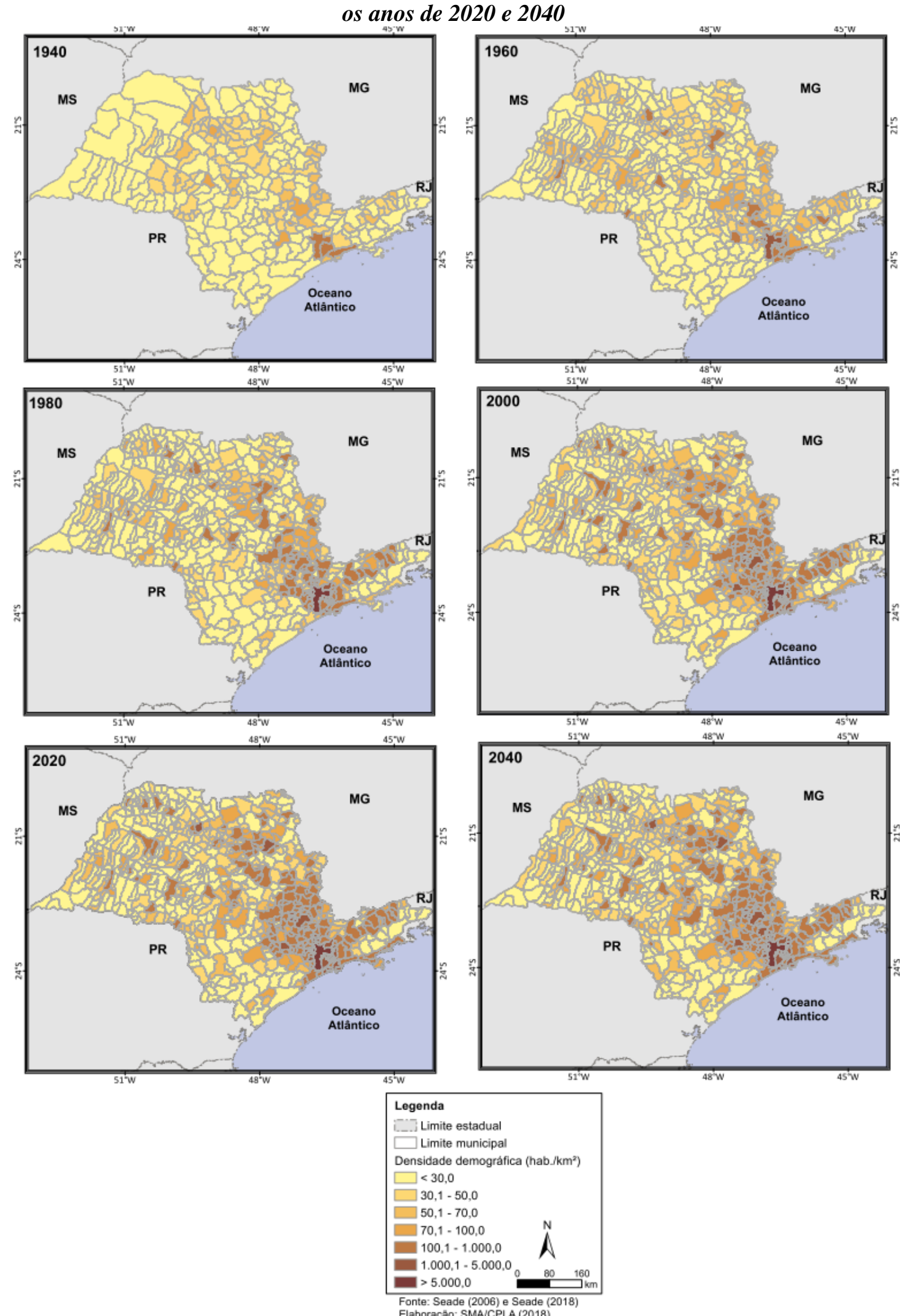

Fonte:(SÃO PAULO (ESTADO), 2018a) 
Antes da colonização do Brasil, 81\% do Estado de São Paulo era encoberto pelo bioma Mata Atlântica e o restante era principalmente Cerrado e Campos Naturais. Com o passar dos anos, as pastagens, as culturas agrícolas e o crescimento das áreas urbanizadas reduziram estes remanescentes de vegetação nativa a 17,5\% do território. A maneira fragmentada que esta vegetação está distribuída pelo estado dificulta o fluxo gênico, as funções ecológicas das áreas vegetadas e a conservação da biodiversidade, ampliando os riscos de extinção de espécies e da perda de biodiversidade. A Figura 4 apresenta a distribuição dos remanescentes de vegetação do Estado de São Paulo, onde é possível observar a sua predominância nas proximidades do oceano atlântico e a maior incidência em área de maior declividade ao longo da Serra do Mar e do Vale do Ribeira(SÃO PAULO (ESTADO), 2018a).

Figura 4 - Remanescentes vegetais do Estado de São Paulo - 2008/2009

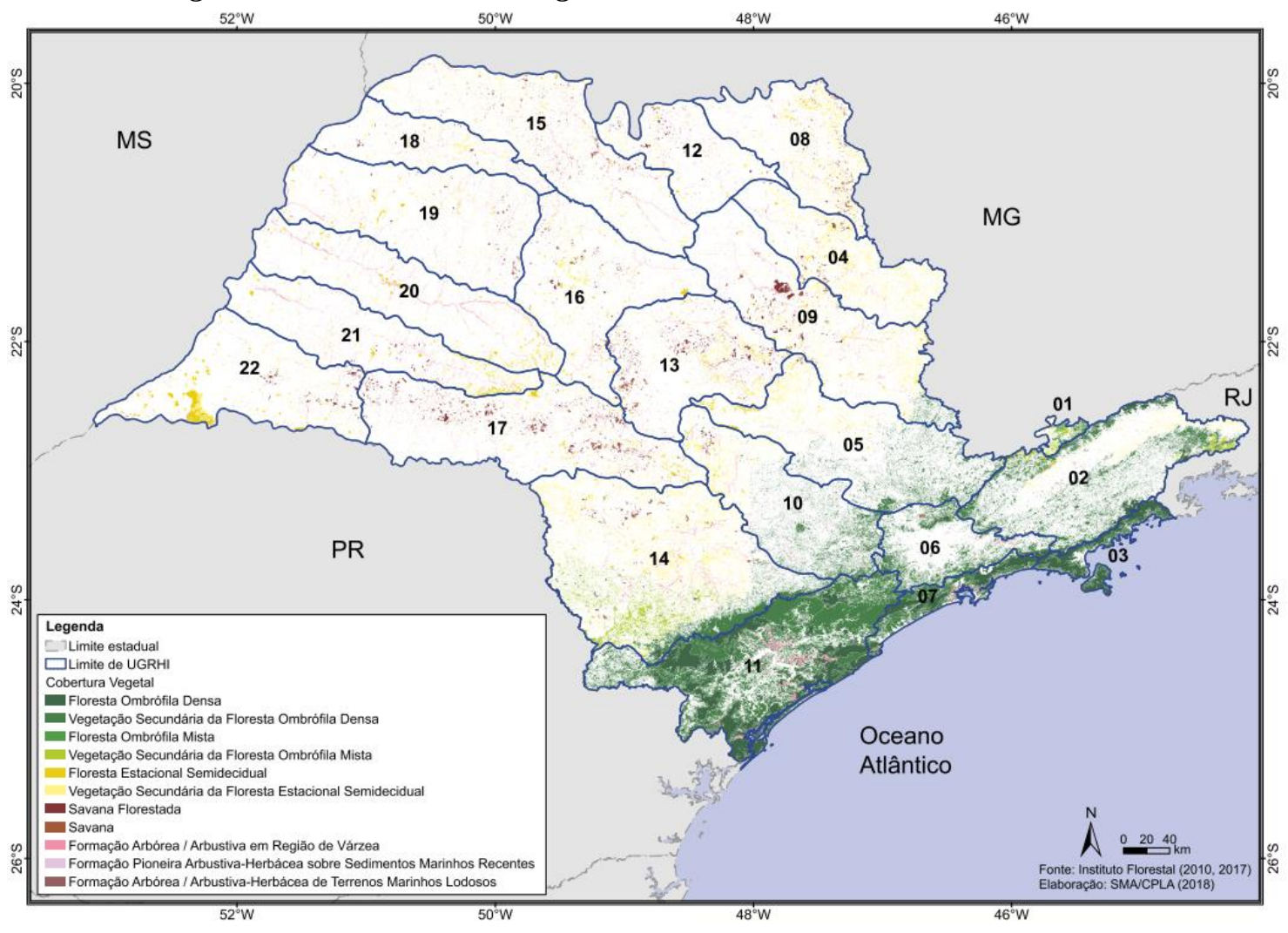

Fonte:(SÃO PAULO (ESTADO), 2018a)

O Estado de São Paulo apresenta diversos desafios em relação ao saneamento ambiental. Ainda que a coleta de esgoto abrangesse $88 \%$ dos efluentes gerados no estado, o índice de tratamento ainda era de $64 \%$ em 2017, tendo o restante despejado diretamente nos corpos d'água. De acordo com um levantamento realizado em 2011, cerca de $60 \%$ dos municípios não possuem cadastro de suas redes de drenagem, o que dificulta o planejamento e manejo das águas pluviais, principalmente com a previsão de ampliação da frequência e intensidade das precipitações. São preocupantes também os dados de doenças relacionadas ao saneamento ambiental inadequado, decorrentes de problemas no 
abastecimento de água, coleta e tratamento de esgotos sanitários, manejo de resíduos sólidos e drenagem de águas pluviais urbanas. Nos últimos dez anos foram observados picos de internações nos anos de 2010 e 2015, com média de 29.303 internações. Ainda que no ano de 2017 o número de internações tenha caído a 14.211 casos, o número de mortes relacionadas a estes problemas seguem em patamares semelhantes aos anos mais críticos, tendo ocorrido 1.530 mortes em 2017, frente a uma média de 1.855 mortes nos anos de 2010 e 2015 (SÃO PAULO (ESTADO), 2018a).

Quanto às ações específicas dos municípios paulistas frente as mudanças climáticas, o relatório do Perfil dos Municípios Brasileiros apresenta o levantamento de que somente 36 municípios paulistas possuem leis específicas sobre a adaptação e mitigação das mudanças climáticas, o equivalente a apenas 5,6\% dos municípios do estado (IBGE, 2018a). Dessa forma, mesmo São Paulo sendo o estado mais rico e populoso da federação, ainda são observadas muitas deficiências em sua gestão climática e ambiental, principalmente no que diz respeito à atuação de seus municípios.

As políticas relacionada às mudanças climáticas no Estado de São Paulo tiveram início em 1995, através da Resolução SMA N²2/1995, com a criação de um Grupo de Trabalho para a elaboração do Programa Estadual de Mudanças Climáticas Globais (SÃO PAULO (ESTADO), 1995), o qual deu origem ao Programa Estadual de Mudanças Climáticas do Estado de São Paulo (PROCLIMA) e ao Programa Estadual de Proteção à Camada de Ozônio (PROZONESP). Como justificativas para a criação deste GT, esta resolução cita as alterações climáticas do planeta e seus efeitos negativos à humanidade, a importância de uma atuação em nível regional, nacional e internacional para a redução das emissões de GEE e a necessidade de serem identificadas medidas mitigadoras e de adaptação.

No ano de 2005, o Decreto Estadual № 49.369 instituiu o Fórum Paulista de Mudanças Climáticas Globais e de Biodiversidade, tendo como finalidade a conscientização e mobilização da sociedade a respeito desses temas. Dentre seus objetivos, este Fórum se propôs a definir normas para a elaboração de uma Política Estadual de Mudanças Climáticas(SÃO PAULO (ESTADO), 2005).

A Política Estadual de Mudanças Climáticas (PEMC) só foi instituída em 2009 pela Lei No 13.798 (SÃO PAULO (ESTADO), 2009), sendo regulamentada no ano seguinte pelo Decreto $N^{o}$ 55.947(SÃO PAULO (ESTADO), 2010). A PEMC tem como principais objetivos estabelecer os compromissos do Estado de São Paulo para o fornecimento de respostas às mudanças climáticas, viabilizar condições para as adaptações necessárias e contribuir para a redução ou estabilização das concentrações de GEE na atmosfera. Dentre os compromissos firmados, o Estado de São Paulo se comprometeu a reduzir, até 2020, as suas emissões de dióxido de carbono $\left(\mathrm{CO}_{2}\right)$ em $20 \%$ frente aos níveis observados no ano de 2005. 
Ainda assim, conforme os dados obtidos no Sistema de Estimativas de Gases de Efeito Estufa (SEEG, 2019), as emissões de $\mathrm{CO}_{2}$ no Estado de São Paulo passaram de 80.896.963 toneladas em 2005 para 104.240.071em 2017. Ressalta-se que o sistema não apresentou as emissões relativas à agropecuária e que as emissões relacionadas a resíduos não aparecem na escala do gráfico, tendo variado entre 45 a 72 mil toneladas por ano entre 2005 e 2017. A evolução das emissões paulistas pode ser observada na Figura 5.

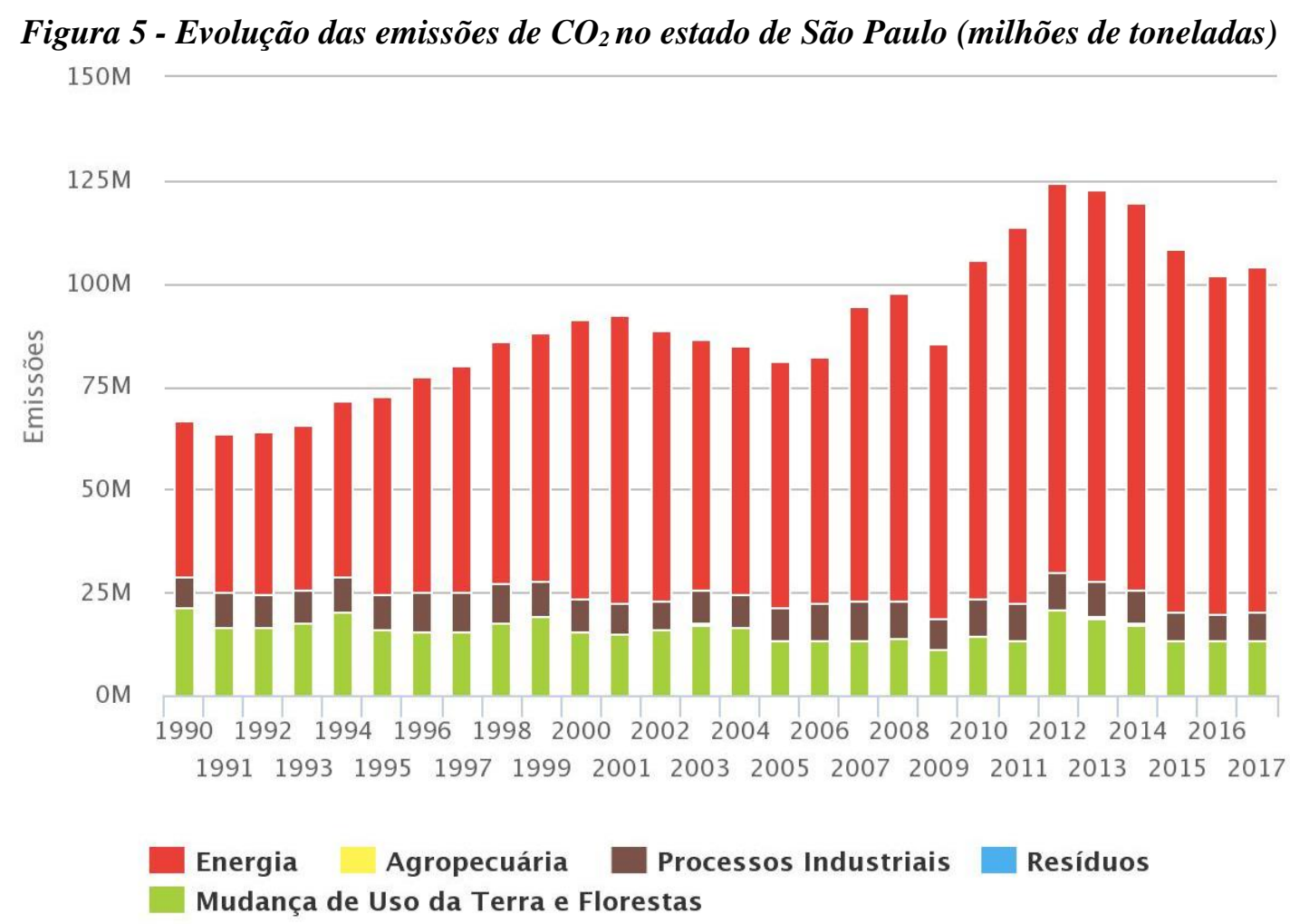

Fonte:(SEEG, 2019)

Dentre os objetivos específicos da PMEC, constam a elaboração das comunicações das emissões estaduais, função cuja coordenação ficou a cargo do PROCLIMA, e a realização da Avaliação Ambiental Estratégica (AAE) para o Estado, prática que até o momento não foi implementada da maneira que deveria. A AAE é o processo de análise integrada dos impactos ambientais e socioeconômicos resultantes das atividades humanas em um determinado território com o objetivo de promover o desenvolvimento sustentável. Sua elaboração deverá contar com a utilização e proposição de indicadores de avaliação e monitoramento, resultando em recomendações para políticas, planos e programas e na identificação de medidas de mitigação aos impactos previstos (SÃO PAULO (ESTADO), 2009, 2010). 
A PEMC apresentou ainda os objetivos a serem alcançados com o disciplinamento do uso do solo urbano e rural, os quais são sintetizados nos itens a seguir(SÃO PAULO (ESTADO), 2009):

- Evitar a ocupação desordenada de áreas vulneráveis;

- Atenuar os efeitos de desastres de origem climática;

- Promover o transporte sustentável e reduzir o consumo de combustível;

- Adaptar a agricultura e as atividades extrativistas aos novos padrões de clima e de disponibilidade hídrica, reduzindo os impactos associados a estas atividades;

- Ordenar os múltiplos usos da água de maneira racional e sustentável;

- Integrar a dimensão climática aos planos de macrodrenagem e recursos hídricos;

- Incorporar formas de proteção do microclima no ordenamento territorial urbano;

- Delimitar, demarcar e recompor com cobertura vegetal, principalmente em áreas protegidas;

- Identificar e mapear as vulnerabilidades existentes nos territórios municipais;

- Mapear áreas a serem preservadas pelo Estado ou Municípios visando a manutenção do equilíbrio bioclimático do território paulista;

- Aumentar a cobertura vegetal das áreas urbanas; e,

- Promover a descentralização da atividade econômica e dos serviços públicos.

Fonte:(SÃO PAULO (ESTADO), 2009)

No âmbito da adaptação, a PEMC estabeleceu o prazo de 2 (dois) anos para a apresentação de um Plano Participativo de Adaptação aos Efeitos das Mudanças Climáticas no Estado de São Paulo. Em janeiro de 2012, foi publicada a SMA Nº15/2012, que exigiu a apresentação de uma versão para consulta pública deste plano participativo. A denominada "Versão Zero" (SÃO PAULO (ESTADO), 2013) foi apresentada no ano de 2013, entretanto, sem que as ações tivessem prosseguimento. Dessa forma, o Estado de São Paulo não possui um planejamento formal para a adaptação, contando somente com um documento preliminar e elaborado sem o crivo da sociedade, estando em desconformidade com o previsto na PEMC.

Outra iniciativa realizada pelo governo do Estado de São Paulo foi a criação do Programa Estadual de Prevenção de Desastres Naturais e de Redução de Riscos Geológicos pelo Decreto $\mathrm{N}^{\mathrm{o}}$ 57.512, de 11 de novembro de 2011, tendo como objetivos elaborar diagnósticos e mapeamentos de áreas de risco; desenvolver estratégias de planejamento do uso e ocupação do solo adequadas aos riscos observados; integrar e estimular estratégias de monitoramento e fiscalização; sistematizar ações institucionais para a redução de riscos; e, promover a capacitação e o treinamento de equipes dos municípios e de outros agentes relacionados à gestão de riscos(SÃO PAULO (ESTADO), 2011). 
No ano de 2015, o Governo do Estado instituiu o Grupo de Trabalho para elaboração do Plano ABC no âmbito do Estado de São Paulo(SÃO PAULO (ESTADO), 2015). Sob a coordenação do Ministério da Agricultura, Pecuária e Abastecimento (MAPA) e da Secretaria de Agricultura e Abastecimento (SSA) do Estado de São Paulo, foi elaborado em 2016 o Plano Estadual de Mitigação e de Adaptação às Mudanças Climáticas para a Consolidação de uma Economia de Baixa Emissão de Carbono na Agricultura - Plano ABC São Paulo (SÃO PAULO (ESTADO), 2016), composto por seis programas com o objetivo de apoiar a mitigação dos GEE pelo setor agropecuário e um que propõe as ações para a adaptação do setor às mudanças climáticas. Para a adaptação, as ações propostas englobam a definição de prioridades para a adaptação agropecuária, a promoção e identificação de fundos de financiamento para pesquisa em adaptação e a identificação e disseminação de técnicas que ampliem a resiliência de sistemas agropecuários (SÃO PAULO (ESTADO), 2016).

Outro importante instrumento proposto pela PEMC para o planejamento ambiental e o desenvolvimento regional é o Zoneamento Ecológico Econômico (ZEE). Partindo das características ambientais e socioeconômicas de cada região, a elaboração do ZEE possibilita a identificação de potencialidades e vocações dos territórios, resultando no estabelecimento das diretrizes de ordenamento e de gestão territorial (SÃO PAULO (ESTADO), 2009, 2017). Atualmente (ano de 2019), o ZEE do Estado de São Paulo encontra-se em elaboração, sendo guiado por diretrizes estratégicas que possuem estreita relação com a temática da adaptação climática. Segundo a cartilha desenvolvida para divulgar os andamentos dos trabalhos (SÃO PAULO (ESTADO), 2018b), o ZEE-SP deverá buscar a Resiliência às Mudanças Climáticas, a Segurança Hídrica, a Salvaguarda da Biodiversidade, a Redução das Desigualdades Regionais e busca por uma Economia Competitiva e Sustentável, atuando simultaneamente nas capacidades específicas e genéricas relacionadas à adaptação climática (DI GIULIO et al., 2016).

Partindo de um diagnóstico do meio físico-biótico, da dinâmica socioeconômica e da organização jurídico institucional do território, o ZEE-SP pretende trabalhar com indicadores e projeções que permitam projetar as tendências das dinâmicas territoriais do estado a longo prazo (SÃO PAULO (ESTADO), 2018b). Neste prognóstico serão identificadas unidades de intervenção que resultarão na definição das zonas ecológicaseconômicas e suas diretrizes e metas específicas. Para isso, o ZEE precisará de informações locais e regionais que subsidiem o entendimento das dinâmicas do território e suas necessidades, sendo fundamental o entendimento das características dos municípios e das regiões metropolitanas do estado.

No final de 2018 foi publicado pela Assessoria Institucional e Internacional Mudanças Climáticas do Governo do Estado de São Paulo um documento contendo os balanços das atividades realizadas naquele ano e as recomendações para a internalizar a temática climática no Sistema Ambiental Paulista e cumprir as atribuições previstas na PEMC. Segundo os autores, um dos principais desafios para a aplicação da PEMC é a 
consolidação da governança, tida como fundamental para o acompanhamento das ações propostas e para o envolvimento dos atores do governo e da sociedade. Para tal, foi proposta a aproximação das ações do estado com os governos locais, os quais, segundo o relatório, "geralmente carecem de acesso à informação e de recursos humanos capacitados, apesar de possuírem maior contato com os problemas locais e capacidade de ação imediata”(SÃO PAULO (ESTADO), 2018c). 


\section{ADAPTAÇÃO CLIMÁTICA EM ÂMBITO LOCAL}

A principal relação entre mudanças climáticas e cidades diz respeito à característica mundial de uma concentração cada vez maior de pessoas em centros urbanos, resultando em um grande desafio para os governos locais que deverão pautar as suas políticas públicas de modo a minimizar os impactos dos eventos extremos sobre essa população. Segundo a Organização das Nações Unidas (ONU, 2014) a população mundial residente em áreas urbanas passará de 54\% em 2014 para $66 \%$ até a metade do século. No Brasil, tal situação é ainda mais complexa, uma vez que, conforme o censo demográfico de 2010 (IBGE, 2010) a população urbana brasileira já atingia $84 \%$.

A Figura 6 demonstra a crescente concentração urbana da população mundial entre os anos de 1950 e 2014, e a sua projeção para 2050, onde observa-se a previsão de ampliação do número de países cuja população em áreas urbanas deve ultrapassar a marca de $75 \%$ (ONU, 2014).

Figura 6 - Evolução do percentual de população residente em áreas urbanas

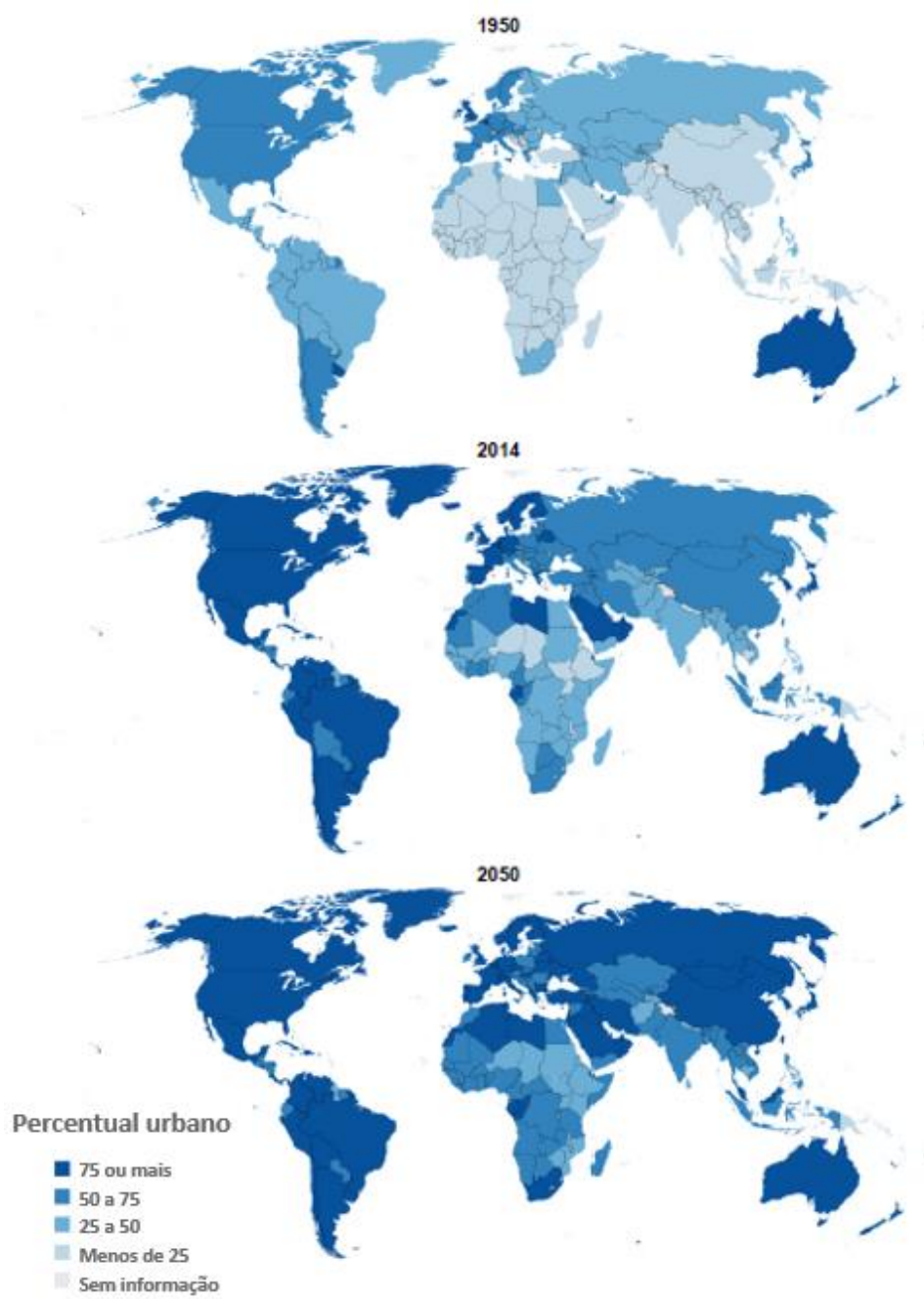

Fonte: (ONU, 2014) 
A região sudeste brasileira, composta pelos estados do Espirito Santo, Minas Gerais, Rio de Janeiro e São Paulo ocupa somente 10,86\% do território brasileiro mas habita 42,13\% da população brasileira (ASSAD; MAGALHÃES, 2014). Já percentual da população residindo em áreas urbanas nesta região é de 92,9\%, ultrapassando os já altos $84 \%$ de habitantes brasileiros em áreas urbanas (IBGE, 2010). A Figura 7 apresenta o percentual da população urbana por município no Estado de São Paulo de acordo com o censo demográfico do IBGE realizado em 2010.

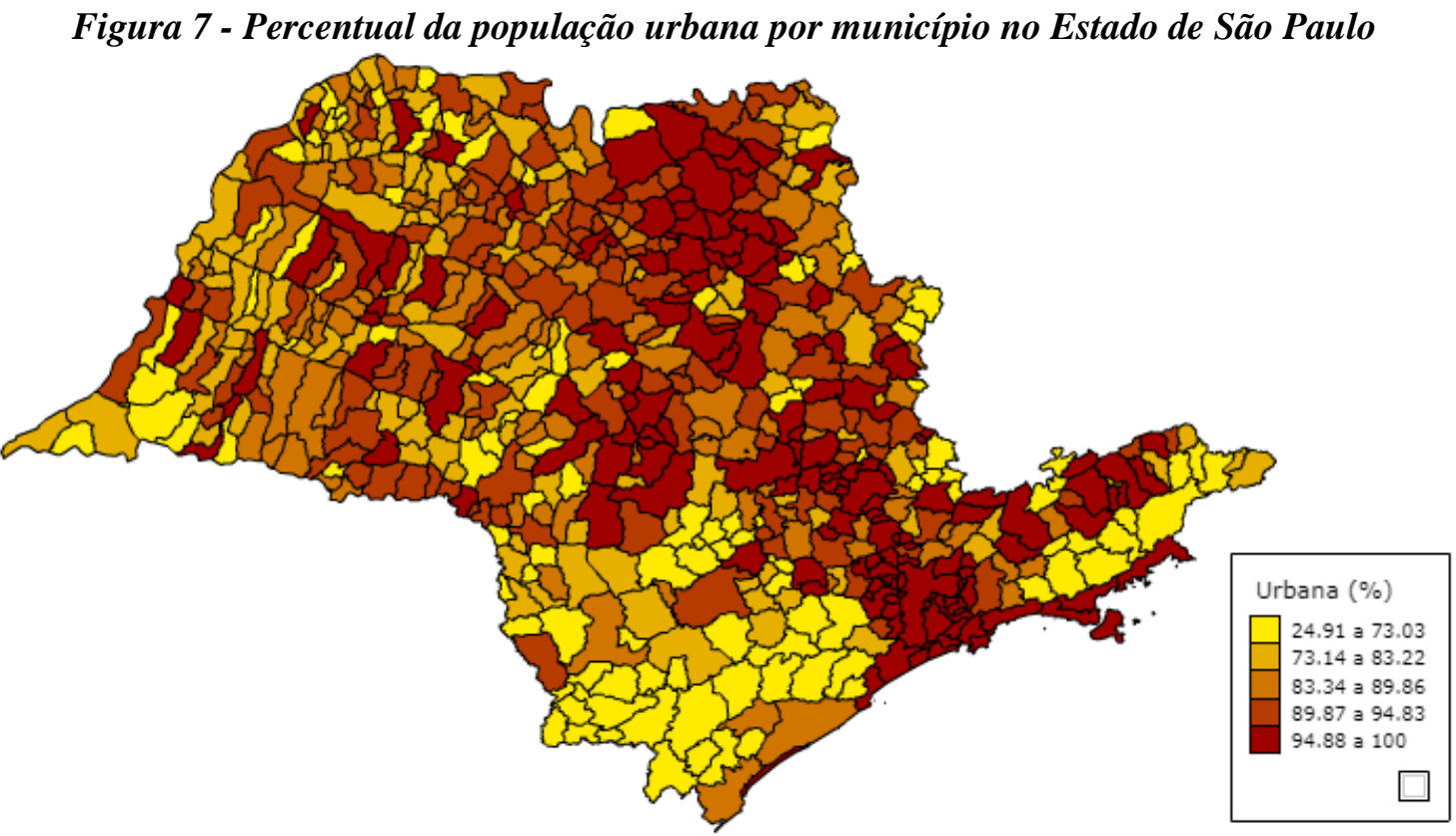

Fonte: (IBGE, 2010)

De acordo com CONINCK et al. (2018), os centros urbanos terão uma ampliação de 70 milhões de habitantes por ano até 2050, sendo que a maioria dessas pessoas residirá em cidades pequenas e médias de países subdesenvolvidos ou em desenvolvimento. O reflexo disso na ocupação do solo ainda é mais preocupante, uma vez que, em média, a expansão das áreas ocupadas crescem o dobro da taxa de crescimento populacional nos centros urbanos(BAZAZ et al., 2018), exigindo políticas imediatas para restringir o espraiamento da mancha urbana.

A expansão das cidades e de sua população em um contexto de aquecimento podem ocasionar ondas de calor ainda mais extremas e aumentar o efeito de ilhas de calor (HOEGH-GULDBERG et al., 2018), além ampliar os índices de emissões de gases de efeito estufa (CONINCK et al., 2018). Em 2014, 70\% das emissões mundiais de GEE relacionadas à energia já eram provenientes de cidades, um percentual que continuará crescendo(FONG et al., 2014). 
Além dos centros urbanos serem um dos principais responsáveis pela emissão de Gases de Efeito Estufa (GEE), o que é intensificado em grandes ou megacidades ${ }^{4}$, é nesses ambientes que os efeitos das mudanças climáticas serão mais devastadores, influenciando diretamente a vida e saúde de bilhões de pessoas ao redor do mundo (MONZONI et al., 2009; NOBRE et al., 2011; RIBEIRO; SANTOS, 2016).

Estudos mostram que esta grande concentração populacional em áreas urbanas e o aumento da frequência de eventos extremos deverão resultar na ampliação de enfermidades como a cólera e outras doenças diarréicas relacionadas com a quantidade e qualidade da água; da mortalidade e de doenças cardiovasculares relacionadas ao calor; da morbimortalidade e traumatismos decorrentes de desastres de origem natural; da desnutrição e subnutrição devido às secas; além de transtornos psicossociais, doenças cardiorrespiratórias, dermatoses e a variação na distribuição espacial e temporal de vetores como dengue, febre amarela, malária, leishmaniose, etc.(IPCC, 2007; OMS, 2008; BRASIL, 2013).

O relatório de 2018 da Lancet Countdown sobre saúde e mudanças climáticas (AMANN et al., 2018) sintetiza as correlações entre esses dois temas. Este relatório avaliou 43 (quarenta e três) indicadores de impacto e resposta organizados em cinco dimensões: impactos das mudanças climáticas, exposição e vulnerabilidade; planejamento da adaptação e resiliência na saúde; ações de mitigação e seus co-benefícios com a saúde; economia e finanças; e, engajamento político e da população. Segundo o relatório, há uma tendência de ampliação de situações já observadas, como por exemplo as alterações na ocorrência de ondas de calor e de doenças disseminadas por vetores, e os impactos na capacidade de trabalho e na segurança alimentar, podendo atingir níveis de risco inaceitáveis para a saúde da população(AMANN et al., 2018).

Além disso, o Lancet Countdown 2018 afirma que o baixo ritmo das reduções de emissões e da ampliação da capacidade adaptativa são uma ameaça tanto para a qualidade de vida da população como para a viabilidade dos sistemas nacionais de saúde. Por fim, apesar desses atrasos na implantação de medidas efetivas, considera que vários setores têm iniciado a sua transição para uma economia de baixo carbono e que a saúde das próximas gerações dependerá da natureza e escala dessas mudanças. Entretanto, caberia também aos profissionais de saúde realizar a internalização das questões climáticas em suas práticas, sendo crucial a inclusão das mudanças climáticas como pontos centrais no planejamento da saúde pública(AMANN et al., 2018). A Figura 8, a seguir, correlaciona os impactos previstos de acidificação dos oceanos, da ampliação das variações e extremos de temperaturas e de uma maior concentração de outros poluentes com impactos associados na saúde humana, como a desnutrição, impactos na saúde mental e doenças

\footnotetext{
${ }^{4}$ A Organização das Nações Unidas (ONU) considera megacidades aquelas habitadas por mais de 10 (dez) milhões de habitantes (ONU, 2014)
} 
cardiovasculares, respiratórias e transmitidas por vetores. Além disso, são apresentadas correlações indiretas com a saúde através de determinantes sociais.

\section{Figura 8 - Correlações das Mudanças Climáticas com a Saúde}

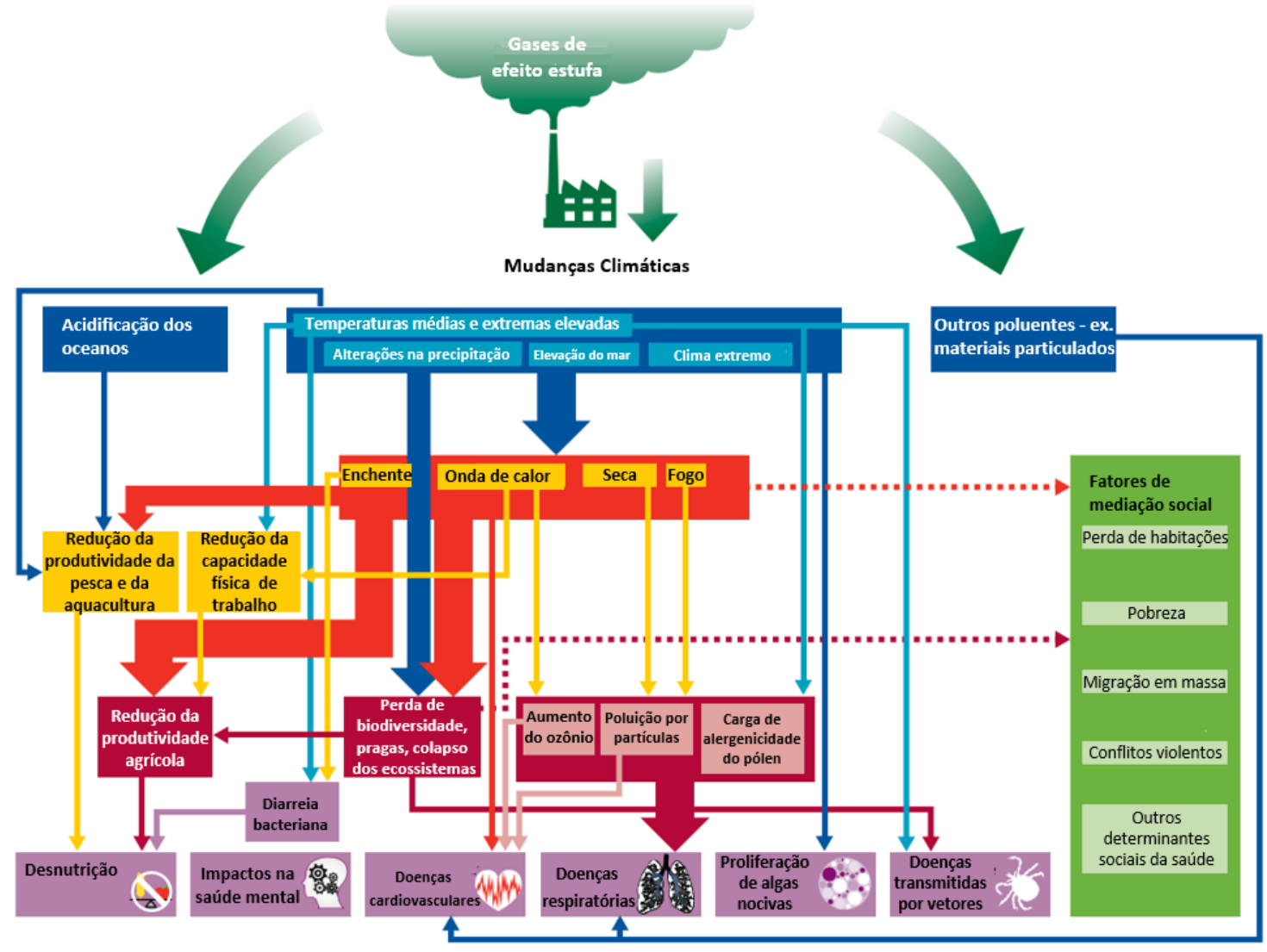

Fonte: Adaptado de (AMANN et al., 2018)

Os governos regionais e locais podem se estruturar para a criação de cidades inteligentes, verdes, resilientes, saudáveis, sustentáveis e adaptadas à esta nova realidade, planejando o seu desenvolvimento de maneira consistente com os impactos previstos pela elevação mínima de temperatura em $1,5^{\circ} \mathrm{C}$, conforme definido pelo Acordo de Paris (CONINCK et al., 2018). Por se tratarem de sistemas dinâmicos, as cidades deverão responder a impactos específicos às suas características locais, dessa forma, os governantes precisam compreender as exposições à que as cidades estão submetidas e suas principais sensibilidades, capacitar o corpo técnico municipal, desenvolver políticas públicas e investir em ações que realmente reduzam a sua vulnerabilidade(THE WORD BANK, 2011).

Na maioria dos casos, um aquecimento de $2^{\circ} \mathrm{C}$ irá causar maiores riscos em áreas urbanas, impacto que será sentido especialmente pelos mais pobres, por aqueles com maior sensibilidade à elevação do nível do mar ou pelo afetados por eventos localizados de estiagem (HOEGH-GULDBERG et al., 2018). Dessa forma, os governos locais deverão 
atuar também na mitigação, através da adoção de medidas que reduzam as suas emissões de gases de efeito estufa (HOEGH-GULDBERG et al., 2018).

Áreas rurais e agrícolas também deverão lidar com os riscos relacionados à mudança do clima. São previstos impactos na disponibilidade de água, na segurança alimentar e no desenvolvimento dos cultivos, forçando diversas regiões do mundo a alterar a localização e espécies cultivadas (FIELD et al., 2014). Com a ajuda dos governos locais, as produções agrícolas e outras técnicas extrativistas deverão ser fortalecidas e tornadas mais resilientes (ALLEN et al., 2018).

Da mesma forma que nos centros urbanos, os impactos sobre o bem-estar das populações rurais mais pobres deverão ser maiores. Esta situação é agravada pelo fato de que no meio rural a maioria das famílias pobres possuem uma maior dependência dos recursos naturais para a sobrevivência, ampliando a sua sensibilidade aos impactos das mudanças do clima(LEMOS et al., 2016). De acordo com FIELD et al. (2014), esta situação deverá afetar principalmente famílias lideradas por mulheres e famílias com pouco acesso à terra, tecnologias modernas, infraestruturas e educação (FIELD et al., 2014), setores que deverão receber especial atenção dos governos locais.

\subsection{Impactos previstos para os municípios}

Os problemas associados à água e ondas de calor afetarão os municípios como um todo, porém a expressão desses riscos e impactos no território está intimamente relacionada com os padrões espaciais de vulnerabilidade e de desigualdade social exigindo, portanto, um nexo direto entre adaptação às mudanças climáticas, planejamento do uso do solo urbano e gestão de riscos(KRELLENBERG et al., 2014).

O relatório para tomadores de decisão de 2014 do IPCC sobre impactos, adaptação e vulnerabilidade afirma que as cidades deverão se preparar para enfrentar uma maior frequência de eventos como chuvas extremas, deslizamentos de terra, inundações, poluição do ar, trombas d'água, aumento da temperatura, secas prolongadas, elevação do nível do mar e ressacas, o que exigirá o aumento da resiliência das cidades(FIELD et al., 2014).

Os longos períodos de estiagem poderão afetar a disponibilização de água e energia, causando impactos no funcionamento e na economia dos municípios. Estas situações poderão resultar, por exemplo, no desabastecimento de água em residências e nos setores agrícola, comercial e industrial, a piora na situação do trânsito e no funcionamento de transportes coletivos sobre trilhos, a paralização de serviços de internet e telefonia, a ampliação da sensação de insegurança por falhas na iluminação urbana, entre outros(RIBEIRO; SANTOS, 2016). 
Segundo (MARENGO et al., 2016), 40\% da população mundial vive a até $60 \mathrm{~km}$ de distância dos oceanos, estando, em maior ou menor grau, expostas à ampliação do nível do mar, tempestades e inundações. A zona costeira brasileira possui mais de oito mil e quinhentos quilômetros, abrangendo aproximadamente 300 municípios e 12 (doze) capitais. Estas áreas demandam um planejamento estratégico para lidar com os riscos e minimizar os impactos ocasionados pelos eventos extremos como inundações costeiras, enchentes, alagamentos, movimentações de massa e erosão costeira (MARENGO et al., 2016). Conforme citado anteriormente, estudos demonstram que a elevação do nível do mar deverá ser menor se o aquecimento global se mantiver em $1,5^{\circ} \mathrm{C}$. Ainda assim, serão observados a ampliação de ocorrência de enchentes, danos em infraestruturas de cidades costeiras e a salinização das águas subterrâneas, cujos impactos poderão atingir, ao redor do mundo, 136 cidades portuárias com mais de um milhão de habitantes (HOEGHGULDBERG et al., 2018).

Os eventos de chuvas extremas e a elevação do nível do mar em um contexto de intensa impermeabilização, ocupação desordenada do solo, má gestão dos efluentes líquidos e resíduos sólidos e infraestruturas subdimensionadas ou com manutenção ineficiente, causarão diversos impactos no funcionamento das cidades e na saúde da população. Isso se dará principalmente pela ampliação e intensificação de eventos que já ocorrem em grande parte das cidades como deslizamentos, desabamentos, inundações e alagamentos, e os problemas a eles relacionados (RIBEIRO; SANTOS, 2016).

Em um aquecimento médio global de $1,5^{\circ} \mathrm{C}$ (acima dos níveis pré-industriais), o dobro de megacidades (como Lagos, na Nigéria e Xangai, na China) poderão ser impactadas pela elevação da temperatura, expondo mais de 350 milhões de pessoas a temperaturas potencialmente letais até o ano de 2050. De acordo com o relatório que avalia os impactos da ampliação da temperatura média global de $1,5^{\circ} \mathrm{C}$ em sistemas naturais e humanos (HOEGH-GULDBERG et al., 2018), qualquer ampliação da temperatura global deverá impactar a saúde humana, entretanto, são previstos menores riscos de desnutrição, de morbidade de mortalidade relacionadas ao calor e mortalidade relacionada ao ozônio se o aquecimento global for limitado em $1,5^{\circ} \mathrm{C}$, não atingindo os $2^{\circ} \mathrm{C}$. A ocorrência de doenças transmitidas por vetores em áreas urbanas, como malária e dengue, também aumentará com a elevação das temperaturas globais, inclusive com alterações em sua incidência e distribuição geográfica (HOEGH-GULDBERG et al., 2018).

Entretanto, os efeitos das mudanças climáticas não atingirão população mundial de maneira uniforme. Além dos diferentes impactos previstos para cada região do globo, os impactos serão maiores para as populações mais pobres que residem em centros urbanos, moradores de assentamentos precários e outros grupos vulneráveis como mulheres, crianças, idosos e pessoas com deficiências (THE WORD BANK, 2011; FIELD et al., 2014; HOEGH-GULDBERG et al., 2018). Dessa forma, FIELD et al. (2014) defendem como ações prioritárias para as cidades a redução do déficit de serviços básicos, melhoria 
no projeto das habitações e a construção de infraestruturas que reduzam efetivamente a vulnerabilidade e exposição da população em áreas urbanas.

Estas características aumentam as pressões sobre os centros urbanos de países em desenvolvimento como o Brasil(RIBEIRO; SANTOS, 2016) que em 2017 contava com $60,6 \%$ de seus municípios com loteamentos irregulares ou clandestinos e 17,2\% em assentamentos precários (IBGE, 2018a). O relatório do Perfil dos Municípios Brasileiros de 2017 demonstra ainda que estas situações ocorrem com maior frequência em municípios de maior porte populacional. Durante os levantamentos realizados, foi constatada a existência de aglomerados subnormais (favelas, mocambos, palafitas ou assemelhados) ou a ocupação de terrenos e prédios por movimentos de moradia em todos os 42 (quarenta e dois) municípios brasileiros com mais de 500 mil habitantes(IBGE, 2018a). Estas informações são apresentadas na Figura 9, a seguir.

Figura 9 - Proporção de municípios com aglomerados subnormais no Brasil em 2017

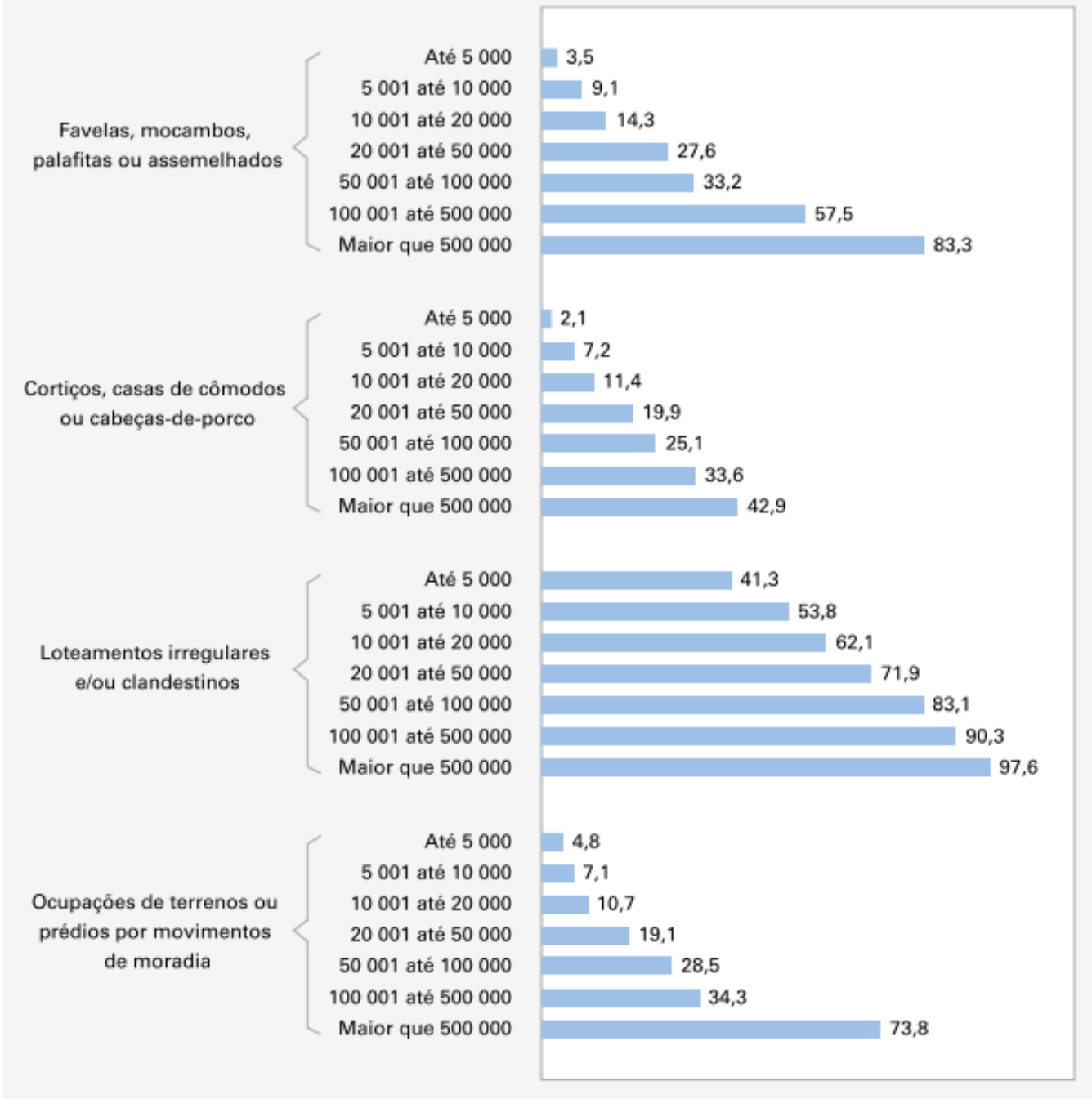

Fonte: (IBGE, 2018a) 
Conforme HOEGH-GULDBERG et al. (2018) esta situação também será agravada com o aquecimento de $1,5^{\circ} \mathrm{C}$, o qual deverá multiplicar o número de pessoas de baixa renda e piorar as condições financeiras dos que já são considerados pobres. Somente as alterações climáticas poderão ser responsáveis por inserir entre 3 e 16 milhões de pessoas na extrema pobreza, principalmente devido aos impactos na agricultura e no preço dos alimentos, impactando mais severamente áreas urbanas e algumas áreas rurais na África Subsaariana e no Sudeste Asiático (HOEGH-GULDBERG et al., 2018).

\subsection{Papel dos governos locais}

As cidades deverão aglutinar os riscos associados ao aquecimento global, sendo afetadas pelo aumento das temperaturas, inundações, novos vetores de doenças, poluição do ar e escassez de água. Dessa forma, caso os poderes locais não se organizem na direção de descarbonizar as atividades urbanas e não forneçam soluções de baixo carbono para o atendimento das necessidades da população em crescimento, haverá uma maior dificuldade em apresentar as respostas necessárias para os impactos das mudanças climáticas(CONINCK et al., 2018).

Segundo o relatório sobre Mudanças Climáticas e Cidades (ROSENZWEIG et al., 2015) e atualizações em sua versão lançada no ano de 2018, a comunidade de pesquisadores concluiu que as alterações no clima causadas pelas ações humanas têm ampliando os riscos em cidades e que áreas urbanas apresentam especiais correlações com a produção de ilhas de calor, redução da qualidade do ar e a aceleração do escoamento superficial das águas pluviais. Segundo os autores, as cidades poderão ser os principais responsáveis pela implementação da adaptação aos efeitos das mudanças climáticas e da mitigação das emissões de gases de efeito estufa, entretanto, para isso, deverão ocorrer profundas alterações em seu modo de organização e de vida de seus habitantes, abrangendo "o uso de energia, transporte, uso da água, uso do solo, ecossistemas, crescimento urbano, padrões de consumo e estilo de vida" (ROSENZWEIG et al., 2015), além de uma maior integração e cooperação entre as áreas urbanas, peri-urbanas, rurais e regiões metropolitanas.

A atuação dos poderes locais poderá ser reforçada com a busca pela igualdade social de seus habitantes, pelo fortalecimento da ecologia urbana e pela participação dos governos locais em redes de ação climática. Além disso, deverá ser realizado um planejamento de longa duração para o aprimoramento de sistemas de transporte, abastecimento de água e produção de energia de modo que os governos locais possam superar as dificuldades que irão ocorrer ao longo das próximas décadas (CONINCK et al., 2018).

De acordo com o Quinto Relatório de Avaliação do IPCC (IPCC, 2014) os governos federais exercem um importante papel no planejamento e implementação da adaptação. 
Entretanto, os governos locais estão cada vez mais sendo reconhecidos como essenciais para a adaptação climáticas devido ao seu potencial de influência sobre as comunidades e na gestão de informações de risco e financiamento das ações(IPCC, 2014).

Desde o Quarto Relatório de Avaliação do IPCC (AR4), foi observado um significativo aumento no planejamento e implantação de medidas de adaptação em comunidades rurais e urbanas em nível local. Ainda assim, o AR5 informa que foram observadas iniciativas de implementação de adaptação através de instrumentos locais (mainstreaming adaptation), mas os pesquisadores observaram que os tomadores de decisão sofrem constantemente com a complexidade da temática da adaptação, com a falta de informações sobre as vulnerabilidades locais e impactos previstos e com o desconhecimento de medias a serem adotadas. Como solução, o relatório defende o auxílio dos governos federais e regionais aos municípios, assim com parcerias com a iniciativa privada e a sociedade civil para a efetiva implementação de respostas locais. Além disso, a institucionalização da governança da adaptação e a sua integração ao planejamento e tomada de decisão, são apresentados como fatores primordiais para a transição do planejamento para a implementação das medidas adaptativas (IPCC, 2014).

No relatório sobre mudanças climáticas e cidades (ROSENZWEIG et al., 2015) os autores afirmam que o planeta está sob o maior período de urbanização de sua história e sob rápida alteração climática, e por isso, as cidades devem iniciar o desenvolvimento e implementação e ações climáticas imediatamente para garantir o potencial transformacional necessário. Nesse sentido, são apresentadas 05 (cinco) ações a serem implementadas para uma transformação urbana mais resiliente e sustentável, a saber:

1. Integração da redução de riscos climáticos e da adaptação às mudanças climáticas em políticas de desenvolvimento urbano.

2. Integração da mitigação das emissões e da adaptação aos efeitos das mudanças climáticas na arquitetura e no planejamento e desenho urbano, seja através de medidas de engenharia, de adaptação baseada em ecossistemas, programas sociais, entre outros, devendo levar em consideração as especificidades de cada cidade.

3. Elaboração de avaliações de risco e planos de ações climáticas em parceria com stakeholders (partes interessadas) e a academia.

4. Inclusão das necessidades e demandas de populações mais pobres e sob situação de vulnerabilidade no planejamento e ações climáticas, a fim de ampliar a capacidade de resposta do município às mudanças climáticas.

5. Ampliação do acesso dos municípios a fundos climáticos, fortalecimento de instituições e participação de redes de ações climáticas.

(ROSENZWEIG et al., 2015)

Os governos locais também deverão atuar na adaptação dos impactos que atingirão as áreas rurais dos municípios, principalmente a agricultura, a disponibilidade de água, a 
silvicultura e a biodiversidade (FIELD et al., 2014). Segundo Bebbington (1999 apud. LEMOS et al., 2016) as características da capacidade adaptativa de comunidades rurais podem ser divididas em cinco classes: o capital humano, abrangendo as características socioeconômicas locais como saúde e educação; o capital natural, com as características ambientais relacionadas à qualidade do solo e disponibilidade de recursos hídricos; o capital físico, com as infraestruturas e tecnologias disponíveis; o capital social, influenciado pelas relações sociopolíticas existentes; e, o capital financeiro e de produção, abrangendo a composição da renda dos habitantes e sua situação financeira. Dessa forma, devem ser elaboradas políticas específicas para o contexto rural que consideram as capacidades genéricas e específicas desta população em se adaptar às alterações climáticas (LEMOS et al., 2016).

Um exemplo de ampliação da capacidade genérica de adaptação focando na classe do capital financeiro e de produção é a revisão nas práticas de comercialização dos produtores rurais e a realização de investimentos para ampliar o acesso de pequenos produtores ao mercado(FIELD et al., 2014). Ainda não atue diretamente na redução dos riscos climáticos, políticas como estas possuem o potencial de reduzir a vulnerabilidade econômica destas famílias e ampliar disponibilização de alimentos à sociedade.

Para BAZAZ et al. (2018) os tomadores de decisão em nível local serão essenciais para que o aquecimento da terra seja limitado a $1,5^{\circ} \mathrm{C}$ e para que as comunidades se adaptem às mudanças climáticas. Além disso, os autores afirmam que os efeitos da atuação dos governos locais não ficarão restritas aos seus limites administrativos, podendo servir de inspiração ou subsídio para a tomada de decisão de outros municípios (BAZAZ et al., 2018).

\subsection{Planejamento urbano e a necessidade da sustentabilidade ambiental}

As diretrizes internacionais para o planejamento urbano e territorial, Habitat III - New Urban Agenda (ONU, 2016), reconhece que centros urbanos possuem características que podem torná-los, e seus habitantes, vulneráveis aos impactos adversos das mudanças climáticas. Além disso, cita que a forma que as cidades são planejadas e geridas causam impactos diretos sobre a sua sustentabilidade e resiliência, o que ultrapassa os limites administrativos do município. Dessa forma, o Habitat III apresenta o compromissos de incluir a adaptação e mitigação das mudanças climáticas no processo de planejamento das cidades através da construção da resiliência urbana e pela redução das emissões de GEE, de modo a colaborar no atendimento das metas do Acordo de Paris (ONU, 2016).

UITTENBROEK, JANSSEN-JANSEN e RUNHAAR (2013) afirmam que o planejamento urbano pode ser utilizado para criar inovações tecnológicas e sociais que 
promovam a adaptação climática, além de se tratar de um instrumento que usualmente abrange múltiplos objetivos, podendo resultar em novas correlações sobre o tema. $\mathrm{O}$ Plano Nacional de Adaptação também tratou dessa correlação ao apresentar entre as suas diretrizes prioritárias para cidades que a adaptação à mudança do clima seja considerada no aperfeiçoamento de modelos de planejamento urbano. Segundo o PNA, esta diretriz visa a integração do planejamento do uso e ocupação do solo à preservação ambiental, com o objetivo de prevenir os riscos de desastres naturais (BRASIL - MMA, 2016a).

De acordo com ROSENZWEIG et al., (2015) o planejamento urbano e o desenho das cidades possuem um papel primordial para a resposta global às mudanças climáticas. Para isso, as estratégias de mitigação e adaptação às mudanças climáticas devem exercer um papel central no planejamento das cidades. Dentre as medidas possíveis, os autores citam a melhoria da eficiência dos sistemas urbanos para a redução da emissão de calor residual e de gases de efeito estufa; a alteração das técnicas de construções e bairros para a promoção da ventilação e resfriamento, o que ainda poderá trazer benefícios para a redução no consumo de energia e redução no escoamento superficial pela implantação de mais áreas verdes; a seleção de materiais de construção e a utilização de elementos que ampliem a reflectância das radiações solares (albedo); e, a ampliação da cobertura vegetal das cidades, atuando na redução das temperaturas, do consumo de energia nas residências, do escoamento superficial e da poluição, ao mesmo tempo que o sequestro de carbono é ampliado (ROSENZWEIG et al., 2015).

Conforme apresentado pelo Guia de Adaptação às Mudanças do Clima para Entes Federativos (MARGULIS, 2017), dentre os 5.570 municípios brasileiros, somente 51 possuem iniciativas climáticas. Seguindo um padrão global onde a adaptação ainda é tratada como secundária (RODRIGUES FILHO et al., 2016), as principais ações desses municípios também focam majoritariamente a temática da mitigação. Os autores afirmam que municípios com menores índices populacionais deverão enfrentar maiores desafios para a inserção da questão climática em sua agenda de prioridades, uma vez que estes poderão enfrentar maiores dificuldades técnicas, financeiras e institucionais, além de uma disputa com as demandas sociais prioritárias, como políticas de saúde, segurança e educação (MARGULIS, 2017).

MARGULIS (2017) não determina um tamanho mínimo dos municípios para os quais os planos de adaptação deverão ser elaborados, exatamente pelas especificidades de cada localidade, conforme apresentado no parágrafo anterior. Entretanto, o autor avalia que $68,4 \%$ dos municípios possuem até 20 mil habitantes, os quais concentram somente $15,8 \%$ da população brasileira, e, por outro lado, apenas 17 municípios possuem mais de um milhão de habitantes, nos quais habitam 45,2 milhões de pessoas, ou $21,9 \%$ da população nacional. Se considerados os 41 municípios e as regiões metropolitanas com mais de 500 mil habitantes, atinge-se mais da metade da população nacional, e são esses municípios ou regiões para as quais o autor defende que sejam incorporadas a agenda da mudança do clima(MARGULIS, 2017). 
Entretanto, o próprio Guia recomenda cautela quanto a essa indicação. Inúmeros municípios de pequeno porte poderão sofrer sérios riscos climáticos, resultando em extensas regiões com baixas capacidades de entendimento dos riscos a que estão submetidos e de planejamento de sua adaptação, incumbindo ao poder público estadual ou federal a elaboração de planos ou propostas preliminares de adaptação (MARGULIS, 2017). Tal solução dificilmente terá a mesma força para os diferentes estados brasileiros, já que, desde dezembro de 2015, quando foi lançada a Regions Adap da Rede de Governos Regionais para o Desenvolvimento Sustentável, que visa a ação, colaboração e reporte de ações de adaptação, somente 9 estados brasileiros se credenciaram (MARGULIS, 2017; “RegionsAdapt - NRG4SD," 2018).

Dadas as dificuldades verificadas pelos municípios brasileiros em planejar a sua adaptação por meio de instrumentos especificamente elaborados para este fim, buscou-se avaliar outros instrumentos que poderiam abarcar as temáticas da adaptação e da sustentabilidade, dentre os quais destaca-se o Plano Diretor. Conforme o art. $182^{\circ}$ da Constituição Federal de 1988 (BRASIL, 1988), matéria regulamentada em 2001 pelo Estatuto da Cidade (BRASIL, 2001), o plano diretor é o instrumento básico da política de desenvolvimento e expansão urbana e sua elaboração é obrigatória para municípios com mais de 20 mil habitantes. O Estatuto da Cidade define ainda outras condições de obrigatoriedade da elaboração do Plano Diretor, entre elas, para municípios integrem regiões metropolitanas ou aglomerações urbanas ou que apresentem em seu território áreas suscetíveis à ocorrência de deslizamentos ou inundações de grandes proporções, matéria incluída pela Política Nacional de Proteção e Defesa Civil. Nesse último caso, deverão ser apresentadas diversas medidas de planejamento e controle como o mapeamento das áreas suscetíveis, planejamento de intervenções preventivas, medidas de drenagem urbana, diretrizes para a regularização fundiária e a identificação e elaboração de diretrizes para a preservação de áreas verdes municipais e para a redução da impermeabilização do solo (BRASIL, 2012a).

Além das possíveis correlações com o planejamento da gestão de riscos, os planos diretores apresentam diretrizes, objetivos e metas para diferentes setores municipais, como de mobilidade urbana, habitação, áreas verdes, saneamento ambiental, uso do solo urbano e rural, entre outros, as quais poderiam ser elaboradas levando em consideração a questão climática, visando a ampliação da capacidade adaptativa municipal(BRASIL MMA, 2016b).

O relatório Perfil dos Municípios Brasileiros (IBGE, 2016) apresentou o panorama do planejamento urbano nos municípios brasileiros, verificando que em 2015 existiam 2.786 municípios com Plano Diretor e 691 municípios com este instrumento em elaboração (totalizando 62,4\% dos municípios brasileiros). Além disso, dentre os 655 municípios com mais de 50.000 habitantes, somente 9 (nove) não possuíam plano diretor, dos quais 8 (oito) estavam em elaboração. Apesar do baixo percentual de municípios brasileiros incluídos na faixa populacional onde a elaboração dos planos diretores é obrigatória 
(MARGULIS, 2017), os dados acima e a Figura 10 demonstram que o número de municípios brasileiros que já elaboraram ou estão elaborando estes instrumento urbanístico é expressivo.

Figura 10 - Percentual de municípios brasileiros com Plano Diretor - 2005/2015

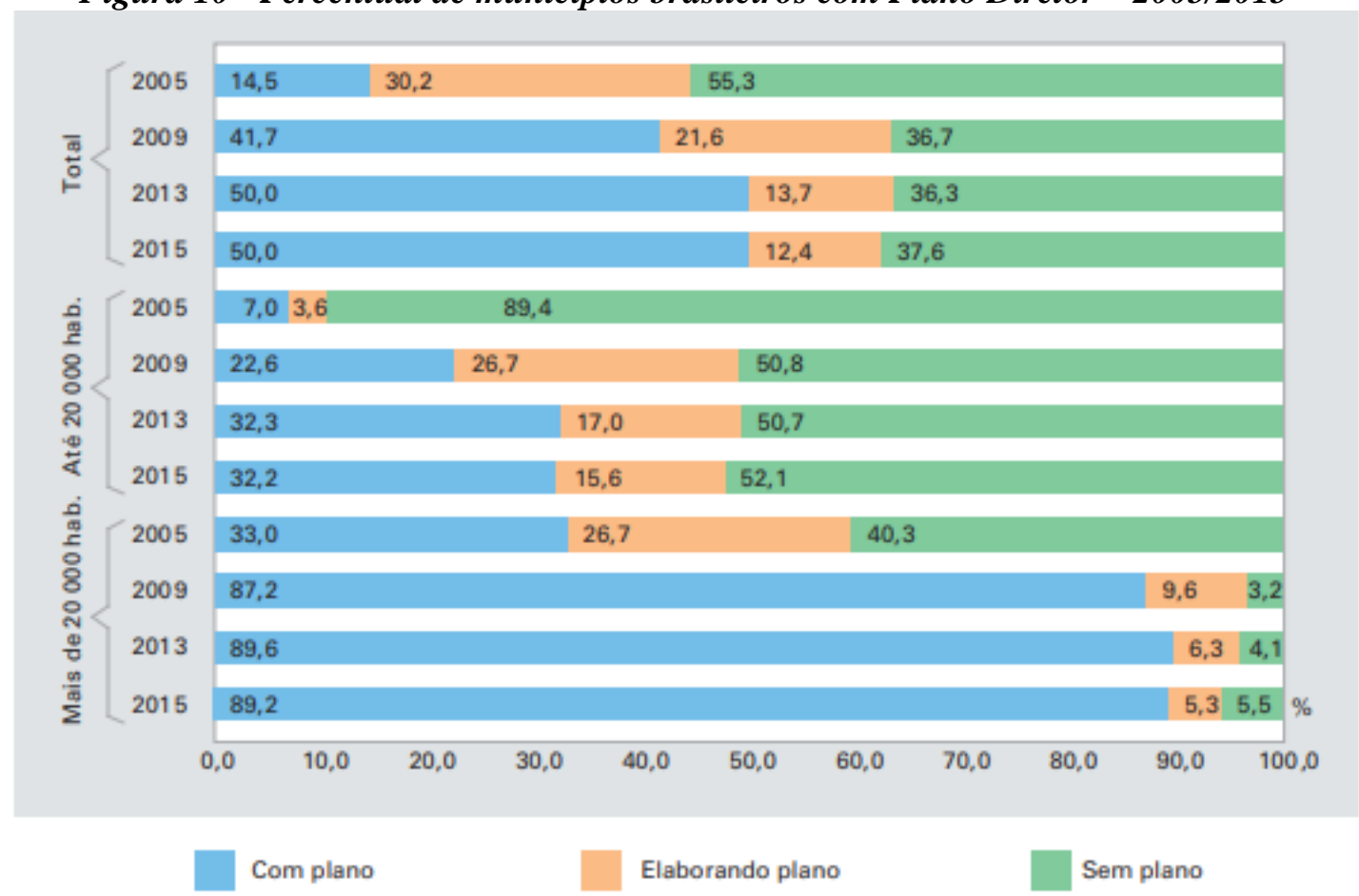

Fonte (IBGE, 2016)

Dessa forma, devido ao potencial de alcance que os planos diretores têm na realidade brasileira, inclusive em municípios de pequeno porte (IBGE et al., 2016); atendendo à diretriz do Plano Nacional de Adaptação (BRASIL - MMA, 2016b) de que a adaptação às mudanças do clima seja considerada no aperfeiçoamento de modelos de planejamento urbano; pelo planejamento urbano poder ser utilizado para a criação de inovações tecnológicas e sociais que promovam a adaptação climática, além de se tratar de um instrumento que usualmente aborda múltiplas temáticas (UITTENBROEK et al., 2013); e, por possuir metodologia e prática consolidadas, com procedimentos familiares aos agentes públicos (MARTINS; FERREIRA, 2010); o Plano Diretor se apresenta como uma excelente opção para a promoção e disseminação de práticas de adaptação climática no contexto brasileiro. Além disso, sua característica multidisciplinar poderá influenciar a formulação de outras políticas públicas que incluam a adaptação climática em seu eixo de estruturação, principalmente nas temáticas de habitação, mobilidade urbana, agricultura sustentável, gestão ambiental e resposta aos impactos climáticos, temas centrais deste trabalho.

Entretanto, a estratégia de ampliação da capacidade adaptativa dos municípios através deste instrumento de desenvolvimento urbano e de outras políticas a ele relacionadas, deverá levar e consideração como os planos diretores incorporam as questões ambientais, 
e em especial a questão climática. No artigo "Climate change adaptation in the urban planning and design research: missing links and research agenda", Dhar $\mathrm{e}$ Khirfan (2016) analisaram 157 artigos publicados entre 2000 a 2013, avaliando como o planejamento urbano tratou a questão da adaptação às mudanças do clima. Os autores concluíram que a falta de interdisciplinaridade, ausência de transferência de conhecimento, conflito de escalas e escassez de métodos de pesquisa são entraves na conexão entre adaptação climática e planejamento urbano. Além do mais, afirmam que embora os estudiosos das temáticas de planejamento e desenho urbano estejam cada vez mais conscientes das questões da adaptação às mudanças climáticas, é necessária uma maior integração dessa temática no planejamento urbano, dado que os desafios trazidos pelas mudanças do clima no ambiente urbano são multidimensionais, multidisciplinares e multiescalarares (DHAR; KHIRFAN, 2016).

Conforme Denton (DENTON et al., 2014), adaptação climática e desenvolvimento sustentável possuem diversas conexões, particularmente no que se refere ao fato de que muitos dos determinantes para a ampliação da capacidade adaptativa de um sistema e indicadores do desenvolvimento sustentável se sobrepõem. Além disso, o desenvolvimento da capacidade adaptativa de uma comunidade também pode influenciar o seu bem-estar social e ambiental.

Dentre os Objetivos do Desenvolvimento Sustentável (ODS) propostos em 2015 (ONU, 2015b), dois apresentaram especial relação com a questão das mudanças climáticas em cidades: o ODS 11 - Transformar as cidades e os assentamentos humanos inclusivos, seguros resilientes e sustentáveis e o ODS 13 - Tomar medidas urgentes para combater a mudança do clima e seus impactos. Uma análise do ODS relacionado às cidades, por exemplo, revela metas associadas a proporcionar transportes seguros e sustentáveis (meta 11.2), aumento da urbanização inclusiva e sustentável (meta 11.3), redução do número de mortes e de pessoas afetadas por catástrofes (meta 11.5) e "aumentar substancialmente o número de cidades e assentamentos humanos adotando e implementando políticas e planos integrados para a inclusão, a eficiência dos recursos, mitigação e adaptação à mudança do clima" (meta 11.b) (ONU, 2015b). Segundo ROSENZWEIG et al. (2015), o ODS 11 não poderá ser atendido se as cidades não reconhecerem a questão climática como um componente chave em seu desenvolvimento, cujas respostas deverão ser aplicadas no contexto da sustentabilidade.

Quanto ao ODS relacionado às mudanças climáticas, verificam-se metas relacionadas a reforçar a resiliência e a capacidade de adaptação a riscos climáticos (meta 13.1), integração de medidas da mudança do clima em políticas, estratégias e planejamentos nacionais (meta 13.2), aumentar a consciência e capacidade institucional sobre adaptação à mudança do clima (meta 13.3), e promoção de mecanismos para subsidiar o planejamento relacionado à mudança do clima (meta 13.b)(ONU, 2015b). 
Em 1999, Philippi Jr e colaboradores já defendiam a impossibilidade da elaboração de novos Planos Diretores sem a articulação entre temas urbanos e o meio ambiente, dado que os problemas ambientais se concentram, em sua grande maioria, nas cidades. Além disso, foi ressaltada a necessidade da comunidade estar envolvida em todas as fases do processo de desenvolvimento dos planos diretores, de modo a compreender de maneira mais profunda as características e demandas consideradas como prioritárias pelos habitantes de cada localidade do município (PHILIPPI JR et al., 1999).

Conforme o Perfil dos Municípios Brasileiros de 2015 (IBGE, 2016), dentre os 2.786 municípios com planos diretores vigentes, somente 38,6\% integraram o zoneamento ambiental aos seus planos diretores, $24 \%$ apresentaram unidades de conservação e 28,9\% inseriram o instrumento de avaliação de impacto ambiental. Quando avaliados somente os municípios acima de 20 mil habitantes com Planos Diretores - PD (1.554 município dos 1.742 existentes), os quais são obrigados a elaborar estas leis, os percentuais continuam semelhantes: $41 \%$ dos planos apresentaram zoneamento ambiental - ZA, $24,7 \%$ unidades de conservação - UC e 29,8\% o instrumento de avaliação prévia de impacto ambiental - AIA. Na Tabela 2 pode ser observado que este padrão se repete nas demais faixas populacionais, com uma queda mais acentuada para os municípios mais populosos, principalmente quanto à inserção do zoneamento ambiental como parte integrante do plano diretor. Estes dados demonstram que em todas as faixas populacionais, a integração do planejamento urbano com a questão ambiental ainda é pequena, devendo ser aprimorada.

Tabela 2 - Instrumentos ambientais nos planos diretores

\begin{tabular}{|c|c|c|c|c|c|}
\hline & $\begin{array}{l}\text { Total de } \\
\text { Municípios }\end{array}$ & $\begin{array}{l}\text { Municípios } \\
\text { com PD }\end{array}$ & $\begin{array}{l}\% \text { de PD } \\
\text { com ZA }\end{array}$ & $\begin{array}{l}\% \text { de PD } \\
\text { com UC }\end{array}$ & $\begin{array}{l}\% \text { de PD } \\
\text { com AIA }\end{array}$ \\
\hline Municípios com PD & 5.570 & 2.786 & $38,6 \%$ & $24 \%$ & $28,9 \%$ \\
\hline $\begin{array}{c}\text { Municípios > de 20mil } \\
\text { hab. com PD }\end{array}$ & 1.742 & 1.554 & $41 \%$ & $24,7 \%$ & $29,8 \%$ \\
\hline $\begin{array}{c}\text { Municípios > de 50mil } \\
\text { hab. com PD }\end{array}$ & 655 & 646 & $44,6 \%$ & $25,4 \%$ & $29,5 \%$ \\
\hline $\begin{array}{c}\text { Municípios > de 100mil } \\
\text { hab. com PD }\end{array}$ & 302 & 302 & $43,7 \%$ & $25,1 \%$ & $27,8 \%$ \\
\hline $\begin{array}{c}\text { Municípios > de 500mil } \\
\text { hab. com PD }\end{array}$ & 41 & 41 & $24,4 \%$ & $21,9 \%$ & $26,8 \%$ \\
\hline
\end{tabular}

Fonte: elaborado pelo autor com dados de IBGE (2016)

Segundo EGLER et al. (2013), a inclusão da sustentabilidade no processo de planejamento deve ir além da inclusão da questão ambiental, sendo necessário garantir as condições de vida das futuras gerações. Dessa forma, um planejamento pautado pela busca da sustentabilidade deve ter a garantia da qualidade de vida de seus habitantes como um item central de sua elaboração(EGLER et al., 2013). 
Em sua tese, Maglio (2005) avaliou a sustentabilidade ambiental no planejamento urbano de São Paulo entre o período de 1971 a 2004, quando foram aprovados os Plano Diretor Estratégico de São Paulo (2002) e a respectiva Lei de uso e Ocupação do Solo e Planos Regionais Estratégicos (2004). Ao longo desses anos, foram observadas como principais ameaças à sustentabilidade ambiental do município a expansão urbana sobre áreas ambientalmente frágeis e o adensamento construtivo em áreas centrais do município, sem a devida atenção à capacidade de suporte de infraestrutura existente na região. Como destaque, foi apontada a questão da mobilidade urbana, concluindo que o planejamento urbano realizado no município não introduziu a sustentabilidade ambiental através da aplicação de seus instrumentos. Por fim, o autor sugere a aplicação de processo de avaliação de impactos cumulativos para a ampliação da sustentabilidade ambiental de futuros planejamentos urbanos, avaliando o efeito do aumento do aproveitamento construtivo na infraestrutura de circulação viária, na qualidade do ar, infraestrutura urbana, áreas verdes, espaços livres e equipamentos urbanos (MAGLIO, 2005).

HUANG et al. (2015) propuseram 12 diretrizes ambientais para o planejamento das cidades, as quais abrangeram as seguintes temáticas:

- Controle do espraiamento urbano

- Desenvolvimento da cidade próximo ao transporte público

- Incentivo do uso misto (residencial e comercial)

- Construção de quadras menores

- Ampliação de áreas verdes públicas

- Incentivo para o transporte não motorizado (caminhada e bicicletas)

- Ampliação das redes de transporte público

- Desestímulo do uso de carros

- Incentivos para construções sustentáveis

- Geração renovável e decentralizada energia

- Gerenciamento dos resíduos sólidos, e

- Gestão eficiente dos recursos hídricos.

Fonte: (HUANG; et al., 2015).

Estas medidas auxiliam de alguma forma a redução das emissões de gases de efeito estufa e a relação dos habitantes com os extremos climáticos. Dentre elas, ressalta-se a importância da ampliação de áreas verdes urbanas, que auxilia na redução dos efeitos das ilhas de calor e aumenta a permeabilidade da cidade, e do controle do espraiamento urbano com a proteção de áreas ambientalmente sensíveis ao redor da cidade, o que ajudaria a reduzir a ocupação de áreas de várzeas, encostas e mananciais e possibilitando a produção de alimentos próximo às cidades. A gestão sustentável dos recursos hídricos 
também é incentivada pelas diretrizes de construções sustentáveis, gestão de resíduos e de recursos hídricos, seja na prevenção de cheias, como na ampliação da disponibilidade hídrica em eventos de estiagem.

Na edição do Perfil dos Municípios Brasileiros de 2017 foi avaliada a existência de instrumentos de planejamento e gestão de risco nos municípios brasileiros. $\mathrm{O}$ estudo demonstra que, comparativamente aos dados de 2013, o percentual dos municípios cujo plano diretor contempla a prevenção de enchentes passou de $17,2 \%$ para 23,5\%. Já a prevenção de escorregamentos era contemplada por 7,7\% dos municípios em 2013, passando para 11,4\% em 2017. Quando considerados somente os municípios com planos diretores em 2017, cerca de $62 \%$ incluíram a prevenção de enchentes e $28 \%$ a prevenção a escorregamentos (IBGE, 2018a). Apesar da melhora de alguns indicadores, a implementação de diretrizes adaptativas através deste instrumento urbanístico terá ainda o desafio de superar a maneira que os planos diretores vêm sendo elaborados. Um dos caminhos para isso é a sensibilização dos gestores para os riscos a que estão ou estarão submetidos e das possíveis medidas de adaptação que podem ser aplicadas, pontos fundamentais para a redução da vulnerabilidade e ampliação da resiliência do município (MARENGO et al., 2016).

Ainda em 1961, Jane Jacobs (JACOBS, 2011) lançava o seu livro Morte e Vida de Grandes Cidades Americanas (The death and life of great american cities), denominandoo como um "ataque aos fundamentos do planejamento urbano e da reurbanização ora vigentes". Naquela obra, a autora questionou os preceitos do planejamento urbano que, em grande medida, podem ser verificados até os dias atuais, defendendo que as cidades tenham uma diversidade de uso mais complexa e densa, de modo a propiciar uma base para a sua sustentação econômica e social. Além disso, Jacobs atribui parte da "erosão" das cidades ao planejamento direcionado aos automóveis, transformando as ruas em espaços sem vida, pouco atrativos e inseguros para as pessoas (JACOBS, 2011).

Esta mesma visão foi apresentada mais recentemente no livro Cidades para Pessoas de Jan Gehl (GEHL, 2013). Para o autor, o ponto de partida do planejamento urbano deve estar centrado na dimensão humana, buscando a criação ou transformação das cidades em ambientes seguros, sustentáveis, saudáveis e vivos, onde diversificados grupos de pessoas se sintam atraídos a usufruí-los. Como exemplo, Gehl defende a implantação de calçadas mais largas, plantio de árvores para o sombreamento, implantação de bancos etc. Outro importante ponto apresentado foi a correlação entre o volume de tráfego e a infraestrutura de transporte disponível, onde, quanto mais vias são construídas, mais tráfego por automóveis é criado. Entretanto, seguindo a mesma lógica, ao instalar infraestruturas para a locomoção por bicicletas ou a pé, esses modais também passam a crescer, permitindo a redução dos transportes individuais por veículos motorizados e viabilizando deslocamentos mais rápidos, baratos, saudáveis e ambientalmente amigáveis para a população(GEHL, 2013). 
Tais conceitos são utilizados por Freire e Monteiro (2014) para a definição de cidades compactas, indo além da questão específica da densidade populacional. Os autores defendem que as cidades compactas devem compreender uma relação entre a densidade e diversidade, ou seja, além de possibilitar a redução dos trajetos a partir do adensamento populacional em regiões providas de oportunidades de trabalho e a prestação de serviços, as cidades compactas devem garantir um alto índice de diversidade social coexistindo em um mesmo espaço(FREIRE; MONTEIRO, 2014). Além disso, é importante que estas áreas incluam quesitos mínimos de permeabilidade, arborização e áreas verdes. BAZAZ et al. (2018) ressalta que apesar da ampliação da densidade urbana reduzir as emissões de gases de efeito estufa e melhorar o deslocamento das pessoas pela cidade, dependendo do modo que for implantada, ela poderá aumentar os desafios de adaptação, principalmente pela ampliação das ilhas de calor(BAZAZ et al., 2018).

\subsection{Intervenções urbanas e políticas públicas adaptativas}

Os planos diretores são instrumentos que tratam de diferentes políticas setoriais, incluindo diretrizes e metas para o planejamento da atuação dos governos locais. A verificação de como os municípios estão abordando a adaptação climática em seu planejamento pode fornecer dicas das principais ações e instrumentos que podem ser aplicados para a ampliação da capacidade adaptativa municipal. Dessa forma, este item apresenta um levantamento de trabalhos científicos, instrumentos legais e relatórios técnicos que relacionam o planejamento urbano com ações de adaptação, os quais auxiliaram no entendimento de como o planejamento das cidades pode ser adequado para a ampliação da resiliência local.

Entre um de seus princípios, o Guia Internacional de Planejamento Urbano e Territorial da UN-Habitat (UN-Habitat, 2015) cita a contribuição do planejamento urbano-territorial para o aumento da segurança da população, podendo ser beneficiada por meio do fortalecimento da resiliência socioeconômica e ambiental; do aumento das medidas de mitigação e adaptação às mudanças climáticas; e, da melhoria no manejo dos riscos naturais e ambientais. $\mathrm{O}$ documento sugere que as autoridades locais formulem seus planos urbanos e territoriais visando subsidiar ações de mitigação das emissões de GEE e a adaptação às mudanças climáticas, de modo a ampliar a resiliência dos aglomerados urbanos, especialmente em assentamentos subnormais e aqueles localizados em regiões de alta vulnerabilidade (UN-Habitat, 2015).

Ao avaliarem as respostas necessárias para o aquecimento de $1,5^{\circ} \mathrm{C}, \mathrm{CONINCK}$ et al. (2018) afirmam que a adaptação só será efetivamente aplicada por políticas de planejamento e desenho urbano que levem em consideração a ocorrência de eventos extremos e que reduzam a necessidade de relocação de populações por conta de riscos climáticos(CONINCK et al., 2018). 
Para Rosenzweig et al. (2015) o planejamento e desenho urbano devem incorporar estratégias que ultrapassem os limites físicos do território, as competências municipais e os mandatos dos prefeitos. Além disso, devem ser priorizados investimentos em medidas de mitigação que produzam benefícios adaptativos simultâneos (ROSENZWEIG et al., 2015). Como exemplo, pode ser observada a questão do abastecimento de água na cidade de São Paulo. Com a sua vulnerabilidade explicitada na estiagem ocorrida nos anos de 2014/2015, São Paulo se viu dependente dos reservatórios de Guarapiranga e Cantareira, sofrendo com "a falta de eficiência no gerenciamento do abastecimento do sistema paulista” (MARENGO et al., 2015).

O plano diretor, um instrumento do planejamento urbano participativo que ultrapassa o período de gestões político-partidárias, teria o potencial de atuar na amenização dos efeitos desta crise ao promover, entre outras medidas: o uso consciente da água, captação de água da chuva, ampliação de áreas verdes, proteção de nascentes e mananciais, recuperação de córregos e fundos de vales (JACOBI et al., 2015), além da redução dos efeitos de ilhas de calor - uma das hipóteses levantadas por Marengo et al. (2015) para a redução das chuvas na região do reservatório Cantareira. Estas ações auxiliariam o aumento da disponibilidade hídrica do município e reduziriam a dependência da população a um único modal de abastecimento.

O Relatório Mudanças Climáticas e Cidades do Painel Brasileiro de Mudanças Climáticas (RIBEIRO; SANTOS, 2016) ressalta que o planejamento das cidades deve considerar o "conhecimento das vulnerabilidades existentes e riscos associados a eventos extremos" para que os municípios sejam remodelados e planejados de acordo com prioridades definidas para torná-los resilientes aos efeitos das mudanças climáticas. O Quadro 4, adaptado do Painel Brasileiro de Mudanças do Climáticas (PBMC), apresenta uma série de estratégias de adaptação que poderiam ser implementadas por meio do planejamento urbano.

Este relatório do PBMC apresenta ainda outras medidas que podem ser aplicadas em âmbito local para reduzir a vulnerabilidade da população aos efeitos das mudanças climáticas. Em relação a escassez de água, por exemplo, é sugerido que sejam reduzidos os níveis de vazamento de água tratada durante a sua distribuição, a diversificação das fontes de captação de água e o aprimoramento das técnicas de armazenamento, aplicação de técnicas de gerenciamento local das águas, com a coleta águas pluviais e o reuso de águas residuais, encorajamento do uso de processos eficientes de água para os usos domésticos, industriais e agrícolas, entre outros (RIBEIRO; SANTOS, 2016). 
Quadro 4 - Estratégias de Adaptação no Planejamento Urbano

\begin{tabular}{|c|c|}
\hline Riscos Climáticos & 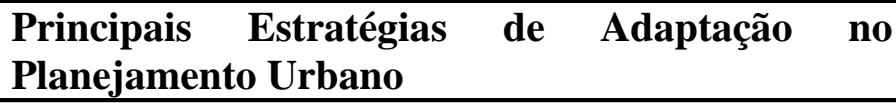 \\
\hline Temperatura, ondas de calor & $\begin{array}{l}\text { Mudanças nos códigos de construção civil para } \\
\text { resistir à maior carga de energia, tanto para } \\
\text { aquecimento como resfriamento de ambientes como } \\
\text { telhados verdes e reflexivos, pavimentos permeáveis, } \\
\text { materiais que favoreçam a controle térmico etc. } \\
\text { Serviços ecossistêmicos com o aumento da cobertura } \\
\text { de árvores urbanas e criação de espaços verdes. }\end{array}$ \\
\hline $\begin{array}{l}\text { Precipitação, inundações e } \\
\text { secas }\end{array}$ & $\begin{array}{l}\text { Restringir o desenvolvimento em áreas propensas a } \\
\text { inundações, deslizamentos, incêndios e mudança no } \\
\text { código da construção civil para abranger uma maior } \\
\text { drenagem, com o uso de pavimentos permeáveis etc. }\end{array}$ \\
\hline $\begin{array}{l}\text { Aumento no nível do mar e } \\
\text { tempestades }\end{array}$ & $\begin{array}{l}\text { Restringir o desenvolvimento ou a expansão de } \\
\text { ambientes construídos em áreas costeiras. } \\
\text { Mudança nos códigos de construção civil para } \\
\text { reduzir impactos, ex.: elevar edificações, obras de } \\
\text { proteção de construções/ edificações. } \\
\text { No caso de áreas urbanas em zonas costeiras onde os } \\
\text { esforços de proteção não sejam viáveis, desenvolver } \\
\text { planos para a retirada das construções e populações e } \\
\text { a criação de novos assentamentos. }\end{array}$ \\
\hline
\end{tabular}

Fonte: Adaptado de RIBEIRO e SANTOS (2016)

Moraci et al. (2018) apresentam a resiliência como um novo paradigma a ser considerado no planejamento de cidades menos vulneráveis. Entretanto, para tal, os autores ressaltam a importância da ampliação do conhecimento e engajamento da população sobre a adaptação climática, principalmente quanto aos benefícios que esta população terá com a efetiva implementação das medidas propostas. Dessa forma, o governo municipal pode se valer não só do apoio ou da redução da resistência da população frente às medidas propostas, como também da colaboração ativa dessas pessoas e organizações em ações pontuais e mudanças nas práticas do dia-a-dia, permitindo a sua permanente conexão com a adaptação climática. Nesse contexto, cidades resilientes devem ir além da simples adaptação aos efeitos das mudanças climáticas, sendo modificadas a partir da construção de novas relações sociais, econômicas e ambientais para que resistam aos estresses ambientais que poderão ocorrer (MORACI et al., 2018). Neste mesmo artigo, os autores tratam como urgente a necessidade de uma abordagem pragmática e com base em avanços científicos para a inovação dos instrumentos de planejamento que deem conta da complexidade dos territórios e garantam a ampliação da resiliência das cidades (MORACI et al., 2018).

Em 2016, Londres publicou o The London Plan (Londres, 2017), instrumento com as diretrizes para o desenvolvimento urbano de Londres que deverão ser atendidas nos planos das 32 subprefeituras do município (Local Plans). A questão climática foi 
apresentada com destaque neste plano, contendo um capítulo exclusivo para o tema (cap. 5 - London's Response to Climate Change). Os principais impactos previstos para Londres são relacionados a ondas de calor, ilhas de calor, invernos mais amenos com o aumento da probabilidade de enchentes e verões mais quentes e secos, podendo ocasionar eventos de escassez hídrica. Para se adaptar a estas mudanças, o plano propôs as seguintes estratégias:

- Incentivar construções e espaços para reduzir ou evitar o superaquecimento ou a geração excessiva de calor;

- Incentivar a arborização urbana e a criação de infraestruturas verdes multifuncionais;

- Incentivar a criação de projetos com telhados e paredes verdes e áreas para plantio;

- Atuar em conjunto com diferentes órgãos de meio ambiente para combater as inundações atuais e previstas para minimizar os riscos destes eventos de uma forma sustentável e economicamente eficiente;

- Desenvolver sistemas de drenagem urbana sustentáveis, reproduzindo o escoamento superficial encontrado na natureza e gerenciando as chuvas o mais próximo de suas fontes;

- Atuar em cooperação com agências locais para garantir a existência de infraestrutura adequada de esgotamento sanitário e proteger e melhorar a qualidade das águas superficiais;

- Atuar em cooperação com agências locais para garantir o suprimento de água com a redução da utilização de recursos naturais e financeiros.

Fonte: (LONDRES, 2017)

Para o município de Roterdã, na Holanda, a principal prioridade frente aos impactos relacionados com as mudanças climáticas é proteger a cidade das enchentes. Apesar de já apresentar uma estrutura para a gestão das cheias, com as dunas ao longo da costa e um sistema de contenção com barragens ao longo dos rios, e áreas alagáveis para a drenagens das águas, o poder municipal decidiu elaborar uma estratégia de adaptação para aumentar a resiliência do local. O território foi dividido conforme os usos existentes e a disponibilidade de áreas para a implantação de projetos. As áreas mais adensadas deverão receber praças alagáveis (water squares) e telhados verdes, e os canais existentes na cidade serão regulados para que o potencial de armazenamento em eventos de cheias seja ampliado. Além disso, será expandida a área permeável do território com a implantação de mais áreas verdes e áreas não pavimentadas. Estas diretrizes serão elaboradas compondo uma "estratégia azul e vede" com o objetivo de promover um ambiente urbano mais atrativo e agradável para seus habitantes. A Figura 11 apresenta um projeto de Water Square, apresentado ao governo local por um grupo de arquitetos denominado como "De Urbanisten". O instrumento conta com áreas alagáveis, conjunto de canais e dissipadores de energia, fazendo que as águas permaneçam por mais tempo no terreno, reduzindo a 
possibilidade de enchentes em terrenos mais baixos, além de disponibilizar áreas de lazer para a população (MORACI et al., 2018).

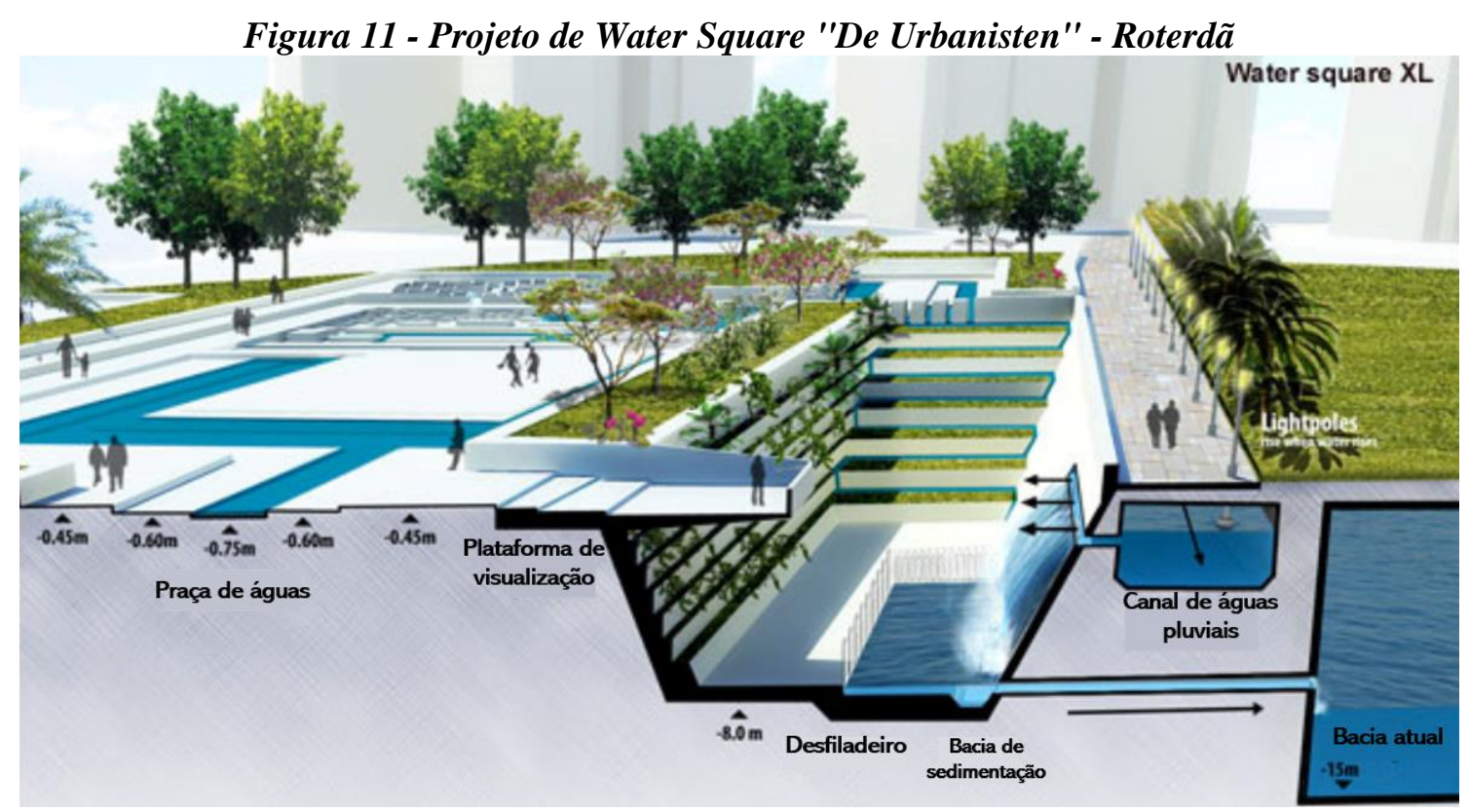

Fonte: Traduzido de MORACI et al., 2018

O município de Medelin (Colômbia) decidiu aplicar estratégias que visam a redução dos riscos climáticos através do planejamento espacial e projetos urbanos com uma maior preocupação ambiental (CHU et al., 2017). As principais ações implantadas através do planejamento territorial buscaram restringir o espraiamento urbano, manejar áreas sujeitas a riscos de deslizamentos de terra e proteger ecossistemas com a criação de cinturões verdes ao redor da cidade. Este projeto, denominado de Cinturón Verde, buscou proteger a população residente de áreas de risco de escorregamento com a construção de cerca de 74 quilômetros de intervenções urbanas e ambientais. Dividido em três áreas de atuação, este projeto delimitou uma faixa com zonas de proteção, para a preservação de encostas, seguida de uma zona de transição, onde foram criados novos parques com opções de lazer para a população, e instalação de infraestruturas de manejo de riscos. Abaixo dessas faixas, foram delimitadas as zonas consolidadas, readequadas pela implantação de novas áreas verdes, projetos de habitação e redes de transportes públicos. É importante ressaltar que, para a execução do projeto, foi prevista a relocação de aproximadamente 230 mil habitantes (CHU et al., 2017).

As cidades costeiras deverão sofrer cada vez mais com eventos relacionados à elevação do nível do mar, tais como, enchentes e danos a infraestruturas. Uma das possíveis medidas de adaptação é a construção e ampliação de diques de contenção, os quais poderão reduzir significativamente os riscos a que estas cidades estarão submetidas. Entretanto, a implantação e readequação dessas infraestruturas deverão levar em consideração previsões como as apresentadas por HOEGH-GULDBERG et al. (2018) 
que afirmam que diques existentes deverão ser ampliados em até 2 (dois) metros de altura para suportar os impactos estimados, o que pode encarecer muito essas soluções de engenharia construtiva.

Constantemente ameaçadas pela elevação do nível do mar e pela redução da disponibilidade hídrica, as municipalidades holandesas de Schiedam (localizada no sul do país) e Haarlemmermeer (no norte) desenvolveram projetos urbanísticos que integraram a adaptação climática em seu processo de elaboração. Um exemplo disso ocorreu durante a construção de um novo centro comercial em Schiedam, onde foram planejados sistemas subterrâneos de armazenamento de água, medida que foi incorporado às regras urbanísticas dos municípios, condicionando a aprovação de novas construções à instalação de sistemas próprios de armazenamento de água. Já Haarlemmermeer decidiu instalar barragens (retention ponds) e piscinões (detention ponds) para lidar com os eventos de chuvas intensas e períodos de seca. Estas infraestruturas têm o objetivo de auxiliar o abastecimento de água da cidade e reduzir a velocidade do escoamento superficial das chuvas (UITTENBROEK et al., 2013).

Como opção à técnicas usuais de engenharia, a Adaptação Baseada em Ecossistemas se baseia na aplicação dos conceitos da biodiversidade e dos serviços ecossistêmicos para se atingir os objetivos de adaptação desejados(CARVALHO et al., 2014). Os serviços ecossistêmicos são os serviços fornecidos pelos ecossistemas que atendem as necessidades humanas, como, por exemplo, a produção de água e alimento, regulação climática e de doenças, benefícios estéticos e de recreação etc. Em um recorte sobre as cidades, os autores ressaltam a importância das florestas urbanas e infraestrutura verde nas cidades o que poderia auxiliar na regulação da temperatura urbana, gestão dos recursos hídricos (com um melhor gerenciamento das águas pluviais), atração de polinizadores e ampliação da segurança alimentar, redução da erosão do solo e escorregamentos, purificação do ar, entre outros benefícios (CARVALHO et al., 2014).

Ao analisar como quatro municípios suecos tratam a integração da adaptação baseada em ecossistemas no planejamento municipal, WAMSLER, LUEDERITZ e BRINK (2014) avaliam que as principais ações são a disseminação do conceito de adaptação baseada em ecossistemas e a colaboração entre diferentes departamentos da prefeitura e de outros atores da sociedade. Como uma medida de adaptação alternativa aos impactos costeiros, o principal instrumento de planejamento urbano (comprehensive plan) de Lomma definiu que novos edifícios somente deverão ser construídos a partir de uma altura de 3 metros do nível do mar, regra reforçada posteriormente por uma legislação federal. Além disso, o município vem trabalhando de forma colaborativa com municípios vizinhos na busca por uma melhor gestão dos recursos hídricos e redução da velocidade do escoamento superficial das chuvas (runoff) (WAMSLER et al., 2014).

Com parcelas de seu município abaixo do nível do mar, Kristianstad focava as suas ações de adaptação na construção de diques e sistemas de bombeamento. Com o passar dos 
anos, o município começou a incorporar medidas relacionadas à adaptação baseada em ecossistemas, proibindo a construção de residências nas áreas alagáveis, tratando-as como uma infraestrutura natural para a proteção da cidade contra as enchentes. Já Helsingbord iniciou uma inclusão sistemática da adaptação climática no planejamento do município, tendo como foco principal a recuperação e criação de áreas alagáveis, proteção de áreas costeiras, implantação de telhados verdes e ampliação do plantio de árvores. Além disso, os órgãos de planejamento e meio ambiente utilizaram os conceitos de serviços ecossistêmicos para fundamentar o programa de infraestrutura verde, o qual será a base para a elaboração do próximo plano diretor. Por fim, Malmo utiliza a tecnologia para garantir a ampliação da área verde do município, onde, desde 2009 a prefeitura incluiu em seu processo de planejamento a utilização de uma ferramenta para garantir que novas construções contenham áreas verdes em seus projetos (WAMSLER et al., 2014).

No mesmo sentido, Melbourne, na Austrália, decidiu aplicar o programa federal de "Desenho Urbano Sensível a Água" que tem como objetivo ampliar a resiliência do município por meio do planejamento urbano integrado à gestão das águas, promovendo políticas de redução do consumo de água potável, a ampliação do reuso e a redução da quantidade e melhoria da qualidade das águas descartadas no ambiente. Dentre as medidas aplicadas, destaca-se a promoção da captação de água descentralizada pela cidade, seja pelas residências como por áreas públicas, reduzindo a dependência de sistemas convencionais de abastecimento ao mesmo tempo que gerencia o escoamento superficial resultante de chuvas intensas (ANDRADE; BLUMENSCHEIN, 2013).

A Lei No 12.608, de 10 de Abril de 2012 que instituiu a Política Nacional de Proteção e Defesa Civil - PNPDEC (BRASIL, 2012a) definiu como dever da União, Estados e Municípios a adoção de medidas para a redução dos riscos de desastres, cabendo aos municípios, dentre outras exigências, a identificação e mapeamento das áreas de risco de desastres. Para isso, muitos municípios passaram a elaborar os Planos Municipais de Redução de Riscos - PMRR, instrumento que auxilia o diagnóstico de áreas de risco e o planejamento de intervenções para que a ocorrência de deslizamentos em encostas e solapamento de margens de córregos seja evitada(MIRANDOLA et al., 2015). Segundo os autores, os PMRR fornecem informações sobre a situação de assentamentos em relação à proximidade de encostas ou margens de córregos consideradas críticas. Com base nessas informações, os governos locais podem elaborar programas de recuperação urbana e ambiental das áreas, medidas de regularização fundiária e a definição dos custos das ações e possíveis fontes desses recursos (MIRANDOLA et al., 2015). Segundo o levantamento realizado pelo IGBE em 2017, o percentual de municípios brasileiros que possuem Planos Municipais de Redução de Riscos cresceu de 9,4\% em 2013 para 11,7\% em 2017 (IBGE, 2018a), mas ainda é um percentual pouco expressivo.

Dentre os instrumentos previstos na PNPDEC (BRASIL, 2012a), destaca-se também as Cartas Geotécnicas de Aptidão à Urbanização, obrigatório para municípios inscritos no cadastro nacional de municípios com áreas suscetíveis à ocorrência de deslizamentos de 
grande impacto, inundações bruscas ou processos geológicos ou hidrológicos correlatos. Estas cartas fornecem diretrizes urbanísticas aos gestores municipais para que seja garantida a segurança de novos parcelamentos do solo, além de serem condição para a transferência de recursos da União para a execução de ações de prevenção em áreas de risco(BRASIL, 2010). O número de municípios que possuem cartas geotécnicas de aptidão à urbanização tem aumentado nos últimos anos, mas também apresenta pouca expressividade. Em 2013, 3,5\% dos municípios afirmaram contar com este instrumento, percentual que passou para 5,2\% em 2017(IBGE, 2018a).

NOGUEIRA e CANIL (2017) analisam os potenciais da utilização da carta de aptidão durante o processo de um planejamento urbano considere as questões de adaptação e reposta a eventos extremos. Segundo os autores, esta ferramenta fornece orientações e diretrizes que podem ser consideradas no planejamento do uso e ocupação do solo urbano levando em consideração as fragilidades e potencialidades do território a partir de suas características físicas, dos processos que geram situações de riscos e das formas de uso e ocupação do solo existentes (NOGUEIRA; CANIL, 2017). De modo a subsidiar a elaboração do Plano Diretor Regional do $\mathrm{ABC}$, as cartas de aptidão à urbanização da região foram apresentadas de maneira semafórica: as áreas aptas à urbanização (em verde); em amarelo as áreas aptas à urbanização com restrições, devendo ser observados critérios geodinâmicos, geotécnicos e hidrológicos; em vermelho as áreas inaptas à urbanização ou com condições muito complexas por apresentarem susceptibilidade e/ou histórico de ocorrência de processos geodinâmicos, geotécnicos e hidrológicos; e por fim, as áreas em marrom, compreendendo áreas com alta prioridade para conservação ambiental, não sendo recomendada a sua urbanização, cujo resultado pode ser verificado na Figura 12 a seguir. Os autores ressaltam, entretanto, a necessidade de ampliar a análise para além dos limites políticos-administrativos dos municípios, sugerindo que sejam consideradas as bacias hidrográficas, unidade territorial definida pelo Plano Estadual de Proteção e Defesa Civil para a identificação de riscos de desastres(BRASIL, 2012a; NOGUEIRA; CANIL, 2017). 
Figura 12 - Carta Geotécnica Regional de Aptidão à Urbanização - Síntese do Grande ABC

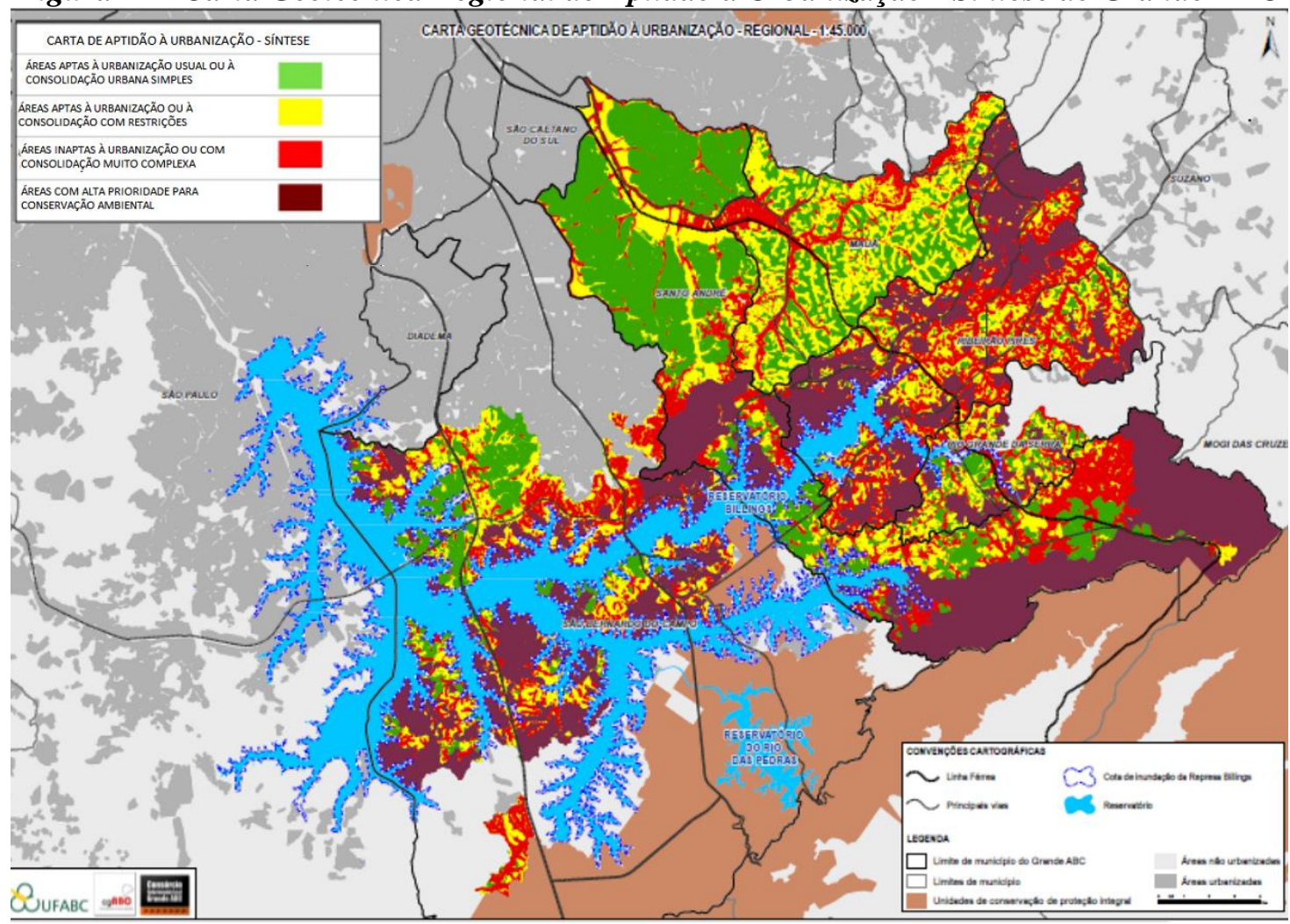

Fonte: Reprodução de (NOGUEIRA; CANIL, 2017)

A relação entre a temática do transporte com a adaptação às mudanças climáticas foi avaliada no documento Adapting Urban Transport to Climate Change (EICHHORST, 2009), onde a autora apresenta os principais impactos que deverão afetar as infraestruturas de transporte e propõe medidas de adaptação a serem aplicadas. Dentre os impactos que podem ser relacionadas com o ambiente urbano estão a deterioração de infraestruturas de transporte pela ampliação das temperaturas médias e pela maior ocorrência de ondas de calor, e a ampliação da ocorrência de tempestades e alagamentos, que deverá afetar todos os modais de transporte, principalmente em áreas mais baixas, várzeas e túneis, onde os sistemas de drenagem ou bombeamento não estejam dimensionados corretamente. Para a minimização destes impactos os municípios poderão ampliar o sombreamento das vias, utilizar materiais e padrões de design mais resilientes para construção de infraestruturas, melhorar os sistemas de drenagem, realizar a manutenção regular de infraestruturas, promover o planejamento urbano para que sejam evitadas áreas de risco e para a redução da necessidade de infraestruturas rodoviárias através do planejamento de cidades compactas, e criar de rotas alternativas para quando ocorrerem obstruções nas vias (EICHHORST, 2009).

EICHHORST(2009) defende ainda a importância das sinergias entre a mitigação e adaptação no transporte urbano de passageiros. Uma das medidas a serem aplicadas pelos municípios é a criação das estruturas necessárias para a alteração do modal do transporte, 
priorizando os transportes não motorizados e o transporte público, além de aplicar medidas para desincentivar o uso de transportes motorizados individuais como a cobrança de taxas e a limitação de vagas de estacionamento. Outra medida é a redução dos deslocamentos diários, seja evitando trajetos ou reduzindo as distâncias percorridas. Estas ações podem ser influenciadas pelo planejamento e uso do solo, através de metodologias de desenvolvimento orientado para o trânsito (transit-oriented development) como a apresentada por EVERS et. al.(2018) que propõe três princípios territoriais a serem seguidos: o crescimento urbano compacto, priorizando o desenvolvimento das cidades próximo a eixos de transporte coletivo e controlando o espraiamento urbano; a construção de centralidade e infraestruturas conectadas, reduzindo as distâncias a serem percorridas, a dependência de deslocamentos motorizados, promovendo a mobilidade urbana sustentável através da promoção do uso misto em toda a área urbana e do transporte ativo e do transporte público coletivo para a conexão de diferentes centralidades; e, a gestão coordenada dos benefícios obtidos com as medidas aplicadas pelo poder público, dividindo com a coletividade os benefícios obtidos com a valorização imobiliária obtida pelos investimentos públicos e pelas regras urbanísticas (EVERS et al., 2018)

Tendo em vista os estudos analisados, as medidas levantadas para a ampliação da resiliência das cidades foram sistematizadas no Quadro 5, sendo divididas entre as temáticas Habitação e Planejamento Urbano, Mobilidade, Produção de Alimentos, Gestão Ambiental e Resposta aos Impactos Climáticos. 


\begin{tabular}{|c|c|c|}
\hline Temáticas & Medidas de Adaptação & Referências \\
\hline $\begin{array}{c}\text { Habitação e } \\
\text { Planejamento } \\
\text { Urbano }\end{array}$ & $\begin{array}{l}\text { Restringir construções a uma cota de } 3 \text { metros em relação do nível do mar } \\
\text { Desenvolver planos para a retirada das construções e populações de áreas de risco e a criação } \\
\text { de novos assentamentos } \\
\text { Restringir o espraiamento urbano } \\
\text { Reduzir a velocidade do escoamento das chuvas } \\
\text { Alterar o código da construção civil (Ampliar áreas verdes, aprimorar a drenagem, implantar } \\
\text { pavimentos permeáveis, reduzir do consumo de água potável, ampliar o reuso e reduzir a } \\
\text { quantidade e melhor a qualidade das águas descartadas no ambiente) }\end{array}$ & $\begin{array}{l}\text { (UITTENBROEK et } \\
\text { al., 2013; WAMSLER } \\
\text { et al., 2014; RIBEIRO; } \\
\text { SANTOS, 2016; CHU } \\
\quad \text { et al., 2017; } \\
\text { LONDRES, 2017) }\end{array}$ \\
\hline Mobilidade & $\begin{array}{l}\text { Evitar a instalação de infraestruturas de transporte em áreas de risco } \\
\text { Utilizar materiais e padrões de design mais resilientes } \\
\text { Realizar a manutenção regular de infraestruturas } \\
\text { Planejar de cidades compactas e reduzir os deslocamentos diários } \\
\text { Construir quadras menores e ampliar o sombreamento das vias } \\
\text { Priorizar os transportes não motorizados e o transporte público } \\
\text { Priorizar o desenvolvimento das cidades junto a eixos de transporte coletivo } \\
\text { Desincentivar o uso de transportes motorizados individuais }\end{array}$ & $\begin{array}{l}\text { (EICHHORST, 2009; } \\
\text { JACOBS, 2011; GEHL, } \\
\text { 2013; CHU et al., 2017; } \\
\text { EVERS et al., 2018) }\end{array}$ \\
\hline $\begin{array}{c}\text { Produção de } \\
\text { Alimento }\end{array}$ & $\begin{array}{l}\text { Controlar o espraiamento urbano possibilitando a produção de alimentos próximo às cidades } \\
\text { Incentivar as agriculturas urbana e periurbana } \\
\text { Atrair de polinizadores } \\
\text { Incentivar a implantação de telhados verdes e hortas urbanas } \\
\text { Adotar de técnicas alternativas de cultivo }\end{array}$ & $\begin{array}{l}\text { (CARVALHO et al., } \\
\text { 2014; CHU et al., 2017; } \\
\text { LONDRES, 2017) }\end{array}$ \\
\hline
\end{tabular}




\begin{tabular}{|c|c|c|}
\hline Temáticas & Medidas de Adaptação & Referências \\
\hline $\begin{array}{c}\text { Gestão } \\
\text { Ambiental }\end{array}$ & $\begin{array}{l}\text { Proteger mananciais } \\
\text { Descentralizar a produção/armazenamento de águas } \\
\text { Implantar praças alagáveis e ampliar de áreas permeáveis } \\
\text { Redimensionar os canais e sistemas de drenagem } \\
\text { Criar florestas urbanas e infraestruturas verdes } \\
\text { Ampliar da arborização urbana } \\
\text { Proteger ecossistemas com a criação de cinturões verdes } \\
\text { Capacitar técnicos municipais sobre AbE }\end{array}$ & $\begin{array}{c}\text { (ANDRADE; } \\
\text { BLUMENSCHEIN, } \\
\text { 2013; CARVALHO et } \\
\text { al., 2014; WAMSLER } \\
\text { et al., 2014; MORACI } \\
\text { et al., 2018) }\end{array}$ \\
\hline $\begin{array}{c}\text { Resposta aos } \\
\text { Impactos } \\
\text { Climáticos }\end{array}$ & $\begin{array}{l}\text { Restringir o desenvolvimento em áreas propensas a inundações e deslizamentos } \\
\text { Melhorar os sistemas de drenagem } \\
\text { Instalar barragens e piscinões } \\
\text { Construir de novas relações sociais, econômicas e ambientais que resistam aos estresses } \\
\text { ambientais } \\
\text { Elaboração dos Planos Municipais de Redução de Riscos - PMRR } \\
\text { Elaboração de Cartas Geotécnicas de Aptidão à Urbanização } \\
\text { Considerar as fragilidades e potencialidades do território } \\
\text { Proibir construções em áreas alagáveis } \\
\text { Manejar áreas sujeitas à processos de deslizamento de terra }\end{array}$ & $\begin{array}{c}\text { (BRASIL, 2012a; } \\
\text { UITTENBROEK et al., } \\
\text { 2013; MIRANDOLA et } \\
\text { al., 2015; RIBEIRO; } \\
\text { SANTOS, 2016; CHU } \\
\text { et al., 2017; } \\
\text { LONDRES, 2017; } \\
\text { NOGUEIRA; CANIL, } \\
\text { 2017; MORACI et al., } \\
\text { 2018) }\end{array}$ \\
\hline
\end{tabular}

Fonte: Elaborado pelo autor 
Esta relação de medidas teve por objetivo sintetizar os pontos considerados como mais importantes para a ampliação da resiliência em âmbito local, conforme os trabalhos técnicos e estudos científicos analisados. Além disso, esta sistematização da literatura visa auxiliar na validação dos indicadores propostos durante a elaboração do UAI, os quais foram aplicados nesta dissertação.

O conjunto de medidas de adaptação apresentado não tem como propósito esgotar as opções que poderiam ser adotadas ou servir como um manual para a atuação dos tomadores de decisão. A aplicação ou não destas medidas deve ser precedida de uma avaliação e compreensão, por parte dos governos locais, sobre as suas características e vulnerabilidades, além da avaliação da relação custo-benefício de cada ação.

Outro entrave para a aplicação das medidas indicadas para a realidade local é a sensibilização dos tomadores de decisão que não entendem a questão climática como um tema prioritário na agenda municipal. Além disso, mesmo para municípios que entendam a adaptação climática como necessária, ainda existem as dificuldades técnicas e financeiras para a elaboração de instrumentos específicos para lidar com os impactos das mudanças climáticas, como estratégias ou planos de adaptação (MARGULIS, 2017).

A opção defendida neste trabalho é que os municípios apliquem as medidas de adaptação transversalmente em outros instrumentos, políticas e processos, viabilizando um ganho simultâneo entre diferentes setores municipais, ao mesmo tempo que influencia a redução de sua vulnerabilidade climática (UITTENBROEK et al., 2014). Para isso, é necessário que os municípios se municiem de alguns instrumentos chave, os quais poderão ser adequados conforme os impactos a que estes municípios estão e estarão submetidos. Uma vez que a temática da adaptação ainda não é muito disseminada (RODRIGUES FILHO et al., 2016), os técnicos municipais poderão apresentar dificuldades na tomada de decisão e priorização de instrumentos e medidas a serem adotadas. Dessa forma, visando sistematizar as informações municipais relevantes para a ampliação da resiliência em âmbito local, foi elaborado, no âmbito do Projeto CiAdapta, um índice para avaliar o potencial dos municípios em se adaptar às mudanças climáticas, o qual poderá auxiliar o planejamento estratégico municipal na resposta aos impactos climáticos. 


\section{O ÍNDICE DE ADAPTAÇÃO URBANA (UAI)}

Desenvolvido no âmbito do projeto CiAdapta, o Índice de Adaptação Urbana (UAI Urban Adaptation Index) baseia-se em dados de intervenções urbanas que apresentem relação com a adaptação climática, conforme diretrizes do Plano Nacional de Adaptação à Mudança do Clima (PNA), focados em cinco conjuntos de políticas públicas (ou cinco dimensões), a saber: Habitação e Planejamento Urbano, Mobilidade, Produção de Alimento, Gestão Ambiental e Resposta aos Impactos Climáticos. Para a construção desse índice, foram utilizados dados do relatório Perfil dos Municípios Brasileiros de 2017, lançado pelo Instituto Brasileiro de Geografia e Estatística - IBGE(IBGE, 2018a).

Considerando um Índice como a síntese de um conjunto de indicadores com o objetivo auxiliar o impulsionamento de ações de tomadores de decisão, o UAI agrega informações sobre os principais elementos que podem influenciar a capacidade de um município para adaptação climática, possibilitando aos governos locais a análise de suas fragilidades institucionais, e fornecendo subsídios para a definição de medidas a serem tomadas, através da elaboração de proposições/intervenções que ampliem suas capacidades adaptativas.

Devido às características multidimensionais, multidisciplinares e multiescalares dos desafios das mudanças climáticas no ambiente urbano (DHAR; KHIRFAN, 2016), as administrações municipais deverão atuar em diferentes frentes, implantando intervenções urbanas que busquem reduzir as pressões sobre os serviços municipais e o meio ambiente urbano, atuando, simultaneamente, para a redução das emissões dos gases de efeito estufa e da vulnerabilidade da população aos impactos climáticos. Além disso, devem ser consideradas tanto medidas elaboradas especificamente para fornecer respostas aos impactos climáticos já observados, como outras que resultem em benefícios ambientais, sociais ou econômicos, justificáveis independentemente da concretização ou não das alterações climáticas, as chamadas medidas não arrependimento - "no-regrets" (BRASIL, 2017).

Conforme apresentado anteriormente, essas diferentes opções de atuação do poder público são denominadas como Capacidades Adaptativas Diferenciadas (DI GIULIO et al., 2016), sendo composta pela Capacidade Genérica, com medidas que influenciam de alguma forma a capacidade adaptativa dos municípios, como por exemplo a garantia de melhores condições de moradia, saúde, educação, alimentação, entre outros; e a Capacidade Específica, englobando as medidas e mecanismos implementados pelos municípios para uma atuação direta frente aos riscos climáticos existentes ou previstos, como a existência de defesa civil municipal, sistemas de alerta, projetos e obras para minimizar a ocorrência de deslizamentos e enchentes etc.

O Índice de Adaptação Urbana (UAI), em consonância com essa perspectiva analítica, visa sistematizar informações municipais sobre a existência ou não de políticas, ações e 
intervenções, direta ou indiretamente relacionadas com a questão ambiental ou climática, que viabilizem a implantação de medidas e instrumentos para ampliar o potencial dos municípios em mudar para um estado mais desejado frente aos impactos das mudanças climáticas, expandindo a sua capacidade adaptativa. No entanto, o UAI não tem como objetivo avaliar a qualidade, abrangência ou níveis de aplicação desses instrumentos de gestão urbana e ambiental. Entende-se que a existência destes instrumentos e intervenções ofereceriam as condições iniciais para as administrações municipais atuarem, quando sensibilizadas, frente aos impactos das mudanças climáticas.

\subsection{Dimensões do UAI}

O UAI contempla quatro dimensões que poderiam subsidiar a implantação de intervenções urbanas relacionadas às capacidades genéricas dos municípios para ampliar o seu potencial de adaptação (Habitação, Mobilidade Urbana, Agricultura Sustentável e Gestão Ambiental do território) e uma importante dimensão relacionada a proposições e intervenções mais ajustadas à capacidade específica do município, ou seja, sua atuação direta na minimização dos impactos dos eventos climáticos (Resposta aos Impactos Climáticos).

A dimensão Habitação leva em consideração as correlações entre vulnerabilidade climática e as características e localização de moradia da população. Assim, um município deve estar atento à necessidade de relocação da população residente em áreas de risco, melhora de projetos de habitação, redução do déficit de saneamento básico e de construção de infraestruturas que minimizem efetivamente a exposição da população aos riscos climáticos (FIELD et al., 2014).

Já a dimensão Mobilidade Urbana está relacionada à concentração populacional em centros urbanos e à vulnerabilidade dos sistemas de transporte a eventos extremos, como chuvas fortes e enchentes. Segundo EICHHORST(2009) é preciso investir em infraestruturas de transporte mais resilientes em áreas vulneráveis. Para a autora, populações mais pobres possuem maiores dificuldades em se locomover em cidades cujo principal modal de transporte é o motorizado individual, necessitando o desenvolvimento de um sistema de transporte diversificado, inclusivo e seguro, que será de extrema importância em eventos de crise, onde evacuações poderão ser necessárias (EICHHORST, 2009).

A terceira dimensão do UAI, Agricultura Sustentável, está relacionada à infraestrutura verde da cidade, à produção de alimentos e à segurança alimentar, estas últimas sensíveis à ocorrência de eventos extremos, como estiagens mais longas e alterações das temperaturas médias anuais. As agriculturas urbana e periurbana, além de poderem ser adequadas mais facilmente às alterações climáticas de cada localidade, aumentando a 
segurança alimentar de centros urbanos, servem como uma medida eficaz para conter o avanço da mancha urbana sobre áreas protegidas, promover oportunidades de trabalho e aumentar as áreas verdes e permeáveis no município (ONU, 2018).

Já a dimensão de Gestão Ambiental engloba de maneira mais abrangente as capacidades genéricas do município ao tratar de questões como biodiversidade, prestação de serviços ecossistêmicos, saneamento, poluição atmosférica etc. Esta dimensão apresenta especial correlação com a estratégia de Adaptação Baseada em Ecossistemas (AbE), focada em medidas que visem a garantia de ambientes saudáveis, conservação da biodiversidade, sequestro de carbono e gestão sustentável das águas, desempenhando papel essencial para a redução da vulnerabilidade do ambiente e ampliação da segurança humana (CARVALHO et al., 2014).

Finalmente, a dimensão Resposta aos Impactos Climáticos foca em intervenções municipais específicas que possuam como finalidade a minimização dos impactos de eventos extremos e a melhoria das respostas institucionais frente a esta temática. Esta dimensão abrange ações mais diretas, as quais exigem um alto grau de comprometimento do governo local com a gestão dos riscos climáticos.

Como o intuito do UAI é retratar o potencial adaptativo dos municípios, por meio da existência ou não de instrumentos ou intervenções que influenciem as suas capacidades adaptativas, cada dimensão contempla indicadores específicos que serão apresentados no item a seguir.

\subsection{Indicadores do UAI}

Segundo MEADOWS (1998), indicadores são essenciais para o entendimento do mundo, tomadas de decisão e planejamento de ações, podendo ser utilizados como instrumentos para mudança, conhecimento e até propaganda. A autora ressalta os riscos da definição de indicadores de estado de um sistema que sejam fracos ou errados, podendo resultar em reações super ou subdimensionadas e na piora da situação analisada. Indicadores podem ser objetivos, permitindo uma medida exata e tendo a sua validação facilitada, ou subjetivos, apresentando a visão de quem fornece a informação, retratando a questão de uma forma mais qualitativa do que quantitativa (MEADOWS, 1998).

O Relatório Ambiental Urbano Integrado - Geo Cidades elaborado pelo Programa das Nações Unidas para o Meio Ambiente - PNUMA, em parceria com o Ministério do Meio Ambiente - MMA, avaliou os efeitos do desenvolvimento urbano no meio ambiente sob a ótica da sustentabilidade, utilizando indicadores de dinâmicas sociais, econômicas, políticas e territoriais. Para isso, o relatório apresentou o modelo de indicadores a partir de uma matriz que leva em consideração as Pressões, Estado, Impactos e Respostas (PEIR 
- ou SPIR em inglês) de uma determinada temática em uma área de interesse (PNUMA, 2002).

Segundo Philippi Jr e Malheiros (2012), os modelos PEIR aplicados atualmente têm como base os trabalhos de Tony Friend e David Rapport de 1979 que buscavam a organização de informação de estatísticas ambientais, em uma iniciativa conjunta da Statistics Canada com o Escritório de Estatística das Nações Unidas, fundamentados na noção de estresse e resposta. Esta metodologia englobava as estatísticas de atividades estressoras e dos estresses ambientais, além das respostas humanas e ambientais, estrutura que foi posteriormente adaptada a outras metodologias, entre elas o PEIR utilizado pelo GEO Cidades(PHILIPPI JR; MALHEIROS, 2012).

O relatório GEO Cidades afirma que a matriz PEIR tem como objetivo a elaboração de vínculos entre seus diferentes componentes de modo a orientar a avaliação de uma situação ambiental específica, avaliando as pressões a que está submetido, os efeitos dessas pressões e as respostas necessárias para uma reação. O modelo PEIR corresponde à tentativa de responder a quatro questões norteadoras, sendo elas: $\mathrm{O}$ que está ocorrendo? Por que está ocorrendo? O que pode ser feito e o que está sendo feito a respeito? E, o que ocorrerá se não haver uma atuação imediata? A resposta a estas questões são a base do PEIR, sendo a Pressão os motivos e ações humanas que pressionam o meio ambiente; o Estado as condições que aquele meio se encontra após estar submetido às pressões; o Impacto os efeitos dessas pressões sobre o meio ambiente; e, a Resposta as ações que minimizam ou evitam a ocorrência dos impactos negativos e contribuem para uma melhoria da qualidade de vida da população submetida aqueles impactos (PNUMA, 2002).

A Figura 13, adaptada de (PNUMA, 2002) por PHILLIPI JR. E MALHEIROS (2012), apresenta a correlação entre os componentes da Matriz PEIR. Segundo os autores, as respostas a estas perguntas possibilitam o entendimento da situação atual de um meio, permitindo a definição das estratégias mais apropriadas para a resolução dos problemas ambientais e para a elaboração de políticas apropriadas em âmbito local. 
Figura 13 - Interação dos componentes urbano-ambientais da Matriz PEIR

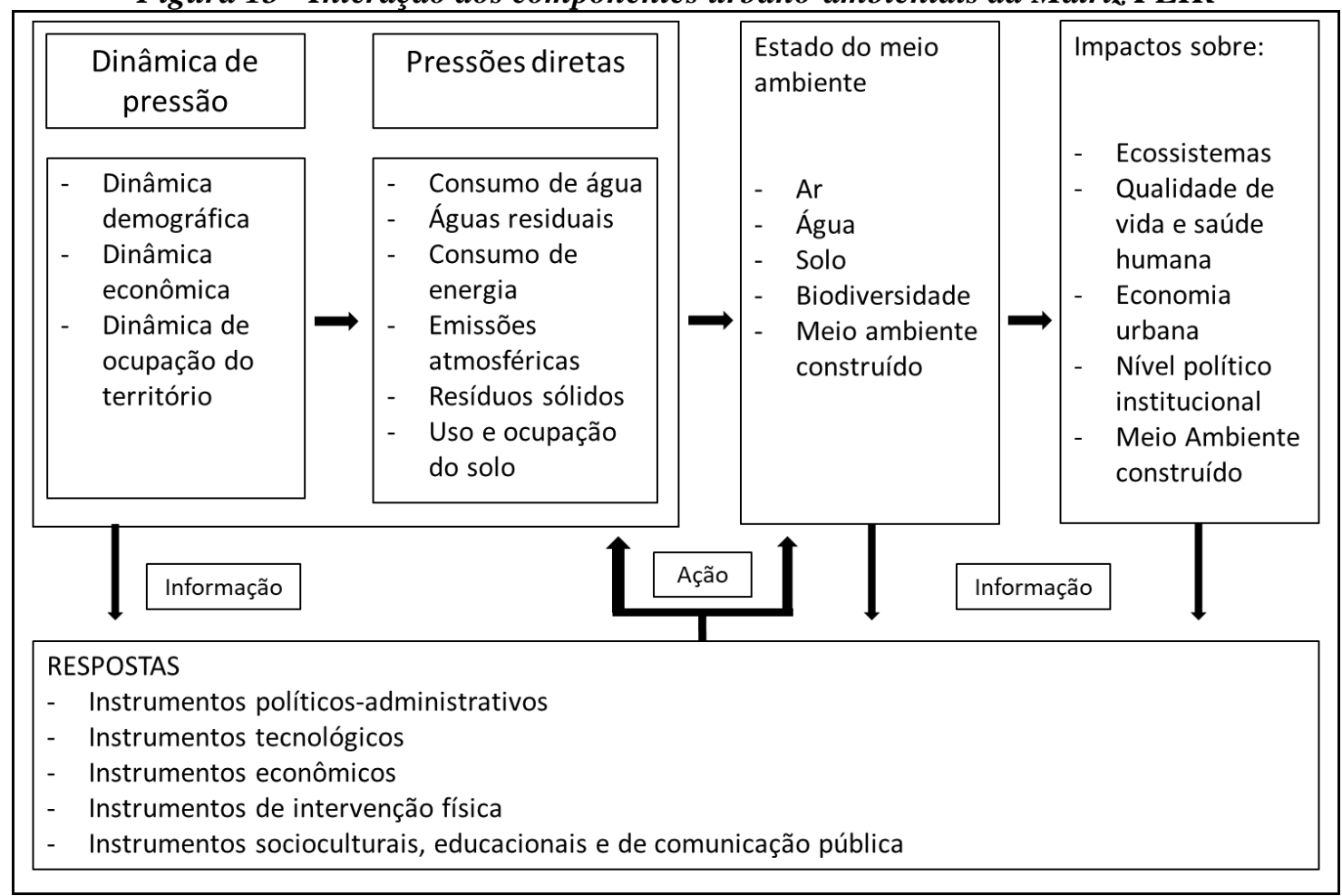

Fonte: (PHILIPPI JR; MALHEIROS, 2012) pág. 65, adaptado de PNUMA (2002)

No contexto da adaptação climática no meio urbano, os indicadores de pressão devem retratar as ações antrópicas que contribuem para as mudanças climáticas, principalmente aquelas que influenciam a produção de Gases de Efeito Estufa, a redução de sumidouros de carbono, ou para o aumento dos riscos a que a população estaria submetida. Os indicadores de Estado retratam as alterações observadas no meio ambiente urbano em decorrência dos efeitos das mudanças climáticas, sejam elas o aumento da temperatura, a ocorrência de eventos extremos, secas prolongadas, enchentes e desbarrancamentos, entre outros. Já os indicadores de Impacto devem demonstrar o efeito dessas alterações sobre o ecossistema, a qualidade de vida das pessoas e sobre a dinâmica político institucional dos municípios. Por fim, os indicadores de Resposta demonstram como o poder público e as populações estão atuando para reduzir estes impactos e se adaptar às novas situações a que estarão submetidos.

Ainda que a matriz PEIR não tenha sido utilizada durante a definição dos indicadores do UAI, a compreensão do papel de cada tipo de indicador auxilia no uso que será feito deles. Uma vez que o UAI contempla proposições/intervenções que poderiam ser aplicadas pelos municípios para antecipação e minimização dos impactos das mudanças climáticas, é possível associar os indicadores do UAI com os Indicadores de Resposta propostos pela matriz PEIR. 
A análise de indicadores pode ser realizada em conjunto, formando sistemas de indicadores. Segundo SEPE e GOMES (2008), sistemas de indicadores são ótimas ferramentas para o planejamento de políticas públicas, já que indicadores tratam de uma maneira simples questões complexas. Além disso, afirmam que a alimentação destes sistemas com séries históricas de dados permite o diagnóstico da situação atual, o acompanhamento da evolução da situação a longo prazo e a avaliação dos resultados das políticas públicas e das ações realizadas, subsidiando a tomada de decisão (SEPE; GOMES, 2008).

A combinação matemática de um sistema de indicadores pode ser denominada como um Índice ou Indicador Sintético, como por exemplo o mundialmente conhecido IDH (Índice de Desenvolvimento Humano). Ainda para SEPE e GOMES (2008), o sucesso de um indicador sintético está em sua simplicidade, potencial de comparação e replicação em outros locais e realidades, assim como na possiblidade de acompanhamento da evolução dos seus resultados ao longo do tempo.

Segundo SAISANA e TARANTOLA (2002), os indicadores sintéticos têm como base sub-indicadores que não possuem correlações simples para mensuração ou equiparação. As autoras apresentam ainda alguns pontos positivos e negativos sobre a sua utilização. Entre os pontos positivos, é citado o potencial dos índices em simplificar questões complexas ou multidimensionais; o fornecimento da visão geral de um problema, facilitando a interpretação dos tomadores de decisão; a capacidade de ampliar o interesse do setor público para o tema tratado ao apresentar as informações de maneira resumida, facilitando a comparação entre diferentes localidades; além da redução do número de informações a serem analisadas para a tomada de decisão. Como pontos contrários, são citados os riscos de índices mal construídos influenciarem políticas de maneira confusa ou negativa; a generalização resultar em políticas simplistas; a necessidade de cuidado para que a escolha dos sub-indicadores sejam ser realizadas de maneira técnica e transparente para que não ocorram disputas políticas sobre o tema; e, que os índices ampliam a quantidade de informações a serem levantadas, já que todos os sub-indicadores devem ser alimentados(SAISANA; TARANTOLA, 2002).

Avaliando as diferenças entre os indicadores sintéticos e sistemas de indicadores, NETO et al. (2008) defendem que sejam aplicadas propostas integradas onde os tomadores de decisão possam utilizar tanto dos resultados do índice como das análises intermediárias do sistema de indicadores que o formou. Os autores defendem ainda que sejam utilizadas ferramentas gráficas e recursos visuais para facilitar o uso e o entendimento das informações pelos técnicos ou gestores(NETO et al., 2008).

Conforme será apresentado a seguir, observa-se correlações entre os pontos levantados por NETO et al. (2008) e a proposta do UAI, uma vez que são possibilitados diferentes níveis de análise aos municípios. Após o levantamento das informações, os técnicos e gestores poderão analisar o resultado de cada indicador, de cada uma das dimensões ou o 
resultado final do UAI, definindo para cada situação o nível mais adequado a ser utilizado. Além disso, a apresentação dos resultados finais e de cada uma das dimensões de maneira espacializada facilita o planejamento local e regional.

Um ponto importante para a definição dos indicadores do UAI foi a disponibilidade e confiabilidade de dados referentes aos municípios brasileiros. Assim, em conjunto com os pesquisadores do CiAdapta, foram selecionados 26 (vinte e seis) indicadores derivados dos dados disponibilizado no relatório Perfil dos Municípios Brasileiros (IBGE, 2018a), resultado da $15^{\mathrm{a}}$ Pesquisa de Informações Básicas Municipais (Munic 2017) elaborada pelo IBGE $^{5}$. Uma vantagem da utilização desses dados é que tais informações são atualizadas periodicamente, assim, os municípios, regiões metropolitanas e o Governo do Estado poderão atualizar as pontuações do UAI de cada município. Isso possibilitará a avaliação da evolução dos potenciais municipais de adaptação às mudanças climáticas e o subsídio aos tomadores de decisão para o desenvolvimento de políticas públicas.

Dentre as informações divulgadas neste relatório do IBGE, foram utilizadas aquelas que demonstram o potencial institucional dos municípios para se adaptar às mudanças do clima, indicando a existência (sim) ou inexistência (não) de determinados instrumentos ou iniciativas.

Os indicadores na Dimensão Habitação buscaram verificar a existência, ou não, de instrumentos que possibilitem a inserção da adaptação às mudanças climáticas no desenvolvimento da cidade. A literatura consultada demonstra que há uma conexão entre vulnerabilidade social e sensibilidade aos impactos climáticos (KRELLENBERG et al., 2014). Aqueles que vivem em áreas de risco de deslizamento ou de inundações, ou que não têm acesso à infraestrutura para se proteger dos riscos dos eventos extremos, seja por falta de saneamento e/ou dificuldade de acesso à água potável, tendem a ser mais atingidos pelos impactos climáticos. Além disso, populações pobres em centros urbanos e moradores de assentamentos precários estarão submetidos a impactos maiores, onde a melhoria nas condições de vida dessas pessoas também resultará na redução dos impactos a que elas estarão submetidas(THE WORD BANK, 2011; FIELD et al., 2014; HOEGHGULDBERG et al., 2018). Assim, na dimensão habitação, o UAI busca avaliar as ferramentas institucionais estruturais que os municípios podem lançar mão para, através das condições de habitação da população, ampliar a sua capacidade adaptativa.

\footnotetext{
${ }^{5}$ Cabe ressaltar que o levantamento realizado por esse órgão incluiu um conjunto de indicadores de avaliação e de monitoramento institucional e administrativo dos municípios brasileiros. Para isso, o IBGE coletou, em conjunto com as prefeituras municipais e entre os meses de abril e agosto de 2017, informações sobre a gestão e estrutura dos 5570 municípios brasileiros, as quais foram divididas em 7 (sete) temas: perfil do gestor, recursos humanos, habitação, transporte, agropecuária, meio ambiente e gestão de riscos e resposta a desastres, cada um composto por diversos indicadores (IBGE, 2018a).
} 
Nesse contexto, esta dimensão contempla os seguintes indicadores: Existência de Plano Municipal de Habitação, Conselho Municipal de Habitação e Fundo Municipal de Habitação. Entende-se que com estes instrumentos os municípios têm meios para promover uma política habitacional que possa reduzir a sua vulnerabilidade socioambiental, ampliar a urbanização de assentamentos precários e a relocação de famílias em áreas de riscos. A existência do Plano Municipal de Habitação poderá promover melhores condições de vida à população, seja por medidas de regularização fundiária, como pela inclusão de técnicas e diretrizes que integrem a mitigação e a adaptação nos projetos e desenho urbano(ROSENZWEIG et al., 2015; RIBEIRO; SANTOS, 2016). A existência de um conselho de habitação, em tese, indica que existem um fórum de discussão para a priorização das ações do município e que as decisões sobre o desenvolvimento habitacional são compartilhadas, envolvendo a população, o que amplia o potencial de sucesso das medidas aplicadas pela inclusão daqueles que são impactados no processo de tomada de decisão. Como a viabilização dos projetos habitacionais enfrentarão as barreiras financeiras para a sua efetiva implantação, incluiuse a existência de um fundo específico para a aplicação das medidas definidas.

No caso dos indicadores que compõem a dimensão mobilidade urbana, a literatura mostra a necessidade de planejamentos para transportes públicos mais inclusivos e de melhor qualidade, com a criação de rotas alternativas para responder a eventos extremos e a identificação de infraestruturas críticas (EICHHORST, 2009). Dessa forma, um dos indicadores selecionados nesta dimensão no UAI inclui a existência ou não de Planos Municipais de Transporte (ou Planos Municipais de Mobilidade Urbana), instrumento que pode organizar o desenvolvimento dos sistemas de transporte a longo prazo, definindo a alocação de recursos e orientando o desenvolvimento do sistema municipal de transporte para uma condição mais sustentável. Outra vantagem da elaboração deste instrumento é que a sua aprovação é uma das condições para a obtenção de recursos federais, de acordo com a Política Nacional de Mobilidade Urbana (BRASIL, 2012b). A literatura consultada afirma ainda a necessidade de desincentivo de transportes motorizados individuais e da ampliação na disponibilização de transportes não motorizados e sistemas de transporte público sejam priorizados(EICHHORST, 2009). Dessa forma, os outros indicadores contemplados estão relacionados à necessidade de que as cidades considerem estes outros modais de transporte, verificando, assim, a disponibilização pelo município de Ciclovias, Bicicletários e Transporte Coletivo por Ônibus Municipal e Intermunicipal.

Os efeitos das mudanças climáticas deverão impactar a produção de alimentos em todas as regiões do país, forçando o meio agrícola a se adaptar aos novos padrões de temperatura e disponibilidade hídrica, inclusive exigindo a alteração da localização e espécies cultivadas (ASSAD; MAGALHÃES, 2014; FIELD et al., 2014). Os governos locais deverão atuar para o fortalecimento das produções agrícolas e de outras técnicas extrativistas, tornando-as mais resilientes e que garantam o sustento da população rural, 
de modo a reduzir a situação de vulnerabilidades que essas pessoas se encontram (LEMOS et al., 2016; ALLEN et al., 2018). Assim, para minimizar os impactos à insegurança alimentar, iniciativas em diversos municípios têm mostrado os ganhos de experiências de agriculturas urbana e periurbana, aproximando a produção de alimentos dos consumidores e reduzindo as perdas durante o transporte. Estas experiências de agricultura também podem ser pensadas à luz da adaptação, uma vez que estas áreas podem servir como barreiras naturais contra o espraiamento das cidades sobre áreas sensíveis ambientalmente e áreas de risco, ao mesmo tempo que aumentam as áreas verdes e permeáveis do município (ONU, 2018), amenizando os efeitos das ilhas de calor. Considerados este conjunto de fatores, foram definidos cinco indicadores para a dimensão de Agricultura Sustentável relacionados ao desenvolvimento, ou não, de programas ou ações das prefeituras de estímulo à Agricultura Orgânica, à Agricultura Familiar, à Produção de Hortas Comunitárias e ao Associativismo (associações de produtores, cooperativas, etc.). $\mathrm{O}$ quinto indicador, o qual pode ser relacionado com a capacidade específica dos municípios em se adaptar, verifica o desenvolvimento municipal de Programas ou Ações de Prevenção Contra Problemas Climáticos para o Setor Agropecuário.

Os indicadores que compõem a dimensão Gestão Ambiental se relacionam, direta e indiretamente, às ações dos municípios que podem promover a preservação ambiental, a mitigação e adaptação às mudanças climáticas, melhoria do bem-estar e saúde dos residentes e equilíbrio ecológico local e regional. Os impactos climáticos deverão pressionar a disponibilidade hídrica para o consumo humano e a dessedentação de animais, ampliando a importância de políticas de saneamento básico, de proteção dos recursos hídricos e de revitalização de áreas produtoras de água. A ampliação das temperaturas médias deverão aumentar os riscos relacionados a doenças respiratórias, principalmente em crianças e idosos e, quando associada aos eventos de picos de precipitações, deverá influenciar na disseminação e dinâmica de doenças vetoriais, situações potencializadas com a ocorrência de enchentes (ASSAD; MAGALHÃES, 2014; FIELD et al., 2014). Nesse sentido, além da melhoria das políticas de saneamento, ressalta-se o papel da infraestrutura verde e da biodiversidade no equilíbrio ambiental em âmbito local, conforme preconiza a metodologia de Adaptação Baseada em Ecossistemas, atuando na regulação climática, produção de água, atração de polinizadores essenciais para a produção de alimentos, purificação do ar etc. (CARVALHO et al., 2014).

Tendo em vista essas questões, os indicadores selecionados para a Dimensão de Gestão Ambiental buscam avaliar as condições técnicas e legais existentes que poderão ser utilizadas para que os municípios passem para mais um estado mais desejado frente aos impactos das mudanças climáticas. São avaliados, assim, se os municípios possuem Fundo Municipal de Meio Ambiente, garantindo orçamentos específicos para a promoção de políticas de proteção ambiental, normalmente preterida frente a demandas sociais prioritárias como políticas de saúde, segurança e educação (MARGULIS, 2017); se os 
municípios já têm instrumentos para Pagamento de Serviços Ambientais (PSA), demanda também relacionada com a disponibilização e alocação de recursos, com o foco específico para a geração de serviços ecossistêmicos; se possuem Plano de Gestão Integrada de Resíduos Sólidos nos termos da Política Nacional de Resíduos Sólidos (Lei no 12.305/10) com a redução da geração e fim do manejo inadequado de resíduos sólidos; e se existem legislações ou instrumentos de gestão ambiental, mesmo que na Lei Orgânica, Plano Diretor, Código Ambiental etc., relacionadas ao Saneamento Básico, Áreas ou Zonas de Proteção ou Controle Ambiental, Poluição do Ar e de Proteção da Biodiversidade.

Assim como na dimensão de agricultura sustentável, a dimensão de gestão ambiental apresenta um indicador que pode ser relacionado com a capacidade específica do município em se adaptar, o qual avalia a existência de Leis ou Instrumentos de gestão ambiental, mesmo que na Lei Orgânica, Plano Diretor, Código Ambiental etc., que trate de Adaptação e Mitigação de Mudança do Clima.

Por fim, na Dimensão de Resposta aos Impactos Climáticos, foram contemplados indicadores como a existência de Plano Municipal de Redução de Riscos, de Carta Geotécnica de Aptidão à Urbanização, de Coordenação Municipal de Defesa Civil (COMDECs), Lei de Uso e Ocupação do Solo que contemple a Prevenção de Enchentes e Inundações, e, Leis de Uso e Ocupação do Solo que contemplem a Prevenção de Escorregamentos ou Deslizamentos de Encostas. Cabe destacar que o Plano Municipal de Redução de Riscos (PMRR) é um importante instrumento para que os municípios conheçam os riscos a que estão submetidos, para a definição das intervenções e dos investimentos necessários e a definição de fontes de financiamento para realizá-los. Estes instrumentos passaram a ser elaborados no Estado de São Paulo a partir de 2004, seguindo os princípios, e através de financiamentos, do Ministério das Cidades(SÃO PAULO (ESTADO), 2017). Compõem a elaboração dos PMRR o treinamento de equipes para a elaboração de diagnósticos, mapeamento das áreas de risco do município, identificação de intervenções estruturais prioritárias para cada setor e definição dos investimentos necessários para a implantação das intervenções sugeridas (MIRANDOLA et al., 2015; SÃO PAULO (ESTADO), 2017)

Apesar das Cartas Geotécnicas de Aptidão à Urbanização só serem obrigatórias para "municípios incluídos no cadastro nacional de municípios com áreas suscetíveis à ocorrência de deslizamentos de grande impacto, inundações buscas ou processos geológicos ou hidrológicos"(BRASIL, 2012a), os demais municípios podem contar com esse instrumento para subsidiar o seu planejamento urbano uma vez que ele fornece orientações e diretrizes para o uso e ocupação do solo a partir da análise das características físicas do terreno, dos processos que geram situações de risco e das formas de ocupação do território (NOGUEIRA; CANIL, 2017). O mesmo vale para a existência ou não de leis de uso e ocupação do solo que contemplem a prevenção de enchentes ou de escorregamentos. Por mais que estes instrumentos não sejam obrigatórios para todos os municípios, a sua elaboração ajudará no planejamento da expansão urbana ou no 
remodelamento da ocupação do solo dos municípios para uma situação de menor vulnerabilidade.

Ainda que no Brasil existam diferentes estruturas de gestão de risco e resposta a desastres, o relatório do IBGE levantou a existência ou não das Unidades de Corpo de Bombeiros, Núcleos Comunitários de Defesa Civil (NUDECs) e Coordenação Municipal de Defesa Civil (COMDECs). O indicador que avalia a existência das COMDECs, também conhecidas como Defesa Civil Municipal, foi selecionado como um dos indicadores da dimensão de Resposta aos Impactos Climáticos por se tratar de uma inciativa do governo municipal para lidar com os riscos climáticos.

O conjunto de dimensões e indicadores do UAI foi avaliado a luz dos estudos analisados no Item 2.4 desta dissertação. Conforme explicado naquele item, foram verificadas medidas para a ampliação da capacidade adaptativa em âmbito local aplicadas por meio do planejamento urbano, instrumento de característica multisetorial e com o potencial de influência direta sobre outras políticas pública municipais. Ainda que se tenha dado especial atenção ao planejamento municipal durante a seleção de medidas de adaptação que poderiam ser implantadas, o planejamento urbano não compõe explicitamente as dimensões do UAI, entretanto, diversos indicadores poderão ser atendidos com um plano diretor que realmente insira a sustentabilidade ambiental em seu eixo de elaboração. Quanto às medidas apresentadas no Quadro 5, ressalta-se que mesmo o município recebendo a pontuação máxima do UAI não seria possível garantir a efetiva implantação dessas medidas, entretanto, todas elas poderiam ser implantadas ou incentivadas através dos instrumentos que compõem os 26 indicadores do UAI.

\subsection{Correlações com o PNA}

Com o intuito de validar os indicadores que compõem as dimensões do UAI, foram avaliadas as possíveis correlações com as diretrizes e ações apresentadas no Plano Nacional de Adaptação (PNA), aprovado no ano de 2016 (BRASIL - MMA, 2016a). O volume II do PNA, foi organizado em 11 (onze) estratégias setoriais e temáticas, contendo diretrizes e estratégias que devem ser adotadas para a promoção da capacidade de adaptação dos entes federativos e para a redução dos riscos relacionados às mudanças climáticas.

Os Quadros 6 a 10 apresentam as correlações identificadas entre os indicadores contemplados nas dimensões do UAI e o PNA. Os indicadores da Dimensão de Habitação foram relacionados com 04 (quatro) diretrizes da Estratégia de Cidades e os indicadores da Dimensão de Mobilidade Urbana apresentaram com 06 (seis) diretrizes da Estratégia Setorial de Infraestrutura do PNA. Os indicadores da Dimensão de Agricultura Sustentável apresentaram correlações com duas estratégias distintas do PNA, a de 
Agricultura, com 04(quatro) diretrizes, e Segurança Alimentar e Nutricional, com 02(duas) diretrizes. A dimensão de Gestão Ambiental também apresentou correlação com diversas Estratégias Setoriais e diretrizes do PNA, a saber, 04(quatro) diretrizes da Estratégia de Recursos Hídricos, 01 (uma) de Indústria e Mineração, 04(quatro) de Cidades, 02(duas) das Estratégias Setoriais de Biodiversidade e Ecossistemas, de Saúde e de Redução de Riscos. Por fim, os indicadores da Dimensão de Resposta aos Impactos Climáticos foram relacionados com uma diretriz das Estratégias de Biodiversidade e Ecossistemas, de Gestão de Risco de Desastres e de Infraestrutura e 04(quatro) diretrizes da Estratégia Setorial de Cidades.

Quadro 6 - Indicadores de Habitação frente às Diretrizes Setoriais do PNA

\begin{tabular}{|c|c|c|}
\hline \multicolumn{3}{|c|}{ HABITAÇÃO } \\
\hline Indicadores & Diretrizes Setorial - PNA & $\begin{array}{l}\text { Diretriz/Setor da } \\
\text { Estratégia }\end{array}$ \\
\hline $\begin{array}{c}\text { Plano Municipal } \\
\text { de Habitação - } \\
\text { existência }\end{array}$ & $\begin{array}{c}\text { Considerar a adaptação à mudança do clima na } \\
\text { promoção da reabilitação de áreas urbanas } \\
\text { consolidadas, degradadas e com infraestrutura } \\
\text { instalada, promovendo a diversidade urbana e } \\
\text { contribuindo para a redução da expansão urbana e da } \\
\text { exposição da população a riscos advindos da ocupação } \\
\text { de áreas suscetíveis; }\end{array}$ & $\begin{array}{c}\text { Diretriz } 2 \text { - Estratégias } \\
\text { de Cidades } \\
\text { (Pág. 78) }\end{array}$ \\
\hline \multirow[t]{2}{*}{$\begin{array}{c}\text { Conselho } \\
\text { Municipal de } \\
\text { Habitação - } \\
\text { existência }\end{array}$} & $\begin{array}{l}\text { Considerar a adaptação à mudança do clima na } \\
\text { promoção da urbanização de assentamentos precários, } \\
\text { visando a elevação da condição de habitabilidade } \\
\text { destes assentamentos e melhoria das condições de vida } \\
\text { da população, por meio de ações integradas de } \\
\text { infraestrutura urbana, produção e melhoria } \\
\text { habitacional, regularização fundiária, recuperação } \\
\text { ambiental e trabalho social; }\end{array}$ & $\begin{array}{c}\text { Diretriz } 3 \text { - Estratégias } \\
\text { de Cidades } \\
\text { (Pág. 78) }\end{array}$ \\
\hline & $\begin{array}{l}\text { Apoiar a coordenação de iniciativas para a revisão de } \\
\text { normas técnicas e regulamentação de parâmetros } \\
\text { edilícios e urbanísticos de forma que estes possam } \\
\text { fomentar soluções resilientes na construção de edifícios } \\
\text { e infraestrutura urbana. }\end{array}$ & $\begin{array}{c}\text { Diretriz } 15 \text { - } \\
\text { Estratégias de Cidades } \\
\text { (Pág. 79) }\end{array}$ \\
\hline $\begin{array}{c}\text { Fundo } \\
\text { Municipal de } \\
\text { Habitação - } \\
\text { existência }\end{array}$ & $\begin{array}{c}\text { Considerar a adaptação à mudança do clima na } \\
\text { produção de habitação social em escala, garantindo às } \\
\text { famílias de baixa renda e em situações de } \\
\text { vulnerabilidade o acesso à moradia bem localizada, } \\
\text { com infraestrutura de qualidade e resiliente, provida de } \\
\text { bens e serviços urbanos, sociais e culturais e } \\
\text { oportunidades de lazer; }\end{array}$ & $\begin{array}{c}\text { Diretriz } 4 \text { - Estratégias } \\
\text { de Cidades } \\
\text { (Pág. 78) }\end{array}$ \\
\hline
\end{tabular}

Fonte: Extraído do Plano Nacional de Adaptação (PNA) de 2016 (BRASIL - MMA, 2016a) 
Quadro 7 - Indicadores de Mobilidade Urbana frente às Diretrizes Setoriais do PNA MOBILIDADE URBANA

Indicadores

Plano
Municipal de
Transporte -
existência

Diretrizes Setorial - PNA

Diretriz/Setor da Estratégia

Considerar, no que couber, as questões de adaptação à mudança do clima em seus planos, programas e projetos

Transporte - Diretriz 2 -

Estratégias de institucionais.

Infraestrutura (Pág. 122)

Elaborar estudos e pesquisas sobre a relação da mudança do clima com a vulnerabilidade da infraestrutura de transportes, visando subsidiar as políticas públicas, o planejamento e a identificação de

Transporte - Diretriz 3 Estratégias de soluções para o setor, considerando a Adaptação

Infraestrutura (Pág. 122) baseada em Ecossistemas (AbE).

Aumentar a capacidade de resposta do setor de transportes frente aos eventos climáticos extremos por meio de planos, protocolos de ação e medidas preventivas.

Transporte - Diretriz 6 Estratégias de Infraestrutura (Pág. 122)

Incorporação do planejamento para adaptação e resiliência no âmbito dos planos de mobilidade urbana, de forma integrada com o planejamento de uso e ocupação do solo nas cidades, considerando princípios de Adaptação baseada em Ecossistemas (AbE);

Fortalecimento e qualificação da infraestrutura de Transporte transporte público coletivo e individual não motorizado, coletivo por provendo condições que estimulem a maior participação onibus destes modos na matriz de viagens urbanas, intramunicipal assegurando a integração intermodal e a flexibilidade

Mobilidade urbana Diretriz 3 - Estratégias de Infraestrutura (Pág. 130) do sistema;

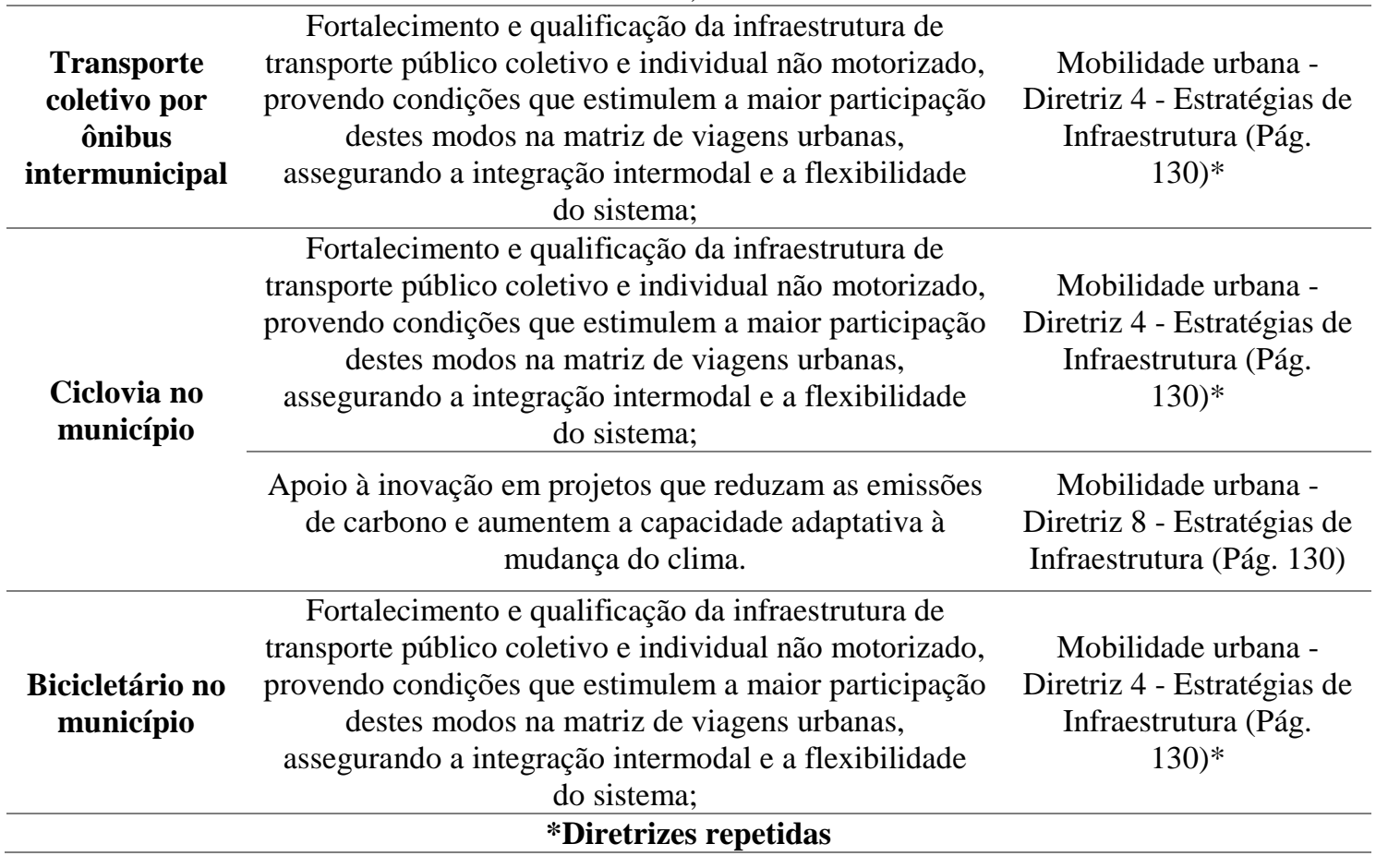
Fonte: Extraído do Plano Nacional de Adaptação (PNA) de 2016 (BRASIL - MMA, 2016a) 
Quadro 8 - Indicadores de Agricultura Sustentável frente às Diretrizes Setoriais do PNA AGRICULTURA SUSTENTÁVEL

\begin{tabular}{|c|c|c|}
\hline Indicadores & Diretrizes Setorial - PNA & Diretriz/Setor da Estratégia \\
\hline $\begin{array}{l}\text { Estímulo à } \\
\text { agricultura } \\
\text { orgânica }\end{array}$ & $\begin{array}{l}\text { Ampliar a inserção da agricultura familiar em } \\
\text { sistemas de produção de base agroecológica, } \\
\text { orgânica e da sociobiodiversidade por meio do } \\
\text { PLANAPO (Plano Nacional de Agroecologia e } \\
\text { Produção Orgânica) e PNBSB (Plano Nacional para } \\
\text { a Promoção dos Produtos da Sociobiodiversidade) }\end{array}$ & $\begin{array}{l}\text { Diretriz } 3 \text { - Estratégia de } \\
\text { Segurança Alimentar } \\
\text { e Nutricional (Pág. 232) }\end{array}$ \\
\hline \multirow[t]{3}{*}{$\begin{array}{l}\text { Estímulo à } \\
\text { agricultura } \\
\text { familiar }\end{array}$} & $\begin{array}{l}\text { Estratégia Regional: a especificação de metas } \\
\text { regionais das ações deverá ser feita com base no } \\
\text { mapeamento de vulnerabilidades, de oportunidades } \\
\text { e/ou investimentos e do perfil social das diferentes } \\
\text { regiões, reconhecendo prioridade de atuação no } \\
\text { segmento da agricultura familiar. A exemplo do } \\
\text { desenvolvimento do Plano ABC, especificidades } \\
\text { regionais e estaduais serão desenvolvidas com a } \\
\text { construção e eventual revisão do Plano ABC } \\
\text { Estadual, de responsabilidade dos Grupos Gestores } \\
\text { Estaduais, já implementados em todas as UFs, e } \\
\text { responsáveis pela implementação e gestão do Plano } \\
\text { ABC em cada UF }\end{array}$ & $\begin{array}{l}\text { Diretriz } 7 \text { - Estratégia de } \\
\text { Agricultura (Pág. 21) }\end{array}$ \\
\hline & $\begin{array}{l}\text { Reduzir a pobreza e a vulnerabilidade de grupos } \\
\text { sociais rurais, por meio do fortalecimento das } \\
\text { políticas de inclusão produtiva rural }\end{array}$ & $\begin{array}{l}\text { Diretriz } 2 \text { - Estratégia de } \\
\text { Segurança Alimentar } \\
\text { e Nutricional (Pág. 231) }\end{array}$ \\
\hline & $\begin{array}{l}\text { Ampliar a inserção da agricultura familiar em } \\
\text { sistemas de produção de base agroecológica, } \\
\text { orgânica e da sociobiodiversidade por meio do } \\
\text { PLANAPO (Plano Nacional de Agroecologia e } \\
\text { Produção Orgânica) e PNBSB (Plano Nacional para } \\
\text { a Promoção dos Produtos da Sociobiodiversidade) }\end{array}$ & $\begin{array}{c}\text { Diretriz } 3 \text { - Estratégia de } \\
\text { Segurança Alimentar } \\
\text { e Nutricional } \\
\text { (Pág. 232) }{ }^{*}\end{array}$ \\
\hline $\begin{array}{c}\text { Estímulo à } \\
\text { produção de } \\
\text { hortas } \\
\text { comunitárias }\end{array}$ & $\begin{array}{l}\text { Reduzir a pobreza e a vulnerabilidade de grupos } \\
\text { sociais rurais, por meio do fortalecimento das } \\
\text { políticas de inclusão produtiva rural }\end{array}$ & $\begin{array}{l}\text { Diretriz } 2 \text { - Estratégia de } \\
\text { Segurança Alimentar } \\
\text { e Nutricional (Pág. 231) * }\end{array}$ \\
\hline $\begin{array}{c}\text { A prefeitura } \\
\text { desenvolve } \\
\text { programa ou } \\
\text { ação de } \\
\text { prevenção } \\
\text { contra } \\
\text { problemas } \\
\text { climáticos } \\
\text { para o setor } \\
\text { agropecuário }\end{array}$ & $\begin{array}{l}\text { As medidas de adaptação devem suprir as } \\
\text { necessidades das culturas frente às várias possíveis } \\
\text { alterações da estrutura climática, incluindo } \\
\text { elevação de temperatura e gradiente térmico, } \\
\text { intensidade e distribuição hídrica, entre outras. A } \\
\text { primeira premissa a considerar é que a } \\
\text { sustentabilidade dos sistemas agrícolas (no sentido } \\
\text { amplo do termo agricultura que envolve os cultivos } \\
\text { agrícolas propriamente ditos, os pecuários e os } \\
\text { florestais, bem como as diversas formas de sistemas } \\
\text { integrados) deve ser alcançada e garantida pelo uso } \\
\text { intensivo de conhecimento para a melhoria de seus } \\
\text { processos. }\end{array}$ & $\begin{array}{l}\text { Diretriz } 3 \text { - Estratégia de } \\
\text { Agricultura (Pág. 20) }\end{array}$ \\
\hline
\end{tabular}




\begin{tabular}{|c|c|c|}
\hline Indicadores & $\begin{array}{l}\text { AGRICULTURA SUSTENTÁ VEL } \\
\text { Diretrizes Setorial - PNA }\end{array}$ & Diretriz/Setor da Estratégia \\
\hline \multirow[t]{2}{*}{$\begin{array}{l}\text { A prefeitura } \\
\text { desenvolve } \\
\text { programa ou } \\
\text { ação de } \\
\text { prevenção } \\
\text { contra } \\
\text { problemas } \\
\text { climáticos } \\
\text { para o setor } \\
\text { agropecuário } \\
\text { (cont.) }\end{array}$} & $\begin{array}{l}\text { O foco das ações para agricultura são iniciativas e } \\
\text { instrumentos que permitirão motivar e criar } \\
\text { condições para que o produtor rural possa estruturar } \\
\text { e manter sistemas de produção sustentáveis, em sua } \\
\text { diversidade de escala, tecnologia, natureza de mão } \\
\text { de obra e direcionamento de mercado. Duas ações } \\
\text { principais deverão ser consideradas nesse sentido, } \\
\text { além do desenvolvimento de tecnologias adequadas } \\
\text { para cada realidade: o estabelecimento do Centro } \\
\text { de Inteligência Climática da Agricultura e o } \\
\text { desenvolvimento do Sistema de Monitoramento e } \\
\text { Simulação de Risco e Vulnerabilidade Agrícola, a } \\
\text { partir de alguns dos instrumentos já existentes e } \\
\text { atuantes. }\end{array}$ & $\begin{array}{l}\text { Diretriz } 5 \text { - Estratégia de } \\
\text { Agricultura } \\
\text { (Pág. 20) }\end{array}$ \\
\hline & $\begin{array}{l}\text { Contágio da gestão do risco nas políticas setoriais: } \\
\text { as políticas setoriais já incluem a preocupação com } \\
\text { risco climático, que é intrínseca do setor } \\
\text { agropecuário. A avaliação dessas políticas, em um } \\
\text { contexto de mudança do clima, deverá acontecer } \\
\text { durante a discussão mais detalhada do Programa de } \\
\text { Adaptação para Agricultura, buscando avaliar sua } \\
\text { pertinência, suas eventuais lacunas e antagonismos, } \\
\text { e estratégias para seu fortalecimento. }\end{array}$ & $\begin{array}{c}\text { Diretriz } 8 \text { - Estratégia de } \\
\text { Agricultura } \\
\text { (Pág. 21) }\end{array}$ \\
\hline $\begin{array}{l}\text { A prefeitura } \\
\text { desenvolve } \\
\text { programa ou } \\
\text { ação para } \\
\text { estímulo ao } \\
\text { associativismo } \\
\text { (associação de } \\
\text { produtores, } \\
\text { cooperativas } \\
\text { etc.) }\end{array}$ & $\begin{array}{l}\text { Reduzir a pobreza e a vulnerabilidade de grupos } \\
\text { sociais rurais, por meio do fortalecimento das } \\
\text { políticas de inclusão produtiva rural }\end{array}$ & $\begin{array}{c}\text { Diretriz } 2 \text { - Estratégia de } \\
\text { Segurança Alimentar } \\
\text { e Nutricional } \\
\text { (Pág. 231)* }\end{array}$ \\
\hline & *Dir & \\
\hline
\end{tabular}

Fonte: Extraído do Plano Nacional de Adaptação (PNA) de 2016 (BRASIL - MMA, 2016a) 
Quadro 9 - Indicadores de Gestão Ambiental frente às Diretrizes Setoriais do PNA GESTÃO AMBIENTAL

\begin{tabular}{|c|c|}
\hline Indicadores & Diretrizes Setorial - PNA \\
\hline & $\begin{array}{l}\text { Incrementar os investimentos em coleta e tratamento de } \\
\text { esgoto, especialmente em bacias sujeitas à escassez de } \\
\text { água, para que a perda de qualidade não configure } \\
\text { obstáculo adicional ao uso dos recursos hídricos. }\end{array}$ \\
\hline & $\begin{array}{l}\text { Aumento de investimentos em medidas de conservação } \\
\text { e recuperação de APP com intuito de reduzir o } \\
\text { assoreamento dos reservatórios e aumentar sua vida útil. }\end{array}$ \\
\hline $\begin{array}{c}\text { O município } \\
\text { possui Fundo } \\
\text { Municipal de } \\
\text { Meio } \\
\text { Ambiente ou } \\
\text { similar }\end{array}$ & $\begin{array}{l}\text { Fomentar práticas de Adaptação baseada em } \\
\text { Ecossistemas (AbE), como ferramenta para incremento } \\
\text { da resiliência territorial e industrial: As medidas } \\
\text { adaptativas voltadas para diminuição da vulnerabilidade } \\
\text { dos territórios aos impactos potenciais da mudança do } \\
\text { clima reduzem de forma sinérgica a vulnerabilidade do } \\
\text { setor industrial. Nesse contexto, o uso da biodiversidade } \\
\text { e dos serviços ambientais, como parte de uma estratégia } \\
\text { de adaptação aos efeitos adversos da mudança do clima, } \\
\text { pode ser uma alternativa para o incremento da resiliência } \\
\text { climática do setor industrial. Por exemplo, iniciativas } \\
\text { regionais de investimento em programas de manejo e } \\
\text { recuperação de bacias hidrográficas poderiam } \\
\text { contribuir para preservação dos mananciais e garantir a } \\
\text { sustentabilidade do fornecimento de água. }\end{array}$ \\
\hline
\end{tabular}

Diretriz/Setor da

Abastecimento urbano -

Diretriz 4 - Estratégia de

Recursos Hídricos

(Pág. 170)

Setor de Energia -

Diretriz 4 - Estratégia de

Recursos Hídricos (Pág.

172)

Diretriz 8 - Estratégia de

Indústria e Mineração

(Pág. 122)

Investir na recuperação de APP.

Qualidade de Água e

Meio Ambiente -

Diretriz 6 - Estratégia de

Recursos Hídricos (Pág. 174)

Considerar a adaptação à mudança do clima na implementação do Plano Nacional de Saneamento Básico (Plansab);

Diretriz 7 - Estratégia de Cidades

(Pág. 79)

Legislação ou
instrumento
sobre
saneamento
básico

Apoiar a implementação e melhorias dos sistemas de abastecimento de água e de esgotamento sanitário que considerem os efeitos econômico-sociais, de saúde pública, ecológicos e infraestruturais das medidas adotadas, de forma a potencializar os efeitos benéficos à saúde e ao meio ambiente diretamente associados a estes sistemas, buscando, em especial, a descontaminação de corpos hídricos, para facilitar os múltiplos usos da água,

Diretriz 9 - Estratégia de Cidades

(Pág. 79) estimulando a eficiência no uso de energia, com a utilização do biogás resultante do tratamento dos esgotos e dos resíduos sólidos urbanos, e de outras energias renováveis;

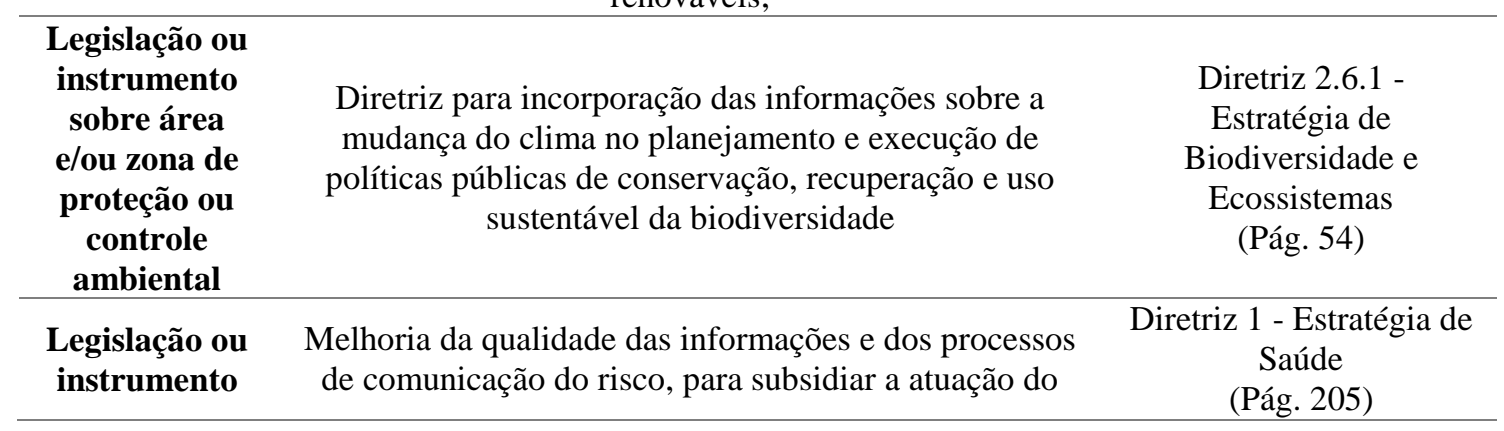




\begin{tabular}{|c|c|c|}
\hline Indicadores & $\begin{array}{l}\text { GESTÃO AMBIENTAL } \\
\text { Diretrizes Setorial - PNA }\end{array}$ & $\begin{array}{l}\text { Diretriz/Setor da } \\
\text { Estratégia }\end{array}$ \\
\hline $\begin{array}{l}\text { sobre poluição } \\
\text { do ar }\end{array}$ & $\begin{array}{l}\text { SUS nas emergências em saúde pública associadas à } \\
\text { mudança do clima. }\end{array}$ & \\
\hline \multirow{2}{*}{$\begin{array}{l}\text { Legislação ou } \\
\text { instrumento } \\
\text { sobre } \\
\text { proteção à } \\
\text { biodiversidade }\end{array}$} & $\begin{array}{c}\text { Diretriz para incorporação das informações sobre a } \\
\text { mudança do clima no planejamento e execução de } \\
\text { políticas públicas de conservação, recuperação e uso } \\
\text { sustentável da biodiversidade }\end{array}$ & $\begin{array}{l}\text { Diretriz 2.6.1 - } \\
\text { Estratégia de } \\
\text { Biodiversidade e } \\
\text { Ecossistemas } \\
\text { (Pág. 54)* }\end{array}$ \\
\hline & $\begin{array}{l}\text { Ação 1. Fortalecer as medidas de conservação, } \\
\text { recuperação e uso sustentável da biodiversidade visando } \\
\text { o aumento da conectividade entre remanescentes dos } \\
\text { ecossistemas e a consolidação de Unidades de } \\
\text { Conservação, refletindo a gestão florestal integrada da } \\
\text { paisagem e propiciando a redução da vulnerabilidade da } \\
\text { biodiversidade; }\end{array}$ & $\begin{array}{l}\text { Ação } 1 \text { - Diretriz } 2.6 .2 \\
\text { (Medidas de Não } \\
\text { Arrependimento) - } \\
\text { Estratégia de } \\
\text { Biodiversidade e } \\
\text { Ecossistemas } \\
\text { (Pág. 56) }\end{array}$ \\
\hline \multirow{2}{*}{$\begin{array}{l}\text { Legislação ou } \\
\text { instrumento } \\
\text { sobre } \\
\text { adaptação e } \\
\text { mitigação de } \\
\text { mudança do } \\
\text { clima }\end{array}$} & $\begin{array}{l}\text { Apoiar a gestão e disseminação de informações } \\
\text { relacionadas às mudanças climáticas, que possam } \\
\text { subsidiar a elaboração de diagnóstico e o } \\
\text { desenvolvimento de estratégias de adaptação em sinergia } \\
\text { com o planejamento urbano; }\end{array}$ & $\begin{array}{l}\text { Diretriz } 11 \text { - Estratégia } \\
\text { de Cidades } \\
\text { (Pág. 79) }\end{array}$ \\
\hline & $\begin{array}{l}\text { Formulação de políticas específicas que aumentem a } \\
\text { resiliência dos grupos sociais de maior vulnerabilidade à } \\
\text { mudança do clima junto às populações do campo, das } \\
\text { águas, da floresta, aos indígenas e às populações de rua. }\end{array}$ & $\begin{array}{l}\text { Diretriz } 06 \text { - Estratégia } \\
\text { de Saúde } \\
\text { (Pág. 208) }\end{array}$ \\
\hline $\begin{array}{l}\text { O município } \\
\text { possui Plano } \\
\text { de Gestão } \\
\text { Integrada de } \\
\text { Resíduos } \\
\text { Sólidos, nos } \\
\text { termos da } \\
\text { Política } \\
\text { Nacional de } \\
\text { Resíduos } \\
\text { Sólidos }\end{array}$ & $\begin{array}{l}\text { Apoiar as ações de melhoria dos sistemas de limpeza } \\
\text { urbana e manejo de resíduos sólidos, visando à } \\
\text { ampliação da coleta seletiva nos municípios, à } \\
\text { disposição adequada dos rejeitos e à erradicação dos } \\
\text { lixões, visto que o aumento de precipitações pluviais } \\
\text { intensas decorrentes de mudança do clima ocasiona } \\
\text { maior carreamento de chorume dos lixões para os corpos } \\
\text { hídricos e potencializa os efeitos de descartes } \\
\text { inadequados de resíduos urbanos, feitos de maneira } \\
\text { desordenada, junto a cursos d'água, tanto em lixões, } \\
\text { quanto em áreas urbanas adensadas, agravando o } \\
\text { problema das enchentes; }\end{array}$ & $\begin{array}{l}\text { Diretriz } 10 \text { - Estratégia } \\
\text { de Cidades } \\
\text { (Pág. 79) }\end{array}$ \\
\hline \multirow{3}{*}{$\begin{array}{l}\text { O município } \\
\text { paga } \\
\text { diretamente } \\
\text { por serviços } \\
\text { ambientais - } \\
\text { PSA }\end{array}$} & Medidas de Adaptação baseadas em Ecossistemas (EbA) & $\begin{array}{c}\text { Diretriz } 2 \text { - Estratégia de } \\
\text { Risco de Desastres } \\
\text { (Pág. 100) }\end{array}$ \\
\hline & $\begin{array}{c}\text { Considerar o instrumento de Pagamento por Serviços } \\
\text { Ambientais (PSA) para recuperação e conservação das } \\
\text { bacias hidrográficas }\end{array}$ & $\begin{array}{l}\text { Instrumento } \\
\text { complementar de } \\
\text { recursos hídricos } 7 \text { - } \\
\text { Estratégia de Recursos } \\
\text { Hídricos (Pág. 184) }\end{array}$ \\
\hline & Izes repetidas & \\
\hline
\end{tabular}

Fonte: Extraído do Plano Nacional de Adaptação (PNA) de 2016 (BRASIL - MMA, 2016a) 


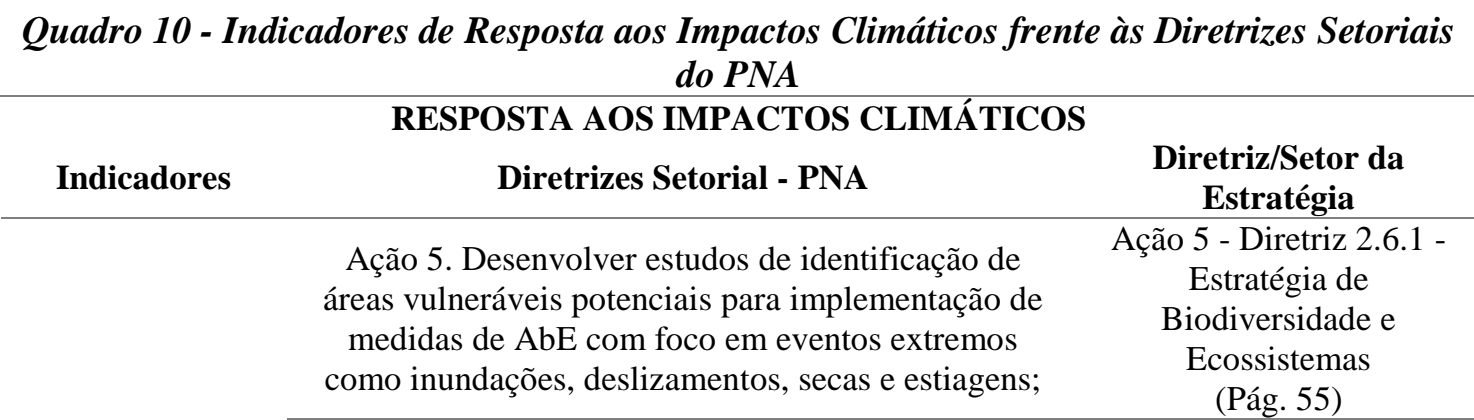

Fortalecer os processos de planejamento da expansão urbana com a perspectiva de prevenção à ocorrência de desastres naturais e o surgimento

Lei de Uso e

Ocupação do Solo que contemple a prevenção de enchentes ou inundações graduais, ou enxurradas ou inundações bruscas de riscos, por meio de projetos específicos de expansão urbana, orientando processos de

parcelamento, uso e ocupação do solo urbano dentro de padrões adequados e adaptados aos riscos relacionados à mudança do clima;

Fortalecer as ações de Drenagem Urbana Sustentável voltadas à redução das enchentes e inundações, considerando obras e serviços que visem à implementação de reservatórios de amortecimento de cheias, adequação de canais para a redução da velocidade de escoamento, sistemas de drenagem por infiltração, implantação de parques fluviais, recuperação de várzeas e renaturalização de fundos de

Diretriz 5 - Estratégia de Cidades (Pág. 78)
Diretriz 8 - Estratégia de Cidades

(Pág. 79) vale, além de ações de caráter complementar. Tais ações de drenagem sustentável devem observar, sempre que possível, princípios de adaptação baseada em ecossistemas (AbE);

Considerar a adaptação à mudança do clima no aperfeiçoamento de modelos de planejamento urbano, buscando melhorar a gestão do uso e ocupação do solo correlacionada à preservação ambiental associada, em especial, à prevenção de

Diretriz 14 - Estratégia de Cidades (Pág. 79) risco em desastres naturais;

Ação 5. Desenvolver estudos de identificação de áreas vulneráveis potenciais para implementação de medidas de $\mathrm{AbE}$ com foco em eventos extremos como inundações, deslizamentos, secas e estiagens;
Ação 5 - Diretriz 2.6.1 Estratégia de

Biodiversidade e Ecossistemas (Pág. 55) *
Lei de Uso e Ocupação do Solo que contemple a prevenção de escorregamentos ou deslizamentos de encostas
Fortalecer os processos de planejamento da expansão urbana com a perspectiva de prevenção à ocorrência de desastres naturais e o surgimento de riscos, por meio de projetos específicos de expansão urbana, orientando processos de parcelamento, uso e ocupação do solo urbano dentro de padrões adequados e adaptados aos riscos relacionados à mudança do clima;

Fortalecer as ações relacionadas a obras de contenção de encostas e elaboração de Plano Municipal de Redução de Riscos (PMRR), ampliando o número de municípios beneficiados, principalmente entre aqueles inseridos no Cadastro Nacional de Municípios com Áreas Suscetíveis à Ocorrência de Deslizamentos, Inundações ou
Diretriz 5 - Estratégia de Cidades

(Pág. 78) *
Diretriz 6 - Estratégia de Cidades

(Pág. 78) 


\begin{tabular}{|c|c|c|}
\hline \multicolumn{3}{|c|}{ RESPOSTA AOS IMPACTOS CLIMÁTICOS } \\
\hline Indicadores & Diretrizes Setorial - PNA & $\begin{array}{l}\text { Diretriz/Setor da } \\
\text { Estratégia }\end{array}$ \\
\hline \multirow[b]{2}{*}{$\begin{array}{c}\text { Lei de Uso e } \\
\text { Ocupação do } \\
\text { Solo que } \\
\text { contemple a } \\
\text { prevenção de } \\
\text { escorregamentos } \\
\text { ou } \\
\text { deslizamentos } \\
\text { de encostas } \\
\text { (cont.) }\end{array}$} & $\begin{array}{l}\text { Processos Geológicos ou Hidrológicos Correlatos } \\
\text { (CadRisco), previsto na Lei } \mathrm{n}^{\circ} 12.608 \text {, de } 10 \text { de abril } \\
\text { de } 2012\end{array}$ & \\
\hline & $\begin{array}{l}\text { Considerar a adaptação à mudança do clima no } \\
\text { aperfeiçoamento de modelos de planejamento urbano, } \\
\text { buscando melhorar a gestão do uso e ocupação do } \\
\text { solo correlacionada à preservação ambiental } \\
\text { associada, em especial, à prevenção de risco em } \\
\text { desastres naturais; }\end{array}$ & $\begin{array}{l}\text { Diretriz } 14 \text { - Estratégia } \\
\text { de Cidades } \\
\text { (Pág. 79)* }\end{array}$ \\
\hline \multirow[b]{2}{*}{$\begin{array}{l}\text { Plano Municipal } \\
\text { de Redução de } \\
\text { Riscos }\end{array}$} & $\begin{array}{l}\text { Fortalecer os processos de planejamento da } \\
\text { expansão urbana com a perspectiva de prevenção } \\
\text { à ocorrência de desastres naturais e o surgimento } \\
\text { de riscos, por meio de projetos específicos de } \\
\text { expansão urbana, orientando processos de } \\
\text { parcelamento, uso e ocupação do solo urbano dentro } \\
\text { de padrões adequados e adaptados aos riscos } \\
\text { relacionados à mudança do clima; }\end{array}$ & $\begin{array}{c}\text { Diretriz } 5 \text { - Estratégia de } \\
\text { Cidades } \\
\text { (Pág. 78) } *\end{array}$ \\
\hline & $\begin{array}{c}\text { Fortalecer as ações relacionadas a obras de } \\
\text { contenção de encostas e elaboração de Plano } \\
\text { Municipal de Redução de Riscos (PMRR), } \\
\text { ampliando o número de municípios beneficiados, } \\
\text { principalmente entre aqueles inseridos no Cadastro } \\
\text { Nacional de Municípios com Áreas Suscetíveis à } \\
\text { Ocorrência de Deslizamentos, Inundações ou } \\
\text { Processos Geológicos ou Hidrológicos Correlatos } \\
\text { (CadRisco), previsto na Lei no } 12.608 \text {, de } 10 \text { de abril } \\
\text { de } 2012 ;\end{array}$ & $\begin{array}{c}\text { Diretriz } 6 \text { - Estratégia de } \\
\text { Cidades } \\
\text { (Pág. 78)* }\end{array}$ \\
\hline $\begin{array}{l}\text { Carta } \\
\text { geotécnica de } \\
\text { aptidão à } \\
\text { urbanização }\end{array}$ & $\begin{array}{l}\text { Fortalecer os processos de planejamento da } \\
\text { expansão urbana com a perspectiva de prevenção } \\
\text { à ocorrência de desastres naturais e o surgimento } \\
\text { de riscos, por meio de projetos específicos de } \\
\text { expansão urbana, orientando processos de } \\
\text { parcelamento, uso e ocupação do solo urbano dentro } \\
\text { de padrões adequados e adaptados aos riscos } \\
\text { relacionados à mudança do clima; }\end{array}$ & $\begin{array}{c}\text { Diretriz } 5 \text { - Estratégia de } \\
\text { Cidades } \\
\text { (Pág. 78)* }\end{array}$ \\
\hline \multirow{3}{*}{$\begin{array}{l}\text { Coordenação } \\
\text { Municipal de } \\
\text { Defesa Civil } \\
\text { (COMDECs) }\end{array}$} & $\begin{array}{l}\text { Consolidação de um Sistema de Alertas Precoces } \\
\text { (Early Warning System) }\end{array}$ & $\begin{array}{c}\text { Diretriz } 3 \text { - Estratégia de } \\
\text { Gestão de Risco de } \\
\text { Desastres (Pág. 100) }\end{array}$ \\
\hline & $\begin{array}{l}\text { Aprimorar a produção e disponibilização de } \\
\text { informações sobre eventos extremos relacionados ao } \\
\text { sistema de transporte. }\end{array}$ & $\begin{array}{l}\text { Transporte - Diretriz } 5 \text { - } \\
\text { Estratégias de } \\
\text { Infraestrutura (Pág. 122) }\end{array}$ \\
\hline & *Diretrizes repetidas & \\
\hline
\end{tabular}

Fonte: Extraído do Plano Nacional de Adaptação (PNA) de 2016 (BRASIL - MMA, 2016a) 


\section{APLIAÇÃO DO UAI NOS MUNICÍPIOS PAULISTAS PARA O ANO DE 2017}

Para a aplicação do Índice de Adaptação Urbana (UAI) aos municípios do Estado de São Paulo, assim como na proposta originalmente desenvolvida no âmbito do Projeto CiAdapta, foram substituídas por " 1 ” (um) todas as repostas afirmativas dos indicadores selecionados. Já para os casos nos quais a resposta foi uma negativa ou quando os municípios não forneceram as informações solicitadas, foi atribuído o valor “0” (zero) ao indicador. Os resultados de cada dimensão foram obtidos pela média aritmética simples dos seus indicadores, variando de "0" (zero) para situações menos desejadas, quando os municípios não dispunham de nenhum dos instrumentos consultados, até "1" (um) para situações consideradas como ideais. Dessa forma, quanto mais instrumentos os municípios possuírem, maior o seu potencial em lidar com os efeitos climáticos adversos dentro daquela dimensão. Ao considerar a ausência das informações e dos instrumentos com a mesma pontuação, além de sistematizar as intervenções municipais que podem ser aplicadas para a ampliação do potencial adaptativo municipal, espera-se que o UAI incentive uma melhor organização dos dados municipais e uma maior capacitação dos gestores públicos, possibilitando a ampliação do conhecimento de suas fragilidades e potencialidades.

Cabe destacar que a elaboração do UAI considera cada dimensão com a mesma importância e, portanto, com mesmo peso. Assim, o UAI é formado pela média aritmética simples dos resultados obtidos nas dimensões de Habitação, Mobilidade Urbana, Agricultura Sustentável, Gestão Ambiental e Resposta aos Impactos Climáticos.

Os resultados da aplicação do UAI aos municípios paulistas são apresentados no Anexo 8.1, inclusive com a apresentação dos resultados parciais por dimensões. Além disso, foram elaborados mapas para apresentar como os resultados do UAI e das dimensões avaliadas estão distribuídos no território paulista. Para facilitar a visualização gráfica destes resultados, foram criadas cinco (05) faixas iguais de valores apresentadas de maneira semafórica, variando entre a pior situação em vermelho escuro até a melhor situação em verde escuro, conforme apresentado na Tabela 3.

Tabela 3 - Faixas de pontuações do UAI

\begin{tabular}{|c|}
\hline Faixas UAI \\
\hline $0-0,2000$ \\
\hline $0,2001-0,4000$ \\
\hline $0,4001-0,6000$ \\
\hline $0,6001-0,8000$ \\
\hline $0,8001-1$ \\
\hline
\end{tabular}

Fonte: Elaborado pelo autor 
De modo a auxiliar a utilização deste índice por governos locais e regionais, as informações de cada dimensão foram apresentadas individualmente em mapas específicos e utilizando a mesma distribuição da pontuação do UAI.

A maneira que o UAI foi construído permite diferentes dimensões de análises aos gestores públicos. A primeira delas é a avaliação dos resultados individuais de cada indicador, partindo de um filtro de quais indicadores poderiam ser priorizados para a ampliação de seu potencial adaptativo. A segunda opção de análise abrange os resultados de cada dimensão, onde os municípios poderão verificar como eles se encontram frente a cada uma das 05 (cinco) dimensões e criar estratégias setoriais de atuação para ampliar o seu potencial adaptativo priorizando as temáticas que considerem mais importantes. Por fim, a análise dos resultados do UAI permitirá a compreensão da situação de cada município ou região quanto ao potencial desses locais e, se adaptar aos efeitos das mudanças climáticas. Com estas características, pretende-se minimizar as deficiências do uso de indicadores sintéticos apontadas pela literatura analisada (SAISANA; TARANTOLA, 2002; SEPE; GOMES, 2008; NETO et al., 2008).

Os mapas elaborados serão apresentados adiante, de acordo com as discussões realizadas.

\subsection{Dimensão de Habitação}

A Dimensão Habitação possui três indicadores, possibilitando o enquadramento dos municípios em somente quatro faixas distintas, sendo a mais baixa para os municípios que não contam com nenhum dos instrumentos consultados e a mais alta para aqueles que possuem todos. Quase metade dos 645 municípios paulistas $(48,52 \%)$ não contam com Planos, Conselhos ou Fundos Municipais de Habitação, enquanto somente 19,7\% possuem todos os instrumentos.

Observa-se uma maior concentração de municípios que não contam com nenhum dos instrumentos consultados na parcela oeste do estado, inclusive com concentrações regionais, formando grandes manchas vermelhas no território. Já os melhores resultados estão concentrados nas Regiões Metropolitanas de São Paulo, Campinas e Baixada Santista e na Aglomeração Urbana de Jundiaí. A maior disparidade em regiões metropolitanas foi observada na Região Metropolitana de Sorocaba onde 10 (dez) municípios contam com todos os instrumentos e 9 (nove) não possuem nenhum dos instrumentos consultados. Esta distribuição espacial dos resultados pode ser observada na Figura 14 a seguir. 
Figura 14 - Dimensão Habitação do UAI Municípios Paulistas

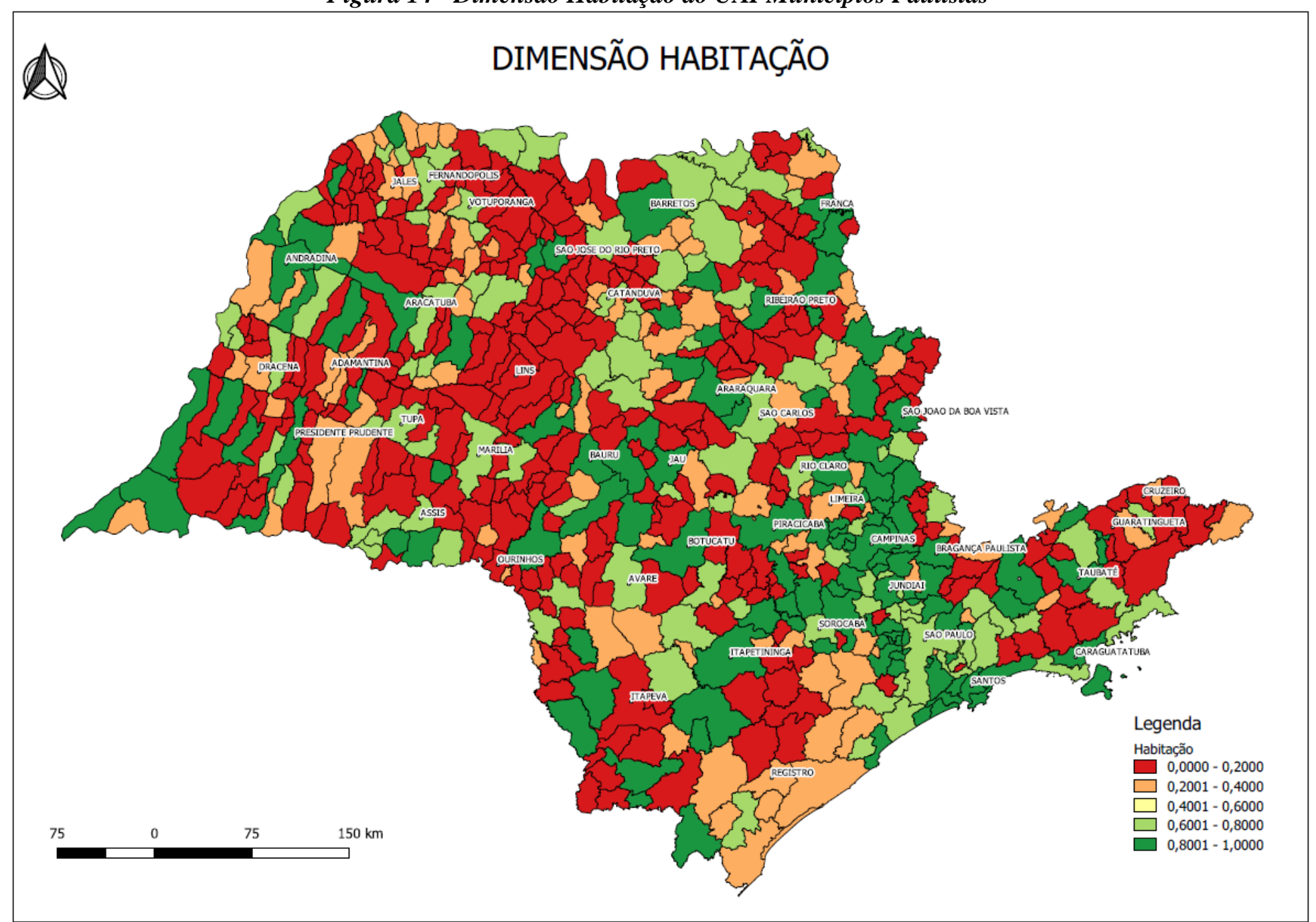

Fonte: Elaborado pelo autor 
De modo geral, os municípios com as melhores pontuações na Dimensão de Habitação coincidem com as maiores densidades demográficas municipais (hab/ $\mathrm{km}^{2}$ ), conforme apresentado na Figura 15 com dados da Fundação SEADE de 2017. Isso é mais facilmente observado nas regiões metropolitanas e aglomerações urbanas citadas anteriormente, entretanto, também pode-se observar que alguns municípios como Ribeirão Preto e São José do Rio Preto, com densidade demográfica maior do que 1.000 habitantes por $\mathrm{km}^{2}$, possuíam todos os instrumentos consultados.

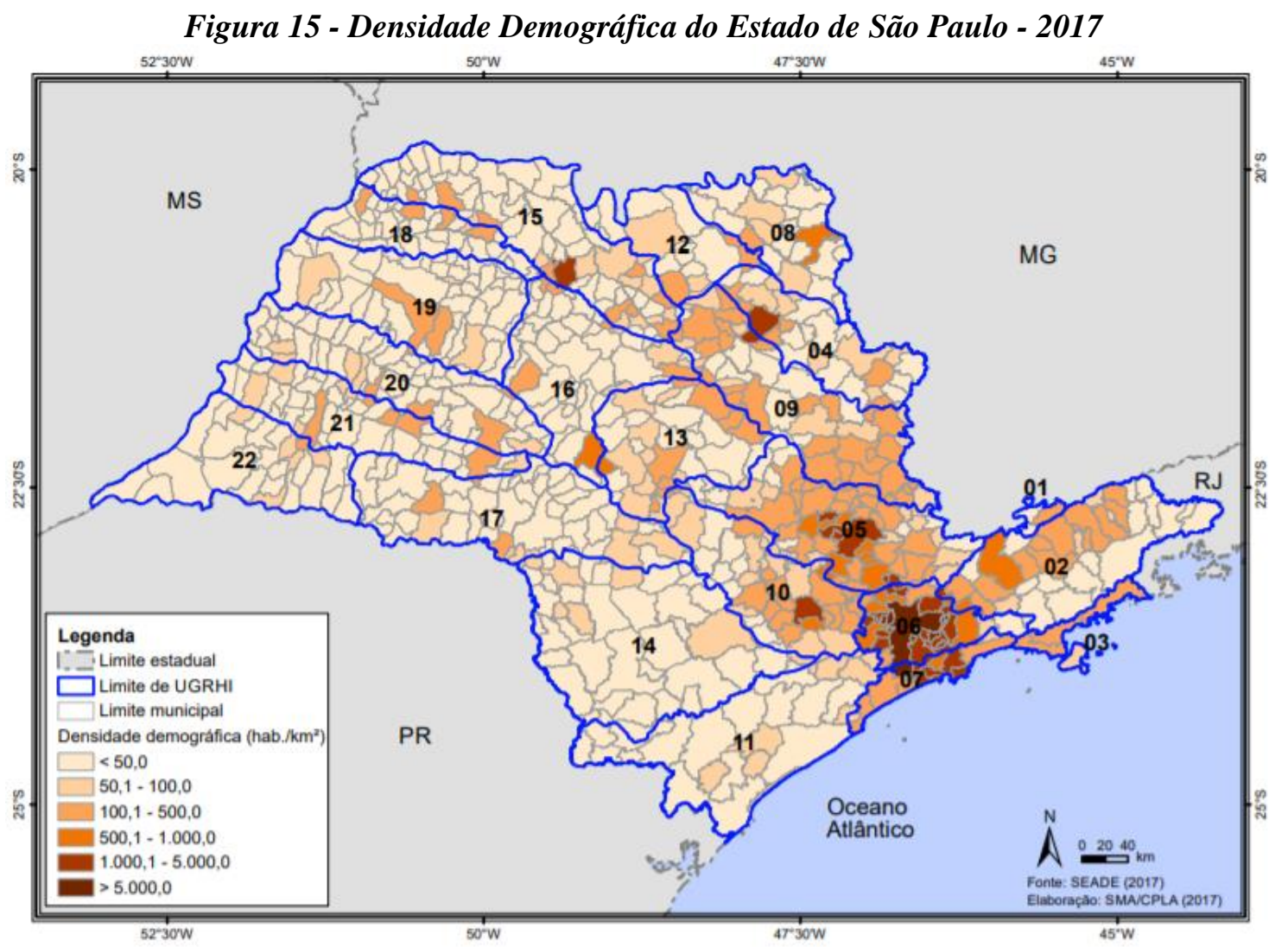

Fonte: Fundação SEADE 2017 - Apud (SÃO PAULO (ESTADO), 2017)

Esta correlação demonstra que municípios com elevadas densidades demográficas estão aplicando mais instrumentos de gerenciamento da questão habitacional municipal, seja por vontade política ou por obrigação legal. A análise conjunta destes indicadores pode auxiliar municípios com maiores densidades demográficas a priorizarem a atuação nos indicadores de habitação que ainda não possuem, ampliando assim o seu Índice de Adaptação Urbana, ao mesmo tempo que se estrutura para uma demanda municipal crescente.

Por outro lado, as regiões com menores déficits habitacionais podem estar desconsiderando a aplicação de tais instrumentos, recebendo uma menor pontuação na dimensão. Conforme explicitado anteriormente, a priorização para a atuação dos governos locais deve ser precedida de uma análise de suas condições e demandas, de modo que a ampliação do UAI signifique realmente uma ampliação do potencial de 
adaptação daquele município. Ainda assim, entende-se que mesmo não sendo uma questão urgente para o município, a aplicação dos instrumentos que compõe a dimensão de habitação resultaria em um melhor planejamento da cidade e na ampliação da qualidade de vida de sua população.

O Gráfico 1 demonstra o número de municípios que possuem os indicadores da dimensão habitação. Observa-se que os três indicadores apresentaram resultados semelhantes, sendo que o Conselho Municipal de Habitação foi observado em um número maior de municípios (39,5\%), seguido por municípios com Fundo Municipal de Habitação (34,3\%) e então pela existência de Planos Municipais de Habitação em 32,4\% dos municípios. O baixo número de municípios com estes instrumentos preocupa, uma vez que eles são condições para que os municípios possam receber os recursos provenientes do Fundo Nacional de Habitação de Interesse Social - FNHIS, conforme o disposto no art. 12 da lei $\mathrm{n}^{\mathrm{o}}$ 11.124, de 16 de junho de 2005 (BRASIL, 2005). Dessa forma, municípios que possuam somente um ou dois dos instrumentos selecionados, e que tenham interesse em acessar os recursos deste fundo para a produção e melhoria de habitações de interesse social ou implantação de saneamento básico, infraestrutura e equipamentos urbanos, deverão priorizar a instituição dos demais instrumentos da dimensão.

Gráfico 1 - Número de municípios com instrumentos da Dimensão de Habitação
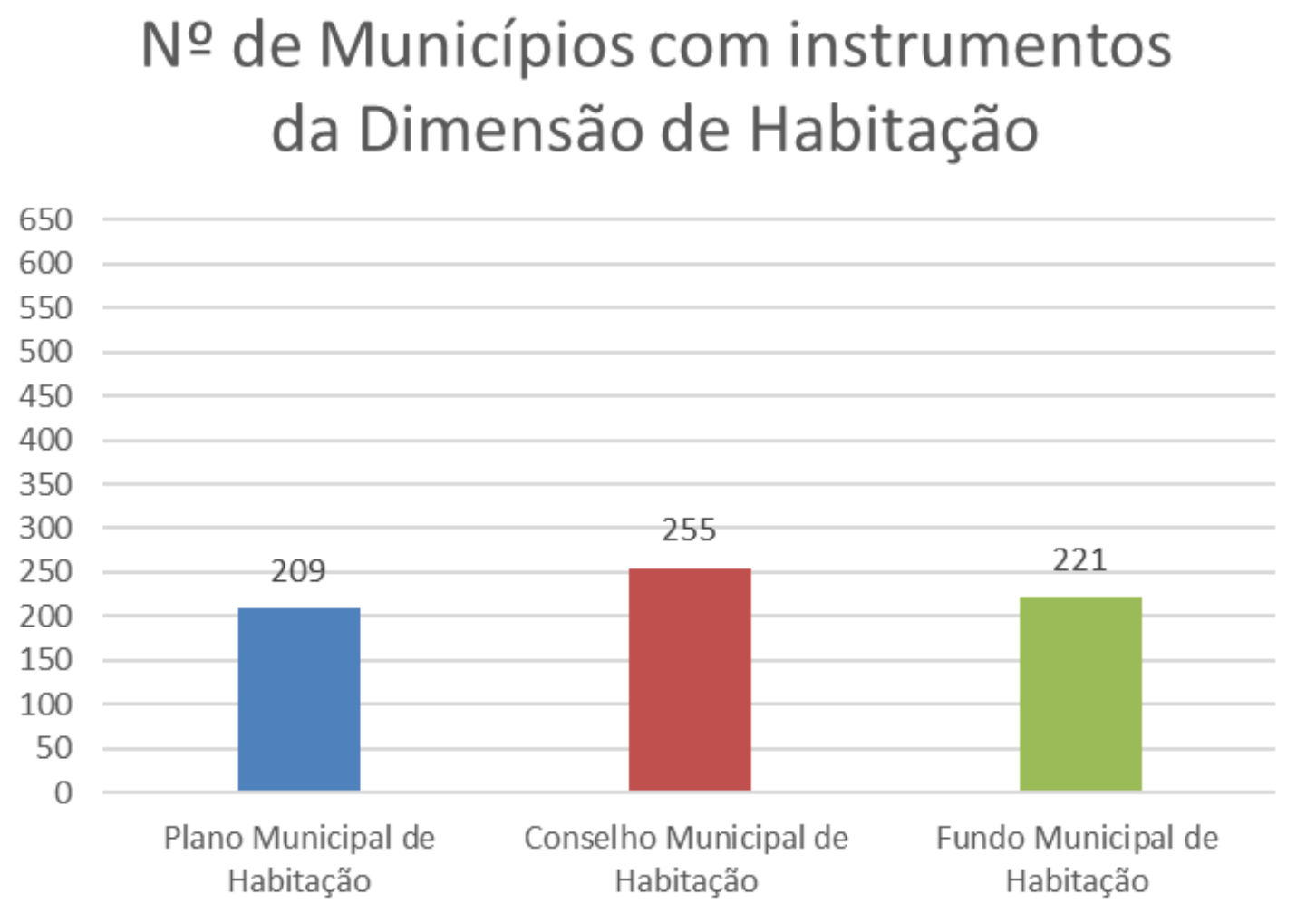

Fonte: Elaborado pelo autor a partir de IBGE, 2018 a 


\subsection{Dimensão de Mobilidade Urbana}

Na Dimensão de Mobilidade Urbana, somente 12 (doze) municípios apresentaram todos os indicadores. Observou-se que esta dimensão também apresentou os melhores resultados concentrados nas proximidades das regiões metropolitanas. Entretanto três municípios que não estão incluídos em nenhuma dessas organizações regionais obtiveram a pontuação máxima do indicador: Amparo, município limítrofe à Região Metropolitana de Campinas, e, Catanduva e Pontal do Paranapanema, localizados na parcela norte e oeste do Estado de São Paulo.

Conforme pode ser observado no Gráfico 2, dos 645 municípios paulistas, somente 70 (setenta) contam com Plano Municipal de Transporte, 192 (cento e noventa e dois) com ciclovias e 65 (sessenta e cinco) com bicicletários. O baixo percentual de municípios com Plano Municipal de Transporte, no qual são definidos os objetivos e diretrizes para o desenvolvimento do transporte e mobilidade no âmbito municipal, reflete uma realidade nacional apresentada pelo Munici 2017 (IBGE, 2018a), que revela que somente 7\% dos municípios brasileiros possuem este instrumento de planejamento. $\mathrm{O}$ relatório aponta ainda uma maior presença deste instrumento em municípios com mais de 500.000 habitantes, atingindo 36,6\% da população brasileira. O mesmo se observa no Estado de São Paulo onde, dentre os 09 (nove) municípios do estado com mais de 500.000 habitantes, somente Campinas não possui o instrumento.

Cabe destacar que diversos municípios possuem somente ciclovias ou bicicletários, estruturas que se implantadas em conjunto poderiam incentivar a alteração do modal de transporte da população. Um ponto novo que futuramente poderá ser abrangido pelo Munic 2017 é o compartilhamento de bicicletas, patinetes e até veículos elétricos, prática já implementada em diversos municípios brasileiros, em especial nas capitais, como mais uma alternativa de transporte, ou de complementação dos deslocamentos realizados em transporte coletivo (last mile solution), em municípios com grandes aglomerações urbanas cujos congestionamentos estão se tornando cada vez mais frequentes. 
Gráfico 2 - Número de municípios com instrumentos da Dimensão de Mobilidade Urbana

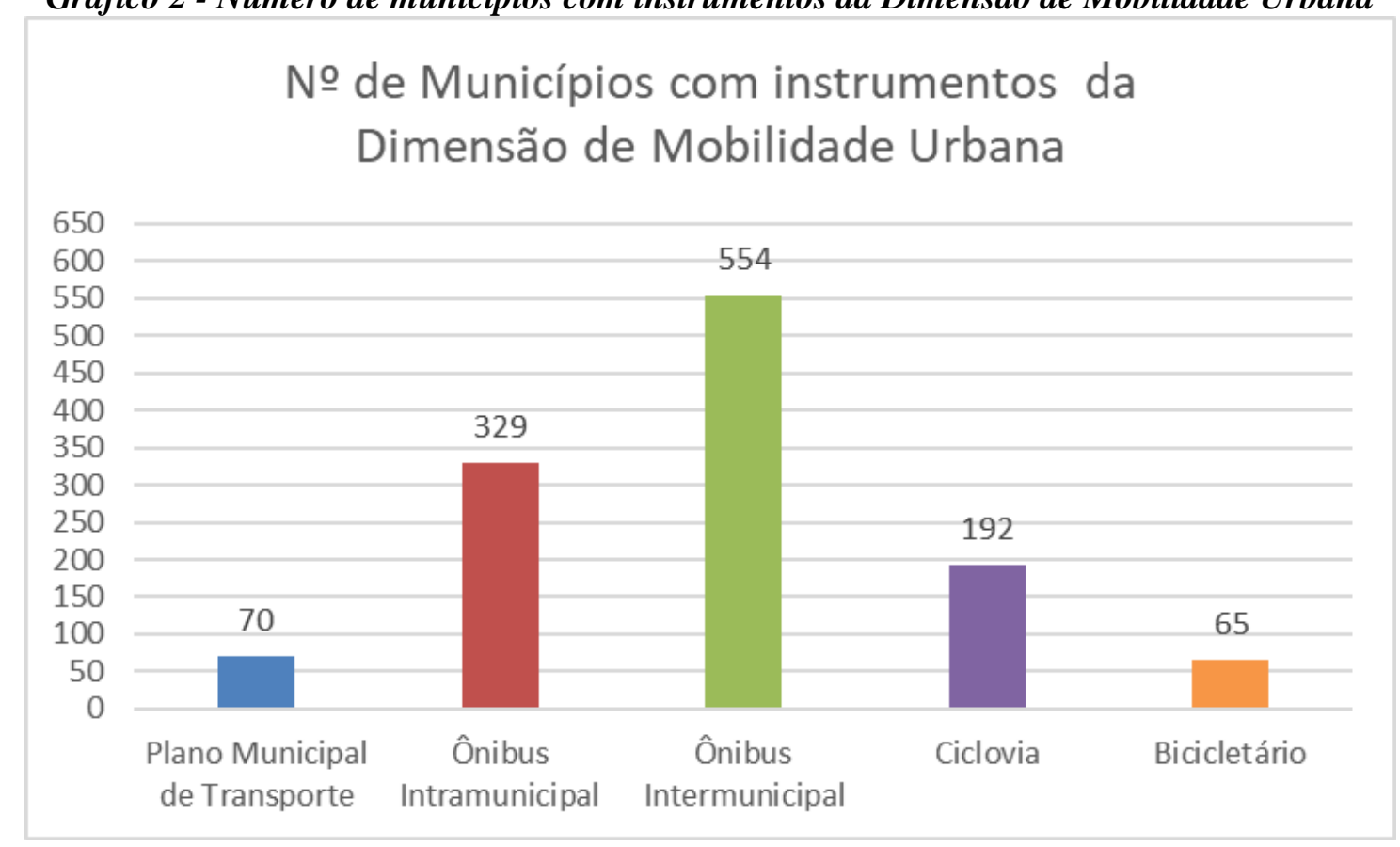

Fonte: Elaborado pelo autor a partir de IBGE, 2018 a

A mobilidade por ônibus é a mais representativa dentre os municípios do estado, principalmente quando analisada a existência de transporte público por ônibus intermunicipal, que abrange $85,9 \%$ dos municípios sendo, muitas vezes, de responsabilidade do governo do estado ou das regiões metropolitanas. Já a disponibilização de transporte público por ônibus dentro dos limites municipais está restrita a $51 \%$ dos municípios. Conforme pontuado anteriormente, nos casos onde o porte dos municípios não justifique a implantação de frotas próprias de ônibus, estes poderão optar pela implantação das ciclovias, melhorar as condições das calçadas para incentivar a walkability (que vem sendo denominado como caminhabilidade em português), ou implantar transportes públicos alternativos, medidas que diminuem a dependência das pessoas por veículos motorizados individuais e que ampliam as opções de mobilidade da população, principalmente durante eventos extremos.

A situação de cada município paulista na Dimensão de Mobilidade Urbana pode ser verificada na Figura 16 a seguir. 
Figura 16 - Dimensão Mobilidade Urbana do UAI Municípios Paulistas

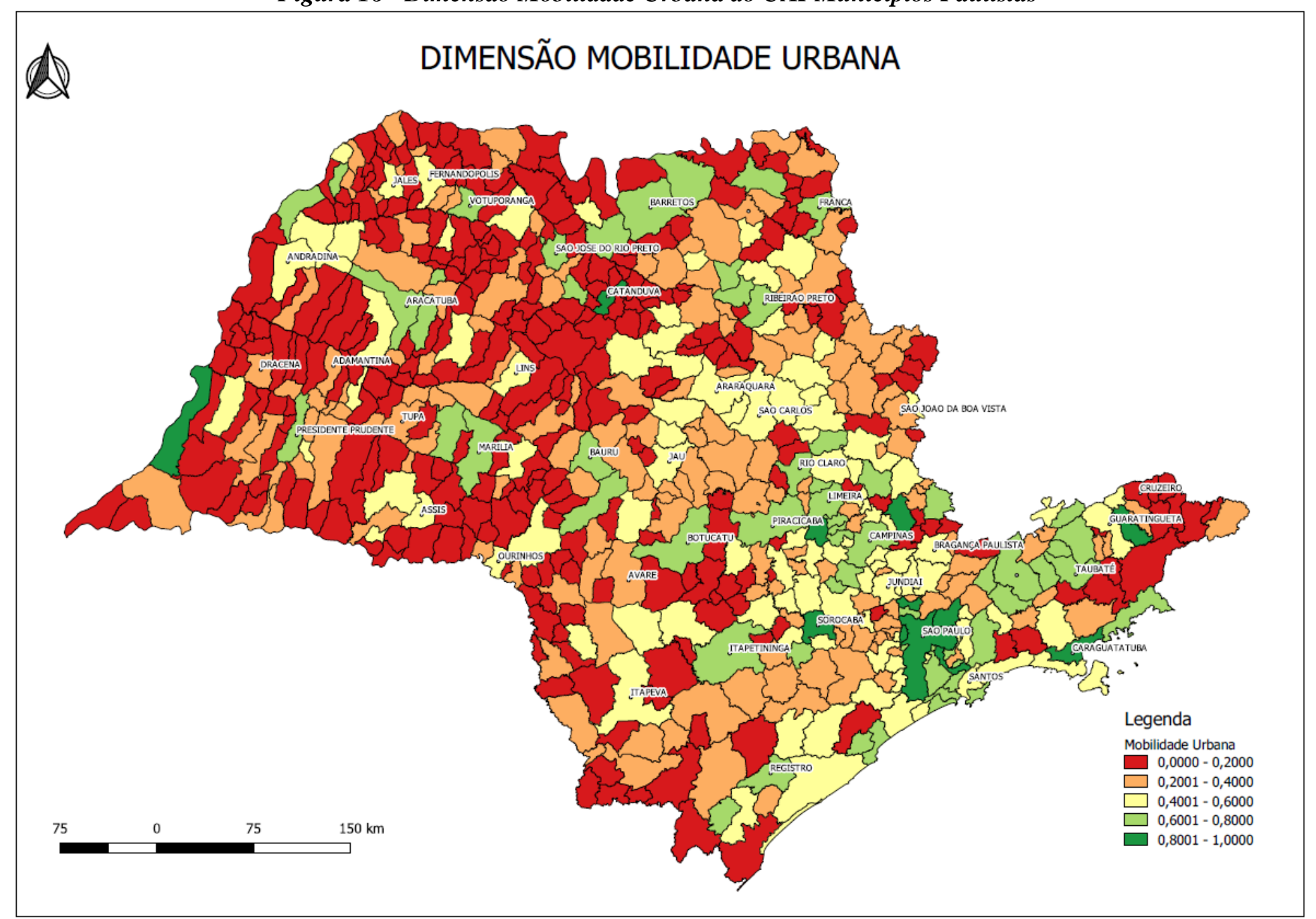

Fonte: Elaborado pelo autor 


\subsection{Dimensão de Agricultura Sustentável}

Os resultados da dimensão Agricultura Sustentável apresentam uma distribuição espacial mais uniforme de municípios com pontuações setoriais mais baixas e altas. De acordo com as informações preliminares disponibilizadas pelo IBGE sobre o Censo Agropecuário de 2017 (IBGE, 2018b) o Estado de São Paulo possui 188,6mil estabelecimentos agropecuários, abrangendo uma área de 16,5 milhões de hectares, cuja distribuição no território é apresentada na Figura 17 a seguir. Dessas áreas, 49\% são lavouras, $30 \%$ pastagens, $18 \%$ matas e florestas e 3\% outros usos. A aglomeração de estabelecimentos agropecuários na parcela sul do estado (IBGE, 2018b) coincide com a região onde, de forma geral, o conjunto de municípios apresentou melhores resultados quando analisada a dimensão de Agricultura Sustentável do UAI.

Figura 17 - Distribuição dos Estabelecimentos Agropecuários do Estado de São Paulo - 2017

\section{Número de estabelecimentos agropecuários, por municípios}

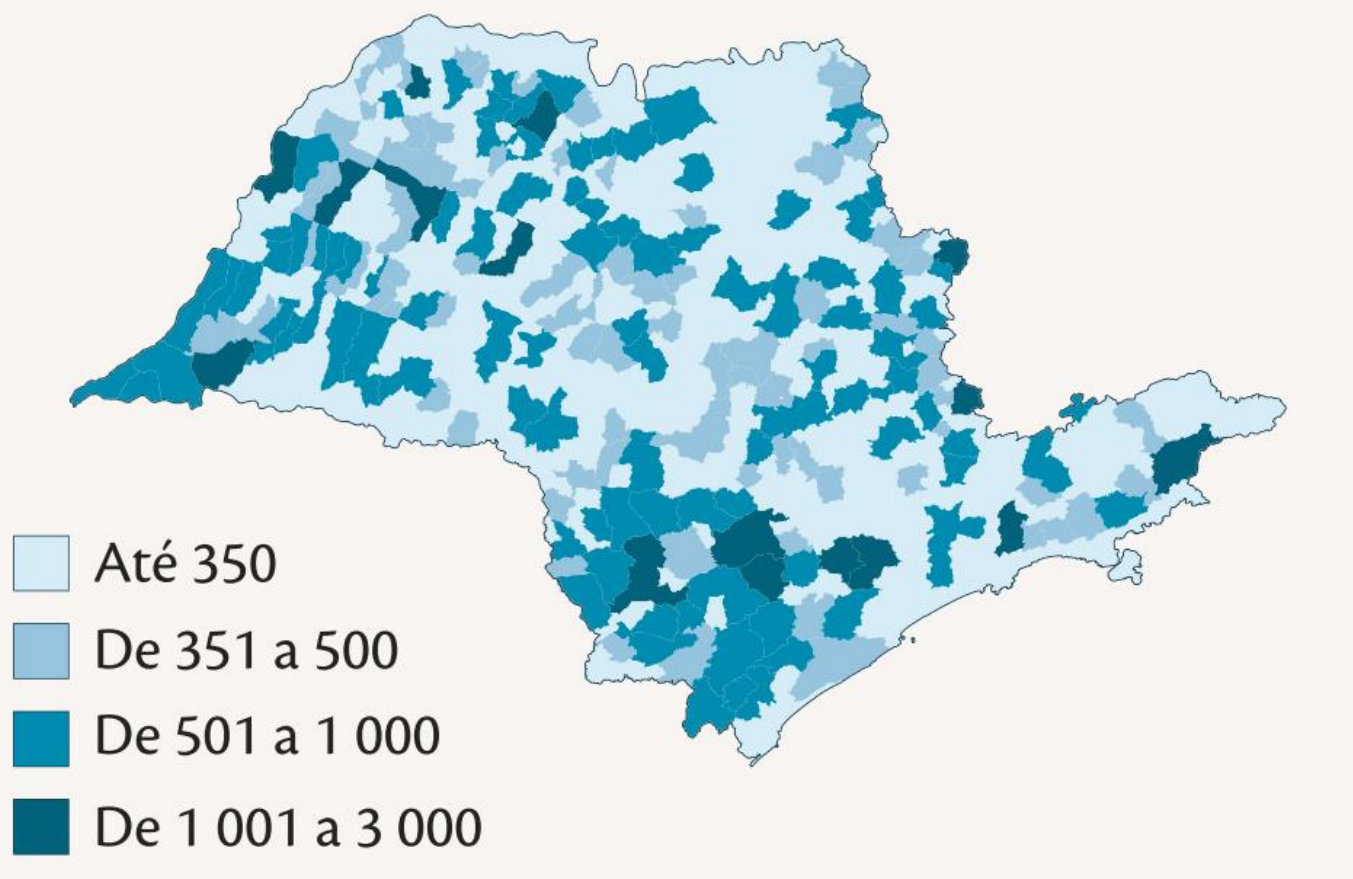

Fonte: Resultados preliminares do Senso Agro 2017 (IBGE, 2018b)

Os instrumentos que mais municípios possuem, dentre os verificados nesta dimensão, foram programa ou ação de estímulo à Agricultura Familiar e ao Associativismo, abrangendo, respectivamente, $71,3 \%$ e $63,6 \%$ dos municípios, conforme apresentado no Gráfico 3. 
Gráfico 3 - Número de municípios com instrumentos da Dimensão Agricultura Sustentável

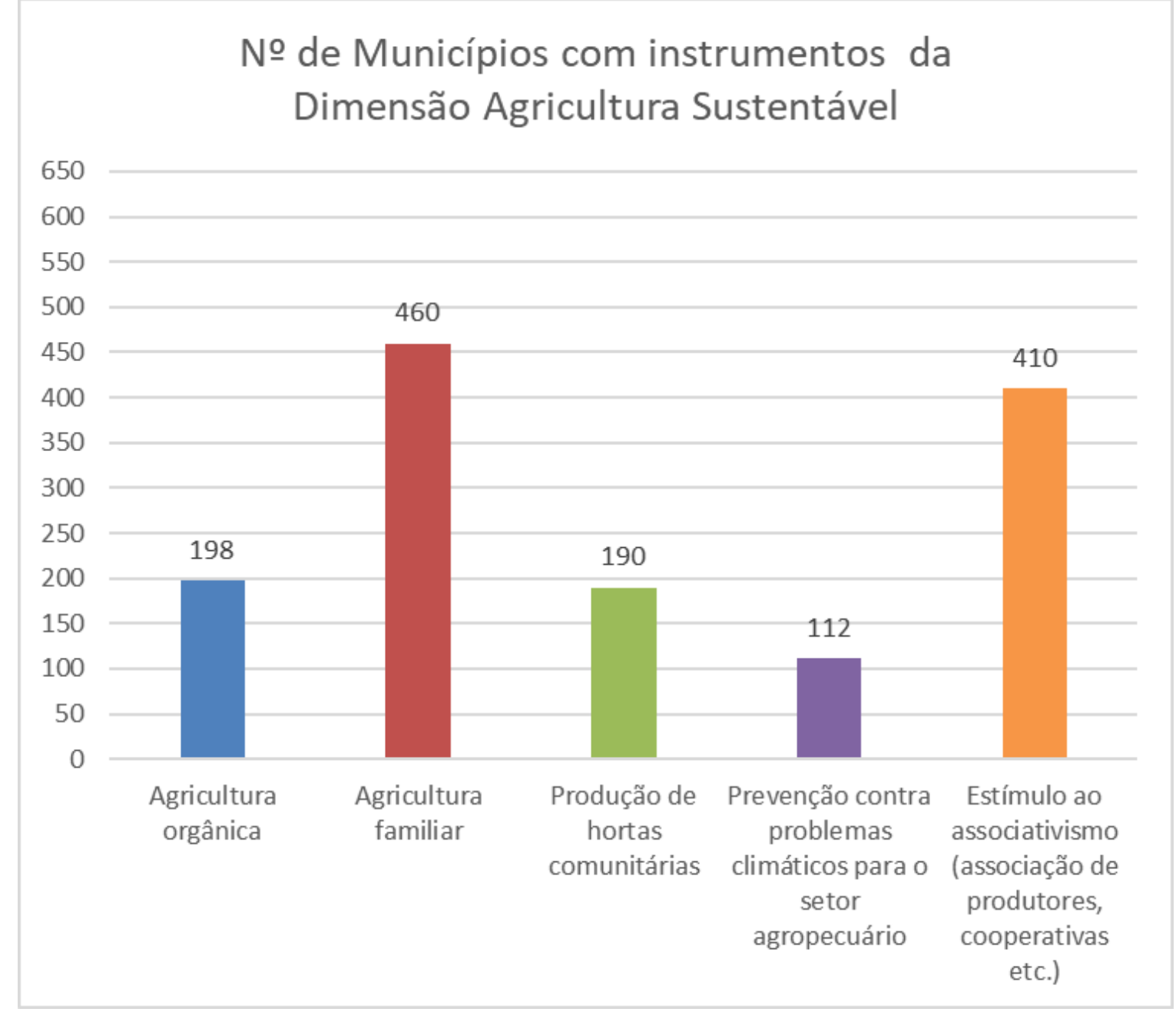

Fonte: Elaborado pelo autor a partir de IBGE (2018a)

As iniciativas municipais para o estímulo à agricultura orgânica e à produção de hortas comunitárias abrangeram somente cerca de $30 \%$ dos municípios, sendo que muitas vezes, os municípios incentivam somente uma das metodologias. Contudo, segundo informações preliminares do Censo Agropecuário de 2017(IBGE, 2018b), 57\% dos estabelecimentos paulistas informaram não utilizar agrotóxicos, percentual que poderia ser ampliado caso mais gestores municipais incentivassem esta prática.

Por fim, o indicador de desenvolvimento de programa ou ação de prevenção contra problemas climáticos para o setor agropecuário apresentou o pior resultado na dimensão, ao ser contemplado por apenas $17,4 \%$ dos municípios. É importante salientar que, como abordado anteriormente, trata-se de um indicador relacionado a uma capacidade específica do município em se adaptar aos efeitos das mudanças climáticas (DI GIULIO et al., 2016), o que exige maior sensibilização dos gestores para o tema (MARENGO et al., 2016). 
Na Figura 18 pode ser observada uma distribuição mais homogênea dos resultados sobre agricultura sustentável e uma concentração de melhores resultados nas parcelas ao sul do estado, tendo como principais exceções os municípios de Apiaí e Itapirapuã Paulista que não possuíam nenhum dos instrumentos consultados, seguidos por Ribeirão Branco, Cajati e Jacupiranga que apenas possuem políticas de incentivo à Agricultura Familiar. 
Figura 18 - Dimensão Agricultura Sustentável do UAI Municípios Paulistas

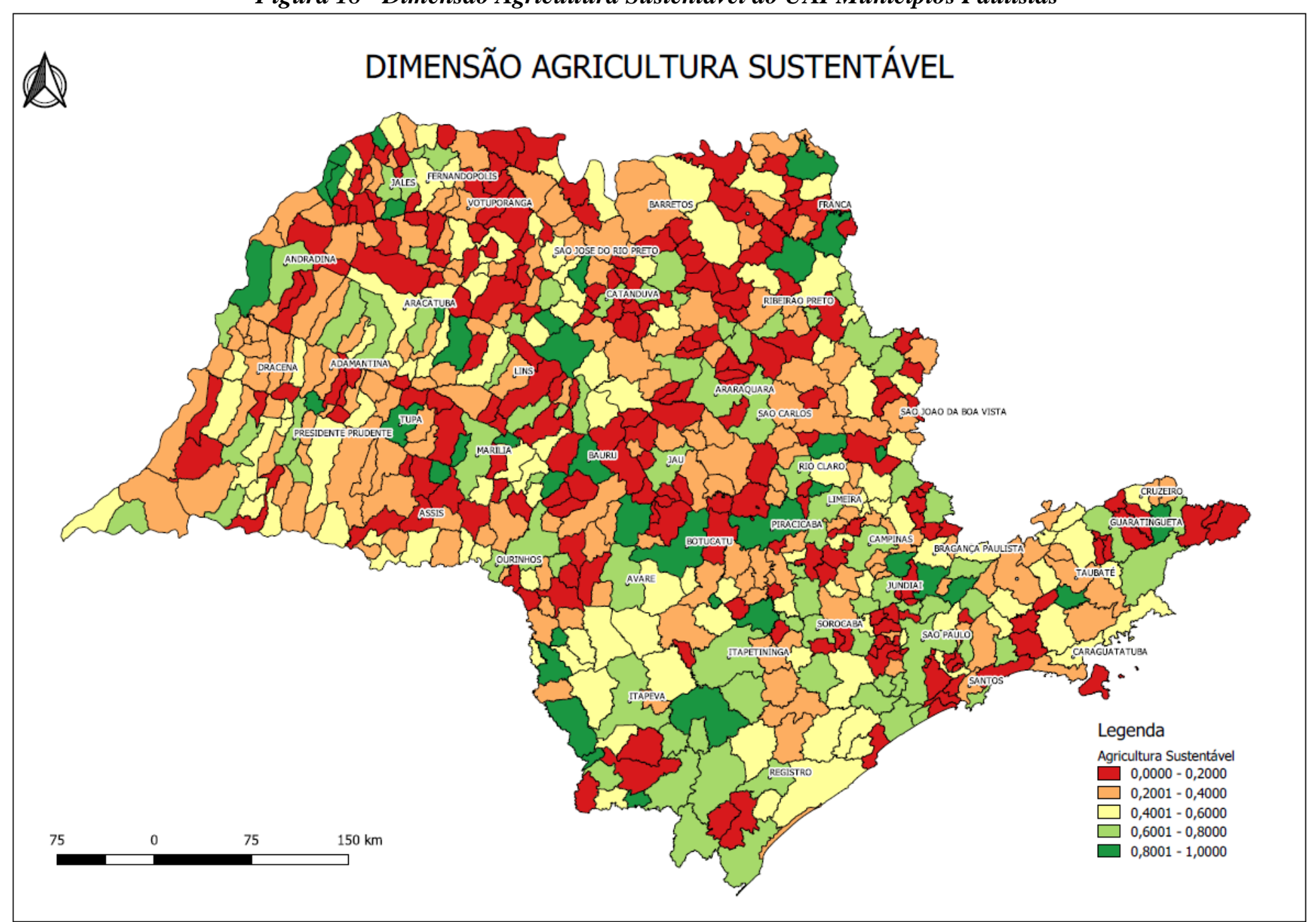

Fonte: Elaborado pelo autor 


\subsection{Dimensão de Gestão Ambiental}

A dimensão de Gestão Ambiental foi a que apresentou maiores diferenças entre os indicadores. Dos instrumentos contemplados nesta dimensão, o Plano de Gestão Integrada de Resíduos Sólidos nos termos da Política Nacional de Resíduos Sólidos é o mais abrangido pelos municípios paulistas (76\%). Três indicadores são aplicados por cerca de metade dos municípios, sendo eles a existência de Fundo Municipal de Meio Ambiente $(55,5 \%)$ e de legislação ou instrumentos de gestão sobre saneamento básico $(57,8 \%)$ e poluição do ar $(48,6 \%)$. Já os instrumentos para áreas de proteção ou controle ambiental só existem em 29,9\% dos municípios, para proteção da biodiversidade em $14,1 \%$ e políticas de pagamento por serviços ambientais (PSA) só são aplicadas por 13,6\% dos municípios paulistas. Assim como na Dimensão de Agricultura Sustentável, o pior resultado observado para esta dimensão foi o indicador relacionado à capacidade específica do município em responder aos impactos das mudanças climáticas, uma vez que a existência de lei ou instrumento sobre adaptação e mitigação só foi observada em 36 municípios, o equivalente a 5,6\% dos municípios paulistas. Estes dados podem ser observados no Gráfico 4, a seguir. 


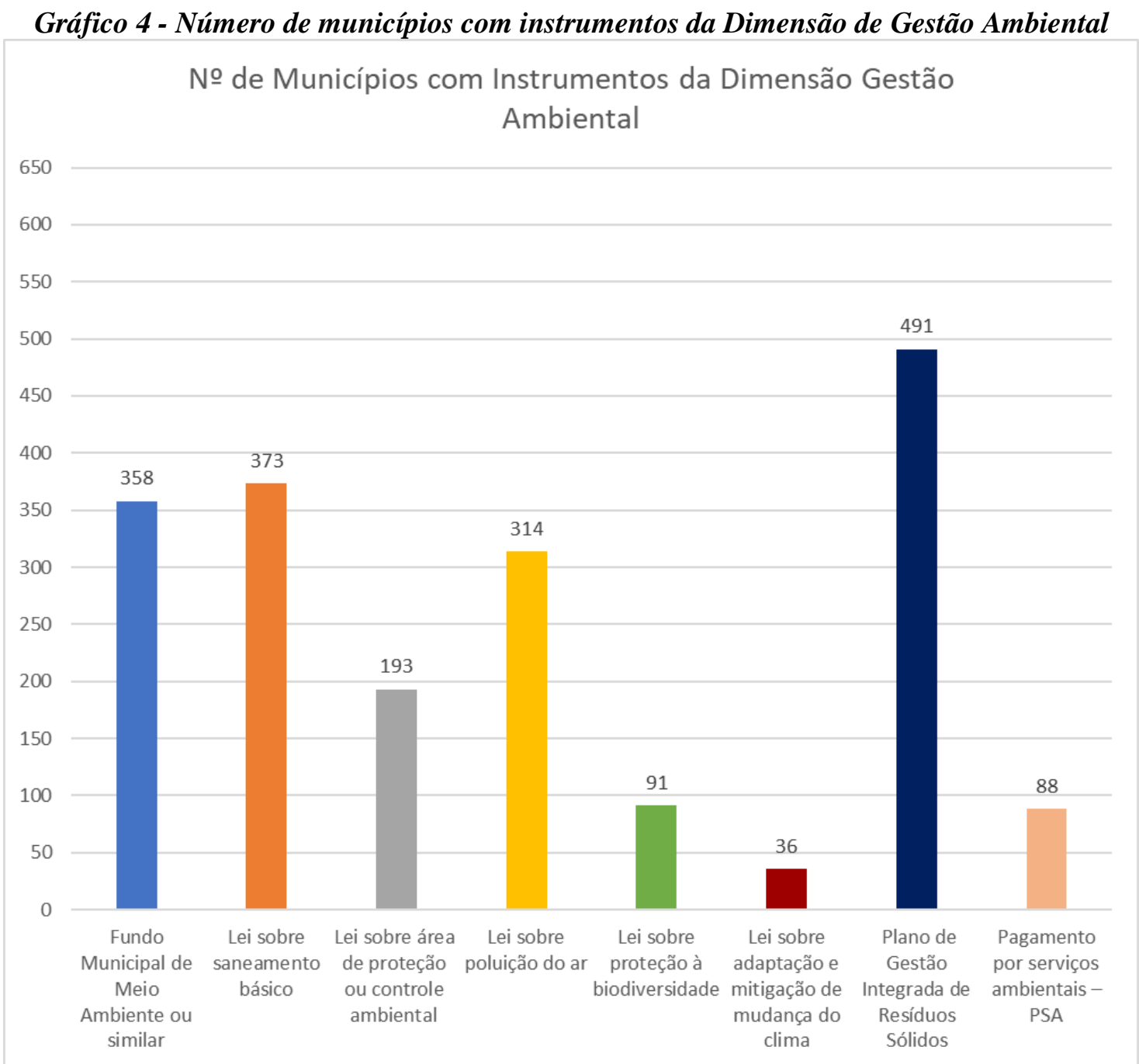

Fonte: Elaborado pelo autor a partir de IBGE, 2018 a

A Figura 19 apresenta a distribuição espacial dos municípios de acordo com o número de instrumentos da Dimensão Gestão Ambiental que cada município possui. Dentre os 645 municípios paulistas, somente 27 (vinte e sete) foram enquadrados na categoria mais alta da dimensão, sendo que 07 (sete) municípios contemplam todos os indicadores (Botucatu, Campinas, Cândido Mota, Ibirarema, Olímpia, Santa Cruz do Rio e Santa Isabel). Os outros 20 (vinte) não contemplam um dos indicadores. Já a segunda maior faixa foi composta por 95 (noventa e cinco) municípios, os quais possuíam 05 (cinco) ou 06 (seis) dos 08 (oito) indicadores consultados. Esse conjunto de municípios situados nas duas primeiras faixas da dimensão representam 18,9\% dos municípios paulistas, demonstrando a necessidade de elaboração de políticas públicas nesse setor. Observa-se que a distribuição destes municípios no mapa não é uniforme e que as altas pontuações não se restringem a municípios mais populosos. Por exemplo, dentre os municípios que afirmaram contar com todos os instrumentos, estão Campinas, com 1.182.429 habitantes, e Ibirarema, com 7.540 habitantes (estimativa populacional de 2017 do IBGE). 
Figura 19 - Dimensão Gestão Ambiental do UAI Municípios Paulistas

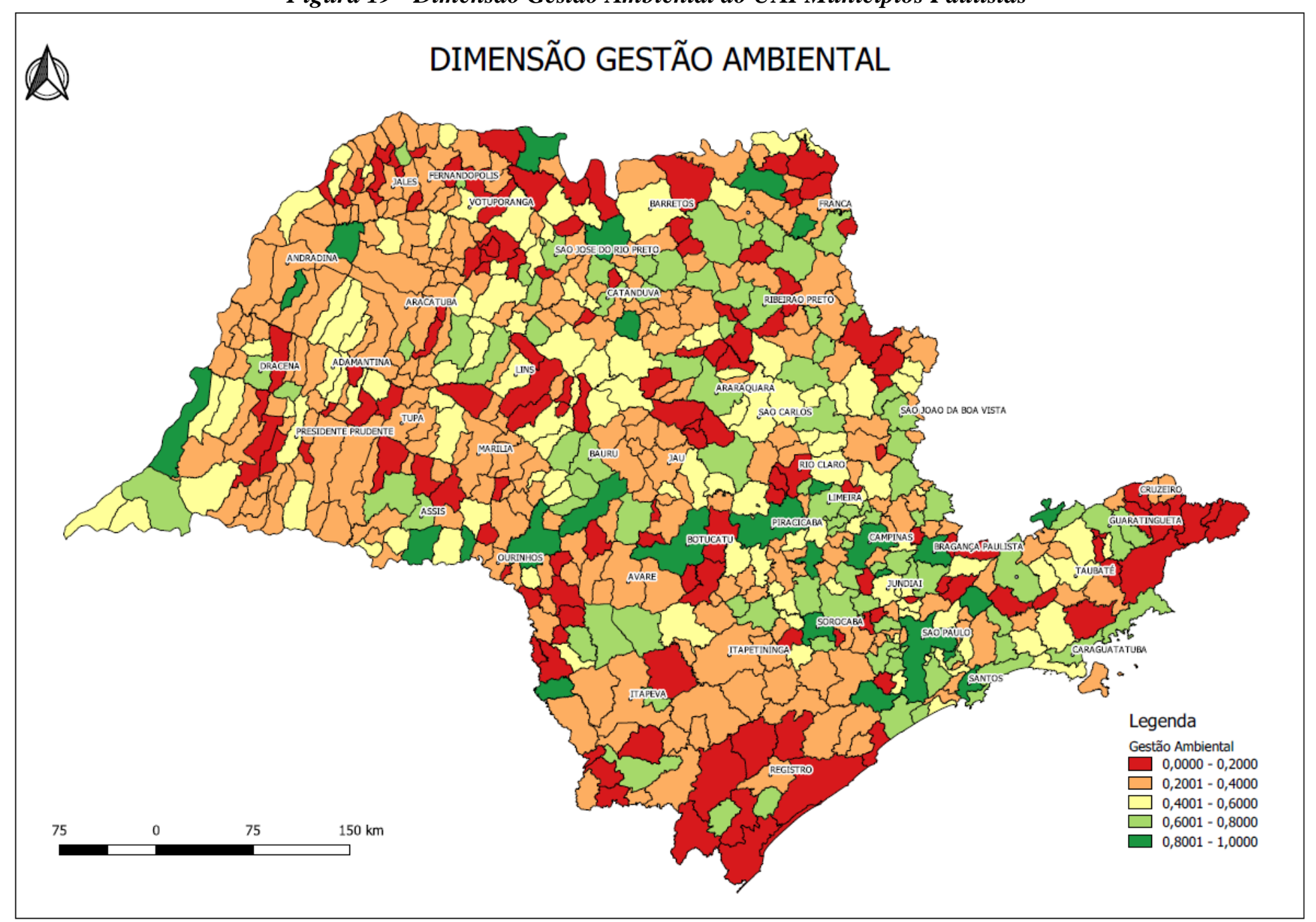

Fonte: Elaborado pelo autor 
A parcela sul do estado apresentou uma particularidade quando comparados os resultados das dimensões de agricultura sustentável com a gestão ambiental. Enquanto a maioria dos municípios dessa região possui instrumentos relacionados à agricultura sustentável, foi nesta área onde se concentraram os piores resultados para gestão ambiental. Outra região onde este mesmo efeito pode ser observado é na parcela sudeste do estado. Conforme pode ser observado na Figura 20, que apresenta o percentual de vegetação nativa por município relativa aos anos de 2008 e 2009, esta concentração de resultados piores na dimensão de gestão ambiental coincide com os municípios que ainda possuem mais de $30 \%$ de sua vegetação nativa. Como os instrumentos relacionados à proteção do meio ambiente e da biodiversidade são essenciais para a manutenção da qualidade ambiental destas áreas, os poderes locais e regionais podem priorizar a implantação de instrumentos relacionados à manutenção de sua qualidade ambiental, como a criação de um fundo municipal de meio ambiente, legislações sobre saneamento, existência de planos de gestão de resíduos, e, em especial, a criação de políticas de pagamentos por serviços ambientais. O PSA ainda poderia viabilizar novas opções para o desenvolvimento econômico local, ao mesmo tempo que mantém a preservação ambiental de ambientes que prestam serviços fundamentais à ampliação da capacidade adaptativa dos habitantes do Estado de São Paulo, através da proteção da biodiversidade, controle climático, produção de água, proteção de áreas com riscos de deslizamento etc.

Figura 20 - Percentual de cobertura vegetal nativa por município - 2008/2009

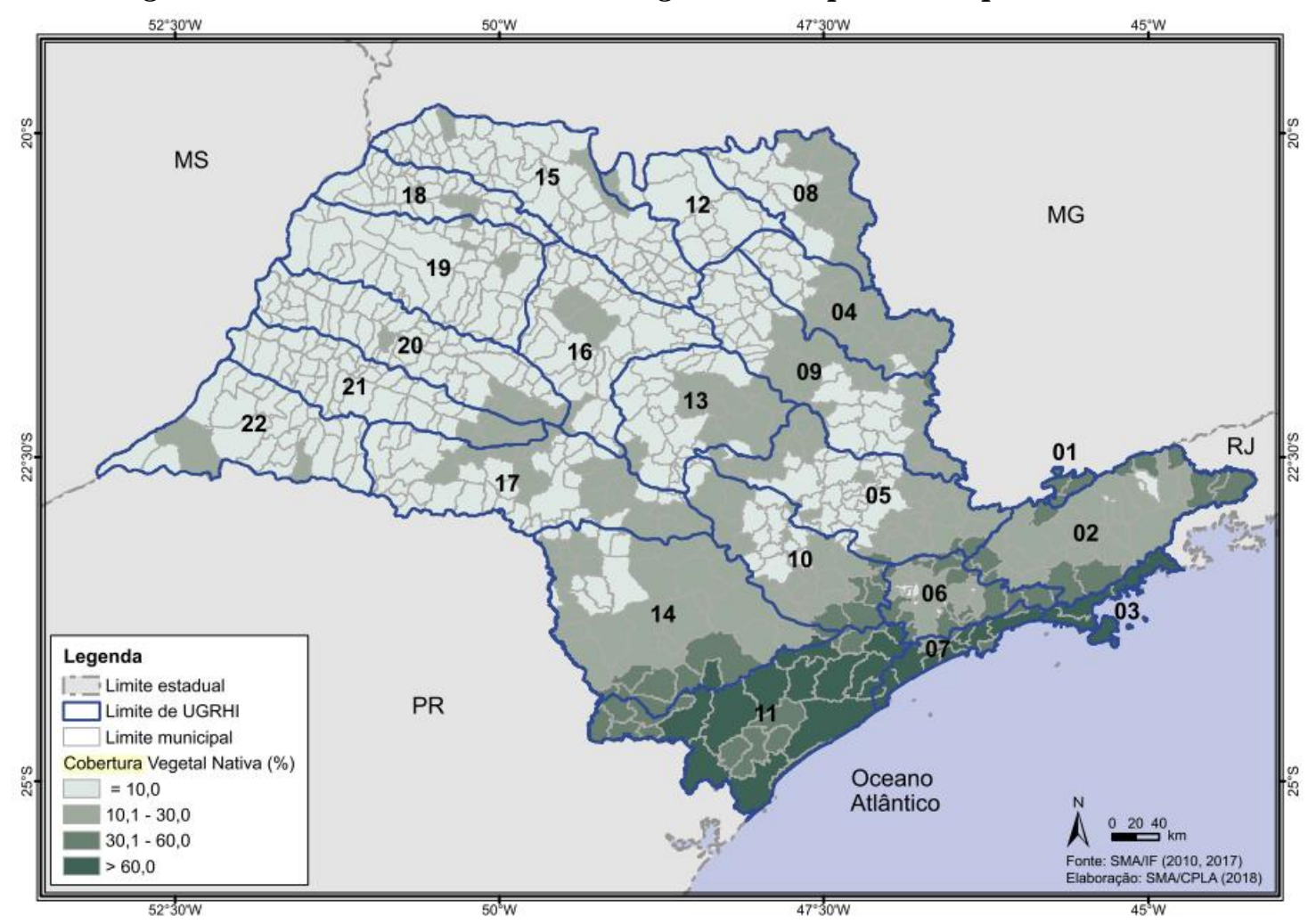

Fonte: Instituto Florestal do Estado de São Paulo, 2010 - Elaborado por SMA/CPLA para o RQA 2018 (SÃO PAULO (ESTADO), 2018a) 
Por outro lado, as parcelas oeste e noroeste do estado concentram as áreas com menores índices de cobertura nativa do estado, o que amplia a vulnerabilidade dos residentes dessas áreas aos efeitos das mudanças climáticas, principalmente quanto aos efeitos das ilhas de calor, da poluição do ar e de inundações (RIBEIRO; SANTOS, 2016). Nestes locais, a atuação dos municípios poderá focar na instituição de instrumentos de proteção e controle ambiental, de proteção à biodiversidade e de adaptação e mitigação dos efeitos da mudança do clima.

O baixo percentual de leis que visem a proteção da biodiversidade $(14,1 \%)$ é preocupante, devendo ser aprimorada por todos os municípios. De acordo com o SR1,5, ainda que a perda da biodiversidade seja menor com o aquecimento do planeta em $1,5^{\circ} \mathrm{C}$ frente ao aquecimento de $2^{\circ} \mathrm{C}$, em ambos os casos, deverão ocorrer perdas de espécies e extinção(IPCC, 2018).

A Figura 21, elaborada no âmbito do Relatório de Qualidade Ambiental de 2017 da Secretaria de Meio Ambiente (SÃO PAULO (ESTADO), 2017), apresenta a taxa de mortalidade municipal de doenças relacionadas ao saneamento ambiental inadequado ao longo do ano de 2016. Segundo o relatório, 200 municípios apresentaram casos de óbitos relacionados à deficiência no saneamento ambiental em 2016, sendo que $91 \%$ destes municípios apresentaram até um caso por 10.000 habitantes. Os principais causadores de óbitos foram a hepatite e a diarreia com 425 casos, e a gastroenterite com 335 casos.

Figura 21 - Taxa de mortalidade por doenças relacionadas ao saneamento ambiental inadequado (DRSAI) no Estado de São Paulo em 2016

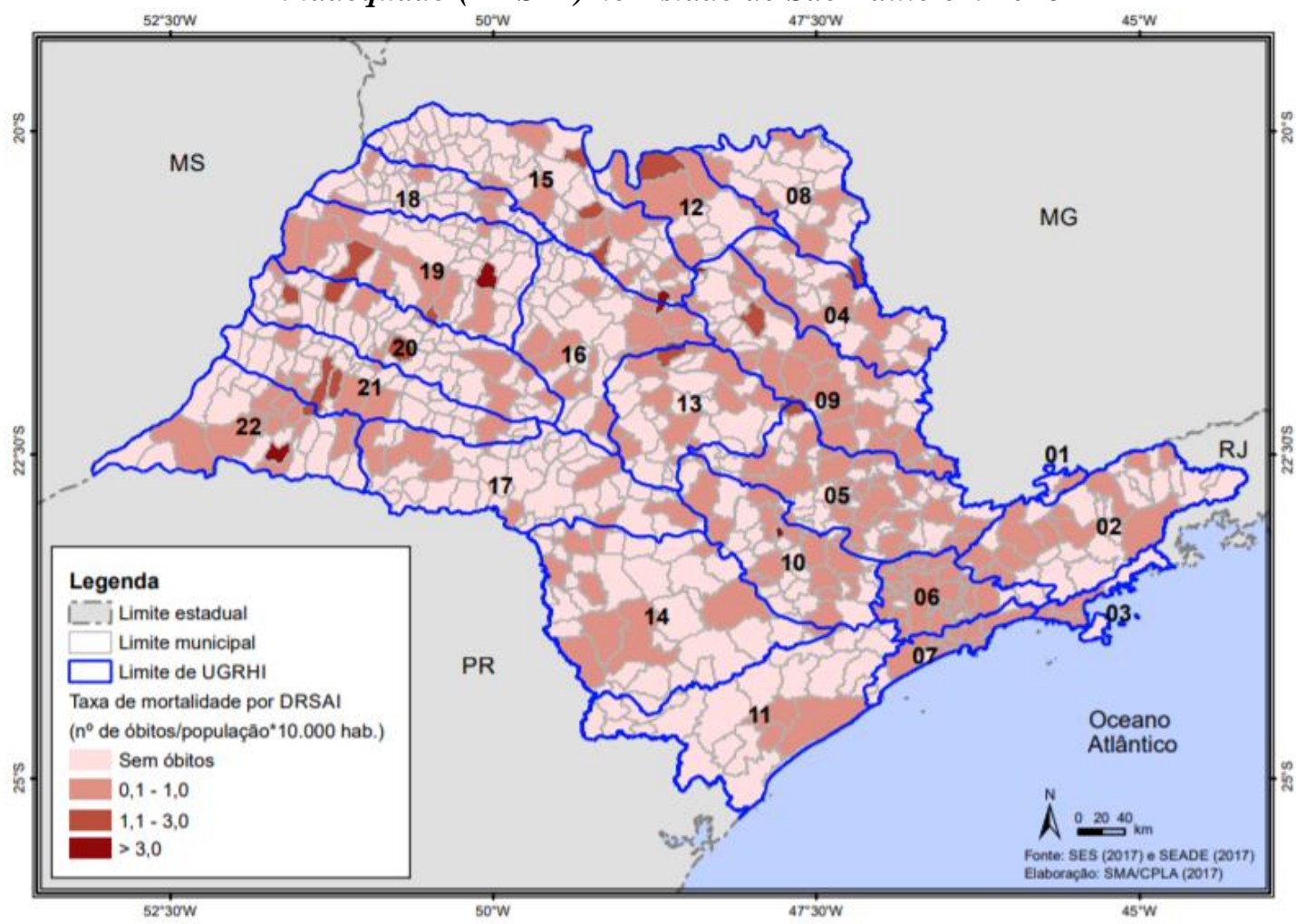

Fonte: Secretaria de Estado de Saúde e SEADE, 2017 - Apud (SÃO PAULO (ESTADO), 2017) 
Em cinco municípios foram verificados mais de três óbitos por 10.000 habitantes, sendo que Estrela do Norte, Jumirim, Taquaral e Zacarias só tiveram um óbito cada e Fernando Prestes teve dois óbitos(SÃO PAULO (ESTADO), 2017). Deve ser ressaltado que, por se tratarem de municípios com populações pequenas, estas ocorrências resultaram em altos índices de óbitos por 10.000 habitantes. Entretanto, se analisada a situação destes municípios na Dimensão de Gestão Ambiental do UAI verifica-se que a pontuação destes municípios varia entre 0,25 e 0,5. Apesar da baixa pontuação destes municípios na dimensão de gestão ambiental, verifica-se que somente Jumirim e Estrela do Norte não contam com leis ou instrumentos de gestão sobre saneamento básico. Além disso, os 05 (cinco) municípios possuem plano de gestão de resíduos sólidos. Com posse dessas informações, os municípios que não possuem regulamentações sobre saneamento básico poderão priorizar a sua elaboração. Além disso, aqueles municípios que já possuem estes instrumentos deverão verificar as possíveis alterações necessárias de modo a reduzir a ocorrência de óbitos relacionados à deficiência de saneamento ambiental. As mesmas recomendações poderão ser seguidas pelos outros 195 municípios que apresentaram óbitos em 2016 por estas causas.

Outra informação importante que pode ser obtida no Relatório de Qualidade Ambiental de 2017 é a taxa de mortalidade de idosos (idade > 60 anos) devido a doenças do aparelho respiratório. Conforme pode ser observado na Figura 22, a grande maioria dos municípios paulistas, 596 municípios, apresentou óbitos enquadrados nesta categoria durante o ano de 2016, sendo que $73 \%$ deles registrou entre 20 a 50 óbitos para cada 10.000 habitantes. Uma vez que as alterações climáticas ampliam os riscos associados a doenças respiratórias, especialmente em crianças e idosos (ASSAD; MAGALHÃES, 2014), os municípios com maiores incidências destes tipos de ocorrências deverão imprimir maior esforço para atuar frente à poluição do ar e por medidas que amenizem os efeitos das ilhas de calor, representadas nesta dimensão pela elaboração legislação ou instrumento de gestão sobre poluição do ar, proteção à biodiversidade e sobre adaptação e mitigação à mudança do clima. 
Figura 22 - Taxa de mortalidade de idosos por doenças do aparelho respiratório no Estado de

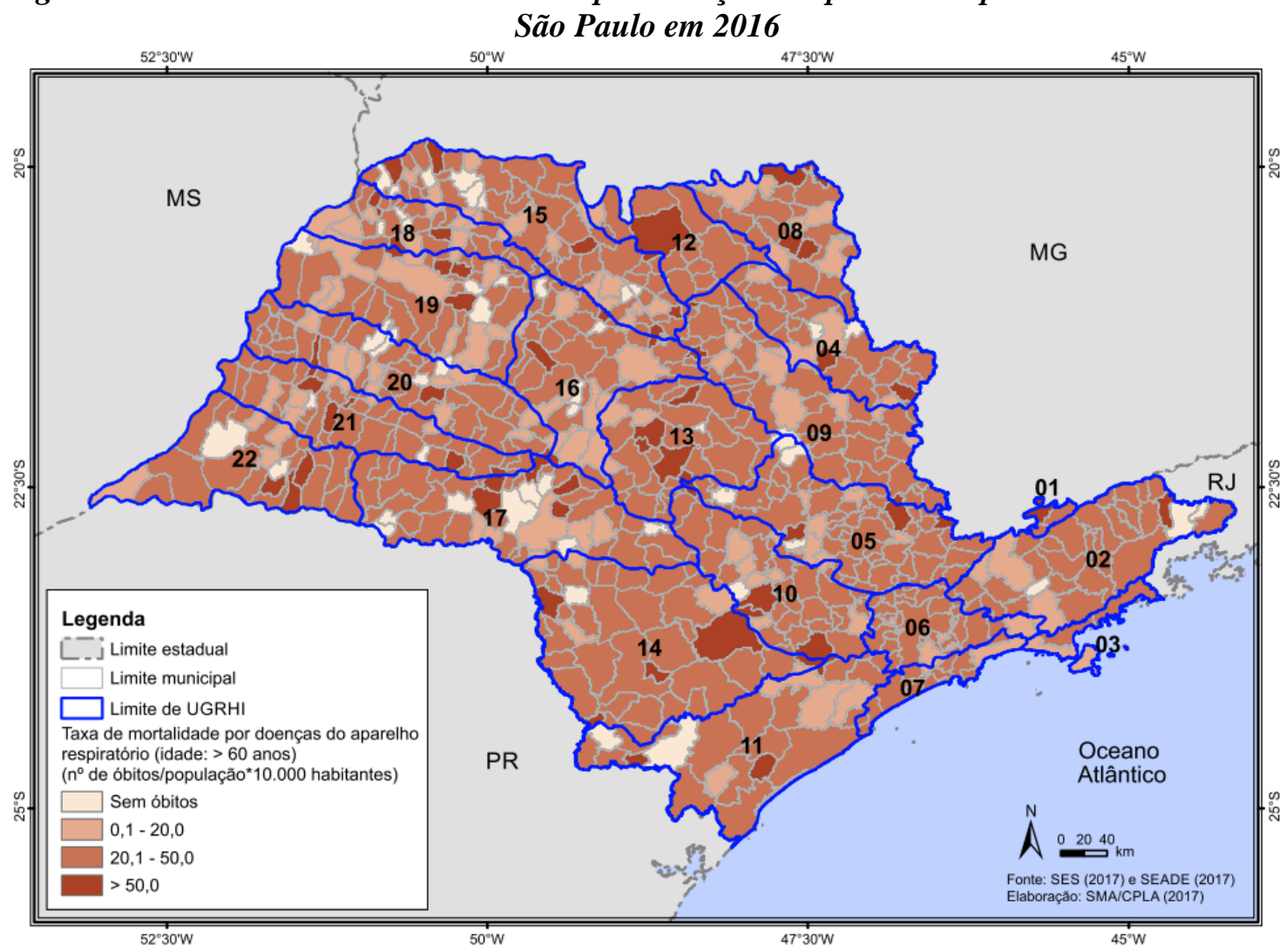

Fonte: Secretaria de Estado de Saúde e SEADE, 2017 - Apud (SÃO PAULO (ESTADO), 2017)

\subsection{Dimensão de Resposta aos Impactos Climáticos}

A dimensão de Resposta aos Impactos Climáticos foi a que apresentou os piores resultados setoriais. Foram observados 113 municípios que não contam com nenhum dos indicadores avaliados, recebendo a pontuação " 0 " nesta dimensão. Além disso, mais da metade dos municípios paulistas $(51,3 \%)$ possui somente um dos instrumentos avaliados - em sua grande maioria a defesa civil municipal - recebendo a pontuação " 0,2 ", conforme pode ser observado na Figura 23. Dessa forma, aproximadamente $70 \%$ dos municípios paulistas foram enquadrados na menor faixa do UAI, possuindo no máximo um indicador da dimensão, os quais poderiam ser objeto de políticas estaduais para esta situação ser revertida.

Somente sete municípios possuem todos os instrumentos consultados, sendo eles, Campinas, São Bernardo do Campo, Santo André, Santos, Taboão da Serra, Rio Claro e São José do Rio Preto, sendo que este último é o único que não está incluído em uma Região Metropolitana ou em uma Aglomeração Urbana. As regiões que concentraram os melhores resultados da dimensão de Resposta aos Impactos Climáticos coincidiram em grande parte com as Regiões Metropolitanas da Baixada Santista, de São Paulo e de 
Campinas, além da Aglomeração Urbana de Jundiaí, todas inseridas na Macrometrópole Paulista. Conforme citado anteriormente, a concentração de melhores resultados em regiões metropolitanas e aglomerações urbanas para a dimensão de Resposta aos Impactos Climáticos já era esperada, uma vez que estes municípios são obrigados a elaborar seus planos diretores (BRASIL, 2001), o que muitas vezes é acompanhado das leis de uso e ocupação do solo, facilitando o atendimento a dois dos cinco indicadores da dimensão. Além disso, ao desenvolver os seus planos de desenvolvimento urbanos integrados (BRASIL, 2015), os municípios são incentivados a delimitar as áreas com restrição à urbanização. Ainda assim, muitos municípios localizados nas demais regiões metropolitanas e aglomerações urbanas do Estado apresentaram resultados ruins para a dimensão de Resposta aos Impactos Climáticos. Como os riscos da ausência destes instrumentos são maiores em áreas com elevada densidade populacional, sugere-se que estes municípios priorizem a elaboração de tais intervenções. 
Figura 23 - Dimensão Resposta aos Impactos Climáticos do UAI Municípios Paulistas

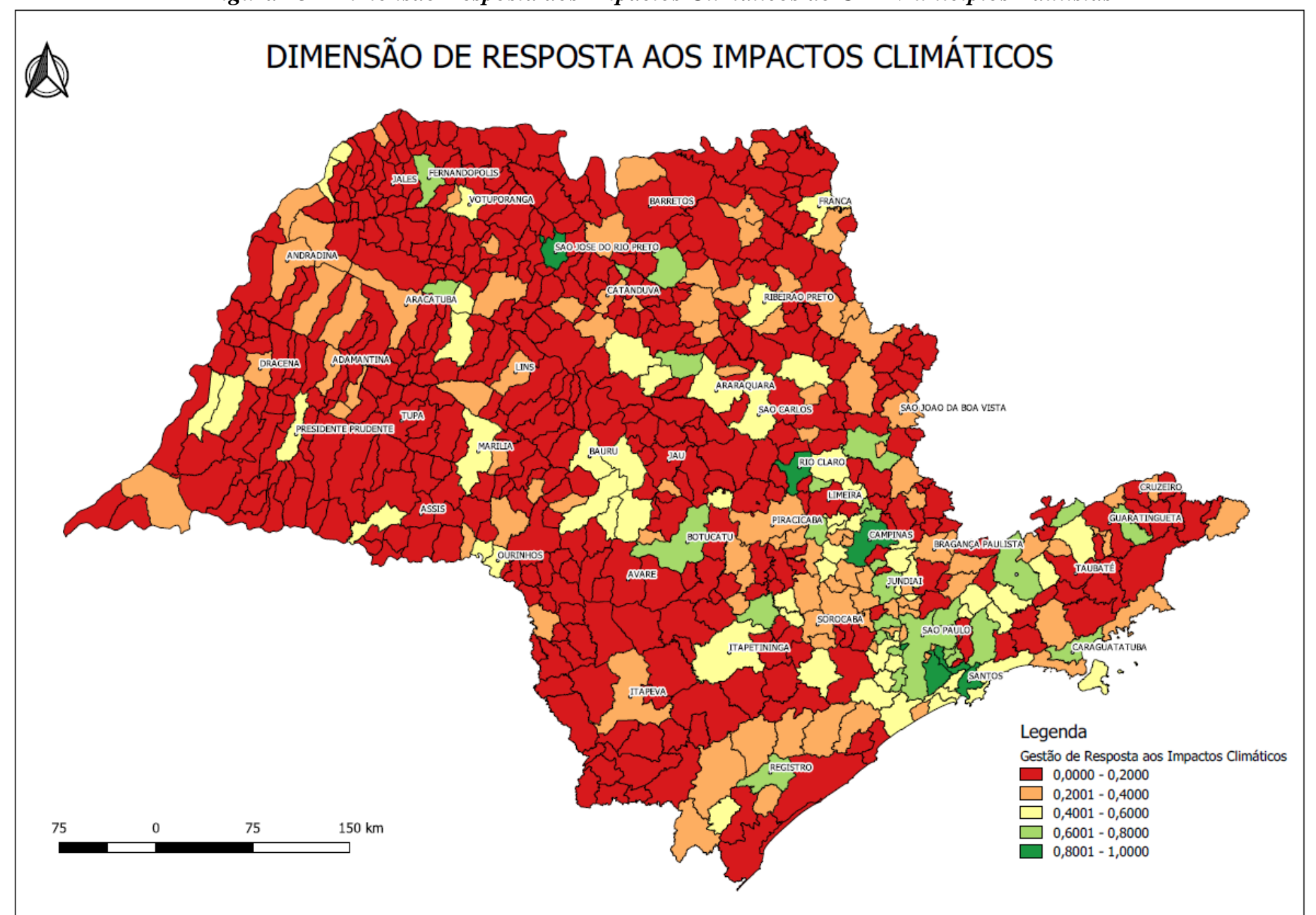

Fonte: Elaborado pelo autor 
O Gráfico 5 apresenta o número de municípios que possuem cada um dos instrumentos avaliados pela dimensão de Resposta aos Impactos Climáticos.

\section{Gráfico 5 - Número de municípios com instrumentos da Dimensão de Resposta aos Impactos Climáticos}

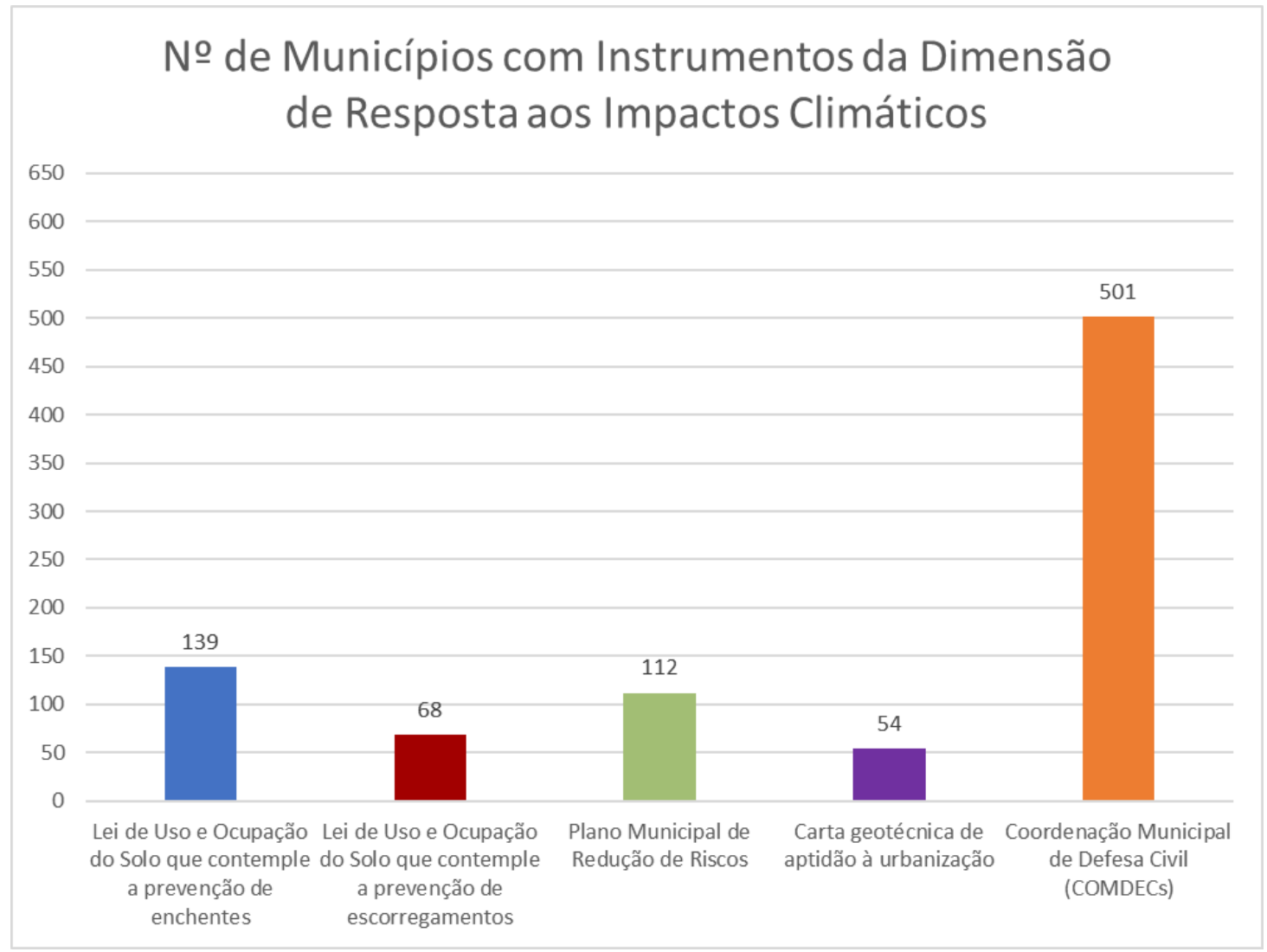

Fonte: Elaborado pelo autor a partir de IBGE, 2018 a

A análise dos resultados desta dimensão demonstra uma grande disparidades entre o indicadore de existência da defesa civil municipal e os demais instrumentos consultados. Verificou-se que mais de $77 \%$ dos municípios paulistas contam com uma coordenação Municipal de Defesa Civil, cabendo aos gestores municipais um esforço para universalizar este serviço no estado, dada a importância deste órgão durante eventos climáticos extremos.

Dois indicadores desta dimensão avaliam a composição da Lei de Uso e Ocupação do Solo do município, verificando se ela contempla a prevenção de enchentes ou de escorregamentos, o que ocorre apenas em $21,5 \%$ e $10,5 \%$ dos municípios, respectivamente. Observou-se ainda que em diversos casos os municípios só contam com um dos dois indicadores, os quais poderão incluir o outro em uma revisão de sua lei de uso e ocupação do solo, sem a necessidade de criação de novos instrumentos.

O Relatório de Qualidade Ambiental de 2018 da SMA apresenta o histórico de acidentes por tipo de evento entre os anos de 1997 e 2016, conforme pode ser observado na Figura 
24, levantamento que pode ajudar na priorização das ações por parte dos poderes locais e regionais. Dentre as informações apresentadas, destacam-se os municípios de Eldorado, São Sebastião, Taubaté e Ubatuba que apresentaram um grande número de acidentes relacionados a eventos geológicos e hidrológicos, mas nenhum deles conta com leis de uso e ocupação do solo contemplando a prevenção de enchentes e escorregamentos. 
Figura 24 - Acidentes relacionados a fenômenos Geológicos (A), Hidrológicos(B), Meteorológicos (C) e Climatológicos (D) entre 1997 e 2016
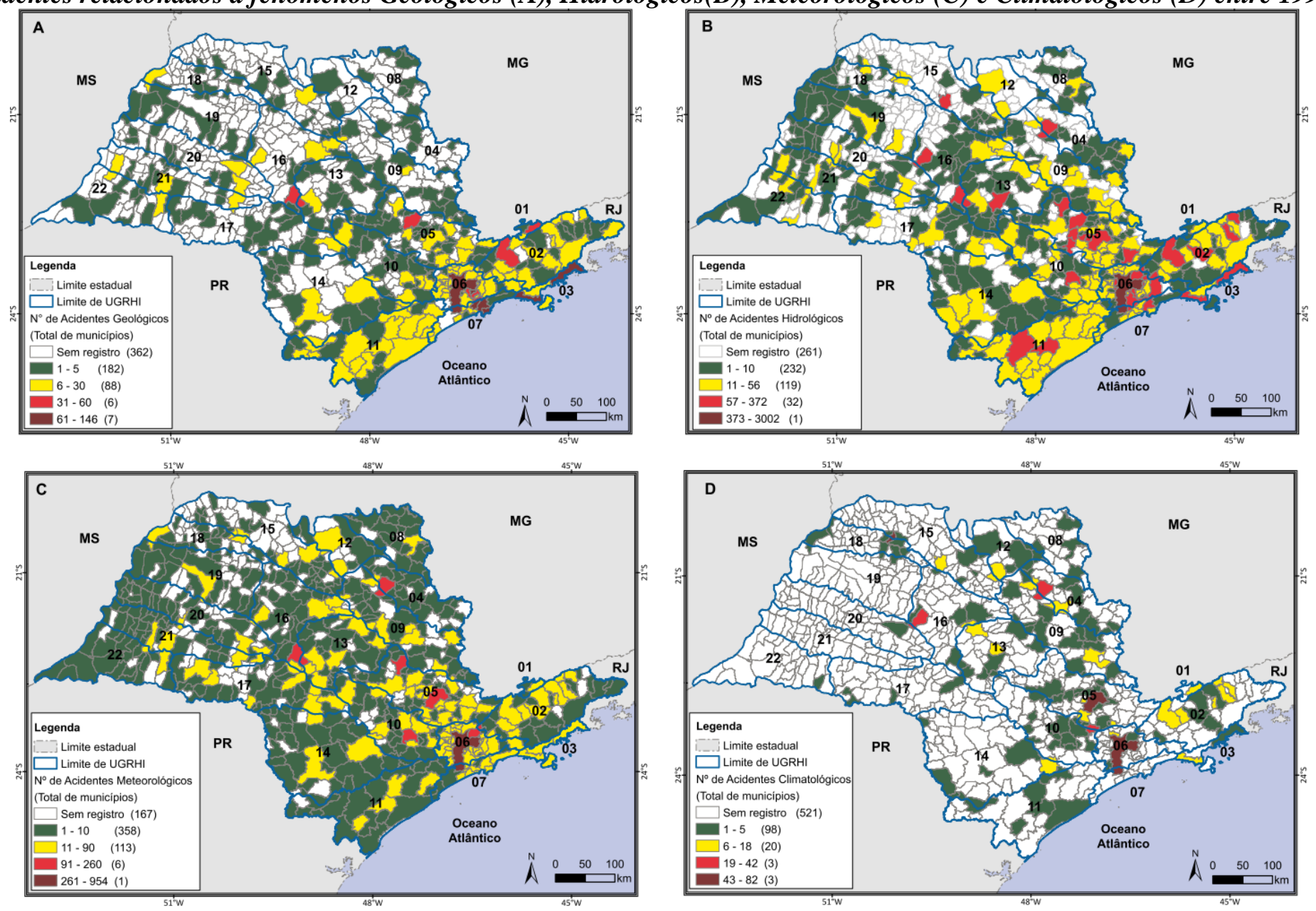

Fonte: SMA/IG (2017) - Apud. SÃO PAULO (ESTADO) (2018a) 
Os outros indicadores desta dimensão avaliam a existência de Planos Municipais de Redução e Riscos e de Cartas Geotécnicas de Aptidão à Urbanização, os quais são aplicados por $17,4 \%$ e $8,4 \%$ dos municípios paulistas, respectivamente. A Figura 25 (SÃO PAULO (ESTADO), 2018a) apresenta a quantificação e espacialização dos municípios com o mapeamento de risco realizado entre os anos de 2003 a 2016; municípios com Planos de Redução de Riscos (PMRR) elaborados de 2004 a 2016; municípios com Setorização de Ricos Alto e Muito Alto entre os anos de 2012 a 2016, instrumento que visa a elaboração de sistemas de alarme e alerta; e, municípios com Carta de Susceptibilidade de Escorregamento e Inundação elaborados até o ano de 2016.

Ainda que o levantamento elaborado pela da Secretaria de Meio Ambiente tenha sido realizado somente até o ano de 2016, observou-se uma diferença entre as informações dispostas neste relatório e os valores divulgados no documento Munic 2017 (IBGE, 2018a). O relatório de qualidade ambiental verificou a elaboração de 33 Planos Municipais de Redução de Riscos, enquanto, para o ano de 2017, o IBGE verificou a existência de 112 planos. Além disso, a SMA levantou a existência de 47 cartas de susceptibilidade de escorregamentos e inundação, enquanto o IBGE verificou a existência de 54 cartas geotécnicas de aptidão à urbanização, instrumentos cujas similaridades de conteúdo deveriam ser avaliadas. Estas diferenças podem ser explicadas tanto pelas diferenças de metodologia de levantamento das informações entre a SMA e o IBGE, como por um crescimento do interesse dos municípios em gerenciar estes riscos, sendo necessário aguardar a publicação do novo Relatório de Qualidade Ambiental da SMA para concluir esta análise. 
Figura 25 - Distribuição dos municípios com mapeamento de Áreas de Risco (A), Planos Municipais de Redução de Risco (B), Setorização de Ricos Alto e Muito Alto (c) e Carta de Susceptibilidade de Escorregamento e Inundação (D)
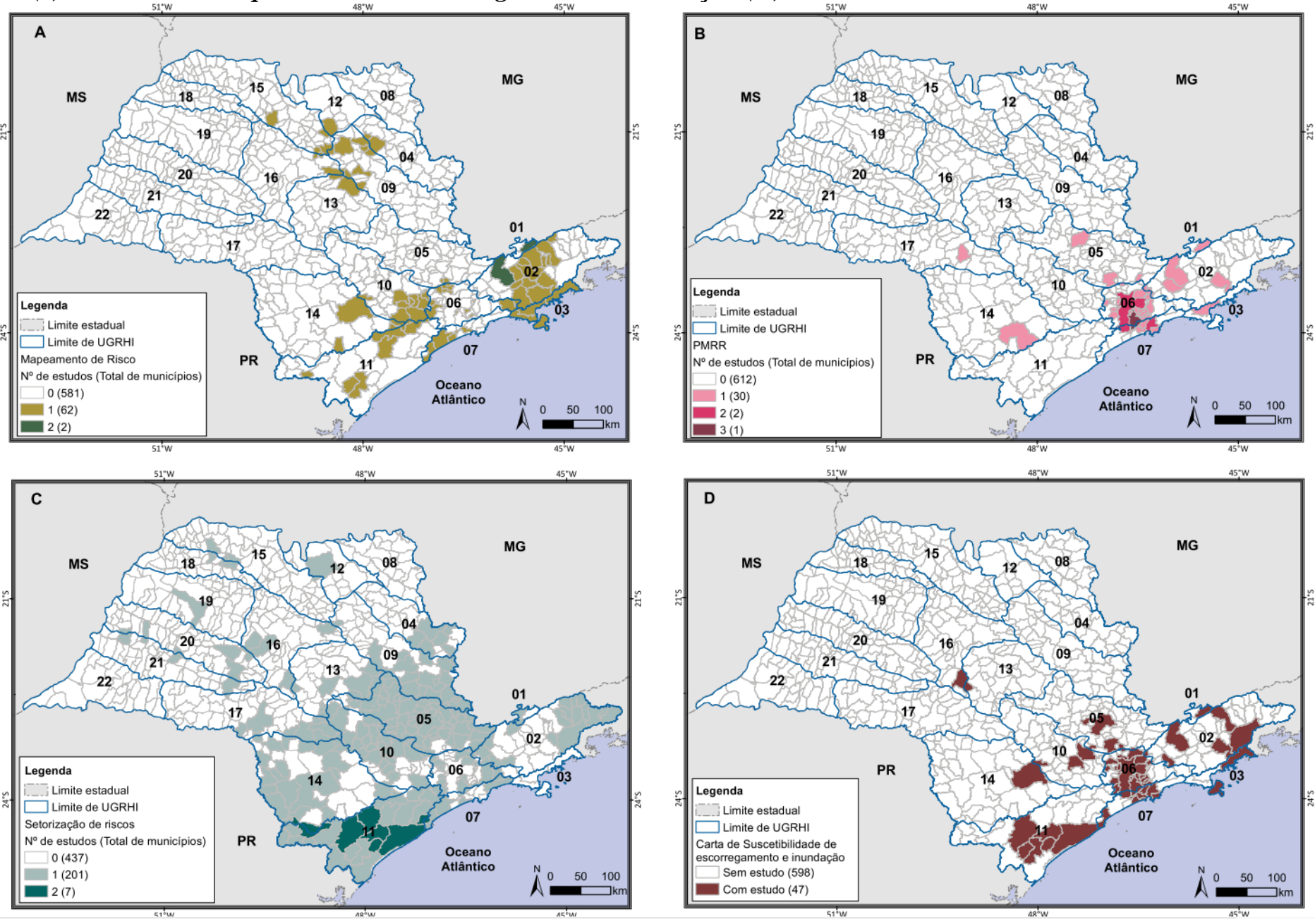

Fonte: Casa Militar/CEDEC (2016), Brollo e Ferreira (2016) e SMA/IG (2017) - Apud. SÃO PAULO (ESTADO) (2018a) 
A análise das diferentes dimensões e seus componentes permitiu a observação de que os indicadores relacionados à capacidade específica dos municípios em se adaptar aos efeitos das mudanças climáticas, em sua maioria abrangidos pela Dimensão de Resposta aos Impactos Climáticos, aparecem com menos frequência nas iniciativas das administrações municipais. Isso pode ser explicado em partes pelas correlações entre instrumentos relacionados com a capacidade genérica e outras necessidades locais, como a melhoria do transporte público e a questão habitacional. Mas também deve ser levado em consideração incipiência do tema da adaptação, o que dificulta o acesso dos gestores e técnicos municipais a informações que direcionem a sua atuação.

Observou-se uma maior concentração de municípios com melhores resultados para a dimensão de Resposta aos Impactos Climáticos próximo às regiões metropolitanas. A concentração populacional dessas áreas pode ser um dos fatores que influenciam esta situação, uma vez que na ocorrência de eventos climáticos extremos mais pessoas seriam atingidas, exigindo um maior planejamento dos gestores públicos para que catástrofes sejam evitadas. Além disso, a atuação de órgãos de controle e da imprensa sobre esses casos pode pressionar ainda mais os governos locais a se municiarem com a elaboração de instrumentos de planejamento e redução de riscos.

Ainda que priorização de quais ações os governos locais devem implantar dependa de suas características e demandas, recomenda-se que os instrumentos que visam uma resposta direta aos impactos climáticos estejam entre as prioridades da administração. Estes instrumentos permitem um melhor conhecimento das vulnerabilidades municipais e o planejamento da atuação frente a eventos extremos.

\subsection{UAI dos Municípios Paulistas}

Conforme pode ser observado na Tabela 4, a análise do UAI dos municípios paulistas demonstra que 65,9\% dos municípios estão localizados nas duas faixas inferiores do índice, sendo 127 municípios na faixa entre 0 e 0,2000 e 298 municípios na faixa entre 0,2001 e 0,400 . Na faixa intermediária, que compreende os municípios com UAI variando entre 0,4001 a 0,6000, existem 137 municípios, o equivalente a 21,2\% dos municípios paulistas. As duas faixas superiores do UAI foram compostas por 12,87\% dos municípios paulistas, sendo 73 municípios na faixa entre 0,6001 a 0,800 e somente 10 (dez) municípios receberam notas que variaram entre 0,8001 a 1 , o equivalente a $1,55 \%$ dos municípios paulistas.

Ainda que $66 \%$ dos municípios estejam enquadrados nas duas (02) faixas inferiores do UAI, em termos populacionais os resultados são diferentes, já que estes municípios abrigam somente $12,2 \%$ da população do estado. Dessa forma, é importante observar que, 
se por um lado a maioria dos municípios paulistas está localizado nas faixas mais baixas do UAI, a maioria da população do estado vive em municípios com melhores resultados.

Tabela 4 - Distribuição dos municípios paulistas por faixas do UAI

\begin{tabular}{|c|c|c|c|}
\hline Faixas UAI & $\begin{array}{c}\text { Número de } \\
\text { municípios }\end{array}$ & $\begin{array}{c}\text { Percentual de } \\
\text { municípios }\end{array}$ & $\begin{array}{c}\text { População } \\
\text { Estimada } \\
2017\end{array}$ \\
\hline $0,8001-1$ & 10 & $2 \%$ & 15.102 .971 \\
\hline $0,6001-0,8000$ & 73 & $11 \%$ & 14.463 .585 \\
\hline $0,4001-0,6000$ & 137 & $21 \%$ & 10.022 .295 \\
\hline $0,2001-0,4000$ & 298 & $46 \%$ & 4.327 .158 \\
\hline $0-0,2000$ & 127 & $20 \%$ & 1.178 .857 \\
\hline Total & $\mathbf{6 4 5}$ & $\mathbf{1 0 0 \%}$ & $\mathbf{4 5 . 0 9 4 . 8 6 6}$ \\
\hline
\end{tabular}

Fonte: Elaborado pelo autor

O único UAI igual a " 0 " (zero) foi o de Echaporã, um município localizado no centrooeste paulista, entre Marília e Assis, com população estimada de 6.141 habitantes (IBGE CIDADES, 2018). Dentre os indicadores avaliados, observou-se que o município não possui nenhum dos instrumentos das dimensões relacionadas às capacidades genéricas do município e não apresentou informações sobre os indicadores da dimensão Resposta aos Impactos Climáticos, demonstrando uma falta de controle das informações municipais ou um desconhecimento sobre o tema.

Nenhum município paulista atingiu a nota máxima do UAI. Os 10 (dez) municípios com as melhores pontuações foram Campinas, Botucatu, Cordeirópolis, Bauru, Santa Bárbara d'Oeste, Piracicaba, São José do Rio Preto, Caraguatatuba e Tatuí. As duas melhores pontuações foram de Campinas e Botucatu, com a nota 0,92, seguidos de Cordeirópolis com a nota 0,895 e Bauru com a pontuação 0,8300 , tendo como pior nota a dimensão Resposta aos Impactos Climáticos, uma vez que o município não conta com lei de uso e ocupação do solo que contemple a prevenção de escorregamentos e deslizamentos de encostas e nem com carta geotécnica de aptidão à urbanização.

Os resultados do Índice de Adaptação Urbana (UAI) relativo ao ano de 2017 podem ser observados na Figura 26 a seguir. 
Figura 26 - UAI Municípios Paulistas

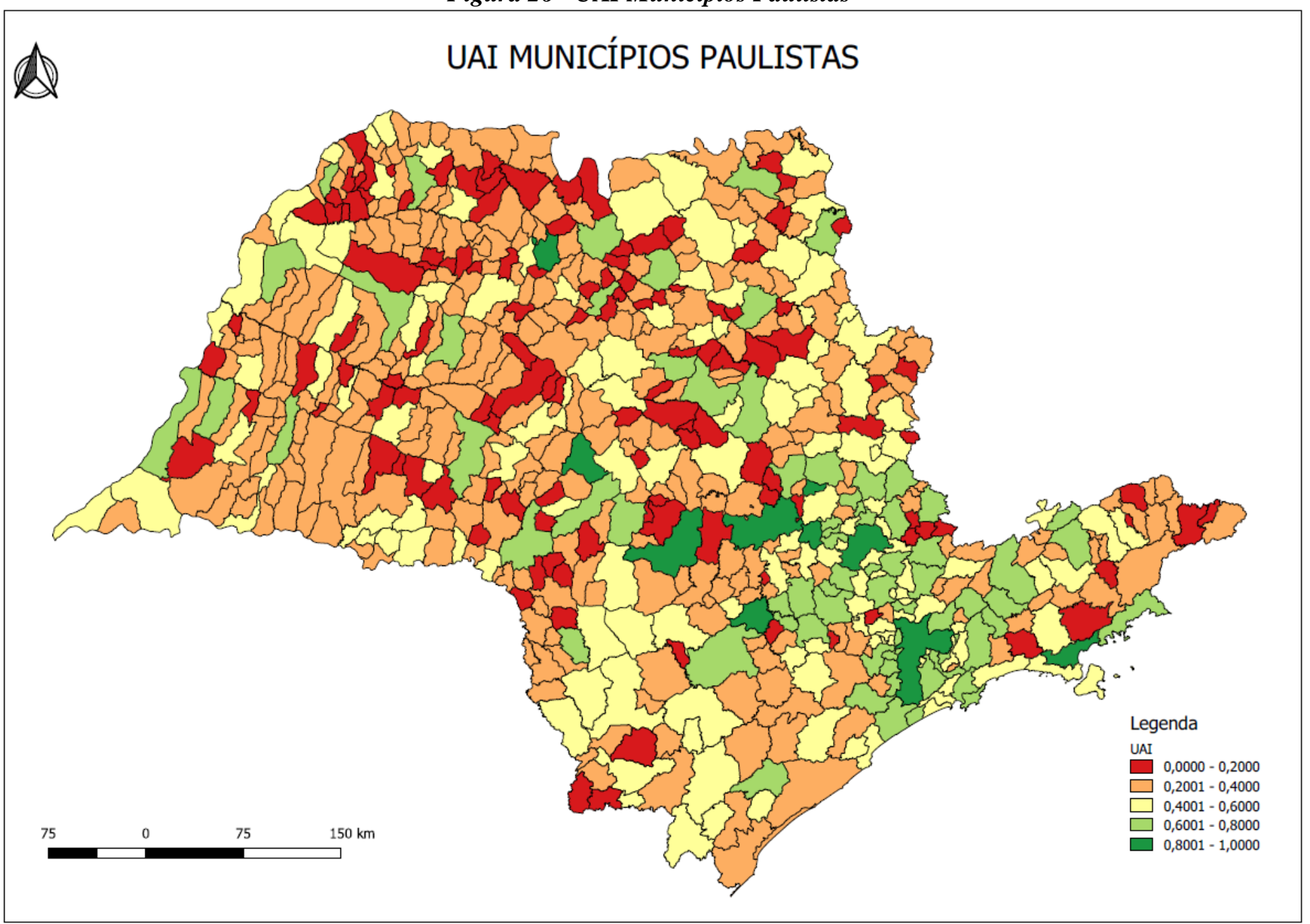

Fonte: Elaborado pelo autor 
A análise dos resultados do UAI para os municípios paulistas possibilitou a verificação de uma maior concentração de municípios com melhores pontuações do UAI nas Regiões Geográficas Intermediárias de Campinas e São Paulo, abrangendo as parcelas centrooeste e sudeste do Estado de São Paulo. Já os piores resultados se concentram nos setores Oeste e Noroeste do estado, principalmente nas Regiões Geográficas Intermediárias de Presidente Prudente, Araçatuba e São José do Rio Preto. As maiores disparidades foram verificadas nas regiões de Bauru, Sorocaba e São José dos Campos, com municípios abrangendo de forma mais homogênea faixas melhores e piores do UAI (IBGE- MALHA MUNICIPAL, 2015). A localização destas regiões pode ser observada na Figura 27, a seguir.

Figura 27 - Regiões Geográficas Intermediárias do Estado de São Paulo - IBGE

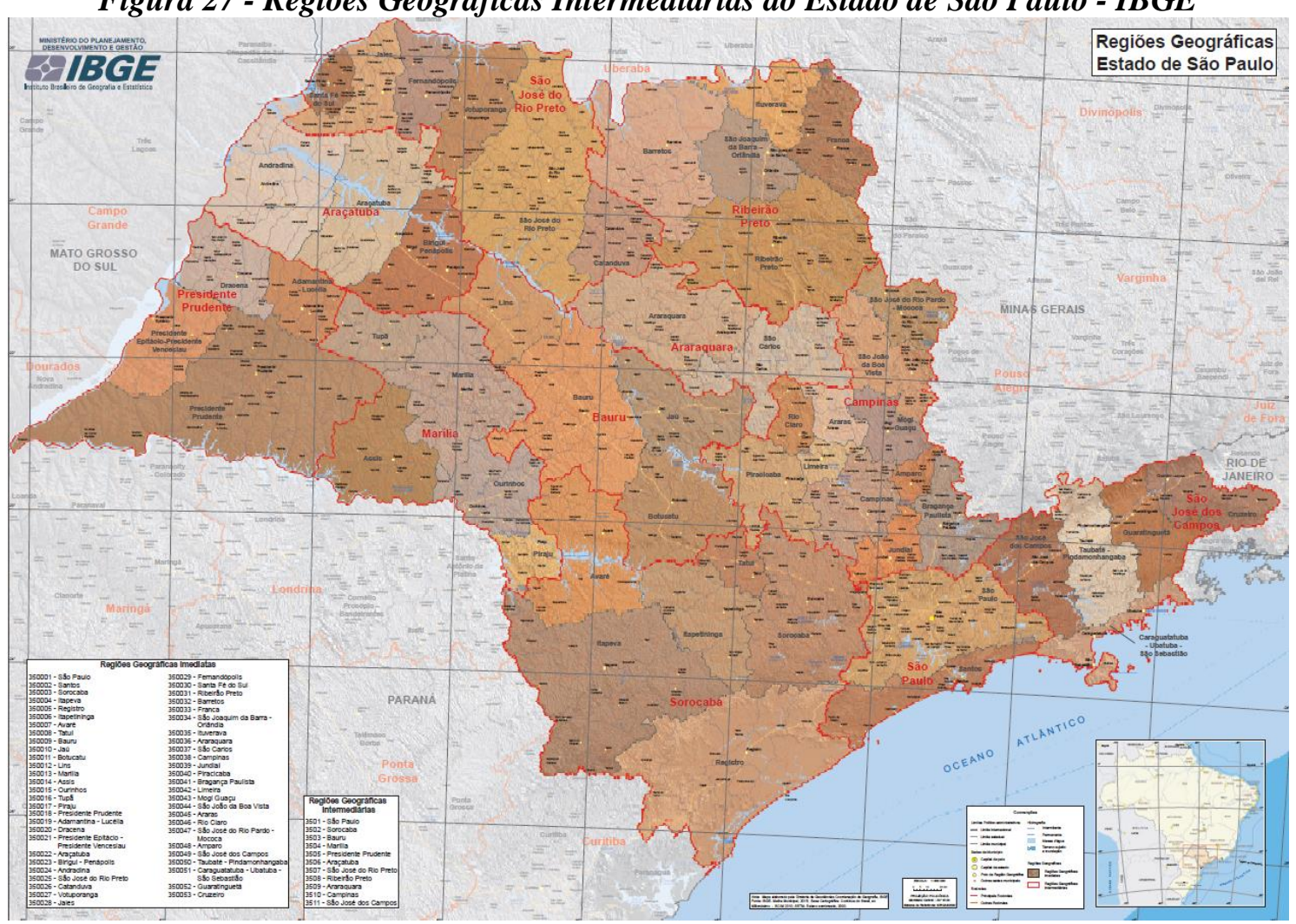

Fonte: (IBGE- MALHA MUNICIPAL, 2015)

De maneira geral, observou-se a correlação entre os melhores resultados do UAI com as regiões metropolitanas e aglomerações urbanas do Estado de São Paulo, em especial as inseridas na Macrometrópole Paulista (MMP). Estas regiões são regradas pelo Estatuto da Metrópole, sendo formadas por dois ou mais municípios que se complementam ou apresentam interações nas dinâmicas geográficas, ambientais, políticas e socioeconômicas (BRASIL, 2015). Algumas diretrizes e instrumentos previstos no Estatuto da Metrópole podem influenciar os municípios na elaboração de instrumentos considerados pelo UAI e, consequentemente, melhorar a sua colocação no Índice. 
A localização destas regiões metropolitanas e das aglomerações urbanas é apresentada na Figura 28, conforme dados obtidos no site da Empresa Paulista de Planejamento Metropolitano em 2018(EMPLASA, 2018a).

Figura 28 - Aglomerações Urbanas e Regiões Metropolitanas do Estado de São Paulo - 2018

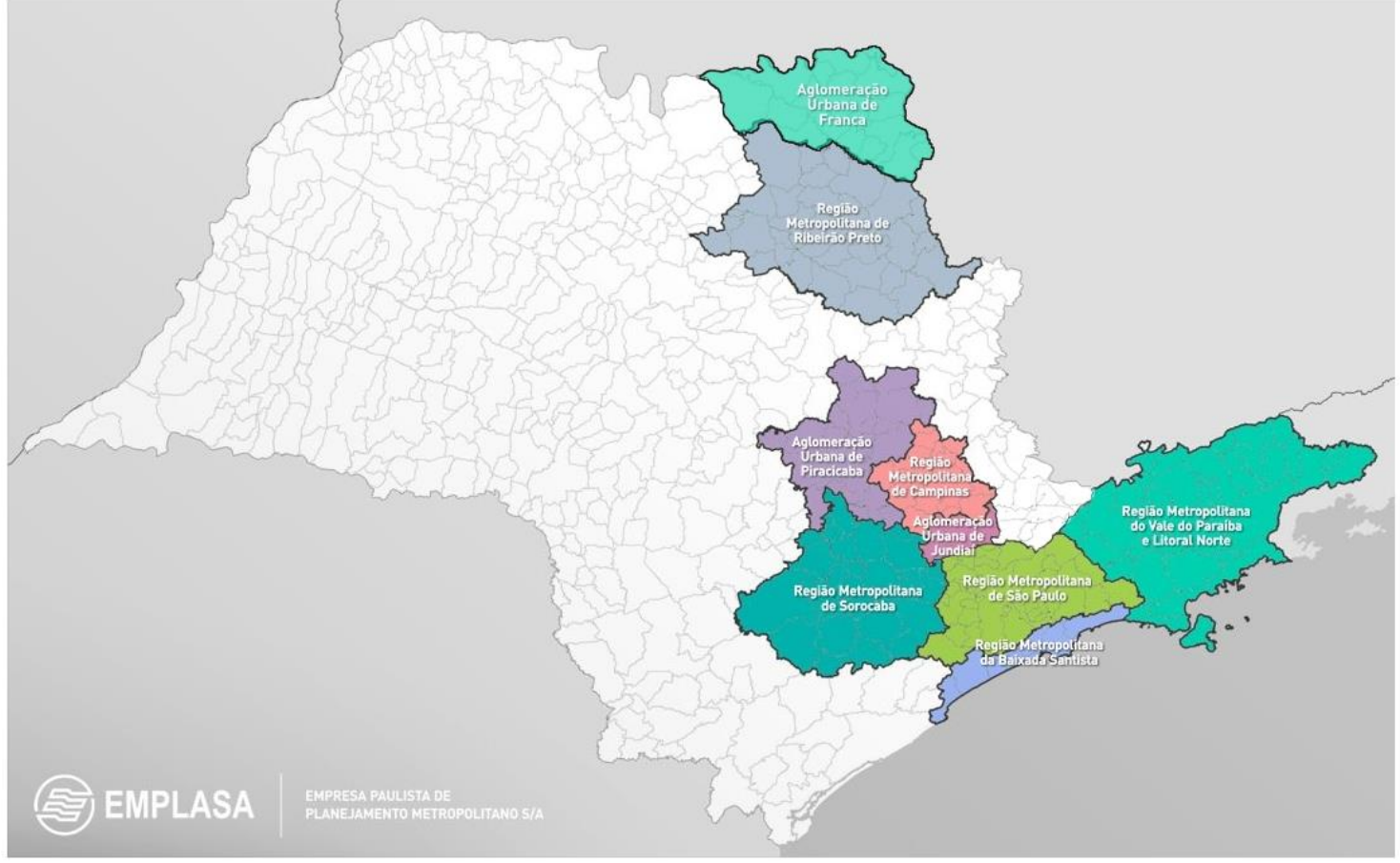

Fonte: (EMPLASA, 2018a)

Além de contar com uma governança interfederativa específica, responsável por planejar o conjunto de municípios buscando o desenvolvimento sustentável, estas unidades territoriais contam com alguns instrumentos de desenvolvimento urbano integrado que possuem correlações com alguns indicadores do UAI. Dentre estes instrumentos, ressaltase a criação de fundos públicos, a compensação por serviços ambientais prestados pelo município e a elaboração de planos de desenvolvimento urbanos integrados, os quais devem incluir a delimitação de áreas com restrição à urbanização, seja pela proteção dos patrimônios ambientais e culturais, ou pela presença de áreas sujeitas a controle especial pelo risco de desastres naturais (BRASIL, 2015).

Esta correlação foi avaliada para os vinte municípios da Região Metropolitana de Campinas, que conta com uma autarquia própria (AGEMCAMP - Agência Metropolitana de Campinas), onde $85 \%$ dos municípios possuem Fundos de Habitação (frente a um percentual de 34,3\% do estado) e o mesmo percentual possui Fundos de Meio Ambiente (existentes em 55,5\% dos municípios paulistas). Entretanto, somente 15\% dos municípios afirmaram possuir políticas de Pagamento por Serviços Ambientais, ainda acima dos 13,6\% quando analisado todos os municípios do estado, ou Cartas de Aptidão à Urbanização, presente em somente 8,7\% dos municípios paulistas. Dessa forma, verificase que, mesmo apresentando melhores resultados do que o conjunto dos municípios 
paulistas, temas mais incipientes como a aplicação do PSA e a elaboração de Cartas de Aptidão não foram priorizados pelos governos locais desta região.

Ao avaliar cada uma dessas áreas individualmente, verifica-se que a região metropolitana que apresentou os piores resultados foi a de Ribeirão Preto, em conjunto com a Aglomeração Urbana de Franca, onde poucos municípios foram enquadrados nas três faixas superiores do UAI. Dentre eles, somente os municípios de Ribeirão Preto e Patrocínio Paulista ficaram na segunda melhor faixa do índice, ambos com UAI 0,685. Por outro lado, nas Regiões Metropolitanas de São Paulo, Campinas e Baixada Santista e na Aglomeração Urbana de Jundiaí predominam municípios com o UAI acima de 0,5, apresentando uma média muito superior frente ao resto do estado. Já as Regiões Metropolitanas de Sorocaba e do Vale do Paraíba e Litoral Norte e a Aglomeração Urbana de Piracicaba apresentaram algumas sub-regiões com melhores pontuações, entretanto, outras localidades devem ter a sua gestão municipal aprimorada caso a governança metropolitana decida ampliar o potencial adaptativo destes locais.

Dessa forma, a Macrometrópole Paulista (MMP) concentrou os melhores resultados observado no Estado de São Paulo. A Macrometrópole é formada por 174 municípios e tem uma população de aproximadamente 30 milhões de habitantes, o equivalente a 74,4\% da população paulista. Este aglomerado urbano concentra 81,9\% do PIB brasileiro, entretanto, 2,68 milhões de pessoas vivem em assentamentos precários (EMPLASA, 2018b; TAVARES, 2018). A região abrangida pela MMP é apresentada na Figura 29 e os resultados do UAI para seus municípios na Figura 30.

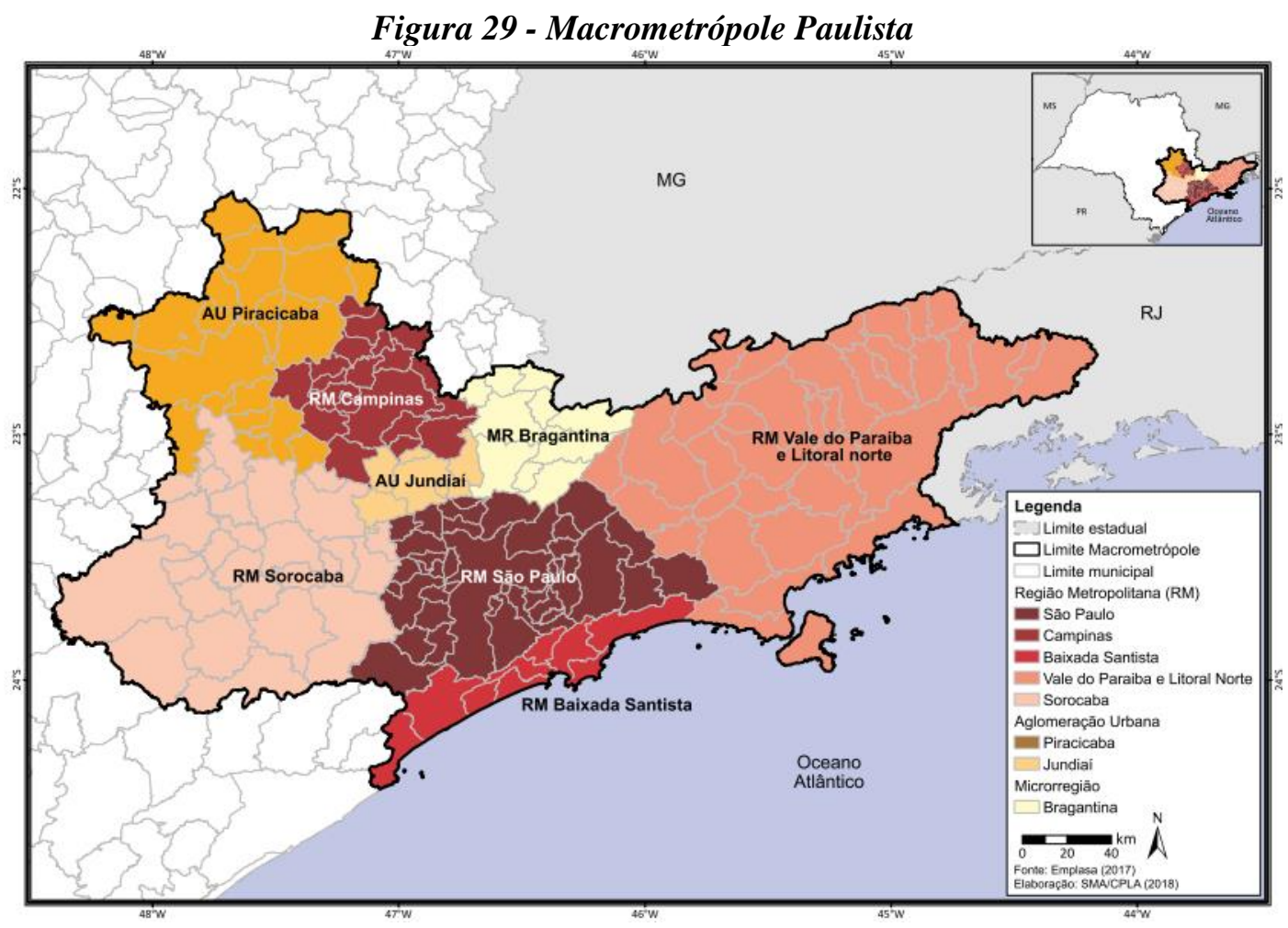

Fonte: (SÃO PAULO (ESTADO), 2018a) 


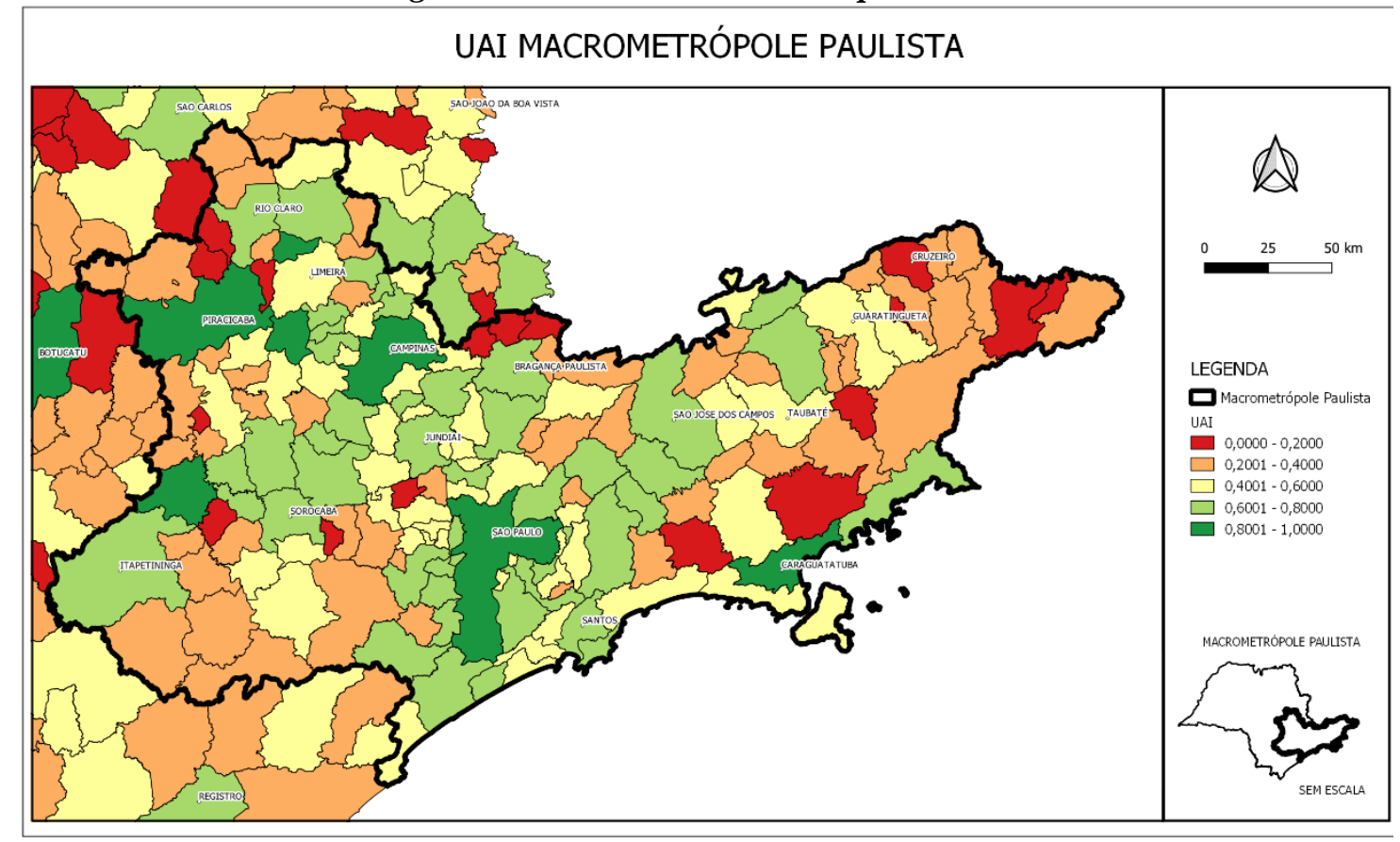

Fonte: Elaborado pelo autor

Chama atenção uma concentração de piores resultados do UAI nas bordas da Macrometrópole Paulista (MMP), especialmente em municípios da Região Metropolitana de Sorocaba e no Vale do Paraíba. Seguindo o padrão observado para todo o estado de São Paulo, observou-se uma correlação onde, quanto maior a riqueza municipal maior o UAI. O Nível de Riqueza dos municípios paulistas é parte do Índice Paulista de Responsabilidade Social (IPRS) e seus resultados para o ano de 2014 foram apresentado no RQA da CETESB em 2018 (SÃO PAULO (ESTADO), 2018a), conforme pode ser observado na Figura 31, a seguir. 


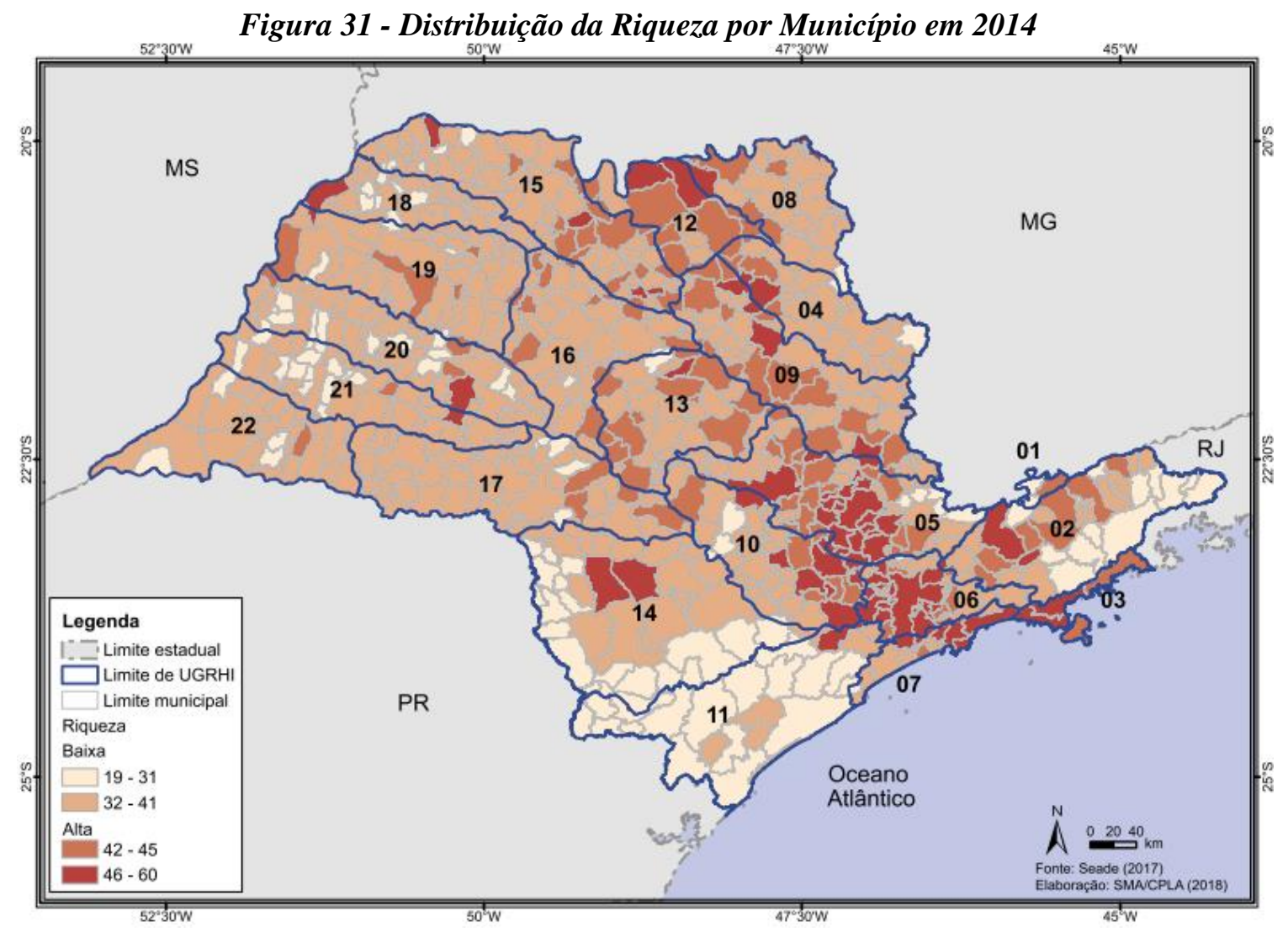

Fonte: Seade, 2017 - Apud (SÃO PAULO (ESTADO), 2018a)

A análise da correlação entre os UAI dos municípios com os Níveis de Riqueza dos municípios paulistas foi realizada utilizando o Coeficiente de Correção Linear de Pearson (r), que relaciona duas matrizes de valores retornando uma correlação entre eles (CORREA, 2003), através da ferramenta disponível Office Excel (CORREL) variando de 1 (total correlação positiva), passando por 0 (sem correlação), indo até -1 (correlação negativa). Segundo CORREA (2003), o resultado do Coeficiente de Correção Linear de Pearson " 0 " até " 0,3 " indica uma correlação fraca e difícil de estabelecer uma relação entre as variáveis; " 0,3 " a " 0,6 " uma correlação fraca, mas podendo ser considerada a existência de correlação entre as variáveis; e, de " 0,6 a " 1 " uma correlação média para forte, com uma relação significativa.

Para o estado de São Paulo esta correlação foi de 0,45 (45\%), ainda que considerada como uma correlação fraca, demonstra uma tendência do UAI ser maior para municípios mais ricos. O gráfico de dispersão a seguir (Gráfico 6) apresenta a pontuação de cada município em relação a sua riqueza, onde essa tendência pode ser melhor observada. 
Gráfico 6 - UAI x Riqueza Municipal

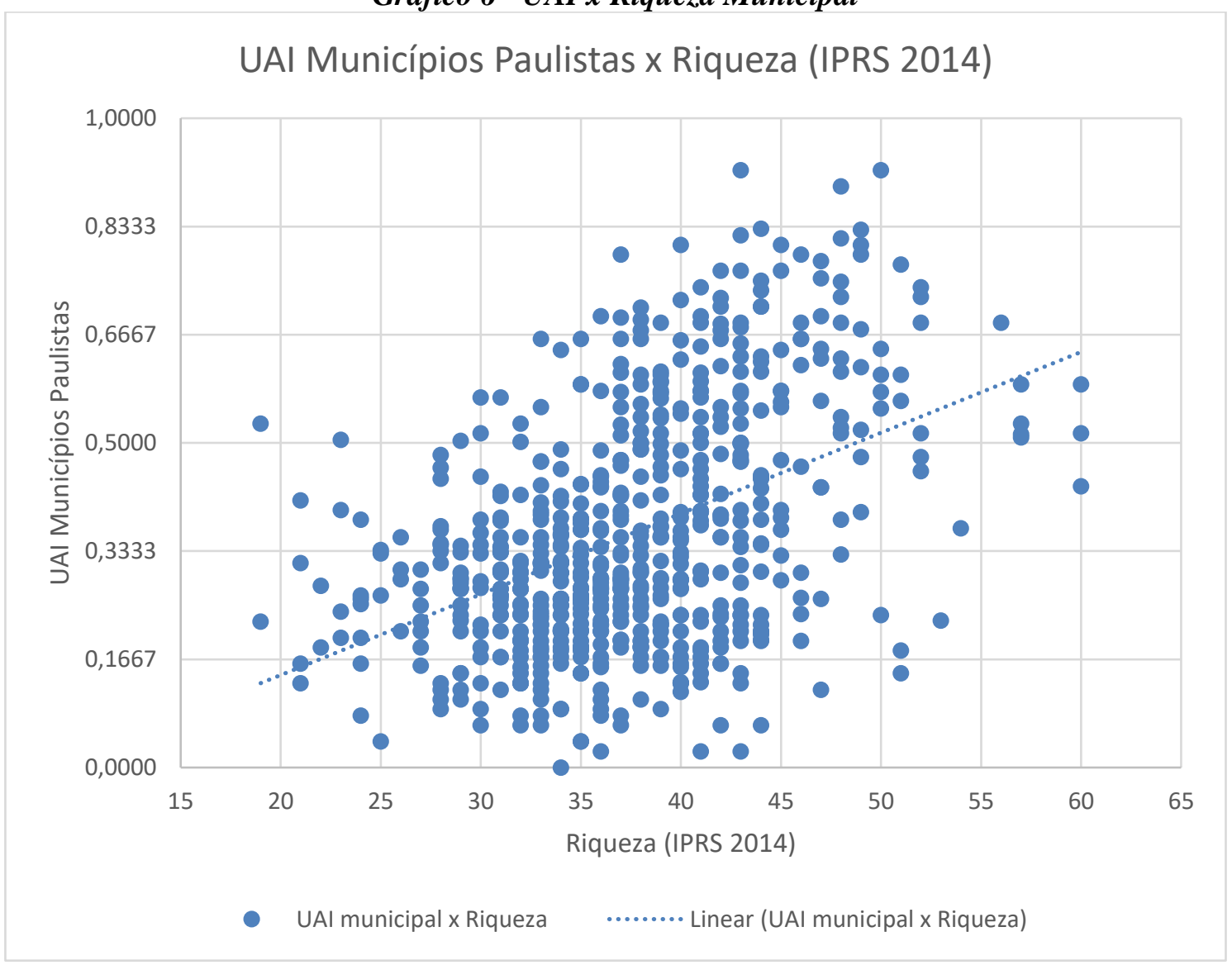

Fonte: Elaborado pelo Autor com IPRS, 2014 apud (SÃO PAULO (ESTADO), 2018a)

A Macrometrópole Paulista segue o mesmo padrão, uma vez que os municípios com os piores resultados do UAI também apresentaram níveis de riqueza mais baixo em relação aos demais.

Quando avaliada a correlação de cada dimensão do UAI com a Riqueza, observa-se que a dimensão de Agricultura Sustentável se relaciona de maneira diferente com esta temática, com $r=-0,09$, onde não seria possível verificar uma tendência de crescimento ou declínio do UAI conforme a riqueza.

É importante ressaltar que o Índice de Adaptação Urbana utiliza o mesmo conjunto de indicadores para tratar municípios com características sociais, ambientais e econômicas distintas. Se por um lado isso auxilia a comparação entre os municípios e o direcionamento de políticas públicas locais e regionais, o resultado do UAI para um município não significa, necessariamente, que os indicadores que ele possui estejam relacionados às suas prioridades.

Um município de pequeno porte, cuja locomoção é realizada majoritariamente a pé seria pouco beneficiado pela implantação de ônibus intramunicipais ou ainda pela implantação 
de ciclovias, ainda que a existência de ambos certamente seria benéfica para a população (win-win). Por outro lado, caso este município tenha a sua renda baseada na agricultura, a promoção dos instrumentos previstos para a dimensão de agricultura sustentável ou gestão ambiental certamente resultariam em benefícios maiores para a sua população.

Dessa forma, cabe à administração municipal avaliar as dimensões e indicadores mais adequados para o fornecimento de respostas aos impactos climáticos previstos ou aos quais o município já está submetido. Esta análise pode ainda subsidiar a transformação do município a uma situação mais desejada, preparando-o para os desafios futuros, seja durante a ampliação de sua área urbana, na alteração de sua atividade econômica principal ou em sua relação com os municípios do entorno. O mesmo vale para o direcionamento dos investimentos públicos pelos governos estaduais ou federal no âmbito de suas parcelas de responsabilidade conforme regrado pelo pacto federativo.

Outra análise realizada foi a correlação entre o UAI de cada município com o Índice de Desenvolvimento Humano Municipal (IDHM). A Correlação entre o UAI e o IDHM calculado para o ano de 2010 foi de $r=0,46(46 \%)$, pouco maior do que o observado com a riqueza. O Gráfico 7 apresenta o UAI de cada município em relação a seu IDMH.

Gráfico 7 - UAI x IDHM 2010

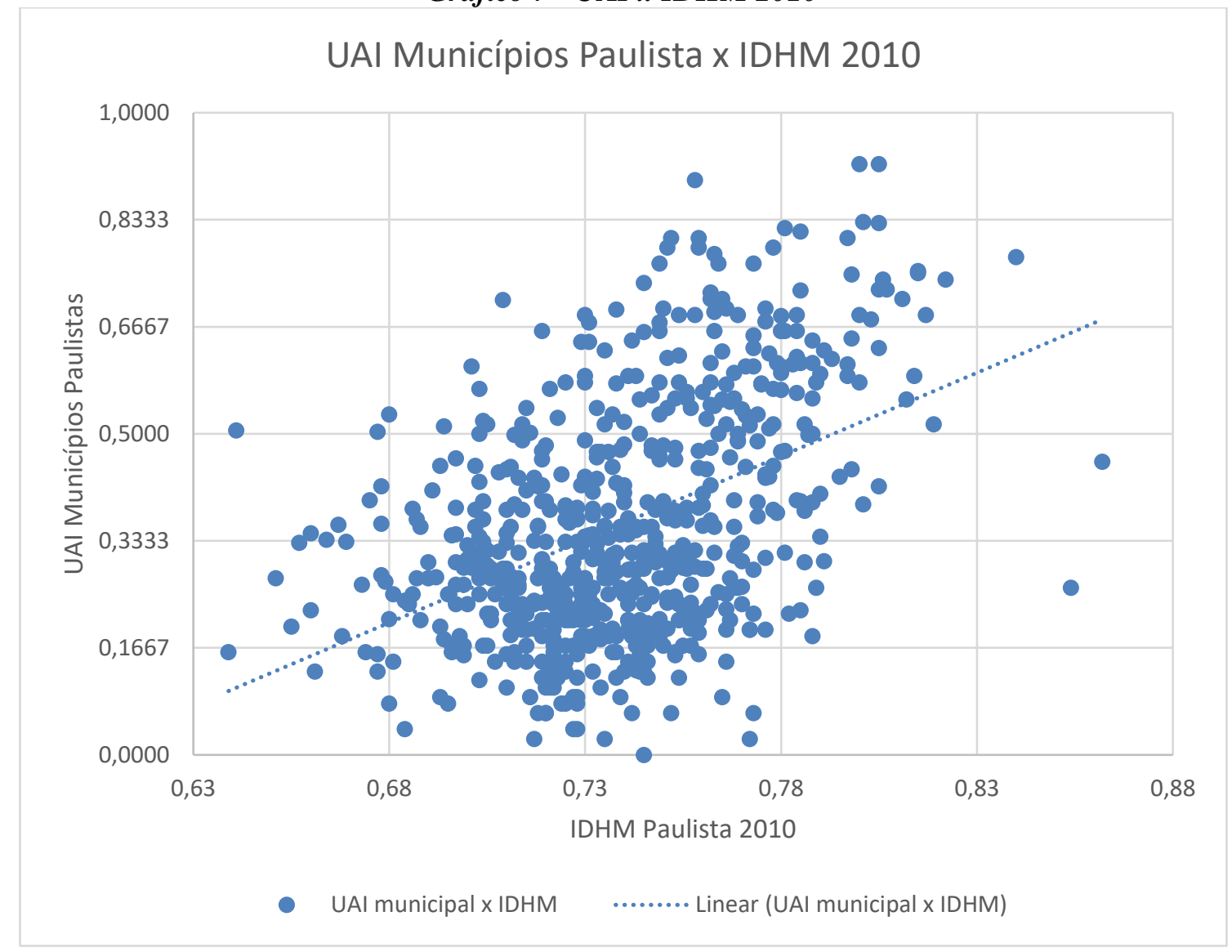

Fonte: Elaborado pelo Autor 
Quando esta correlação é avaliada com cada uma das dimensões do UAI, verifica-se que a dimensão de mobilidade urbana á a que apresenta a maior correlação com o IDHM $(0,477)$. Da mesma forma com o observado na correlação entre a Dimensão de Agricultura Sustentável com os índices de riqueza, esta dimensão se destoou das demais, apresentando uma distribuição quase que uniforme, não sendo possível verificar a sua variação conforme IDHM maiores ou menores, atingindo o índice de correlação de 0,002125 .

O processo de elaboração do ZEE do estado de São Paulo apresentou alguns elementos discutidos por EGLER et al. (2013) ao citar entre seus princípios norteadores a busca pelo fortalecimento da coesão territorial, o policentrismo e sustentabilidade no Estado de São Paulo. A coesão territorial visa reduzir as desigualdades regionais expressivas, o que pode ser obtido pela atuação conjunta e colaborativa de agentes em programas e projetos desenvolvidos em um determinado território. O policentrismo complementa o conceito de coesão territorial dada a influência que certos municípios polo podem exercer sobre o seu entorno. Dessa maneira, a policentralidade deve ser incentivada para que seja alterado o modelo de polarização de serviços especializados na Macrometrópole Paulista, contribuindo para a ampliação da coesão territorial do Estado(EGLER et al., 2013). Complementarmente, os autores e a proposta do ZEE afirmam a importância de que a questão da sustentabilidade seja considerada, o que deve ocorrer através da inserção da qualidade de vida como um item prioritário, compondo o eixo estrutural do processo de planejamento do território.

Os resultados do UAI refletem esta leitura do território ao apresentar uma grande polarização de melhores resultados na Macrometrópole Paulista. O fortalecimento de um policentrismo no Estado poderia influenciar em uma melhor distribuição dos resultados do UAI para outras regiões. Dessa forma, este trabalho pode fornecer importantes diretrizes para a definição de políticas públicas e investimentos prioritários a serem incentivados em cada uma das centralidades propostas pelo ZEE, ampliando assim a coesão territorial do Estado. Por fim, a relação do ZEE com questões que influenciarão a qualidade de vida da população paulista nas próximas décadas poderá fornecer os subsídios necessários para que o planejamento estadual seja pautado pela sustentabilidade. 


\section{CONCLUSÕES}

A redução da cobertura vegetal, os altos níveis de impermeabilização do solo e a ocupação de áreas com riscos de enchente e desbarrancamento ampliam a susceptibilidade das cidades e seus habitantes frente aos impactos das mudanças climáticas. A crescente concentração populacional nessas áreas, o estilo de vida de seus habitantes e as desigualdades sociais que marcam os grandes centros urbanos deixam esta situação ainda mais complexa. Além das cidades serem responsáveis por grande parte da ampliação das emissões de Gases de Efeito Estufa (GEE)(FONG et al., 2014; ROSENZWEIG et al., 2015), as características da ocupação do solo urbano brasileiro ampliam o número de impactados pelos efeitos das mudanças climáticas. Com isso, os governos locais passaram a ser cruciais tanto para o desenvolvimento de atividades que reduzam as emissões de GEE, como para a adoção de medidas que ampliem a capacidade de adaptação de seus habitantes, sendo necessário alterar profundamente o modo que as cidades são planejadas(ROSENZWEIG et al., 2015; CONINCK et al., 2018).

Entretanto, como as cidades são sistemas dinâmicos e com peculiaridades, não existem soluções simples a serem aplicadas. A primeira barreira a ser superada é a compreensão por parte dos gestores públicos de que a questão climática é importante e que ela deve permear todas as esferas do governo municipal, dado que as suas causas, impactos e soluções são multisetoriais. Em seguida é necessário capacitar o corpo técnico municipal para o desenvolvimento de políticas públicas que reduzam a vulnerabilidade local e definir fontes de financiamento para que os projetos e ações sejam efetivamente realizadas(IPCC, 2014; ROSENZWEIG et al., 2015). Municípios com menores índices populacionais ainda deverão superar desafios maiores, uma vez que a implementação da agenda climática acaba competindo com demandas sociais prioritárias, como saúde, segurança e educação (MARGULIS, 2017).

O Índice de Adaptação Urbana (UAI) tem como objetivo atuar nesses diferentes momentos e contextos, fornecendo as diretrizes para que os municípios disponham das ferramentas necessárias para a ampliação de sua capacidade adaptativa. Considerando o Modelo PEIR(PNUMA, 2002; PHILIPPI JR; MALHEIROS, 2012), o UAI é composto por indicadores de resposta que demonstram as ações realizadas pelos gestores municipais que fornecem as condições para que medidas de adaptação sejam aplicadas. Dessa forma, após calculado, o UAI fornece um diagnóstico da situação atual do município, apresentando, nas diferentes dimensões, os setores mais ou menos vulneráveis da gestão municipal aos impactos das mudanças climáticas.

Ao selecionar os principais instrumentos que devem ser elaborados no âmbito local, o UAI disponibiliza os subsídios necessários para que os governantes abordem a adaptação de forma transversal em suas políticas(UITTENBROEK et al., 2014). Além disso, este Índice auxilia o aprofundamento da ação municipal ao abranger tanto a capacidade 
específica, incentivando a elaboração de medidas focadas na atuação frente às alterações climáticas, como a capacidade genérica, enfrentando as causas sociais e ambientais das vulnerabilidades locais, elemento essencial para que as medidas de adaptação sejam eficazes(DI GIULIO et al., 2016).

Com a aplicação do UAI para todos os municípios paulistas foi possível observar o seu potencial para ser utilizado local ou regionalmente. Por tratar de municípios com características diferentes, o UAI não consegue apresentar a mesma representatividade a todos eles, mas pode auxiliar os gestores públicos na priorização de ações para um desenvolvimento local mais resiliente. Ainda que o simples aumento do UAI para um município já signifique que a administração está ampliando o seu potencial para lidar com riscos climáticos, a seleção dos instrumentos que serão objeto de atuação pelos tomadores de decisão deve ser realizada de acordo com as características sociais, ambientais e econômicas de cada local.

Para que a ampliação do potencial adaptativo de um município seja mais efetiva, os gestores devem direcionar a sua atuação para setores mais críticos, seja devido à importância daqueles temas para o dia a dia do município ou no intuito de se preparar para impactos previstos. Os governos podem ainda realizar atualizações periódicas em sua pontuação conforme os instrumentos vão sendo elaborados, promovendo a comparação com os seus resultados anteriores ou regionalmente com municípios que sirvam de inspiração.

A priorização de ações também deve ocorrer se o UAI for utilizado pelo governo do estado ou por um conjunto de municípios, onde poderão ser criadas políticas específicas frente às fragilidades ou potencialidades regionais. Além disso, o UAI pode ser utilizado para o desenvolvimento de políticas complementares em diferentes municípios de uma mesma região, o que pode ser realizado através de um planejamento regional estratégico, como é o caso do ZEE.

Os resultados da dimensão de Habitação seguiram o padrão espacial do UAI para os municípios do Estado de São Paulo ao concentrar os melhores resultados nas proximidades da Macrometrópole Paulista (MMP). Por outro lado, esta dimensão apresentou uma maior concentração de municípios que não contavam com nenhum dos instrumentos na parcela oeste do estado. A observação de que os melhores resultados coincidiram com municípios com maiores densidades demográficas indica a correlação de que, por possuírem maiores dificuldades para o gerenciamento da demanda habitacional, estes municípios priorizaram a aplicação desses instrumentos. Da mesma forma, uma menor densidade habitacional nas parcelas sul e oeste do estado poderia explicar a baixa presença desses instrumentos nas políticas municipais.

A distribuição dos resultados da dimensão de Mobilidade Urbana também foi semelhante ao UAI dos municípios paulistas. Observou-se uma maior concentração dos instrumentos 
avaliados nas regiões metropolitanas, sugerindo uma relação entre as altas demandas de transporte com a elaboração de planos de mobilidade e a disponibilização de opções alternativas de transporte, seja por transporte coletivo inter ou intramunicipal ou por bicicleta.

A dimensão de Agricultura Sustentável apresentou uma distribuição mais uniforme de resultados altos e baixos por todo o estado. Diferentemente do padrão observado no UAI e nas demais dimensões, não foi observada uma concentração expressiva de bons resultados na MMP. A concentração de estabelecimentos agropecuários na parcela sul do território paulista influenciou os resultados desta dimensão, região que aglutinou os melhores resultados relacionados à agricultura sustentável.

Ainda que a parcela sul do estado tenha uma maior relação com o meio ambiente, ao concentrar grande parte dos remanescentes de vegetação nativa do estado e pela presença de um grande número de estabelecimentos agropecuários, cujo sustento depende dos serviços ambientais prestados pela natureza, esta foi a área que reuniu os piores resultados para a dimensão de gestão ambiental. Isso demonstra a fragilidade das políticas municipais e estaduais de gestão ambiental em fornecer os subsídios necessários para que as medidas de preservação ambiental nestas áreas possam coexistir com a produção agrícola, principalmente com a criação de incentivos como é o caso das políticas de PSA.

De maneira geral, os resultados dos municípios paulistas para a dimensão de Gestão Ambiental foram baixos, sendo que somente 07 (sete) municípios possuíam todos os instrumentos. Ainda que os municípios inseridos na MMP tenham concentrado bons resultados, a distribuição das pontuações boas e ruins dessa dimensão ocorreu de maneira mais homogênea pelo estado, não apresentando uma correlação direta com áreas mais habitadas.

Os piores resultados observados nas dimensões de agricultura sustentável e de gestão ambiental foram para os dois instrumentos relacionados à capacidade específica dos municípios em se adaptar. Conforme apresentado anteriormente, estas ações exigem um comprometimento direto dos gestores municipais, o que ainda é pouco observado na realidade brasileira. Seguindo este mesmo padrão, a dimensão de Resposta aos Impactos Climáticos, que é composta somente por indicadores relacionados à capacidade específica, apresentou os piores resultados quando comparada com as demais dimensões. Aproximadamente $70 \%$ dos municípios paulistas possuía um ou nenhum dos instrumentos consultados. Dessa forma, para além da indicação de que os municípios priorizem a sua atuação nas dimensões a que são mais sensíveis, recomenda-se que todos os municípios busquem implantar os instrumentos desta dimensão, os quais apresentam um potencial de resposta mais direto aos impactos previstos

A dimensão de Resposta aos Impactos Climáticos, também apresentou uma maior concentração de melhores resultados na MMP, o que se repetiu em praticamente todas as 
regiões metropolitanas ou aglomerações urbanas. Os instrumentos de gestão territorial que estes municípios dispõem, suas características de uso do solo que ampliam a dimensão das tragédias relacionadas a eventos climáticos e a pressão da sociedade e órgão de controle para a redução desses eventos podem explicar essa concentração. Mesmo assim, muitos municípios dessas regiões ainda apresentaram resultados ruins, em especial os localizados no Vale do Paraíba, os quais deverão priorizar a implantação desses instrumentos devido aos riscos causados por suas elevadas densidades populacionais ou localização em regiões costeiras.

Os resultados do UAI dos municípios paulistas para o ano de 2017 revelou que apenas 10 (dez) municípios foram incluídos na faixa mais alta de pontuação, sendo eles Campinas, Botucatu, Cordeirópolis, Bauru, Santa Bárbara d'Oeste, Piracicaba, São José do Rio Preto, Caraguatatuba e Tatuí, entretanto, nenhum deles atingiu a pontuação máxima.

Mesmo que $66 \%$ dos municípios tenham sido enquadrados nas duas faixas inferiores do UAI, estes municípios abrigam somente $12,2 \%$ da população do estado de São Paulo. Esta situação corrobora com a conclusão de que os melhores resultados do UAI se concentraram nas regiões metropolitanas, em especial na abrangência da Macrometrópole Paulista, o que estes resultados podem ter sido influenciado pelas regras específicas de gestão definidas pelo Estatuto da Metrópole (BRASIL, 2015). Outra correlação que explica estes resultados, inclusive dentro da própria MMP, é a concentração de riqueza de cada município, dada a tendência dos municípios com maiores índices de riqueza apresentarem também maiores pontuações no UAI.

Os resultados do UAI refletiram a baixa coesão territorial do estado, uma vez que apresentaram correlações diretas com os índices de desenvolvimento econômico dos municípios paulistas. A busca que será realizada pelo Governo do Estado para ampliar esta coesão territorial e promover o policentrismo durante a elaboração do Zoneamento Ecológico Econômico(EGLER et al., 2013) poderá alterar este cenário, resultando na ampliação do potencial de adaptação de municípios que não estão inseridos em regiões metropolitanas ou aglomerações urbanas. Além disso, como a proposta do ZEE procura inserir a sustentabilidade como eixo estruturante do planejamento estadual, o diagnóstico apresentado pela aplicação do UAI aos municípios paulistas poderá auxiliar na criação de um instrumento de planejamento que reduza as vulnerabilidades socioambientais da população e amplie a capacidade de adaptação do estado aos efeitos das mudanças climáticas.

É importante ressaltar que a pontuação atribuída aos municípios que possuem os instrumentos consultados não significa que estes foram bem elaborados ou que seus objetivos incluem de maneira satisfatória a questão climática. A proposta do UAI parte do pressuposto que a existência desses instrumentos aumenta o potencial adaptativo municipal por viabilizar uma ferramenta a ser aplicada, mas, entende que o município só 
estará mais adaptado se e quando estes instrumentos incluírem diretrizes para a redução das vulnerabilidades locais.

A utilização de uma base com informações oficiais levantadas pelo IBGE permitiu a aplicação do UAI a todos dos municípios paulistas. Uma vez que o IBGE disponibilizou estas informações para a totalidade do país, e as atualizará periodicamente, o UAI poderá ser calculado para qualquer nível de organização da federação, podendo servir de subsídio para a elaboração de diferentes políticas públicas que ampliem o potencial de adaptação dos municípios brasileiros.

Ainda que esta dissertação tenha como foco a atuação dos governos locais, de acordo com a Política Nacional de Mudanças Climáticas(BRASIL, 2008) e o Artigo $225^{\circ}$ da Constituição Federal(BRASIL, 1988), a preservação do meio ambiente para as presentes e futuras gerações é dever de todos, cabendo à academia, setores públicos, produtivos e à sociedade civil organizada a adoção de medidas que ampliem a capacidade adaptativa dos diferentes sistemas aos efeitos das mudanças climáticas(BAZAZ et al., 2018).

Considera-se que esta dissertação atendeu plenamente os objetivos sendo possível avaliar o potencial adaptativo dos municípios paulistas aos efeitos das mudanças climáticas, levando em conta a existência ou não de instrumentos e políticas públicas municipais que podem ser utilizadas como ferramentas para a ampliação da capacidade adaptativa local.

Como produto final, os resultados do UAI para os municípios paulistas são apresentados no Anexo 9.1, que, em conjunto com os mapas exibidos, poderão ser utilizados por governos locais e regionais durante a elaboração de políticas públicas. 


\section{CONSIDERAÇÕES GERAIS}

O Índice de Adaptação Urbana foi elaborado inicialmente no âmbito do projeto CiAdapta para ser aplicado para seis cidades brasileiras. A aplicação deste índice para os municípios paulistas demonstra o potencial de replicação do instrumento a localidades de características distintas. Dessa forma, entende-se que outros Estados poderão fazer uso deste instrumento no desenvolvimento de políticas públicas que visem a ampliação do potencial adaptativo de seus municípios.

Ainda que os impactos das mudanças climáticas, e suas soluções, ultrapassem os limites administrativos municipais, o modelo atual de desenvolvimento urbano ainda trata o território de maneira segregada. Até o ano de 2021 as regiões metropolitanas e as aglomerações urbanas deverão elaborar os seus Planos de Desenvolvimento Urbano Integrado, instrumentos que definem as diretrizes para o desenvolvimento regional e metropolitano. Estes planos também poderão utilizar os resultados do UAI como uma ferramenta de planejamento, auxiliando na definição de diretrizes e metas regionais.

Uma fragilidade que pôde ser observada na aplicação do Índice foi a questão dos pesos iguais para dimensões com número diferente de indicadores, em especial as dimensões de habitação, que conta com apenas 3 (três) indicadores, e a de gestão ambiental, que conta com 8 (oito) indicadores. Embora existam diferenças na complexidade para a implantação de cada um dos instrumentos, um município que busque somente a ampliação do seu UAI poderá decidir priorizar instrumentos de dimensões com menos indicadores. Ainda que, dificilmente um município investiria recursos e esforços para a implantação de instrumentos que não se justifique para a realidade local, um possível aprimoramento do UAI poderia levar em consideração a definição de pesos distintos entre as dimensões ou o ajuste no número de indicadores para que a sua quantidade por dimensão fosse igualada.

Além disso, pesquisas futuras poderão ser realizadas para avaliar possíveis variações do UAI conforme o tamanho da população, distribuição demográfica, uso do solo e outras características dos municípios. Uma opção aventada para isso é definição de pesos para cada uma das dimensões em grupos específicos de municípios, onde a participação dos indicadores mais importantes para cada uma das regiões seria incentivada, resultando em uma aplicação amplie mais significativamente o potencial daqueles municípios em se adaptar às mudanças climáticas. Para tal, poderia ser aprofundada a análise da correlação dos resultados com outros indicadores municipais através da clusterização (clusters), método de combinações dos resultados e características locais que poderia demonstrar particularidades do UAI e suas dimensões por regiões. 


\section{REFERÊNCIAS BIBLIOGRÁFICAS}

ALLEN, M.; PAULINE DUBE, O.; SOLECKI, WILLIAM; et al. Chapter 1 - Framing and Context - In: Global warming of $1.5^{\circ} \mathrm{C} .2018$.

AMANN, M.; ARNELL, N.; AYEB-KARLSSON, S.; et al. The 2018 report of the Countdown on health and The report of the Lancet climate shaping health of nations for centuries to come - Review. The lancet, p. 36, 2018. Disponível em: <www.thelancet.com>. .

AMBRIZZI, T.; ARAUJO, M. Base científica das mudanças climáticas. Contribuição do Grupo de Trabalho 1 do Painel Brasileiro de Mudanças Climáticas ao Primeiro Relatório da Avaliação Nacional sobre Mudanças Climáticas. Rio de Janeiro, 2014.

ANDRADE, H. V. DE. Mapeamento das Políticas Estaduais de Adaptação das Cidades às Mudanças Climáticas no Brasil. Revista geográfica acadêmica., v. 11, n. 2, p. 24-49, 2017.

ANDRADE, L. M. S. DE A.; BLUMENSCHEIN, R. N. Cidades sensíveis à água: cidades verdes ou cidades compactas, eis a questão? Água \& Sociedade - Paranoá, v. 10, p. 5976, 2013.

ASSAD, E. D.; MAGALHÃES, A. R. Impactos, vulnerabilidades e adaptação às mudanças climáticas. Contribuição do Grupo de Trabalho 2 do Painel Brasileiro de Mudanças Climáticas ao Primeiro Relatório da Avaliação Nacional sobre Mudanças Climáticas. Rio de Janeiro, 2014.

BAZAZ, A.; BERTOLDI, P.; BUCKERIDGE, M.; et al. SUMMARY FOR URBAN POLICYMAKERS - wHAT THE IPCC SPECIAL REPORT ON GLOBAL WARMING OF $1.5^{\circ} \mathrm{C}$ MEANS FOR CITIES URBAN POLICY MAKERS. , 2018. Disponível em: <http://doi.org/10.24943/SCPM.2018>. Acesso em: 20/12/2018.

BRASIL-INDC. PRETENDIDA CONTRIBUIÇÃO NACIONALMENTE DETERMINADA PARA CONSECUÇÃO DO OBJETIVO DA CONVENÇÃOQUADRO DAS NAÇÕES UNIDAS SOBRE MUDANÇA DO CLIMA. Brasilia, 2016.

BRASIL. Constituição da Republica Federativa do Brasil. , 1988. Disponível em: <http://www.planalto.gov.br/ccivil_03/Constituicao/Constituicao.htm\#art183>. Acesso em: 24/2/2018.

BRASIL. Estatuto da Cidade. - Regulamenta os arts. 182 e 183 da Constituição Federal, estabelece diretrizes gerais da política urbana e dá outras providências., 2001. Brasil. Disponível em: <http://www.planalto.gov.br/ccivil_03/leis/leis_2001/110257.htm>. Acesso em: 24/2/2018.

BRASIL. Sistema Nacional de Habitação de Interesse Social - SNHIS. LEI No 11.124, DE 16 DE JUNHO DE 2005, 2005. Disponível em: $<$ http://solucoesparacidades.com.br/wpcontent/uploads/2012/08/lei_11124_habitacao_SNHIS_interesse-social.pdf >. Acesso em: $12 / 12 / 2018$.

BRASIL. DECRETO Nº 6.101, DE 26 DE ABRIL DE 2007 - (Revogado pelo Decreto 
$\mathrm{n}^{\mathrm{o}}$ 8.975, de 24/1/2017, em vigor após 21/2/2017). , 2007a. Disponível em: <http://www2.camara.leg.br/legin/fed/decret/2007/decreto-6101-26-abril-2007-553514normaatualizada-pe.html>. Acesso em: 5/2/2019.

BRASIL. DECRETO No 6.263, DE 21 DE NOVEMBRO DE 2007. , 2007b. Disponível em: <http://www.planalto.gov.br/ccivil_03/_Ato2007-2010/2007/Decreto/D6263.htm>. Acesso em: 5/2/2019.

BRASIL. PLANO NACIONAL SOBRE MUDANÇA DO CLIMA - PNMC - BRASIL Plano Nacional sobre Mudança do Clima PLANO NACIONAL SOBRE MUDANÇA DO CLIMA. COMITÊ INTERMINISTERIAL SOBRE MUDANÇA DO CLIMA, $2008 . \quad$ Disponível em: <http://www.mma.gov.br/estruturas/smcq_climaticas/_arquivos/plano_nacional_mudan ca_clima.pdf $>$. Acesso em: 21/2/2018.

BRASIL. LEI N ${ }^{0}$ 12.187, DE 29 DE DEZEMBRO DE 2009. , 2009. Disponível em: <http://www.planalto.gov.br/ccivil_03/_Ato2007-2010/2009/Lei/L12187.htm\#art12>.

Acesso em: 12/1/2019.

BRASIL. LEI N ${ }^{\circ}$ 12.340, DE $1^{\circ}$ DE DEZEMBRO DE 2010. , 2010. Disponível em: <http://www.planalto.gov.br/ccivil_03/_Ato2007-2010/2010/Lei/L12340.htm>. Acesso em: $11 / 11 / 2018$.

BRASIL. LEI N ${ }^{0}$ 12.608, DE 10 DE ABRIL DE 2012 - Institui a Política Nacional de Proteção e Defesa Civil. , 2012a. Disponível em: <http://www.planalto.gov.br/ccivil_03/_Ato2011-2014/2012/Lei/L12608.htm>. Acesso em: $10 / 11 / 2018$.

BRASIL. Política Nacional de Mobilidade Urbana. , 2012b. Disponível em: <http://www.planalto.gov.br/ccivil_03/_ato2011-2014/2012/lei/112587.htm>. Acesso em: $12 / 11 / 2018$.

BRASIL. Plano Setorial da Saúde para Mitigação e Adaptação à Mudança do Clima. Brasilia, 2013.

BRASIL. Estatuto da Metrópole. , 2015. Disponível em: <http://www.planalto.gov.br/ccivil_03/_ato2015-2018/2015/lei/113089.htm>. Acesso em: $12 / 8 / 2018$.

BRASIL. Plano Nacional de Adaptação à Mudança do Clima: $1^{\circ}$ relatório de monitoramento e avaliação 2016 - 2017. Brasilia, 2017.

BRASIL. DECRETO Nº 9.578, DE 22 DE NOVEMBRO DE 2018. , 2018. Disponível em:

<http://www.planalto.gov.br/ccivil_03/_Ato20152018/2018/Decreto/D9578.htm\#art25>. Acesso em: 12/1/2019.

BRASIL - MMA. Plano Nacional de Adaptação à Mudança do Clima. Volume 1 Estratégia Geral. , 2016a. Brasil. Disponível em: <http://www.mma.gov.br/images/arquivo/80182/PNA_Volume I.pdf>. Acesso em: 21/2/2018.

BRASIL - MMA. Plano Nacional de Adaptação à Mudança do Clima. - Estratégia de Cidades. , 2016b. Brasil.

CARVALHO, J. DE L.; PICARELLI, S. B. N.; CARBONE, A. S.; COUTINHO, S. M. V.; SINISGALli, P. A. DE A. ADAPTAÇÃO BASEADA EM ECOSSISTEMAS 
Oportunidades para políticas públicas em mudanças climáticas. Curitiba, 2014.

CEMADEN. Histórico da criação do Cemaden - Cemaden. Disponível em: $<$ https://www.cemaden.gov.br/historico-da-criacao-do-cemaden/>. Acesso em: 7/2/2019.

CHU, E.; ANGUELOVSKI, I.; ROBERTS, D. Climate adaptation as strategic urbanism: assessing opportunities and uncertainties for equity and inclusive development in cities. Cities, v. 60, p. 378-387, 2017. Elsevier Ltd. Disponível em: <http://dx.doi.org/10.1016/j.cities.2016.10.016>. .

CONINCK, H.; REVI, A.; BABIKER, M.; et al. Chapter 4 - Strengthening and implementing the global response. In: Global warming of $\mathbf{1 . 5}^{\circ} \mathbf{C} .2018$.

CORREA, S. M. B. B. Probabilidade e Estatística. 2nd ed. Belo Horizonte: PUC Minas Virtual, 2003.

CRESWELL, J. W. CRESWELL - Projeto de pesquisa métodos qualitativo, quantitativo. segunda ed ed. Porto Alegre: Artmed, 2007.

DENTON, F.; WILBANKS, T. J.; ABEYSINGHE, A. C.; et al. Climate-resilient pathways: adaptation, mitigation, and sustainable development. Cambridge and New York, 2014.

DHAR, T. K.; KHIRFAN, L. Climate change adaptation in the urban planning and design research: missing links and research agenda. Journal of Environmental Planning and Management, v. 60, n. 4, p. 26, 2016.

DI-GIULIO, G. M.; BEDRAN-MARTINS, A. M. B.; VASCONCELLOS, M. DA P.; RIBEIRO, W. C. Mudanças climáticas, riscos e adaptação na megacidade de São Paulo, Brasil. Sustentabilidade em Debate, v. 8, n. 2, p. 75-87, 2017. Brasília. Disponível em: <http://periodicos.unb.br/index.php/sust/article/view/19868>. .

DI-GIULIO, G. M.; BEDRAN-MARTINS, A. M. B.; VASCONCELLOS, M. DA P.; RIBEIRO, W. C.; LEMOS, M. C. Mainstreaming climate adaptation in the megacity of São Paulo, Brazil. Cities, v. 72, n. B, p. 237-244, 2017. Elsevier. Disponível em: <http://dx.doi.org/10.1016/j.cities.2017.09.001>. .

DI-GIULIO, G. M.; MARTINS, A. M. B.; LEMOS, M. C. Adaptação climática: Fronteiras do conhecimento para pensar o contexto brasileiro. Estudos Avançados, v. 30, n. 88, p. 25-41, 2016. Disponível em: <http://www.scielo.br/scielo.php?script=sci_arttext\&pid=S0103-

40142016000300025\&lng=pt\&tlng=pt>. .

EGLER, C. A. G.; BESSA, V. DE C.; GONÇALVES, A. DE F. Dinâmica territorial e seus rebatimentos na organização regional do estado de São Paulo. Confins, v. 19, p. 27, 2013. Disponível em: <http://confins.revues.org>. Acesso em: 10/3/2019.

EICHHORST, U. Module 5f: Adapting Urban Transport to Climate Change. Eschborn, 2009.

EMPLASA. Planejamento Regional. Disponível em: <https://www.emplasa.sp.gov.br/PlanejamentoRegional>. Acesso em: 25/11/2018a.

EMPLASA. Macrometrópole Paulista. Disponível em: <https://www.emplasa.sp.gov.br/MMP>. Acesso em: 24/2/2019b. 
EVERS, H.; AZEREDO, L.; BETTI, L. P.; et al. DOTS nos Planos Diretores: Guia para inclusão do Desenvolvimento Orientado ao Transporte Sustentável no Planejamento Urbano. 2018.

FIELD, C. B.; BARROS, V.; STOCKER, T. F.; et al. IPCC, 2012 - Summary for Policymakers. In: Managing the Risks of Extreme Events and Disasters to Advance Climate Change Adaptation. New York, 2012.

FIELD, C. B.; V.R. BARROS; D.J. DOKKEN; et al. Climate Change 2014: Impacts,Adaptation, and Vulnerability. Part A: Global and Sectoral Aspects. Contribution of Working Group II to the Fifth Assessment Report of the Intergovernmental Panel on Climate Change. New York: Cambridge University Press, 2014.

FONG, W. K.; SOTOS, M.; DOUST, M.; et al. Global Protocol for Community-Scale Greenhouse Gas Emission Inventories - An Accounting and Reporting Standard for Cities. 2014.

FREIRE, R. A.; MONTEIRO, E. Z. WHEN DENSE IS NOT COMPACT. FLUXUS Technical Networks and Socio- environmental Sustainability Lab, p. 548-560, 2014. Campinas.

GEHL, J. Cidades para pessoas. 2 ed. ed. São Paulo: Editora Pesrpectiva S.A, 2013.

GIL, A. C. Como elaborar projetos de pesquisa. 4th ed. São Paulo: Atlas, 2002.

HOEGH-GULDBERG, O.; JACOB, D.; TAYLOR, M.; et al. Chapter 3 - Impacts of $1.5^{\circ} \mathrm{C}$ Global Warming on Natural and Human Systems. In: Global warming of 1.5 ${ }^{\circ}$ C. 2018.

HUANG;, C.; BUSCH;, C.; HE;, D.; HARVEY, H. 12 GREEN GUIDELINES OCTOBER 2015 DRAFT FOR COMMENT CDBC'S GREEN AND SMART URBAN DEVELOPMENT GUIDELINES. 2015.

IBGE- MALHA MUNICIPAL. Base Cartográfica Contínua do Brasil, ao Milionésimo BCIM 2010; SRTM- Relevo sombreado, 2000. Disponível em: <ftp://geoftp.ibge.gov.br/organizacao_do_territorio/divisao_regional/divisao_regional_d o_brasil/divisao_regional_do_brasil_em_regioes_geograficas_2017/mapas/35_regioes_ geograficas_sao_paulo.pdf>. Acesso em: 27/11/2018.

IBGE. Censo Demográfico 2010. Rio de Janeiro, 2010.

IBGE. Perfil dos Municípios Brasileiros 2017. Rio de Janeiro, 2018a.

IBGE. IBGE | Resultados do Censo Agro 2017. Disponível em: <https://censoagro2017.ibge.gov.br/templates/censo_agro/resultadosagro/index.html>. Acesso em: 8/12/2018b.

IBGE, C. DE; POPULAÇÃO E INDICADORES SOCIAIS; ABRANTES, F. J.; et al. Perfil dos municípios brasileiros: 2015 / IBGE. Rio de Janeiro, 2016.

IBGE CIDADES. IBGE Cidades - Echaporã. Disponível em: <https://cidades.ibge.gov.br/>. Acesso em: 25/11/2018.

ICLEI. Guia de Ação Local pelo Clima. São Paulo, 2016.

IPCC. Climate Change 2007: impacts, adaptation and vulnerability: contribution of 
Working Group II to the fourth assessment report of the Intergovernmental Panel. Cambridge, UK, 2007.

IPCC. IPCC Factsheet: What is the IPCC? Disponível em: <www.ipcc.ch1http://www.ipcc.ch/pdf/tor/TOR_Bureau.pdf>. Acesso em: 23/12/2018.

IPCC. Climate Change 2014 - Synthesis Report. Contribution of Working Groups I, II and III to the Fifth Assessment Report of the Intergovernmental Panel on Climate Change. Geneva, 2014.

IPCC. Summary for Policymakers. Em: Global warming of $1.5^{\circ} \mathrm{C}$. Geneva, Switzerland, 2018.

IPCC. History - IPCC. Disponível em: <https://www.ipcc.ch/about/history/>. Acesso em: 12/1/2019.

JACOBI, P. R.; FRACALANZA, A. P.; SILVA-SÁNCHEZ, S. Governança da água e inovação na política de recuperação de recursos hídricos na cidade de São Paulo. Cadernos Metrópole, v. 17, n. 33, p. 61-81, May. 2015. São Paulo. Disponível em: <http://www.scielo.br/scielo.php?script=sci_arttext\&pid=S2236-

99962015000100061\&lng=pt\&tlng=pt>. .

JACOBS, J. Morte e Vidas de Grandes Cidades. 3 ed. ed. São Paulo: Editora WMF Martins Fontes, 2011.

KRELLENBERG, K.; JORDÁN, R.; REHNER, J.; et al. Adaptation to climate change in megacities of Latin America. Santiago, 2014.

LEMOS, M. C.; LO, Y.-J.; NELSON, D. R.; EAKIN, H.; BEDRAN-MARTINS, A. M. Linking development to climate adaptation: Leveraging generic and specific capacities to reduce vulnerability to drought in NE Brazil. Global Environmental Change, v. 39, p. 170-179, 2016. Disponível em: <http://dx.doi.org/10.1016/j.gloenvcha.2016.05.001>. Acesso em: 2/2/2019.

LONDRES. THE LONDON PLAN 2016 - THE SPATIAL DEVELOPMENT STRATEGY FOR LONDON CONSOLIDATED WITH ALTERATIONS SINCE 2011. London, 2017.

MAGLIO, I. C. A sustentabilidade ambiental no planejamento urbano do município de São Paulo: 1971-2004, 2005. São Paulo: Biblioteca Digital de Teses e Dissertações da Universidade de São Paulo. Disponível em: <http://www.teses.usp.br/teses/disponiveis/6/6134/tde-05062008-160111/>. Acesso em: 13/10/2018.

MARENGO, J. A.; NOBRE, C. A.; SELUCHI, M. E.; et al. A seca e a crise hídrica de 2014-2015 em São Paulo. Revista USP, , n. 106, p. 31-44, 2015. Disponível em: <http://www.revistas.usp.br/revusp/article/view/110101>. .

MARENGO, J. A.; SCARANO, F. R.; KLEIN, A. F.; SOUZA, C. R. G.; CHOU, S. C. Impacto, vulnerabilidade e adaptação das cidades costeiras brasileiras às mudanças climáticas : Relatório Especial do Painel Brasileiro de Mudanças Climáticas. Rio de Janeiro, 2016.

MARGUlis, S. GUIA DE ADAPTAÇÃO ÀS MUDANÇAS DO CLIMA Para entes federativos. Brasília, 2017. 
MARTINS, R. D.; FERREIRA, L. DA C. Oportunidades e barreiras para políticas locais e subnacionais de enfrentamento das mudanças climáticas em áreas urbanas: evidências de diferentes contextos. Ambiente \& sociedade, v. 13, n. 2, p. 223-242, 2010. Disponível em: $\quad<$ http://www.scopus.com/inward/record.url?eid=2-s2.079957760581\&partnerID=tZOtx3y1>. .

MEADOWS, D. Indicators and Information Systems for Sustainable Development. 1998.

MIRANDOLA, F. A.; NOGUEIRA, F. R.; MACEDO, E. S. DE. O PMRR (Plano Municipal de Redução de Riscos) como instrumento na Gestão Regional de Riscos Urbanos: o exemplo da região do $\mathrm{ABC}$ paulista. $1^{\circ}$ Congresso Brasileiro de Geologia de Engenharia e Ambiental, 2015. Disponível em: <http://cbge2015.hospedagemdesites.ws/trabalhos/trabalhos/305.pdf >. Acesso em: $11 / 11 / 2018$.

MMA. Brasil atinge meta de redução de emissões. Disponível em: <http://www.mma.gov.br/informma/item/15310-brasil-atinge-meta-de-redução-deemissões.html>. Acesso em: 12/1/2019.

MONZONI, M.; FELDMANN, F.; BIDERMAN, R. Diretrizes para formulação de políticas públicas em mudanças climáticas no Brasil. São Paulo, 2009.

MORACI, F.; ERRIGO, M.; FAZIA, C.; BURGIO, G.; FORESTA, S. Making Less Vulnerable Cities: Resilience as a New Paradigm of Smart Planning. Sustainability, v. 10, n. 3, p. 755, 2018. Multidisciplinary Digital Publishing Institute. Disponível em: <http://www.mdpi.com/2071-1050/10/3/755>. Acesso em: 13/3/2018.

NETO, W. J. S.; JANNUZZI, P. DE M.; SILVA, P. L. DO N. Sistemas de Indicadores ou Indicadores Sintéticos: do que precisam os gestores de programas sociais? Anais do XVI Encontro Nacional de Estudos Populacionais. Anais... . p.1-14, 2008. Caxumbu: ABEP - Associação Brasileira de Estudos Populacionais. Disponível em: <http://www.abep.org.br/publicacoes/index.php/anais/article/view/1875/1833>. Acesso em: 26/2/2019.

NOBRE, C. A.; YOUNG, A. F.; SALDIVA, P. H. N.; et al. Vulnerabilidades Das Megacidades Brasileiras Às Mudanças Climáticas: Região Metropolitana de São Paulo - Relatório Final. São José dos Campos, 2011.

NOGUEIRA, F. R.; CANIL, K. Cartas Geotécnicas De Aptidão À Urbanização: Instrumento De Prevenção De Desastres E Para a Gestão Do Uso Do Solo. Sessão Temática 8: Técnicas E Métodos Para Análise Urbana E Regional Resumo, p. 1-15, 2017.

OMS. Mudança climática e saúde humana - riscos e respostas: resumo atualizado. Brasilia, 2008.

ONU. World Urbanization Prospects: The 2014 Revision, Highlights. New York, 2014.

ONU. Sendai Framework for Disaster Risk Reduction 2015 - 2030. Sendai, 2015a.

ONU. Transformando Nosso Mundo: A Agenda 2030 para o Desenvolvimento Sustentável. 2015b.

ONU. UN-HABITAT III - NOVA AGENDA URBANA. Quito, 2016. 
ONU. Adaptation in human settlements: key findings and way forward. Bonn, 2018. PACHAURI, R. K.; MEYER, L. SUMÁRIO DO RELATÓRIO DO IPCC PARA OS TOMADORES DE DECISÃO - WGII AR5 - Tradução Iniciativa Verde. São Paulo, 2014.

PHILIPPI JR, A.; MAGLIO, I. C.; COIMBRA, J. DE Á. A.; FRANCO, R. M. Municípios e meio ambiente: perspectivas para a municipalização da gestão ambiental no Brasil. São Paulo, 1999.

PHILIPPI JR, A.; MALHEIROS, T. F. (EDS.). Indicadores de sustentabilidade e gestão ambiental. $1^{a}$ edição ed. Barueri, SP: Manole, 2012 - Coleção Ambiental 12, 2012.

PNUMA. Geo Cidades: Relatório Ambiental Urbano Integrado - Informe Geo. Rio de Janeiro, 2002.

RegionsAdapt - NRG4SD. .Disponível em: <http://www.nrg4sd.org/climatechange/regionsadapt/>. Acesso em: 3/6/2018.

RIBEIRO, S. K.; SANTOS, A. S. Mudanças Climáticas e Cidades: Relatório Especial do Painel Brasileiro de Mudanças Climáticas. Rio de Janeiro, 2016.

RODRIGUES FILHO, S.; LINDOSO, D. P.; BURSZTYN, M.; NASCIMENTO, C. G. O Clima Em Transe: Políticas De Mitigação E Adaptação No Brasil. Revista Brasileira de Climatologia, v. 19, n. 12, p. 74-90, 2016.

ROSENZWEIG, C.; SOLECKI, W.; ROMERO-LANKAO, P.; et al. Climate Change and Cities. Second Assessment Report of the Urban Climate Change Research Network. New York, 2015.

RUNHAAR, H.; WILK, B.; PERSSON, Å.; UITTENBROEK, C.; WAMSLER, C. Mainstreaming climate adaptation: taking stock about "what works" from empirical research worldwide. Regional Environmental Change, v. 18, n. 4, p. 1201-1210, 2017. Regional Environmental Change.

SAISANA, M.; TARANTOLA, S. State-of-the-art Report on Current Methodologies and Practices for Composite Indicator Development. Ispra, 2002.

SÃO PAULO (ESTADO). RESOLUÇÃO SMA No 22, DE 08 DE JUNHO DE 1995. , 1995. Disponível em: <https://cetesb.sp.gov.br/proclima/wpcontent/uploads/sites/36/2014/08/resolucao_sma_22.pdf>. Acesso em: 10/2/2019.

SÃO PAULO (ESTADO). Decreto $\mathrm{N}^{\circ}$ 49.369, de 11 de fevereiro de 2005. , 2005. Disponível em: <https://cetesb.sp.gov.br/proclima/wpcontent/uploads/sites/36/2014/08/Decreto-49369_bra.cl_.dec_SP.pdf $>$. Acesso em: $10 / 2 / 2019$.

SÃO PAULO (ESTADO). LEI No 13.798, DE 9 DE NOVEMBRO DE 2009. , 2009.

Disponível em: <https://cetesb.sp.gov.br/proclima/wpcontent/uploads/sites/36/2014/08/lei_13798_09nov_09_portugues.pdf>. Acesso em: $10 / 2 / 2019$.

SÃO PAULO (ESTADO). DECRETO N ${ }^{\circ}$ 55.947, DE 24 DE JUNHO DE 2010. , 2010. Disponível em: <https://cetesb.sp.gov.br/proclima/wpcontent/uploads/sites/36/2014/08/decreto_55947_2010.pdf>. Acesso em: 10/2/2019. 
SÃO PAULO (ESTADO). Decreto $\mathrm{N}^{0}$ 57.512, de 11.11.2011. , 2011. Disponível em: $<$ https://www.al.sp.gov.br/repositorio/legislacao/decreto/2011/decreto-57512-

11.11.2011.html>. Acesso em: 10/2/2019.

SÃO PAULO (ESTADO). Plano Participativo de Adaptação às Mudanças Climáticas - Versão Zero para Consulta Pública. São Paulo, 2013.

SÃO PAULO (ESTADO). Decreto $n^{\circ}$ 61.710, de 15 de dezembro de 2015. , 2015. Disponível em: <https://www.al.sp.gov.br/repositorio/legislacao/decreto/2015/decreto61710-15.12.2015.html>. Acesso em: 16/2/2019.

SÃO PAULO (ESTADO). Plano Estadual de Mitigação e de Adaptação às Mudanças Climáticas para a Consolidação de uma Economia de Baixa Emissão de Carbono na Agricultura. 2016.

SÃO PAUlO (ESTADO). Meio Ambiente Paulista: Relatório de Qualidade Ambiental - RQA 2017. São Paulo, 2017.

SÃO PAULO (ESTADO). Relatório de Qualidade Ambiental - RQA 2018. São Paulo, 2018a.

SÃO PAULO (ESTADO). Zoneamento econômico-ecológico do estado de São Paulo - ZEE: entender para participar. 1st ed. São Paulo: Imprensa Oficial do Estado S/A Imesp., 2018b.

SÃO PAULO (ESTADO). MUDANÇAS CLIMÁTICAS: BALANÇO E RECOMENDAÇÕES GOVERNO DO ESTADO DE SÃO PAULO SECRETARIA DO MEIO AMBIENTE SÃO PAULO, 2018. São Paulo, 2018c.

SEEG. Emissões Totais | SEEG - Sistema de Estimativa de Emissão de Gases. Disponível em: 〈http://plataforma.seeg.eco.br/total_emission>. Acesso em: 10/3/2019.

SEPE, P. MARRA; GOMES, S. Indicadores Ambientais e Gestão Urbana Desafi os para a Construção da Sustentabilidade na Cidade de São Paulo. São Paulo, 2008.

TAVARES, J. Formação da macrometrópole no Brasil: Construção teórica e conceitual de uma região de planejamento. Eure, v. 44, n. 133, p. 115-134, 2018.

THE WORD BANK. Guide to Climate Change Adaptation in Cities - Executive Summary. 2011.

UITTENBROEK, C. J.; JANSSEN-JANSEN, L. B.; RUNHAAR, H. A. C. Mainstreaming climate adaptation into urban planning: overcoming barriers, seizing opportunities and evaluating the results in two Dutch case studies. Regional Environmental Change, v. 13, n. 2, p. 399-411, 2013. Disponível em: <https://linkspringer-com.ez67.periodicos.capes.gov.br/content/pdf/10.1007\%2Fs10113-012-03488.pdf>. Acesso em: 24/2/2018.

UITTENBROEK, C. J.; JANSSEN-JANSEN, L. B.; SPIT, T. J. M.; SALET, W. G. M.; RUNHAAR, H. A. C. Political commitment in organising municipal responses to climate adaptation: the dedicated approach versus the mainstreaming approach. Environmental Politics, v. 23, n. 6, p. 1043-1063, 2014. Routledge. Disponível em: <http://dx.doi.org/10.1080/09644016.2014.920563>. .

UNFCCC. Acordo de Paris. Paris, 2015.

UNFCCC. UNFCCC eHandbook - Startpage. Disponível em: 
$<$ https://unfccc.int/resource/bigpicture/index.html\#content-the-paris-agreemen>. Acesso em: 13/1/2019a.

UNFCCC. History of the Convention | UNFCCC. Disponível em: $<$ https://unfccc.int/process/the-convention/history-of-the-convention\#eq-2>. Acesso em: $13 / 1 / 2019 b$.

WAMSLER, C.; LUEDERITZ, C.; BRINK, E. Local levers for change: Mainstreaming ecosystem-based adaptation into municipal planning to foster sustainability transitions. Global Environmental Change, v. 29, p. 189-201, 2014. 


\section{Anexos}

8.1 Resultados dos Indicadores UAI Municípios Paulistas

\begin{tabular}{|c|c|c|c|c|c|c|}
\hline Dimensão & Habitação & $\begin{array}{c}\text { Mobilidade } \\
\text { Urbana }\end{array}$ & $\begin{array}{c}\text { Agricultura } \\
\text { Sustentável }\end{array}$ & $\begin{array}{c}\text { Gestão } \\
\text { Ambiental }\end{array}$ & $\begin{array}{c}\text { Gestão de } \\
\text { Risco }\end{array}$ & $\begin{array}{c}\text { UAl Municípios } \\
\text { Paulistas }\end{array}$ \\
\hline Adamantina & 0,3333 & 0,4000 & 0,4000 & 0,5000 & 0,4000 & 0,4067 \\
\hline Adolfo & 0,0000 & 0,2000 & 0,8000 & 0,5000 & 0,2000 & 0,3400 \\
\hline Aguaí & 0,0000 & 0,2000 & 0,4000 & 0,3750 & 0,0000 & 0,1950 \\
\hline Águas da Prata & 0,0000 & 0,6000 & 0,2000 & 0,3750 & 0,4000 & 0,3150 \\
\hline Águas de Lindóia & 0,0000 & 0,4000 & 0,2000 & 0,3750 & 0,2000 & 0,2350 \\
\hline Águas de Santa Bárbara & 0,3333 & 0,2000 & 0,2000 & 0,2500 & 0,2000 & 0,2367 \\
\hline Águas de São Pedro & 0,0000 & 0,6000 & 0,0000 & 0,5000 & 0,2000 & 0,2600 \\
\hline Agudos & 1,0000 & 0,8000 & 0,4000 & 0,8750 & 0,6000 & 0,7350 \\
\hline Alambari & 0,3333 & 0,2000 & 0,4000 & 0,2500 & 0,0000 & 0,2367 \\
\hline Alfredo Marcondes & 0,0000 & 0,2000 & 0,6000 & 0,2500 & 0,0000 & 0,2100 \\
\hline Altair & 0,3333 & 0,6000 & 0,2000 & 0,5000 & 0,2000 & 0,3667 \\
\hline Altinópolis & 1,0000 & 0,4000 & 0,6000 & 0,2500 & 0,2000 & 0,4900 \\
\hline Alto Alegre & 0,3333 & 0,2000 & 0,4000 & 0,5000 & 0,2000 & 0,3267 \\
\hline Alumínio & 0,0000 & 0,4000 & 0,0000 & 0,1250 & 0,2000 & 0,1450 \\
\hline Álvares Florence & 0,0000 & 0,0000 & 0,0000 & 0,0000 & 0,2000 & 0,0400 \\
\hline Álvares Machado & 0,6667 & 0,2000 & 0,4000 & 0,1250 & 0,2000 & 0,3183 \\
\hline Álvaro de Carvalho & 0,0000 & 0,2000 & 1,0000 & 0,3750 & 0,2000 & 0,3550 \\
\hline Alvinlândia & 0,0000 & 0,2000 & 0,8000 & 0,3750 & 0,0000 & 0,2750 \\
\hline Americana & 1,0000 & 0,8000 & 0,4000 & 0,7500 & 0,6000 & 0,7100 \\
\hline Américo Brasiliense & 0,3333 & 0,6000 & 0,0000 & 0,2500 & 0,2000 & 0,2767 \\
\hline Américo de Campos & 0,0000 & 0,0000 & 0,2000 & 0,2500 & 0,2000 & 0,1300 \\
\hline
\end{tabular}




\begin{tabular}{|c|c|c|c|c|c|c|}
\hline $\begin{array}{l}\text { Dimensão } \\
\text { Municípios }\end{array}$ & Habitação & $\begin{array}{c}\text { Mobilidade } \\
\text { Urbana }\end{array}$ & $\begin{array}{l}\text { Agricultura } \\
\text { Sustentável }\end{array}$ & $\begin{array}{c}\text { Gestão } \\
\text { Ambiental }\end{array}$ & $\begin{array}{l}\text { Gestão de } \\
\text { Risco }\end{array}$ & $\begin{array}{c}\text { UAI Municípios } \\
\text { Paulistas }\end{array}$ \\
\hline Amparo & 1,0000 & 1,0000 & 0,6000 & 0,2500 & 0,2000 & 0,6100 \\
\hline Analândia & 0,0000 & 0,2000 & 0,4000 & 0,2500 & 0,2000 & 0,2100 \\
\hline Andradina & 1,0000 & 0,6000 & 0,8000 & 0,2500 & 0,4000 & 0,6100 \\
\hline Angatuba & 0,6667 & 0,6000 & 0,4000 & 0,5000 & 0,2000 & 0,4733 \\
\hline Anhembi & 0,0000 & 0,2000 & 0,2000 & 0,1250 & 0,2000 & 0,1450 \\
\hline Anhumas & 0,6667 & 0,2000 & 0,4000 & 0,2500 & 0,2000 & 0,3433 \\
\hline Aparecida & 0,0000 & 0,4000 & 0,2000 & 0,5000 & 0,4000 & 0,3000 \\
\hline Aparecida dOeste & 0,0000 & 0,0000 & 0,2000 & 0,2500 & 0,2000 & 0,1300 \\
\hline Apiaí & 1,0000 & 0,4000 & 0,0000 & 0,6250 & 0,2000 & 0,4450 \\
\hline Araçariguama & 1,0000 & 0,6000 & 0,6000 & 0,0000 & 0,4000 & 0,5200 \\
\hline Araçatuba & 1,0000 & 0,8000 & 0,6000 & 0,2500 & 0,4000 & 0,6100 \\
\hline Araçoiaba da Serra & 0,3333 & 0,6000 & 0,4000 & 0,0000 & 0,2000 & 0,3067 \\
\hline Aramina & 0,0000 & 0,2000 & 0,4000 & 0,2500 & 0,4000 & 0,2500 \\
\hline Arandu & 0,0000 & 0,2000 & 0,4000 & 0,3750 & 0,2000 & 0,2350 \\
\hline Arapeí & 0,0000 & 0,2000 & 0,0000 & 0,0000 & 0,2000 & 0,0800 \\
\hline Araraquara & 1,0000 & 0,6000 & 0,8000 & 0,7500 & 0,6000 & 0,7500 \\
\hline Araras & 1,0000 & 0,6000 & 0,6000 & 0,5000 & 0,6000 & 0,6600 \\
\hline Arco-Íris & 0,0000 & 0,4000 & 0,2000 & 0,2500 & 0,0000 & 0,1700 \\
\hline Arealva & 0,0000 & 0,4000 & 0,2000 & 0,2500 & 0,2000 & 0,2100 \\
\hline Areias & 0,0000 & 0,2000 & 0,8000 & 0,1250 & 0,2000 & 0,2650 \\
\hline Areiópolis & 0,0000 & 0,2000 & 0,2000 & 0,0000 & 0,0000 & 0,0800 \\
\hline Ariranha & 0,6667 & 0,2000 & 0,0000 & 0,3750 & 0,4000 & 0,3283 \\
\hline Artur Nogueira & 1,0000 & 0,6000 & 0,6000 & 0,5000 & 0,6000 & 0,6600 \\
\hline Arujá & 0,3333 & 0,6000 & 0,2000 & 0,2500 & 0,6000 & 0,3967 \\
\hline Aspásia & 0,0000 & 0,2000 & 0,2000 & 0,5000 & 0,2000 & 0,2200 \\
\hline
\end{tabular}




\begin{tabular}{|c|c|c|c|c|c|c|}
\hline $\begin{array}{l}\text { Dimensão } \\
\text { Municípios }\end{array}$ & Habitação & $\begin{array}{c}\text { Mobilidade } \\
\text { Urbana }\end{array}$ & $\begin{array}{l}\text { Agricultura } \\
\text { Sustentável }\end{array}$ & $\begin{array}{c}\text { Gestão } \\
\text { Ambiental }\end{array}$ & $\begin{array}{l}\text { Gestão de } \\
\text { Risco }\end{array}$ & $\begin{array}{c}\text { UAI Municípios } \\
\text { Paulistas }\end{array}$ \\
\hline Assis & 0,6667 & 0,6000 & 0,2000 & 0,6250 & 0,0000 & 0,4183 \\
\hline Atibaia & 1,0000 & 0,6000 & 1,0000 & 0,7500 & 0,2000 & 0,7100 \\
\hline Auriflama & 0,0000 & 0,2000 & 0,2000 & 0,5000 & 0,2000 & 0,2200 \\
\hline Avaí & 0,0000 & 0,4000 & 0,0000 & 0,7500 & 0,0000 & 0,2300 \\
\hline Avanhandava & 0,0000 & 0,2000 & 0,2000 & 0,5000 & 0,2000 & 0,2200 \\
\hline Avaré & 0,6667 & 0,4000 & 0,8000 & 0,2500 & 0,2000 & 0,4633 \\
\hline Bady Bassitt & 0,0000 & 0,4000 & 0,2000 & 0,1250 & 0,0000 & 0,1450 \\
\hline Balbinos & 0,3333 & 0,2000 & 0,8000 & 0,1250 & 0,2000 & 0,3317 \\
\hline Bálsamo & 0,0000 & 0,2000 & 0,2000 & 0,5000 & 0,2000 & 0,2200 \\
\hline Bananal & 0,3333 & 0,4000 & 0,0000 & 0,0000 & 0,4000 & 0,2267 \\
\hline Barão de Antonina & 0,3333 & 0,2000 & 0,6000 & 0,1250 & 0,0000 & 0,2517 \\
\hline Barbosa & 0,0000 & 0,4000 & 0,4000 & 0,5000 & 0,2000 & 0,3000 \\
\hline Bariri & 1,0000 & 0,4000 & 0,0000 & 0,3750 & 0,2000 & 0,3950 \\
\hline Barra Bonita & 0,6667 & 0,4000 & 0,0000 & 0,5000 & 0,4000 & 0,3933 \\
\hline Barra do Chapéu & 0,0000 & 0,0000 & 0,8000 & 0,1250 & 0,2000 & 0,2250 \\
\hline Barra do Turvo & 1,0000 & 0,2000 & 0,8000 & 0,1250 & 0,4000 & 0,5050 \\
\hline Barretos & 1,0000 & 0,8000 & 0,4000 & 0,5000 & 0,2000 & 0,5800 \\
\hline Barrinha & 0,0000 & 0,4000 & 0,0000 & 0,0000 & 0,0000 & 0,0800 \\
\hline Barueri & 1,0000 & 0,4000 & 0,4000 & 0,3750 & 0,4000 & 0,5150 \\
\hline Bastos & 0,6667 & 0,4000 & 0,4000 & 0,2500 & 0,2000 & 0,3833 \\
\hline Batatais & 0,0000 & 0,6000 & 1,0000 & 0,6250 & 0,0000 & 0,4450 \\
\hline Bauru & 1,0000 & 0,8000 & 1,0000 & 0,7500 & 0,6000 & 0,8300 \\
\hline Bebedouro & 0,6667 & 0,4000 & 0,8000 & 0,7500 & 0,8000 & 0,6833 \\
\hline Bento de Abreu & 0,0000 & 0,0000 & 0,4000 & 0,5000 & 0,0000 & 0,1800 \\
\hline Bernardino de Campos & 0,0000 & 0,0000 & 0,4000 & 0,3750 & 0,2000 & 0,1950 \\
\hline
\end{tabular}




\begin{tabular}{|c|c|c|c|c|c|c|}
\hline $\begin{array}{l}\text { Dimensão } \\
\text { Municípios }\end{array}$ & Habitação & $\begin{array}{c}\text { Mobilidade } \\
\text { Urbana }\end{array}$ & $\begin{array}{l}\text { Agricultura } \\
\text { Sustentável }\end{array}$ & $\begin{array}{c}\text { Gestão } \\
\text { Ambiental }\end{array}$ & $\begin{array}{l}\text { Gestão de } \\
\text { Risco }\end{array}$ & $\begin{array}{c}\text { UAI Municípios } \\
\text { Paulistas }\end{array}$ \\
\hline Bertioga & 1,0000 & 0,6000 & 0,0000 & 0,7500 & 0,6000 & 0,5900 \\
\hline Bilac & 0,0000 & 0,2000 & 0,4000 & 0,7500 & 0,2000 & 0,3100 \\
\hline Birigui & 0,6667 & 0,8000 & 0,8000 & 0,3750 & 0,2000 & 0,5683 \\
\hline Biritiba-Mirim & 0,0000 & 0,2000 & 0,8000 & 0,7500 & 0,2000 & 0,3900 \\
\hline Boa Esperança do Sul & 0,0000 & 0,6000 & 0,0000 & 0,1250 & 0,0000 & 0,1450 \\
\hline Bocaina & 0,0000 & 0,6000 & 0,4000 & 0,2500 & 0,2000 & 0,2900 \\
\hline Bofete & 0,6667 & 0,2000 & 0,4000 & 0,1250 & 0,2000 & 0,3183 \\
\hline Boituva & 1,0000 & 0,6000 & 0,6000 & 0,5000 & 0,6000 & 0,6600 \\
\hline Bom Jesus dos Perdões & 0,0000 & 0,4000 & 0,4000 & 0,1250 & 0,2000 & 0,2250 \\
\hline Bom Sucesso de Itararé & 0,0000 & 0,4000 & 1,0000 & 0,1250 & 0,2000 & 0,3450 \\
\hline Borá & 0,0000 & 0,4000 & 0,0000 & 0,2500 & 0,2000 & 0,1700 \\
\hline Boracéia & 0,0000 & 0,2000 & 0,4000 & 0,2500 & 0,2000 & 0,2100 \\
\hline Borborema & 0,6667 & 0,2000 & 0,6000 & 0,5000 & 0,2000 & 0,4333 \\
\hline Borebi & 0,0000 & 0,2000 & 0,4000 & 0,2500 & 0,6000 & 0,2900 \\
\hline Botucatu & 1,0000 & 0,8000 & 1,0000 & 1,0000 & 0,8000 & 0,9200 \\
\hline Bragança Paulista & 1,0000 & 0,6000 & 0,6000 & 0,8750 & 0,4000 & 0,6950 \\
\hline Braúna & 0,6667 & 0,4000 & 0,6000 & 0,3750 & 0,2000 & 0,4483 \\
\hline Brejo Alegre & 0,0000 & 0,4000 & 1,0000 & 0,1250 & 0,2000 & 0,3450 \\
\hline Brodowski & 0,3333 & 0,4000 & 0,2000 & 0,1250 & 0,4000 & 0,2917 \\
\hline Brotas & 0,6667 & 0,4000 & 0,4000 & 0,7500 & 0,2000 & 0,4833 \\
\hline Buri & 0,6667 & 0,2000 & 0,6000 & 0,1250 & 0,2000 & 0,3583 \\
\hline Buritama & 0,6667 & 0,4000 & 0,6000 & 0,2500 & 0,8000 & 0,5433 \\
\hline Buritizal & 0,0000 & 0,0000 & 0,0000 & 0,1250 & 0,0000 & 0,0250 \\
\hline Cabrália Paulista & 0,0000 & 0,2000 & 0,0000 & 0,5000 & 0,2000 & 0,1800 \\
\hline Cabreúva & 0,6667 & 0,4000 & 0,8000 & 0,6250 & 0,4000 & 0,5783 \\
\hline
\end{tabular}




\begin{tabular}{|c|c|c|c|c|c|c|}
\hline $\begin{array}{ll} & \text { Dimensão } \\
\text { Municípios }\end{array}$ & Habitação & $\begin{array}{c}\text { Mobilidade } \\
\text { Urbana }\end{array}$ & $\begin{array}{l}\text { Agricultura } \\
\text { Sustentável }\end{array}$ & $\begin{array}{c}\text { Gestão } \\
\text { Ambiental }\end{array}$ & $\begin{array}{l}\text { Gestão de } \\
\text { Risco }\end{array}$ & \begin{tabular}{|c|} 
UAl Municípios \\
Paulistas
\end{tabular} \\
\hline Caçapava & 0,0000 & 0,8000 & 0,6000 & 0,5000 & 0,6000 & 0,5000 \\
\hline Cachoeira Paulista & 0,6667 & 0,4000 & 0,0000 & 0,0000 & 0,2000 & 0,2533 \\
\hline Caconde & 0,0000 & 0,2000 & 0,4000 & 0,2500 & 0,2000 & 0,2100 \\
\hline Cafelândia & 0,0000 & 0,2000 & 0,0000 & 0,1250 & 0,0000 & 0,0650 \\
\hline Caiabu & 0,0000 & 0,4000 & 0,4000 & 0,2500 & 0,2000 & 0,2500 \\
\hline Caieiras & 0,6667 & 0,8000 & 0,0000 & 0,5000 & 0,4000 & 0,4733 \\
\hline Caiuá & 0,0000 & 0,2000 & 0,2000 & 0,5000 & 0,6000 & 0,3000 \\
\hline Cajamar & 0,6667 & 0,4000 & 0,0000 & 0,3750 & 0,4000 & 0,3683 \\
\hline Cajati & 0,3333 & 0,8000 & 0,2000 & 0,6250 & 0,6000 & 0,5117 \\
\hline Cajobi & 0,0000 & 0,2000 & 0,2000 & 0,3750 & 0,2000 & 0,1950 \\
\hline Cajuru & 0,0000 & 0,2000 & 0,2000 & 0,2500 & 0,4000 & 0,2100 \\
\hline Campina do Monte Alegre & 0,3333 & 0,0000 & 0,2000 & 0,2500 & 0,2000 & 0,1967 \\
\hline Campinas & 1,0000 & 0,8000 & 0,8000 & 1,0000 & 1,0000 & 0,9200 \\
\hline Campo Limpo Paulista & 1,0000 & 0,6000 & 0,0000 & 0,5000 & 0,4000 & 0,5000 \\
\hline Campos do Jordão & 1,0000 & 0,8000 & 0,6000 & 0,6250 & 0,8000 & 0,7650 \\
\hline Campos Novos Paulista & 0,0000 & 0,2000 & 0,2000 & 0,5000 & 0,2000 & 0,2200 \\
\hline Cananéia & 0,3333 & 0,2000 & 0,8000 & 0,1250 & 0,2000 & 0,3317 \\
\hline Canas & 0,0000 & 0,4000 & 0,0000 & 0,2500 & 0,2000 & 0,1700 \\
\hline Cândido Mota & 1,0000 & 0,2000 & 0,6000 & 1,0000 & 0,0000 & 0,5600 \\
\hline Cândido Rodrigues & 0,0000 & 0,0000 & 0,6000 & 0,5000 & 0,2000 & 0,2600 \\
\hline Canitar & 0,3333 & 0,2000 & 0,4000 & 0,1250 & 0,0000 & 0,2117 \\
\hline Capão Bonito & 1,0000 & 0,4000 & 1,0000 & 0,2500 & 0,2000 & 0,5700 \\
\hline Capela do Alto & 0,0000 & 0,2000 & 0,0000 & 0,3750 & 0,2000 & 0,1550 \\
\hline Capivari & 0,3333 & 0,6000 & 0,2000 & 0,8750 & 0,4000 & 0,4817 \\
\hline Caraguatatuba & 1,0000 & 1,0000 & 0,6000 & 0,6250 & 0,8000 & 0,8050 \\
\hline
\end{tabular}




\begin{tabular}{|c|c|c|c|c|c|c|}
\hline $\begin{array}{l}\text { Dimensão } \\
\text { Municípios }\end{array}$ & Habitação & $\begin{array}{c}\text { Mobilidade } \\
\text { Urbana }\end{array}$ & $\begin{array}{l}\text { Agricultura } \\
\text { Sustentável }\end{array}$ & $\begin{array}{c}\text { Gestão } \\
\text { Ambiental }\end{array}$ & $\begin{array}{l}\text { Gestão de } \\
\text { Risco }\end{array}$ & $\begin{array}{c}\text { UAI Municípios } \\
\text { Paulistas }\end{array}$ \\
\hline Carapicuíba & 1,0000 & 0,6000 & 0,2000 & 0,5000 & 0,6000 & 0,5800 \\
\hline Cardoso & 0,0000 & 0,2000 & 0,4000 & 0,3750 & 0,2000 & 0,2350 \\
\hline Casa Branca & 1,0000 & 0,4000 & 0,6000 & 0,5000 & 0,4000 & 0,5800 \\
\hline Cássia dos Coqueiros & 0,3333 & 0,4000 & 0,6000 & 0,6250 & 0,4000 & 0,4717 \\
\hline Castilho & 0,3333 & 0,2000 & 1,0000 & 0,3750 & 0,2000 & 0,4217 \\
\hline Catanduva & 0,6667 & 1,0000 & 0,8000 & 0,7500 & 0,4000 & 0,7233 \\
\hline Catiguá & 0,3333 & 0,2000 & 0,0000 & 0,2500 & 0,2000 & 0,1967 \\
\hline Cedral & 0,0000 & 0,4000 & 0,6000 & 0,2500 & 0,0000 & 0,2500 \\
\hline Cerqueira César & 0,0000 & 0,4000 & 0,2000 & 0,3750 & 0,2000 & 0,2350 \\
\hline Cerquilho & 0,0000 & 0,4000 & 0,0000 & 0,5000 & 0,2000 & 0,2200 \\
\hline Cesário Lange & 0,0000 & 0,4000 & 0,4000 & 0,2500 & 0,0000 & 0,2100 \\
\hline Charqueada & 0,0000 & 0,4000 & 0,4000 & 0,1250 & 0,0000 & 0,1850 \\
\hline Chavantes & 0,0000 & 0,4000 & 0,2000 & 0,2500 & 0,2000 & 0,2100 \\
\hline Clementina & 0,6667 & 0,2000 & 0,6000 & 0,2500 & 0,2000 & 0,3833 \\
\hline Colina & 0,3333 & 0,2000 & 0,0000 & 0,2500 & 0,2000 & 0,1967 \\
\hline Colômbia & 0,0000 & 0,0000 & 0,4000 & 0,3750 & 0,4000 & 0,2350 \\
\hline Conchal & 0,3333 & 0,6000 & 0,4000 & 0,2500 & 0,0000 & 0,3167 \\
\hline Conchas & 0,0000 & 0,6000 & 0,4000 & 0,5000 & 0,4000 & 0,3800 \\
\hline Cordeirópolis & 1,0000 & 0,8000 & 1,0000 & 0,8750 & 0,8000 & 0,8950 \\
\hline Coroados & 0,0000 & 0,2000 & 0,4000 & 0,1250 & 0,2000 & 0,1850 \\
\hline Coronel Macedo & 0,0000 & 0,2000 & 0,6000 & 0,5000 & 0,2000 & 0,3000 \\
\hline Corumbataí & 0,0000 & 0,2000 & 0,4000 & 0,3750 & 0,2000 & 0,2350 \\
\hline Cosmópolis & 0,0000 & 0,4000 & 0,4000 & 0,6250 & 0,2000 & 0,3250 \\
\hline Cosmorama & 0,0000 & 0,0000 & 0,2000 & 0,1250 & 0,2000 & 0,1050 \\
\hline Cotia & 1,0000 & 0,6000 & 0,2000 & 0,6250 & 0,6000 & 0,6050 \\
\hline
\end{tabular}




\begin{tabular}{|c|c|c|c|c|c|c|}
\hline $\begin{array}{l}\text { Dimensão } \\
\text { Municípios }\end{array}$ & Habitação & $\begin{array}{c}\text { Mobilidade } \\
\text { Urbana }\end{array}$ & $\begin{array}{l}\text { Agricultura } \\
\text { Sustentável }\end{array}$ & $\begin{array}{c}\text { Gestão } \\
\text { Ambiental }\end{array}$ & $\begin{array}{l}\text { Gestão de } \\
\text { Risco }\end{array}$ & $\begin{array}{c}\text { UAI Municípios } \\
\text { Paulistas }\end{array}$ \\
\hline Cravinhos & 0,0000 & 0,6000 & 0,8000 & 0,1250 & 0,4000 & 0,3850 \\
\hline Cristais Paulista & 0,0000 & 0,2000 & 0,6000 & 0,1250 & 0,2000 & 0,2250 \\
\hline Cruzália & 0,6667 & 0,6000 & 0,6000 & 0,3750 & 0,2000 & 0,4883 \\
\hline Cruzeiro & 0,0000 & 0,2000 & 0,6000 & 0,1250 & 0,0000 & 0,1850 \\
\hline Cubatão & 1,0000 & 0,8000 & 0,0000 & 0,2500 & 0,6000 & 0,5300 \\
\hline Cunha & 0,0000 & 0,2000 & 0,8000 & 0,0000 & 0,2000 & 0,2400 \\
\hline Descalvado & 0,3333 & 0,6000 & 0,4000 & 0,5000 & 0,2000 & 0,4067 \\
\hline Diadema & 1,0000 & 0,6000 & 0,2000 & 0,5000 & 0,4000 & 0,5400 \\
\hline Dirce Reis & 0,6667 & 0,2000 & 0,4000 & 0,3750 & 0,2000 & 0,3683 \\
\hline Divinolândia & 0,0000 & 0,0000 & 0,2000 & 0,5000 & 0,2000 & 0,1800 \\
\hline Dobrada & 0,0000 & 0,2000 & 0,0000 & 0,1250 & 0,0000 & 0,0650 \\
\hline Dois Córregos & 0,3333 & 0,4000 & 0,4000 & 0,5000 & 0,2000 & 0,3667 \\
\hline Dolcinópolis & 0,3333 & 0,2000 & 0,4000 & 0,1250 & 0,2000 & 0,2517 \\
\hline Dourado & 0,0000 & 0,4000 & 0,4000 & 0,0000 & 0,0000 & 0,1600 \\
\hline Dracena & 0,3333 & 0,4000 & 0,4000 & 0,6250 & 0,4000 & 0,4317 \\
\hline Duartina & 0,0000 & 0,2000 & 1,0000 & 0,5000 & 0,0000 & 0,3400 \\
\hline Dumont & 0,3333 & 0,0000 & 0,0000 & 0,1250 & 0,2000 & 0,1317 \\
\hline Echaporã & 0,0000 & 0,0000 & 0,0000 & 0,0000 & 0,0000 & 0,0000 \\
\hline Eldorado & 0,3333 & 0,4000 & 0,8000 & 0,1250 & 0,4000 & 0,4117 \\
\hline Elias Fausto & 0,0000 & 0,4000 & 0,0000 & 0,2500 & 0,6000 & 0,2500 \\
\hline Elisiário & 0,3333 & 0,2000 & 0,2000 & 0,5000 & 0,0000 & 0,2467 \\
\hline Embaúba & 0,0000 & 0,2000 & 0,2000 & 0,5000 & 0,8000 & 0,3400 \\
\hline Embu das Artes & 1,0000 & 0,4000 & 0,2000 & 0,7500 & 0,8000 & 0,6300 \\
\hline Embu-Guaçu & 0,6667 & 0,6000 & 0,8000 & 0,5000 & 0,8000 & 0,6733 \\
\hline Emilianópolis & 0,3333 & 0,2000 & 0,4000 & 0,2500 & 0,2000 & 0,2767 \\
\hline
\end{tabular}




\begin{tabular}{|c|c|c|c|c|c|c|}
\hline $\begin{array}{l}\text { Dimensão } \\
\text { Municípios }\end{array}$ & Habitação & $\begin{array}{l}\text { Mobilidade } \\
\text { Urbana }\end{array}$ & $\begin{array}{l}\text { Agricultura } \\
\text { Sustentável }\end{array}$ & $\begin{array}{l}\text { Gestão } \\
\text { Ambiental }\end{array}$ & $\begin{array}{l}\text { Gestão de } \\
\text { Risco }\end{array}$ & $\begin{array}{c}\text { UAI Municípios } \\
\text { Paulistas }\end{array}$ \\
\hline Engenheiro Coelho & 0,6667 & 0,2000 & 0,4000 & 0,0000 & 0,6000 & 0,3733 \\
\hline Espírito Santo do Pinhal & 0,6667 & 0,4000 & 0,6000 & 0,6250 & 0,2000 & 0,4983 \\
\hline Espírito Santo do Turvo & 0,0000 & 0,2000 & 0,4000 & 0,2500 & 0,0000 & 0,1700 \\
\hline Estiva Gerbi & 0,6667 & 0,4000 & 1,0000 & 0,1250 & 0,4000 & 0,5183 \\
\hline Estrela do Norte & 0,0000 & 0,2000 & 0,6000 & 0,2500 & 0,2000 & 0,2500 \\
\hline Estrela dOeste & 0,3333 & 0,2000 & 0,8000 & 0,2500 & 0,2000 & 0,3567 \\
\hline Euclides da Cunha Paulista & 0,3333 & 0,0000 & 0,8000 & 0,5000 & 0,2000 & 0,3667 \\
\hline Fartura & 0,6667 & 0,0000 & 0,4000 & 0,2500 & 0,4000 & 0,3433 \\
\hline Fernando Prestes & 0,3333 & 0,0000 & 0,2000 & 0,3750 & 0,2000 & 0,2217 \\
\hline Fernandópolis & 0,6667 & 0,6000 & 0,6000 & 0,3750 & 0,8000 & 0,6083 \\
\hline Fernão & 0,0000 & 0,2000 & 0,8000 & 0,5000 & 0,2000 & 0,3400 \\
\hline Ferraz de Vasconcelos & 0,6667 & 0,6000 & 0,4000 & 0,2500 & 0,2000 & 0,4233 \\
\hline Flora Rica & 0,0000 & 0,4000 & 0,2000 & 0,6250 & 0,2000 & 0,2850 \\
\hline Floreal & 0,0000 & 0,6000 & 0,4000 & 0,3750 & 0,2000 & 0,3150 \\
\hline Flórida Paulista & 0,0000 & 0,2000 & 0,4000 & 0,3750 & 0,0000 & 0,1950 \\
\hline Florínia & 0,0000 & 0,2000 & 0,6000 & 0,3750 & 0,2000 & 0,2750 \\
\hline Franca & 1,0000 & 0,8000 & 0,2000 & 0,3750 & 0,6000 & 0,5950 \\
\hline Francisco Morato & 1,0000 & 0,4000 & 0,0000 & 0,1250 & 0,6000 & 0,4250 \\
\hline Franco da Rocha & 0,6667 & 1,0000 & 0,8000 & 0,5000 & 0,4000 & 0,6733 \\
\hline Gabriel Monteiro & 0,0000 & 0,4000 & 0,6000 & 0,3750 & 0,2000 & 0,3150 \\
\hline Gália & 0,0000 & 0,2000 & 0,6000 & 0,3750 & 0,2000 & 0,2750 \\
\hline Garça & 0,6667 & 0,6000 & 0,6000 & 0,3750 & 0,2000 & 0,4883 \\
\hline Gastão Vidigal & 0,0000 & 0,0000 & 0,2000 & 0,2500 & 0,2000 & 0,1300 \\
\hline Gavião Peixoto & 0,3333 & 0,4000 & 0,0000 & 0,2500 & 0,2000 & 0,2367 \\
\hline General Salgado & 0,0000 & 0,4000 & 0,4000 & 0,2500 & 0,2000 & 0,2500 \\
\hline
\end{tabular}




\begin{tabular}{|c|c|c|c|c|c|c|}
\hline Dimensão & Habitação & $\begin{array}{c}\text { Mobilidade } \\
\text { Urbana }\end{array}$ & $\begin{array}{c}\text { Agricultura } \\
\text { Sustentável }\end{array}$ & $\begin{array}{c}\text { Gestão } \\
\text { Ambiental }\end{array}$ & $\begin{array}{c}\text { Gestão de } \\
\text { Risco }\end{array}$ & $\begin{array}{c}\text { UAl Municípios } \\
\text { Paulistas }\end{array}$ \\
\hline Getulina & 0,0000 & 0,4000 & 0,4000 & 0,0000 & 0,4000 & 0,2400 \\
\hline Glicério & 0,0000 & 0,2000 & 0,6000 & 0,3750 & 0,2000 & 0,2750 \\
\hline Guaiçara & 0,0000 & 0,4000 & 0,8000 & 0,3750 & 0,2000 & 0,3550 \\
\hline Guaimbê & 0,0000 & 0,2000 & 0,0000 & 0,2500 & 0,0000 & 0,0900 \\
\hline Guaíra & 0,6667 & 0,8000 & 0,6000 & 0,1250 & 0,2000 & 0,4783 \\
\hline Guapiaçu & 0,0000 & 0,2000 & 0,4000 & 0,3750 & 0,2000 & 0,2350 \\
\hline Guapiara & 0,3333 & 0,4000 & 0,8000 & 0,2500 & 0,2000 & 0,3967 \\
\hline Guará & 0,0000 & 0,4000 & 0,4000 & 0,3750 & 0,2000 & 0,2750 \\
\hline Guaraçaí & 1,0000 & 0,4000 & 0,2000 & 0,3750 & 0,0000 & 0,3950 \\
\hline Guaraci & 0,0000 & 0,0000 & 0,6000 & 0,0000 & 0,2000 & 0,1600 \\
\hline Guarani dOeste & 0,0000 & 0,4000 & 0,8000 & 0,1250 & 0,2000 & 0,3050 \\
\hline Guarantã & 0,0000 & 0,2000 & 0,8000 & 0,1250 & 0,2000 & 0,2650 \\
\hline Guararapes & 0,0000 & 0,6000 & 0,8000 & 0,3750 & 0,0000 & 0,3550 \\
\hline Guararema & 0,6667 & 0,6000 & 0,6000 & 0,7500 & 0,6000 & 0,6433 \\
\hline Guaratinguetá & 0,0000 & 0,6000 & 0,8000 & 0,6250 & 0,2000 & 0,4450 \\
\hline Guareí & 0,0000 & 0,2000 & 0,6000 & 0,3750 & 0,2000 & 0,2750 \\
\hline Guariba & 1,0000 & 0,2000 & 0,2000 & 0,5000 & 0,4000 & 0,4600 \\
\hline Guaruján & 1,0000 & 0,8000 & 0,8000 & 0,7500 & 0,6000 & 0,7900 \\
\hline Guarulhos & 1,0000 & 1,0000 & 0,6000 & 0,5000 & 0,8000 & 0,7800 \\
\hline Guatapará & 0,0000 & 0,2000 & 0,8000 & 0,1250 & 0,2000 & 0,2650 \\
\hline Guzolândia & 0,0000 & 0,2000 & 0,4000 & 0,3750 & 0,2000 & 0,2350 \\
\hline Herculândia & 0,0000 & 0,2000 & 0,4000 & 0,2500 & 0,2000 & 0,2100 \\
\hline Holambra & 0,3333 & 0,6000 & 0,6000 & 0,7500 & 0,8000 & 0,6167 \\
\hline Hortolândia & 1,0000 & 0,6000 & 0,2000 & 0,6250 & 0,4000 & 0,5650 \\
\hline lacanga & 0,0000 & 0,2000 & 0,6000 & 0,5000 & 0,2000 & 0,3000 \\
\hline
\end{tabular}




\begin{tabular}{|c|c|c|c|c|c|c|}
\hline $\begin{array}{l}\text { Dimensão } \\
\text { Municípios }\end{array}$ & Habitação & $\begin{array}{c}\text { Mobilidade } \\
\text { Urbana }\end{array}$ & $\begin{array}{l}\text { Agricultura } \\
\text { Sustentável }\end{array}$ & $\begin{array}{c}\text { Gestão } \\
\text { Ambiental }\end{array}$ & $\begin{array}{l}\text { Gestão de } \\
\text { Risco }\end{array}$ & $\begin{array}{l}\text { UAI Municípios } \\
\text { Paulistas }\end{array}$ \\
\hline lacri & 0,0000 & 0,2000 & 0,4000 & 0,1250 & 0,2000 & 0,1850 \\
\hline laras & 0,0000 & 0,4000 & 0,4000 & 0,0000 & 0,0000 & 0,1600 \\
\hline Ibaté & 1,0000 & 0,6000 & 0,2000 & 0,5000 & 0,2000 & 0,5000 \\
\hline Ibirá & 0,0000 & 0,8000 & 0,6000 & 0,5000 & 0,2000 & 0,4200 \\
\hline Ibirarema & 0,0000 & 0,2000 & 0,6000 & 1,0000 & 0,4000 & 0,4400 \\
\hline Ibitinga & 0,6667 & 0,4000 & 0,6000 & 0,5000 & 0,2000 & 0,4733 \\
\hline Ibiúna & 0,3333 & 0,4000 & 0,6000 & 0,3750 & 0,2000 & 0,3817 \\
\hline Icém & 0,0000 & 0,2000 & 0,0000 & 0,1250 & 0,0000 & 0,0650 \\
\hline lepê & 0,0000 & 0,2000 & 0,6000 & 0,2500 & 0,2000 & 0,2500 \\
\hline Igaraçu do Tietê & 0,0000 & 0,4000 & 0,2000 & 0,2500 & 0,0000 & 0,1700 \\
\hline Igarapava & 0,0000 & 0,4000 & 0,4000 & 0,5000 & 0,0000 & 0,2600 \\
\hline Igaratá & 0,0000 & 0,8000 & 0,4000 & 0,3750 & 0,2000 & 0,3550 \\
\hline Iguape & 0,3333 & 0,6000 & 0,6000 & 0,1250 & 0,2000 & 0,3717 \\
\hline Ilha Comprida & 0,3333 & 0,6000 & 0,4000 & 0,1250 & 0,2000 & 0,3317 \\
\hline Ilha Solteira & 0,6667 & 0,8000 & 0,4000 & 0,5000 & 0,4000 & 0,5533 \\
\hline Ilhabela & 1,0000 & 0,6000 & 0,2000 & 0,3750 & 0,6000 & 0,5550 \\
\hline Indaiatuba & 1,0000 & 0,8000 & 0,4000 & 0,6250 & 0,4000 & 0,6450 \\
\hline Indiana & 0,0000 & 0,6000 & 0,4000 & 0,1250 & 0,0000 & 0,2250 \\
\hline Indiaporã & 0,3333 & 0,0000 & 0,6000 & 0,3750 & 0,2000 & 0,3017 \\
\hline Inúbia Paulista & 0,0000 & 0,4000 & 0,2000 & 0,2500 & 0,2000 & 0,2100 \\
\hline Ipaussu & 0,0000 & 0,2000 & 0,6000 & 0,5000 & 0,2000 & 0,3000 \\
\hline Iperó & 1,0000 & 0,4000 & 0,8000 & 0,5000 & 0,6000 & 0,6600 \\
\hline Ipeúna & 0,0000 & 0,2000 & 0,4000 & 0,0000 & 0,2000 & 0,1600 \\
\hline Ipiguá & 0,0000 & 0,2000 & 0,2000 & 0,5000 & 0,2000 & 0,2200 \\
\hline Iporanga & 0,0000 & 0,2000 & 0,8000 & 0,3750 & 0,2000 & 0,3150 \\
\hline
\end{tabular}




\begin{tabular}{|c|c|c|c|c|c|c|}
\hline Dimensão & Habitação & $\begin{array}{c}\text { Mobilidade } \\
\text { Urbana }\end{array}$ & $\begin{array}{c}\text { Agricultura } \\
\text { Sustentável }\end{array}$ & $\begin{array}{c}\text { Gestão } \\
\text { Ambiental }\end{array}$ & $\begin{array}{c}\text { Gestão de } \\
\text { Risco }\end{array}$ & $\begin{array}{c}\text { UAl Municípios } \\
\text { Paulistas }\end{array}$ \\
\hline Ipuã & 0,6667 & 0,2000 & 0,2000 & 0,5000 & 0,0000 & 0,3133 \\
\hline Iracemápolis & 0,0000 & 0,4000 & 0,0000 & 0,3750 & 0,2000 & 0,1950 \\
\hline Irapuã & 0,0000 & 0,2000 & 1,0000 & 0,3750 & 0,0000 & 0,3150 \\
\hline Irapuru & 0,0000 & 0,2000 & 0,4000 & 0,2500 & 0,2000 & 0,2100 \\
\hline Itaberá & 1,0000 & 0,2000 & 0,6000 & 0,2500 & 0,2000 & 0,4500 \\
\hline Itaí & 0,3333 & 0,4000 & 0,6000 & 0,6250 & 0,2000 & 0,4317 \\
\hline Itajobi & 0,0000 & 0,2000 & 0,4000 & 0,3750 & 0,4000 & 0,2750 \\
\hline Itaju & 0,0000 & 0,2000 & 0,2000 & 0,2500 & 0,2000 & 0,1700 \\
\hline Itanhaém & 0,6667 & 0,6000 & 0,8000 & 0,6250 & 0,6000 & 0,6583 \\
\hline Itaóca & 1,0000 & 0,2000 & 1,0000 & 0,2500 & 0,2000 & 0,5300 \\
\hline Itapecerica da Serra & 1,0000 & 0,6000 & 0,4000 & 0,6250 & 0,6000 & 0,6450 \\
\hline Itapetininga & 1,0000 & 0,8000 & 0,8000 & 0,2500 & 0,6000 & 0,6900 \\
\hline Itapeva & 0,0000 & 0,6000 & 0,8000 & 0,2500 & 0,4000 & 0,4100 \\
\hline Itapevi & 1,0000 & 0,4000 & 0,0000 & 0,3750 & 0,8000 & 0,5150 \\
\hline Itapira & 1,0000 & 0,6000 & 0,8000 & 0,7500 & 0,4000 & 0,7100 \\
\hline Itapirapuã Paulista & 0,0000 & 0,2000 & 0,0000 & 0,2500 & 0,2000 & 0,1300 \\
\hline Itápolis & 0,6667 & 0,6000 & 0,4000 & 0,5000 & 0,6000 & 0,5533 \\
\hline Itaporanga & 0,0000 & 0,4000 & 1,0000 & 0,1250 & 0,0000 & 0,3050 \\
\hline Itapuí & 0,0000 & 0,2000 & 0,2000 & 0,2500 & 0,2000 & 0,1700 \\
\hline Itapura & 1,0000 & 0,2000 & 0,4000 & 0,3750 & 0,0000 & 0,3950 \\
\hline Itaquaquecetuba & 1,0000 & 0,6000 & 0,4000 & 0,3750 & 0,2000 & 0,5150 \\
\hline Itararé & 1,0000 & 0,4000 & 1,0000 & 0,2500 & 0,2000 & 0,5700 \\
\hline Itariri & 0,6667 & 0,8000 & 0,6000 & 0,2500 & 0,2000 & 0,5033 \\
\hline Itatiba & 1,0000 & 0,6000 & 1,0000 & 0,7500 & 0,6000 & 0,7900 \\
\hline Itatinga & 0,0000 & 0,2000 & 0,6000 & 0,3750 & 0,2000 & 0,2750 \\
\hline & & & & & \\
\hline
\end{tabular}




\begin{tabular}{|c|c|c|c|c|c|c|}
\hline $\begin{array}{l}\text { Dimensão } \\
\text { Municípios }\end{array}$ & Habitação & $\begin{array}{l}\text { Mobilidade } \\
\text { Urbana }\end{array}$ & $\begin{array}{l}\text { Agricultura } \\
\text { Sustentável }\end{array}$ & $\begin{array}{c}\text { Gestão } \\
\text { Ambiental }\end{array}$ & $\begin{array}{l}\text { Gestão de } \\
\text { Risco }\end{array}$ & $\begin{array}{l}\text { UAI Municípios } \\
\text { Paulistas }\end{array}$ \\
\hline Itirapina & 0,0000 & 0,4000 & 0,0000 & 0,2500 & 0,0000 & 0,1300 \\
\hline Itirapuã & 0,0000 & 0,2000 & 0,2000 & 0,1250 & 0,2000 & 0,1450 \\
\hline Itobi & 0,0000 & 0,0000 & 0,0000 & 0,1250 & 0,0000 & 0,0250 \\
\hline Itu & 1,0000 & 0,6000 & 0,4000 & 0,6250 & 0,4000 & 0,6050 \\
\hline Itupeva & 0,6667 & 0,6000 & 0,6000 & 0,1250 & 0,4000 & 0,4783 \\
\hline Ituverava & 0,6667 & 0,8000 & 0,6000 & 0,8750 & 0,2000 & 0,6283 \\
\hline Jaborandi & 0,3333 & 0,2000 & 0,2000 & 0,0000 & 0,2000 & 0,1867 \\
\hline Jaboticabal & 0,3333 & 0,4000 & 0,4000 & 0,3750 & 0,4000 & 0,3817 \\
\hline Jacareí & 1,0000 & 0,8000 & 0,6000 & 0,1250 & 0,6000 & 0,6250 \\
\hline Jaci & 0,3333 & 0,0000 & 0,2000 & 0,6250 & 0,0000 & 0,2317 \\
\hline Jacupiranga & 0,6667 & 0,6000 & 0,2000 & 0,0000 & 0,2000 & 0,3333 \\
\hline Jaguariúna & 1,0000 & 0,6000 & 0,4000 & 0,6250 & 0,8000 & 0,6850 \\
\hline Jales & 0,3333 & 0,6000 & 0,8000 & 0,2500 & 0,2000 & 0,4367 \\
\hline Jambeiro & 0,3333 & 0,4000 & 0,2000 & 0,0000 & 0,2000 & 0,2267 \\
\hline Jandira & 1,0000 & 0,4000 & 0,0000 & 0,6250 & 0,8000 & 0,5650 \\
\hline Jardinópolis & 0,0000 & 0,6000 & 0,6000 & 0,3750 & 0,2000 & 0,3550 \\
\hline Jarinu & 0,3333 & 0,6000 & 0,2000 & 0,6250 & 0,6000 & 0,4717 \\
\hline Jaú & 1,0000 & 0,6000 & 0,8000 & 0,2500 & 0,2000 & 0,5700 \\
\hline Jeriquara & 0,3333 & 0,0000 & 0,0000 & 0,2500 & 0,0000 & 0,1167 \\
\hline Joanópolis & 0,3333 & 0,2000 & 0,6000 & 0,1250 & 0,2000 & 0,2917 \\
\hline João Ramalho & 0,0000 & 0,2000 & 0,4000 & 0,2500 & 0,2000 & 0,2100 \\
\hline José Bonifácio & 0,6667 & 0,4000 & 0,2000 & 0,5000 & 0,4000 & 0,4333 \\
\hline Júlio Mesquita & 0,0000 & 0,2000 & 0,0000 & 0,2500 & 0,0000 & 0,0900 \\
\hline Jumirim & 0,0000 & 0,2000 & 0,4000 & 0,3750 & 0,0000 & 0,1950 \\
\hline Jundiaí & 1,0000 & 0,6000 & 0,8000 & 0,5000 & 0,8000 & 0,7400 \\
\hline
\end{tabular}




\begin{tabular}{|c|c|c|c|c|c|c|}
\hline $\begin{array}{l}\text { Dimensão } \\
\text { Municípios }\end{array}$ & Habitação & $\begin{array}{l}\text { Mobilidade } \\
\text { Urbana }\end{array}$ & $\begin{array}{l}\text { Agricultura } \\
\text { Sustentável }\end{array}$ & $\begin{array}{c}\text { Gestão } \\
\text { Ambiental }\end{array}$ & $\begin{array}{l}\text { Gestão de } \\
\text { Risco }\end{array}$ & $\begin{array}{l}\text { UAI Municípios } \\
\text { Paulistas }\end{array}$ \\
\hline Junqueirópolis & 0,6667 & 0,2000 & 0,4000 & 0,1250 & 0,2000 & 0,3183 \\
\hline Juquiá & 0,0000 & 0,6000 & 0,4000 & 0,1250 & 0,4000 & 0,3050 \\
\hline Juquitiba & 0,6667 & 0,6000 & 0,8000 & 0,8750 & 0,6000 & 0,7083 \\
\hline Lagoinha & 0,0000 & 0,2000 & 0,6000 & 0,0000 & 0,2000 & 0,2000 \\
\hline Laranjal Paulista & 0,0000 & 0,4000 & 0,4000 & 0,5000 & 0,0000 & 0,2600 \\
\hline Lavínia & 0,0000 & 0,2000 & 0,4000 & 0,5000 & 0,2000 & 0,2600 \\
\hline Lavrinhas & 0,3333 & 0,2000 & 0,4000 & 0,2500 & 0,4000 & 0,3167 \\
\hline Leme & 0,0000 & 0,8000 & 1,0000 & 0,5000 & 0,2000 & 0,5000 \\
\hline Lençóis Paulista & 1,0000 & 0,6000 & 1,0000 & 0,6250 & 0,6000 & 0,7650 \\
\hline Limeira & 0,3333 & 0,8000 & 0,8000 & 0,7500 & 0,2000 & 0,5767 \\
\hline Lindóia & 0,0000 & 0,4000 & 0,2000 & 0,5000 & 0,2000 & 0,2600 \\
\hline Lins & 0,0000 & 0,6000 & 0,4000 & 0,5000 & 0,4000 & 0,3800 \\
\hline Lorena & 0,3333 & 1,0000 & 0,0000 & 0,7500 & 0,8000 & 0,5767 \\
\hline Lourdes & 0,0000 & 0,8000 & 0,2000 & 0,3750 & 0,2000 & 0,3150 \\
\hline Louveira & 0,6667 & 0,4000 & 0,4000 & 0,8750 & 0,2000 & 0,5083 \\
\hline Lucélia & 0,3333 & 0,2000 & 0,2000 & 0,5000 & 0,2000 & 0,2867 \\
\hline Lucianópolis & 0,0000 & 0,2000 & 0,6000 & 0,3750 & 0,4000 & 0,3150 \\
\hline Luís Antônio & 0,0000 & 0,4000 & 0,0000 & 0,5000 & 0,0000 & 0,1800 \\
\hline Luiziânia & 0,3333 & 0,2000 & 0,4000 & 0,3750 & 0,2000 & 0,3017 \\
\hline Lupércio & 0,0000 & 0,4000 & 0,0000 & 0,0000 & 0,0000 & 0,0800 \\
\hline Lutécia & 0,0000 & 0,0000 & 0,2000 & 0,1250 & 0,2000 & 0,1050 \\
\hline Macatuba & 0,0000 & 0,4000 & 0,2000 & 0,3750 & 0,2000 & 0,2350 \\
\hline Macaubal & 0,3333 & 0,2000 & 0,0000 & 0,1250 & 0,0000 & 0,1317 \\
\hline Macedônia & 0,6667 & 0,0000 & 0,8000 & 0,3750 & 0,2000 & 0,4083 \\
\hline Magda & 0,3333 & 0,2000 & 0,0000 & 0,5000 & 0,2000 & 0,2467 \\
\hline
\end{tabular}




\begin{tabular}{|c|c|c|c|c|c|c|}
\hline $\begin{array}{l}\text { Dimensão } \\
\text { Municípios }\end{array}$ & Habitação & $\begin{array}{c}\text { Mobilidade } \\
\text { Urbana }\end{array}$ & $\begin{array}{l}\text { Agricultura } \\
\text { Sustentável }\end{array}$ & $\begin{array}{c}\text { Gestão } \\
\text { Ambiental }\end{array}$ & $\begin{array}{l}\text { Gestão de } \\
\text { Risco }\end{array}$ & $\begin{array}{c}\text { UAI Municípios } \\
\text { Paulistas }\end{array}$ \\
\hline Mairinque & 1,0000 & 0,4000 & 0,0000 & 0,3750 & 0,0000 & 0,3550 \\
\hline Mairiporã & 1,0000 & 0,4000 & 0,8000 & 0,3750 & 0,2000 & 0,5550 \\
\hline Manduri & 0,0000 & 0,2000 & 0,0000 & 0,2500 & 0,0000 & 0,0900 \\
\hline Marabá Paulista & 0,0000 & 0,2000 & 0,0000 & 0,2500 & 0,2000 & 0,1300 \\
\hline Maracaí & 0,6667 & 0,4000 & 0,2000 & 0,3750 & 0,6000 & 0,4483 \\
\hline Marapoama & 0,0000 & 0,2000 & 0,0000 & 0,1250 & 0,0000 & 0,0650 \\
\hline Mariápolis & 0,0000 & 0,4000 & 1,0000 & 0,3750 & 0,0000 & 0,3550 \\
\hline Marília & 0,6667 & 0,8000 & 0,8000 & 0,3750 & 0,6000 & 0,6483 \\
\hline Marinópolis & 0,0000 & 0,2000 & 0,2000 & 0,2500 & 0,2000 & 0,1700 \\
\hline Martinópolis & 0,3333 & 0,4000 & 0,6000 & 0,3750 & 0,2000 & 0,3817 \\
\hline Matão & 1,0000 & 0,6000 & 0,8000 & 0,6250 & 0,8000 & 0,7650 \\
\hline Mauá & 1,0000 & 0,8000 & 0,0000 & 0,8750 & 0,8000 & 0,6950 \\
\hline Mendonça & 0,0000 & 0,2000 & 0,0000 & 0,2500 & 0,2000 & 0,1300 \\
\hline Meridiano & 0,0000 & 0,4000 & 0,4000 & 0,2500 & 0,2000 & 0,2500 \\
\hline Mesópolis & 0,3333 & 0,2000 & 1,0000 & 0,2500 & 0,4000 & 0,4367 \\
\hline Miguelópolis & 0,6667 & 0,2000 & 0,0000 & 0,3750 & 0,2000 & 0,2883 \\
\hline Mineiros do Tietê & 0,0000 & 0,4000 & 0,2000 & 0,2500 & 0,2000 & 0,2100 \\
\hline Mira Estrela & 0,3333 & 0,2000 & 0,2000 & 0,5000 & 0,2000 & 0,2867 \\
\hline Miracatu & 0,3333 & 0,6000 & 0,6000 & 0,3750 & 0,4000 & 0,4617 \\
\hline Mirandópolis & 0,6667 & 0,0000 & 0,4000 & 0,3750 & 0,4000 & 0,3683 \\
\hline Mirante do Paranapanema & 0,0000 & 0,2000 & 0,4000 & 0,5000 & 0,2000 & 0,2600 \\
\hline Mirassol & 1,0000 & 0,2000 & 0,4000 & 0,5000 & 0,0000 & 0,4200 \\
\hline Mirassolândia & 0,0000 & 0,4000 & 0,6000 & 0,3750 & 0,2000 & 0,3150 \\
\hline Mococa & 1,0000 & 0,4000 & 0,8000 & 0,1250 & 0,4000 & 0,5450 \\
\hline Mogi das Cruzes & 0,6667 & 0,8000 & 0,4000 & 0,3750 & 0,8000 & 0,6083 \\
\hline
\end{tabular}




\begin{tabular}{|c|c|c|c|c|c|c|}
\hline $\begin{array}{l}\text { Dimensão } \\
\text { Municípios }\end{array}$ & Habitação & $\begin{array}{c}\text { Mobilidade } \\
\text { Urbana }\end{array}$ & $\begin{array}{l}\text { Agricultura } \\
\text { Sustentável }\end{array}$ & $\begin{array}{c}\text { Gestão } \\
\text { Ambiental }\end{array}$ & $\begin{array}{l}\text { Gestão de } \\
\text { Risco }\end{array}$ & $\begin{array}{c}\text { UAI Municípios } \\
\text { Paulistas }\end{array}$ \\
\hline Mogi Guaçu & 1,0000 & 0,6000 & 0,0000 & 0,2500 & 0,8000 & 0,5300 \\
\hline Mogi Mirim & 1,0000 & 0,8000 & 0,6000 & 0,5000 & 0,2000 & 0,6200 \\
\hline Mombuca & 0,0000 & 0,4000 & 0,6000 & 0,2500 & 0,2000 & 0,2900 \\
\hline Monções & 0,0000 & 0,2000 & 0,4000 & 0,3750 & 0,0000 & 0,1950 \\
\hline Mongaguá & 1,0000 & 0,6000 & 0,8000 & 0,6250 & 0,4000 & 0,6850 \\
\hline Monte Alegre do Sul & 0,0000 & 0,0000 & 0,2000 & 0,7500 & 0,0000 & 0,1900 \\
\hline Monte Alto & 1,0000 & 0,6000 & 0,6000 & 0,3750 & 0,2000 & 0,5550 \\
\hline Monte Aprazível & 0,0000 & 0,2000 & 0,6000 & 0,1250 & 0,2000 & 0,2250 \\
\hline Monte Azul Paulista & 0,0000 & 0,4000 & 0,6000 & 0,6250 & 0,2000 & 0,3650 \\
\hline Monte Castelo & 0,0000 & 0,2000 & 0,4000 & 0,3750 & 0,2000 & 0,2350 \\
\hline Monte Mor & 0,6667 & 0,6000 & 0,2000 & 0,2500 & 0,6000 & 0,4633 \\
\hline Monteiro Lobato & 0,0000 & 0,4000 & 0,4000 & 0,2500 & 0,4000 & 0,2900 \\
\hline Morro Agudo & 0,6667 & 0,4000 & 0,6000 & 0,6250 & 0,2000 & 0,4983 \\
\hline Morungaba & 1,0000 & 0,2000 & 0,4000 & 0,5000 & 0,6000 & 0,5400 \\
\hline Motuca & 0,0000 & 0,2000 & 0,4000 & 0,1250 & 0,0000 & 0,1450 \\
\hline Murutinga do Sul & 0,3333 & 0,2000 & 0,2000 & 0,8750 & 0,2000 & 0,3617 \\
\hline Nantes & 0,0000 & 0,2000 & 0,4000 & 0,3750 & 0,2000 & 0,2350 \\
\hline Narandiba & 0,3333 & 0,4000 & 0,6000 & 0,2500 & 0,2000 & 0,3567 \\
\hline Natividade da Serra & 0,0000 & 0,4000 & 0,4000 & 0,0000 & 0,2000 & 0,2000 \\
\hline Nazaré Paulista & 0,0000 & 0,4000 & 1,0000 & 0,0000 & 0,4000 & 0,3600 \\
\hline Neves Paulista & 0,0000 & 0,4000 & 0,2000 & 0,0000 & 0,0000 & 0,1200 \\
\hline Nhandeara & 0,3333 & 0,2000 & 0,6000 & 0,2500 & 0,0000 & 0,2767 \\
\hline Nipoã & 0,0000 & 0,2000 & 0,4000 & 0,5000 & 0,2000 & 0,2600 \\
\hline Nova Aliança & 0,0000 & 0,2000 & 0,4000 & 0,6250 & 0,2000 & 0,2850 \\
\hline Nova Campina & 0,0000 & 0,2000 & 0,6000 & 0,3750 & 0,2000 & 0,2750 \\
\hline
\end{tabular}




\begin{tabular}{|c|c|c|c|c|c|c|}
\hline $\begin{array}{ll} & \text { Dimensão } \\
\text { Municípios }\end{array}$ & Habitação & $\begin{array}{c}\text { Mobilidade } \\
\text { Urbana }\end{array}$ & $\begin{array}{l}\text { Agricultura } \\
\text { Sustentável }\end{array}$ & $\begin{array}{c}\text { Gestão } \\
\text { Ambiental }\end{array}$ & $\begin{array}{l}\text { Gestão de } \\
\text { Risco }\end{array}$ & $\begin{array}{l}\text { UAI Municípios } \\
\text { Paulistas }\end{array}$ \\
\hline Nova Canaã Paulista & 0,0000 & 0,2000 & 0,2000 & 0,1250 & 0,2000 & 0,1450 \\
\hline Nova Castilho & 0,0000 & 0,2000 & 0,8000 & 0,2500 & 0,2000 & 0,2900 \\
\hline Nova Europa & 0,0000 & 0,2000 & 0,0000 & 0,2500 & 0,0000 & 0,0900 \\
\hline Nova Granada & 0,0000 & 0,2000 & 0,4000 & 0,5000 & 0,2000 & 0,2600 \\
\hline Nova Guataporanga & 0,0000 & 0,2000 & 0,4000 & 0,2500 & 0,2000 & 0,2100 \\
\hline Nova Independência & 0,3333 & 0,2000 & 0,4000 & 0,2500 & 0,2000 & 0,2767 \\
\hline Nova Luzitânia & 0,0000 & 0,0000 & 0,4000 & 0,2500 & 0,2000 & 0,1700 \\
\hline Nova Odessa & 1,0000 & 0,8000 & 0,0000 & 0,7500 & 0,6000 & 0,6300 \\
\hline Novais & 0,0000 & 0,2000 & 0,2000 & 0,1250 & 0,2000 & 0,1450 \\
\hline Novo Horizonte & 0,0000 & 0,2000 & 1,0000 & 0,5000 & 0,2000 & 0,3800 \\
\hline Nuporanga & 0,0000 & 0,2000 & 0,2000 & 0,6250 & 0,0000 & 0,2050 \\
\hline Ocauçu & 0,0000 & 0,2000 & 0,6000 & 0,3750 & 0,0000 & 0,2350 \\
\hline Óleo & 0,0000 & 0,0000 & 0,8000 & 0,1250 & 0,0000 & 0,1850 \\
\hline Olímpia & 0,6667 & 0,8000 & 0,4000 & 1,0000 & 0,4000 & 0,6533 \\
\hline Onda Verde & 0,0000 & 0,2000 & 0,4000 & 0,0000 & 0,0000 & 0,1200 \\
\hline Oriente & 0,0000 & 0,2000 & 1,0000 & 0,2500 & 0,2000 & 0,3300 \\
\hline Orindiúva & 0,0000 & 0,2000 & 0,6000 & 0,2500 & 0,0000 & 0,2100 \\
\hline Orlândia & 0,3333 & 0,6000 & 0,4000 & 0,6250 & 0,4000 & 0,4717 \\
\hline Osasco & 1,0000 & 1,0000 & 0,6000 & 0,3750 & 0,4000 & 0,6750 \\
\hline Oscar Bressane & 1,0000 & 0,2000 & 1,0000 & 0,2500 & 0,2000 & 0,5300 \\
\hline Osvaldo Cruz & 1,0000 & 0,6000 & 0,4000 & 0,5000 & 0,4000 & 0,5800 \\
\hline Ourinhos & 0,0000 & 0,6000 & 0,8000 & 0,2500 & 0,6000 & 0,4500 \\
\hline Ouro Verde & 0,3333 & 0,0000 & 0,6000 & 0,2500 & 0,2000 & 0,2767 \\
\hline Ouroeste & 0,3333 & 0,2000 & 0,4000 & 0,3750 & 0,0000 & 0,2617 \\
\hline Pacaembu & 0,0000 & 0,2000 & 0,6000 & 0,2500 & 0,2000 & 0,2500 \\
\hline
\end{tabular}




\begin{tabular}{|c|c|c|c|c|c|c|}
\hline $\begin{array}{l}\text { Dimensão } \\
\text { Municípios }\end{array}$ & Habitação & $\begin{array}{l}\text { Mobilidade } \\
\text { Urbana }\end{array}$ & $\begin{array}{l}\text { Agricultura } \\
\text { Sustentável }\end{array}$ & $\begin{array}{c}\text { Gestão } \\
\text { Ambiental }\end{array}$ & $\begin{array}{l}\text { Gestão de } \\
\text { Risco }\end{array}$ & $\begin{array}{l}\text { UAI Municípios } \\
\text { Paulistas }\end{array}$ \\
\hline Palestina & 0,0000 & 0,2000 & 0,4000 & 0,1250 & 0,2000 & 0,1850 \\
\hline Palmares Paulista & 0,0000 & 0,2000 & 0,0000 & 0,5000 & 0,2000 & 0,1800 \\
\hline Palmeira dOeste & 0,0000 & 0,2000 & 0,2000 & 0,3750 & 0,0000 & 0,1550 \\
\hline Palmital & 0,6667 & 0,2000 & 0,4000 & 0,5000 & 0,2000 & 0,3933 \\
\hline Panorama & 0,0000 & 0,0000 & 0,4000 & 0,3750 & 0,2000 & 0,1950 \\
\hline Paraguaçu Paulista & 0,0000 & 0,6000 & 0,4000 & 0,6250 & 0,2000 & 0,3650 \\
\hline Paraibuna & 0,0000 & 0,6000 & 0,6000 & 0,5000 & 0,4000 & 0,4200 \\
\hline Paraíso & 0,0000 & 0,2000 & 0,2000 & 0,3750 & 0,2000 & 0,1950 \\
\hline Paranapanema & 0,3333 & 0,6000 & 0,6000 & 0,6250 & 0,0000 & 0,4317 \\
\hline Paranapuã & 0,6667 & 0,2000 & 0,2000 & 0,0000 & 0,0000 & 0,2133 \\
\hline Parapuã & 0,3333 & 0,2000 & 0,6000 & 0,1250 & 0,2000 & 0,2917 \\
\hline Pardinho & 0,0000 & 0,2000 & 0,6000 & 0,1250 & 0,2000 & 0,2250 \\
\hline Pariquera-Açu & 0,3333 & 0,4000 & 0,6000 & 0,6250 & 0,4000 & 0,4717 \\
\hline Parisi & 0,0000 & 0,0000 & 0,4000 & 0,6250 & 0,2000 & 0,2450 \\
\hline Patrocínio Paulista & 1,0000 & 0,4000 & 1,0000 & 0,6250 & 0,4000 & 0,6850 \\
\hline Paulicéia & 0,6667 & 0,2000 & 0,8000 & 0,3750 & 0,2000 & 0,4483 \\
\hline Paulínia & 0,6667 & 0,4000 & 0,0000 & 0,5000 & 0,6000 & 0,4333 \\
\hline Paulistânia & 0,6667 & 0,2000 & 0,2000 & 0,6250 & 0,4000 & 0,4183 \\
\hline Paulo de Faria & 0,6667 & 0,2000 & 0,2000 & 0,8750 & 0,0000 & 0,3883 \\
\hline Pederneiras & 1,0000 & 0,4000 & 0,0000 & 0,3750 & 0,6000 & 0,4750 \\
\hline Pedra Bela & 0,3333 & 0,2000 & 0,0000 & 0,2500 & 0,0000 & 0,1567 \\
\hline Pedranópolis & 0,0000 & 0,0000 & 0,6000 & 0,1250 & 0,2000 & 0,1850 \\
\hline Pedregulho & 0,3333 & 0,4000 & 1,0000 & 0,1250 & 0,2000 & 0,4117 \\
\hline Pedreira & 1,0000 & 0,6000 & 0,4000 & 0,2500 & 0,2000 & 0,4900 \\
\hline Pedrinhas Paulista & 0,6667 & 0,2000 & 0,4000 & 0,5000 & 0,2000 & 0,3933 \\
\hline
\end{tabular}




\begin{tabular}{|c|c|c|c|c|c|c|}
\hline Municípios Dimensão & Habitação & $\begin{array}{c}\text { Mobilidade } \\
\text { Urbana }\end{array}$ & $\begin{array}{c}\text { Agricultura } \\
\text { Sustentável }\end{array}$ & $\begin{array}{c}\text { Gestão } \\
\text { Ambiental }\end{array}$ & $\begin{array}{c}\text { Gestão de } \\
\text { Risco }\end{array}$ & $\begin{array}{c}\text { UAl Municípios } \\
\text { Paulistas }\end{array}$ \\
\hline Pedro de Toledo & 0,3333 & 0,0000 & 0,6000 & 0,3750 & 0,4000 & 0,3417 \\
\hline Penápolis & 1,0000 & 0,6000 & 1,0000 & 0,7500 & 0,6000 & 0,7900 \\
\hline Pereira Barreto & 1,0000 & 0,6000 & 0,2000 & 0,3750 & 0,4000 & 0,5150 \\
\hline Pereiras & 0,0000 & 0,2000 & 0,4000 & 0,3750 & 0,4000 & 0,2750 \\
\hline Peruíbe & 1,0000 & 0,8000 & 0,2000 & 0,1250 & 0,2000 & 0,4650 \\
\hline Piacatu & 0,0000 & 0,2000 & 0,4000 & 0,3750 & 0,2000 & 0,2350 \\
\hline Piedade & 0,3333 & 0,4000 & 0,8000 & 0,3750 & 0,6000 & 0,5017 \\
\hline Pilar do Sul & 0,0000 & 0,4000 & 0,4000 & 0,3750 & 0,2000 & 0,2750 \\
\hline Pindamonhangaba & 0,6667 & 0,8000 & 0,6000 & 0,5000 & 0,6000 & 0,6333 \\
\hline Pindorama & 0,3333 & 0,2000 & 0,0000 & 0,2500 & 0,2000 & 0,1967 \\
\hline Pinhalzinho & 0,0000 & 0,2000 & 0,0000 & 0,2500 & 0,2000 & 0,1300 \\
\hline Piquerobi & 0,0000 & 0,2000 & 0,4000 & 0,2500 & 0,2000 & 0,2100 \\
\hline Piquete & 0,0000 & 0,6000 & 0,2000 & 0,3750 & 0,4000 & 0,3150 \\
\hline Piracaia & 0,0000 & 0,4000 & 0,8000 & 0,5000 & 0,4000 & 0,4200 \\
\hline Piracicaba & 1,0000 & 0,8000 & 1,0000 & 0,8750 & 0,4000 & 0,8150 \\
\hline Piraju & 0,6667 & 0,4000 & 0,2000 & 0,0000 & 0,2000 & 0,2933 \\
\hline Pirajuí & 1,0000 & 0,4000 & 0,2000 & 0,5000 & 0,2000 & 0,4600 \\
\hline Pirangi & 0,0000 & 0,2000 & 0,8000 & 0,6250 & 0,2000 & 0,3650 \\
\hline Pirapora do Bom Jesus & 0,0000 & 0,2000 & 0,0000 & 0,0000 & 0,0000 & 0,0400 \\
\hline Pirapozinho & 1,0000 & 0,4000 & 0,2000 & 0,3750 & 0,2000 & 0,4350 \\
\hline Pirassununga & 0,0000 & 0,6000 & 0,4000 & 0,7500 & 0,2000 & 0,3900 \\
\hline Piratininga & 0,3333 & 0,4000 & 0,2000 & 0,7500 & 0,2000 & 0,3767 \\
\hline Pitangueiras & 1,0000 & 0,4000 & 0,2000 & 0,6250 & 0,4000 & 0,5250 \\
\hline Planalto & 0,6667 & 0,0000 & 0,6000 & 0,2500 & 0,0000 & 0,3033 \\
\hline Platina & 0,0000 & 0,2000 & 0,4000 & 0,2500 & 0,2000 & 0,2100 \\
\hline & & & & & \\
\hline
\end{tabular}




\begin{tabular}{|c|c|c|c|c|c|c|}
\hline $\begin{array}{ll}\text { Municípios } & \text { Dimensão } \\
\end{array}$ & Habitação & $\begin{array}{c}\text { Mobilidade } \\
\text { Urbana }\end{array}$ & $\begin{array}{l}\text { Agricultura } \\
\text { Sustentável }\end{array}$ & $\begin{array}{c}\text { Gestão } \\
\text { Ambiental }\end{array}$ & $\begin{array}{l}\text { Gestão de } \\
\text { Risco }\end{array}$ & $\begin{array}{l}\text { UAI Municípios } \\
\text { Paulistas }\end{array}$ \\
\hline Poá & 1,0000 & 0,8000 & 0,0000 & 0,6250 & 0,6000 & 0,6050 \\
\hline Poloni & 0,3333 & 0,2000 & 0,2000 & 0,0000 & 0,4000 & 0,2267 \\
\hline Pompéia & 0,0000 & 0,8000 & 0,0000 & 0,5000 & 0,2000 & 0,3000 \\
\hline Pongaí & 0,0000 & 0,2000 & 0,2000 & 0,2500 & 0,2000 & 0,1700 \\
\hline Pontal & 0,0000 & 0,8000 & 0,0000 & 0,2500 & 0,0000 & 0,2100 \\
\hline Pontalinda & 0,0000 & 0,2000 & 1,0000 & 0,3750 & 0,2000 & 0,3550 \\
\hline Pontes Gestal & 0,0000 & 0,4000 & 0,0000 & 0,2500 & 0,0000 & 0,1300 \\
\hline Populina & 1,0000 & 0,4000 & 0,6000 & 0,2500 & 0,2000 & 0,4900 \\
\hline Porangaba & 0,0000 & 0,2000 & 0,6000 & 0,3750 & 0,2000 & 0,2750 \\
\hline Porto Feliz & 1,0000 & 0,6000 & 0,8000 & 0,6250 & 0,4000 & 0,6850 \\
\hline Porto Ferreira & 1,0000 & 0,6000 & 0,2000 & 0,5000 & 0,4000 & 0,5400 \\
\hline Potim & 1,0000 & 0,2000 & 0,2000 & 0,1250 & 0,4000 & 0,3850 \\
\hline Potirendaba & 0,0000 & 0,4000 & 0,8000 & 0,3750 & 0,2000 & 0,3550 \\
\hline Pracinha & 0,0000 & 0,4000 & 0,4000 & 0,0000 & 0,0000 & 0,1600 \\
\hline Pradópolis & 0,0000 & 0,4000 & 0,8000 & 0,7500 & 0,2000 & 0,4300 \\
\hline Praia Grande & 1,0000 & 0,8000 & 0,0000 & 0,5000 & 0,6000 & 0,5800 \\
\hline Pratânia & 0,3333 & 0,2000 & 0,4000 & 0,1250 & 0,4000 & 0,2917 \\
\hline Presidente Alves & 0,0000 & 0,2000 & 0,6000 & 0,5000 & 0,2000 & 0,3000 \\
\hline Presidente Bernardes & 0,0000 & 0,4000 & 0,6000 & 0,1250 & 0,2000 & 0,2650 \\
\hline Presidente Epitácio & 1,0000 & 1,0000 & 0,4000 & 0,8750 & 0,2000 & 0,6950 \\
\hline Presidente Prudente & 1,0000 & 0,8000 & 0,8000 & 0,5000 & 0,6000 & 0,7400 \\
\hline Presidente Venceslau & 1,0000 & 0,6000 & 0,6000 & 0,5000 & 0,6000 & 0,6600 \\
\hline Promissão & 0,0000 & 0,2000 & 0,6000 & 0,7500 & 0,2000 & 0,3500 \\
\hline Quadra & 0,6667 & 0,2000 & 0,2000 & 0,6250 & 0,4000 & 0,4183 \\
\hline Quatá & 0,0000 & 0,2000 & 0,4000 & 0,1250 & 0,2000 & 0,1850 \\
\hline
\end{tabular}




\begin{tabular}{|c|c|c|c|c|c|c|}
\hline $\begin{array}{l}\text { Dimensão } \\
\text { Municípios }\end{array}$ & Habitação & $\begin{array}{l}\text { Mobilidade } \\
\text { Urbana }\end{array}$ & $\begin{array}{l}\text { Agricultura } \\
\text { Sustentável }\end{array}$ & $\begin{array}{c}\text { Gestão } \\
\text { Ambiental }\end{array}$ & $\begin{array}{l}\text { Gestão de } \\
\text { Risco }\end{array}$ & $\begin{array}{l}\text { UAI Municípios } \\
\text { Paulistas }\end{array}$ \\
\hline Queiroz & 0,0000 & 0,4000 & 0,2000 & 0,5000 & 0,0000 & 0,2200 \\
\hline Queluz & 0,0000 & 0,2000 & 0,4000 & 0,2500 & 0,2000 & 0,2100 \\
\hline Quintana & 0,6667 & 0,4000 & 0,4000 & 0,2500 & 0,2000 & 0,3833 \\
\hline Rafard & 0,0000 & 0,4000 & 0,8000 & 0,3750 & 0,2000 & 0,3550 \\
\hline Rancharia & 0,3333 & 0,2000 & 0,4000 & 0,3750 & 0,2000 & 0,3017 \\
\hline Redenção da Serra & 0,0000 & 0,2000 & 1,0000 & 0,2500 & 0,2000 & 0,3300 \\
\hline Regente Feijó & 0,0000 & 0,4000 & 0,8000 & 0,3750 & 0,2000 & 0,3550 \\
\hline Reginópolis & 0,3333 & 0,2000 & 0,8000 & 0,1250 & 0,2000 & 0,3317 \\
\hline Registro & 0,3333 & 0,8000 & 0,8000 & 0,3750 & 0,8000 & 0,6217 \\
\hline Restinga & 0,0000 & 0,2000 & 0,4000 & 0,8750 & 0,0000 & 0,2950 \\
\hline Ribeira & 0,0000 & 0,0000 & 0,6000 & 0,1250 & 0,2000 & 0,1850 \\
\hline Ribeirão Bonito & 0,0000 & 0,4000 & 0,4000 & 0,0000 & 0,0000 & 0,1600 \\
\hline Ribeirão Branco & 0,0000 & 0,4000 & 0,2000 & 0,0000 & 0,2000 & 0,1600 \\
\hline Ribeirão Corrente & 0,6667 & 0,2000 & 0,2000 & 0,1250 & 0,2000 & 0,2783 \\
\hline Ribeirão do Sul & 0,3333 & 0,2000 & 0,4000 & 0,0000 & 0,0000 & 0,1867 \\
\hline Ribeirão dos Índios & 0,0000 & 0,0000 & 0,2000 & 0,1250 & 0,2000 & 0,1050 \\
\hline Ribeirão Grande & 1,0000 & 0,2000 & 0,8000 & 0,3750 & 0,2000 & 0,5150 \\
\hline Ribeirão Pires & 0,6667 & 0,4000 & 0,2000 & 0,7500 & 0,8000 & 0,5633 \\
\hline Ribeirão Preto & 1,0000 & 0,8000 & 0,4000 & 0,6250 & 0,6000 & 0,6850 \\
\hline Rifaina & 0,6667 & 0,2000 & 0,4000 & 0,5000 & 0,2000 & 0,3933 \\
\hline Rincão & 0,0000 & 0,2000 & 0,0000 & 0,1250 & 0,2000 & 0,1050 \\
\hline Rinópolis & 0,0000 & 0,2000 & 0,4000 & 0,5000 & 0,2000 & 0,2600 \\
\hline Rio Claro & 0,6667 & 0,8000 & 0,8000 & 0,1250 & 1,0000 & 0,6783 \\
\hline Rio das Pedras & 0,3333 & 0,6000 & 0,4000 & 0,5000 & 0,4000 & 0,4467 \\
\hline Rio Grande da Serra & 0,0000 & 0,8000 & 0,0000 & 0,3750 & 0,2000 & 0,2750 \\
\hline
\end{tabular}




\begin{tabular}{|c|c|c|c|c|c|c|}
\hline $\begin{array}{l}\text { Dimensão } \\
\text { Municípios }\end{array}$ & Habitação & $\begin{array}{c}\text { Mobilidade } \\
\text { Urbana }\end{array}$ & $\begin{array}{l}\text { Agricultura } \\
\text { Sustentável }\end{array}$ & $\begin{array}{c}\text { Gestão } \\
\text { Ambiental }\end{array}$ & $\begin{array}{l}\text { Gestão de } \\
\text { Risco }\end{array}$ & $\begin{array}{c}\text { UAI Municípios } \\
\text { Paulistas }\end{array}$ \\
\hline Riolândia & 0,6667 & 0,4000 & 0,0000 & 0,1250 & 0,2000 & 0,2783 \\
\hline Riversul & 0,0000 & 0,2000 & 0,4000 & 0,8750 & 0,2000 & 0,3350 \\
\hline Rosana & 1,0000 & 0,2000 & 0,6000 & 0,5000 & 0,2000 & 0,5000 \\
\hline Roseira & 1,0000 & 0,4000 & 0,0000 & 0,0000 & 0,0000 & 0,2800 \\
\hline Rubiácea & 0,3333 & 0,0000 & 0,6000 & 0,2500 & 0,2000 & 0,2767 \\
\hline Rubinéia & 0,0000 & 0,2000 & 1,0000 & 0,1250 & 0,6000 & 0,3850 \\
\hline Sabino & 0,0000 & 0,2000 & 0,2000 & 0,0000 & 0,0000 & 0,0800 \\
\hline Sagres & 0,0000 & 0,4000 & 0,2000 & 0,3750 & 0,4000 & 0,2750 \\
\hline Sales & 0,0000 & 0,0000 & 0,6000 & 0,6250 & 0,0000 & 0,2450 \\
\hline Sales Oliveira & 0,0000 & 0,0000 & 0,0000 & 0,1250 & 0,0000 & 0,0250 \\
\hline Salesópolis & 0,0000 & 0,2000 & 0,0000 & 0,5000 & 0,2000 & 0,1800 \\
\hline Salmourão & 0,0000 & 0,2000 & 0,2000 & 0,0000 & 0,2000 & 0,1200 \\
\hline Saltinho & 0,3333 & 0,2000 & 0,2000 & 0,3750 & 0,4000 & 0,3017 \\
\hline Salto & 1,0000 & 0,8000 & 0,6000 & 0,5000 & 0,4000 & 0,6600 \\
\hline Salto de Pirapora & 0,0000 & 0,8000 & 0,6000 & 0,5000 & 0,2000 & 0,4200 \\
\hline Salto Grande & 0,0000 & 0,4000 & 0,6000 & 0,3750 & 0,6000 & 0,3950 \\
\hline Sandovalina & 0,0000 & 0,2000 & 0,8000 & 0,2500 & 0,2000 & 0,2900 \\
\hline Santa Adélia & 0,6667 & 0,2000 & 0,0000 & 0,8750 & 0,2000 & 0,3883 \\
\hline Santa Albertina & 0,3333 & 0,0000 & 0,2000 & 0,2500 & 0,0000 & 0,1567 \\
\hline Santa Bárbara dOeste & 1,0000 & 1,0000 & 0,8000 & 0,5000 & 0,8000 & 0,8200 \\
\hline Santa Branca & 0,6667 & 0,4000 & 0,0000 & 0,2500 & 0,2000 & 0,3033 \\
\hline Santa Clara dOeste & 0,0000 & 0,6000 & 1,0000 & 0,5000 & 0,6000 & 0,5400 \\
\hline Santa Cruz da Conceição & 0,0000 & 0,6000 & 0,2000 & 0,5000 & 0,4000 & 0,3400 \\
\hline Santa Cruz da Esperança & 1,0000 & 0,2000 & 0,8000 & 0,7500 & 0,2000 & 0,5900 \\
\hline Santa Cruz das Palmeiras & 0,3333 & 0,4000 & 0,4000 & 0,5000 & 0,2000 & 0,3667 \\
\hline
\end{tabular}




\begin{tabular}{|c|c|c|c|c|c|c|}
\hline $\begin{array}{l}\text { Dimensão } \\
\text { Municípios }\end{array}$ & Habitação & $\begin{array}{c}\text { Mobilidade } \\
\text { Urbana }\end{array}$ & $\begin{array}{l}\text { Agricultura } \\
\text { Sustentável }\end{array}$ & $\begin{array}{l}\text { Gestão } \\
\text { Ambiental }\end{array}$ & $\begin{array}{l}\text { Gestão de } \\
\text { Risco }\end{array}$ & $\begin{array}{c}\text { UAI Municípios } \\
\text { Paulistas }\end{array}$ \\
\hline Santa Cruz do Rio Pardo & 1,0000 & 0,6000 & 0,8000 & 1,0000 & 0,2000 & 0,7200 \\
\hline Santa Ernestina & 0,6667 & 0,2000 & 0,0000 & 0,5000 & 0,2000 & 0,3133 \\
\hline Santa Fé do Sul & 1,0000 & 0,8000 & 1,0000 & 0,5000 & 0,0000 & 0,6600 \\
\hline Santa Gertrudes & 0,3333 & 0,4000 & 0,0000 & 0,6250 & 0,2000 & 0,3117 \\
\hline Santa Isabel & 0,6667 & 0,4000 & 0,8000 & 1,0000 & 0,6000 & 0,6933 \\
\hline Santa Lúcia & 0,0000 & 0,4000 & 0,2000 & 0,5000 & 0,4000 & 0,3000 \\
\hline Santa Maria da Serra & 0,6667 & 0,2000 & 0,2000 & 0,2500 & 0,6000 & 0,3833 \\
\hline Santa Mercedes & 0,6667 & 0,2000 & 0,4000 & 0,2500 & 0,2000 & 0,3433 \\
\hline Santa Rita do Passa Quatro & 0,6667 & 0,6000 & 0,4000 & 0,6250 & 0,6000 & 0,5783 \\
\hline Santa Rita dOeste & 0,0000 & 0,4000 & 0,6000 & 0,2500 & 0,2000 & 0,2900 \\
\hline Santa Rosa de Viterbo & 0,6667 & 0,6000 & 0,6000 & 0,6250 & 0,2000 & 0,5383 \\
\hline Santa Salete & 0,0000 & 0,2000 & 0,4000 & 0,3750 & 0,0000 & 0,1950 \\
\hline Santana da Ponte Pensa & 0,0000 & 0,0000 & 0,2000 & 0,1250 & 0,0000 & 0,0650 \\
\hline Santana de Parnaíba & 1,0000 & 0,4000 & 0,0000 & 0,7500 & 0,8000 & 0,5900 \\
\hline Santo Anastácio & 1,0000 & 0,4000 & 0,8000 & 0,3750 & 0,2000 & 0,5550 \\
\hline Santo André & 0,6667 & 1,0000 & 0,6000 & 0,5000 & 1,0000 & 0,7533 \\
\hline Santo Antônio da Alegria & 0,3333 & 0,2000 & 0,8000 & 0,3750 & 0,2000 & 0,3817 \\
\hline Santo Antônio de Posse & 1,0000 & 0,2000 & 0,6000 & 0,2500 & 0,2000 & 0,4500 \\
\hline Santo Antônio do Aracanguá & 0,0000 & 0,4000 & 0,2000 & 0,2500 & 0,0000 & 0,1700 \\
\hline Santo Antônio do Jardim & 0,0000 & 0,0000 & 0,4000 & 0,3750 & 0,2000 & 0,1950 \\
\hline Santo Antônio do Pinhal & 0,0000 & 0,4000 & 0,6000 & 0,2500 & 0,2000 & 0,2900 \\
\hline Santo Expedito & 0,0000 & 0,2000 & 0,6000 & 0,5000 & 0,0000 & 0,2600 \\
\hline Santópolis do Aguapeí & 0,0000 & 0,2000 & 0,2000 & 0,2500 & 0,0000 & 0,1300 \\
\hline Santos & 1,0000 & 0,6000 & 0,4000 & 0,8750 & 1,0000 & 0,7750 \\
\hline São Bento do Sapucaí & 0,3333 & 0,6000 & 0,4000 & 0,8750 & 0,2000 & 0,4817 \\
\hline
\end{tabular}




\begin{tabular}{|c|c|c|c|c|c|c|}
\hline $\begin{array}{ll} & \text { Dimensão } \\
\text { Municípios }\end{array}$ & Habitação & $\begin{array}{c}\text { Mobilidade } \\
\text { Urbana }\end{array}$ & $\begin{array}{l}\text { Agricultura } \\
\text { Sustentável }\end{array}$ & $\begin{array}{c}\text { Gestão } \\
\text { Ambiental }\end{array}$ & $\begin{array}{l}\text { Gestão de } \\
\text { Risco }\end{array}$ & $\begin{array}{l}\text { UAI Municípios } \\
\text { Paulistas }\end{array}$ \\
\hline São Bernardo do Campo & 1,0000 & 0,8000 & 0,2000 & 0,6250 & 1,0000 & 0,7250 \\
\hline São Caetano do Sul & 0,3333 & 0,8000 & 0,0000 & 0,7500 & 0,4000 & 0,4567 \\
\hline São Carlos & 0,6667 & 0,6000 & 0,8000 & 0,5000 & 0,6000 & 0,6333 \\
\hline São Francisco & 0,0000 & 0,4000 & 0,0000 & 0,0000 & 0,2000 & 0,1200 \\
\hline São João da Boa Vista & 1,0000 & 0,4000 & 0,4000 & 0,7500 & 0,4000 & 0,5900 \\
\hline São João das Duas Pontes & 0,0000 & 0,0000 & 0,2000 & 0,1250 & 0,0000 & 0,0650 \\
\hline São João de Iracema & 0,6667 & 0,2000 & 0,2000 & 0,3750 & 0,2000 & 0,3283 \\
\hline São João do Pau dAlho & 0,0000 & 0,0000 & 0,4000 & 0,2500 & 0,2000 & 0,1700 \\
\hline São Joaquim da Barra & 0,0000 & 0,4000 & 0,0000 & 0,3750 & 0,4000 & 0,2350 \\
\hline São José da Bela Vista & 0,0000 & 0,2000 & 0,0000 & 0,2500 & 0,0000 & 0,0900 \\
\hline São José do Barreiro & 0,0000 & 0,0000 & 0,0000 & 0,0000 & 0,2000 & 0,0400 \\
\hline São José do Rio Pardo & 0,3333 & 0,4000 & 0,8000 & 0,1250 & 0,2000 & 0,3717 \\
\hline São José do Rio Preto & 1,0000 & 0,8000 & 0,6000 & 0,6250 & 1,0000 & 0,8050 \\
\hline São José dos Campos & 1,0000 & 0,8000 & 0,4000 & 0,6250 & 0,8000 & 0,7250 \\
\hline São Lourenço da Serra & 0,0000 & 0,4000 & 0,8000 & 0,1250 & 0,6000 & 0,3850 \\
\hline São Luís do Paraitinga & 0,6667 & 0,2000 & 0,4000 & 0,2500 & 0,2000 & 0,3433 \\
\hline São Manuel & 0,0000 & 0,4000 & 0,0000 & 0,3750 & 0,0000 & 0,1550 \\
\hline São Miguel Arcanjo & 0,0000 & 0,4000 & 0,8000 & 0,2500 & 0,2000 & 0,3300 \\
\hline São Paulo & 0,6667 & 1,0000 & 0,8000 & 0,8750 & 0,8000 & 0,8283 \\
\hline São Pedro & 0,3333 & 0,4000 & 0,2000 & 0,5000 & 0,2000 & 0,3267 \\
\hline São Pedro do Turvo & 0,0000 & 0,2000 & 0,4000 & 0,2500 & 0,4000 & 0,2500 \\
\hline São Roque & 0,3333 & 0,4000 & 0,8000 & 0,2500 & 0,2000 & 0,3967 \\
\hline São Sebastião & 0,6667 & 0,6000 & 0,4000 & 0,5000 & 0,4000 & 0,5133 \\
\hline São Sebastião da Grama & 0,0000 & 0,2000 & 0,6000 & 0,5000 & 0,2000 & 0,3000 \\
\hline São Simão & 0,0000 & 0,4000 & 0,0000 & 0,3750 & 0,2000 & 0,1950 \\
\hline
\end{tabular}




\begin{tabular}{|c|c|c|c|c|c|c|}
\hline $\begin{array}{l}\text { Dimensão } \\
\text { Municípios }\end{array}$ & Habitação & $\begin{array}{c}\text { Mobilidade } \\
\text { Urbana }\end{array}$ & $\begin{array}{l}\text { Agricultura } \\
\text { Sustentável }\end{array}$ & $\begin{array}{c}\text { Gestão } \\
\text { Ambiental }\end{array}$ & $\begin{array}{l}\text { Gestão de } \\
\text { Risco }\end{array}$ & $\begin{array}{c}\text { UAI Municípios } \\
\text { Paulistas }\end{array}$ \\
\hline São Vicente & 1,0000 & 0,8000 & 0,2000 & 0,3750 & 0,6000 & 0,5950 \\
\hline Sarapuí & 0,0000 & 0,4000 & 0,4000 & 0,2500 & 0,2000 & 0,2500 \\
\hline Sarutaiá & 0,0000 & 0,2000 & 0,4000 & 0,2500 & 0,2000 & 0,2100 \\
\hline Sebastianópolis do Sul & 0,6667 & 0,2000 & 0,2000 & 0,3750 & 0,0000 & 0,2883 \\
\hline Serra Azul & 0,0000 & 0,4000 & 0,4000 & 0,2500 & 0,2000 & 0,2500 \\
\hline Serra Negra & 0,0000 & 0,4000 & 0,2000 & 0,3750 & 0,4000 & 0,2750 \\
\hline Serrana & 0,0000 & 0,2000 & 0,4000 & 0,1250 & 0,2000 & 0,1850 \\
\hline Sertãozinho & 0,6667 & 0,8000 & 0,0000 & 0,7500 & 0,4000 & 0,5233 \\
\hline Sete Barras & 0,0000 & 0,2000 & 0,6000 & 0,1250 & 0,4000 & 0,2650 \\
\hline Severínia & 0,0000 & 0,2000 & 0,4000 & 0,2500 & 0,0000 & 0,1700 \\
\hline Silveiras & 0,0000 & 0,2000 & 1,0000 & 0,0000 & 0,2000 & 0,2800 \\
\hline Socorro & 0,6667 & 0,8000 & 0,8000 & 0,7500 & 0,2000 & 0,6433 \\
\hline Sorocaba & 0,6667 & 1,0000 & 0,8000 & 0,8750 & 0,4000 & 0,7483 \\
\hline Sud Mennucci & 0,3333 & 0,6000 & 0,4000 & 0,8750 & 0,2000 & 0,4817 \\
\hline Sumaré & 1,0000 & 0,8000 & 0,6000 & 0,2500 & 0,4000 & 0,6100 \\
\hline Suzanápolis & 0,0000 & 0,2000 & 0,4000 & 0,2500 & 0,0000 & 0,1700 \\
\hline Suzano & 0,6667 & 0,6000 & 0,8000 & 0,5000 & 0,2000 & 0,5533 \\
\hline Tabapuã & 0,0000 & 0,2000 & 0,4000 & 0,6250 & 0,2000 & 0,2850 \\
\hline Tabatinga & 0,3333 & 0,2000 & 0,4000 & 0,1250 & 0,6000 & 0,3317 \\
\hline Taboão da Serra & 1,0000 & 0,8000 & 0,0000 & 0,6250 & 1,0000 & 0,6850 \\
\hline Taciba & 0,0000 & 0,2000 & 0,4000 & 0,5000 & 0,0000 & 0,2200 \\
\hline Taguaí & 0,0000 & 0,2000 & 1,0000 & 0,1250 & 0,0000 & 0,2650 \\
\hline Taiaçu & 0,3333 & 0,2000 & 0,0000 & 0,2500 & 0,0000 & 0,1567 \\
\hline Taiúva & 0,0000 & 0,2000 & 0,8000 & 0,2500 & 0,2000 & 0,2900 \\
\hline Tambaú & 0,3333 & 0,4000 & 0,4000 & 0,3750 & 0,2000 & 0,3417 \\
\hline
\end{tabular}




\begin{tabular}{|c|c|c|c|c|c|c|}
\hline Dimensão & Habitação & $\begin{array}{c}\text { Mobilidade } \\
\text { Urbana }\end{array}$ & $\begin{array}{c}\text { Agricultura } \\
\text { Sustentável }\end{array}$ & $\begin{array}{c}\text { Gestão } \\
\text { Ambiental }\end{array}$ & $\begin{array}{c}\text { Gestão de } \\
\text { Risco }\end{array}$ & $\begin{array}{c}\text { UAl Municípios } \\
\text { Paulistas }\end{array}$ \\
\hline Tanabi & 0,0000 & 0,6000 & 0,2000 & 0,5000 & 0,2000 & 0,3000 \\
\hline Tapiraí & 0,0000 & 0,4000 & 0,4000 & 0,2500 & 0,2000 & 0,2500 \\
\hline Tapiratiba & 1,0000 & 0,4000 & 0,0000 & 0,2500 & 0,2000 & 0,3700 \\
\hline Taquaral & 0,3333 & 0,2000 & 0,0000 & 0,2500 & 0,0000 & 0,1567 \\
\hline Taquaritinga & 0,3333 & 0,6000 & 0,4000 & 0,3750 & 0,2000 & 0,3817 \\
\hline Taquarituba & 1,0000 & 0,6000 & 0,6000 & 0,6250 & 0,2000 & 0,6050 \\
\hline Taquarivaí & 0,0000 & 0,2000 & 0,4000 & 0,7500 & 0,0000 & 0,2700 \\
\hline Tarabai & 0,0000 & 0,2000 & 0,6000 & 0,3750 & 0,2000 & 0,2750 \\
\hline Tarumã & 1,0000 & 0,2000 & 0,4000 & 0,5000 & 0,2000 & 0,4600 \\
\hline Tatuín & 1,0000 & 0,6000 & 1,0000 & 0,6250 & 0,8000 & 0,8050 \\
\hline Taubaté & 1,0000 & 0,8000 & 0,4000 & 0,5000 & 0,2000 & 0,5800 \\
\hline Tejupá & 0,0000 & 0,2000 & 0,4000 & 0,1250 & 0,2000 & 0,1850 \\
\hline Teodoro Sampaio & 1,0000 & 0,4000 & 0,4000 & 0,7500 & 0,4000 & 0,5900 \\
\hline Terra Roxa & 0,3333 & 0,4000 & 0,0000 & 0,1250 & 0,2000 & 0,2117 \\
\hline Tietê & 1,0000 & 0,6000 & 0,4000 & 0,3750 & 0,2000 & 0,5150 \\
\hline Timburi & 0,0000 & 0,2000 & 0,2000 & 0,1250 & 0,0000 & 0,1050 \\
\hline Torre de Pedra & 0,3333 & 0,0000 & 1,0000 & 0,3750 & 0,2000 & 0,3817 \\
\hline Torrinha & 0,0000 & 0,4000 & 0,4000 & 0,5000 & 0,0000 & 0,2600 \\
\hline Trabiju & 0,0000 & 0,4000 & 0,4000 & 0,0000 & 0,0000 & 0,1600 \\
\hline Tremembé & 0,0000 & 0,8000 & 0,4000 & 0,3750 & 0,4000 & 0,3950 \\
\hline Três Fronteiras & 0,0000 & 0,4000 & 0,6000 & 0,3750 & 0,2000 & 0,3150 \\
\hline Tuiuti & 0,0000 & 0,2000 & 0,4000 & 0,0000 & 0,0000 & 0,1200 \\
\hline Tupã & 0,6667 & 0,4000 & 1,0000 & 0,3750 & 0,2000 & 0,5283 \\
\hline Tupi Paulista & 0,0000 & 0,2000 & 0,4000 & 0,5000 & 0,2000 & 0,2600 \\
\hline Turiúba & 0,3333 & 0,0000 & 0,4000 & 0,2500 & 0,2000 & 0,2367 \\
\hline
\end{tabular}




\begin{tabular}{|c|c|c|c|c|c|c|}
\hline $\begin{array}{l}\text { Dimensão } \\
\text { Municípios }\end{array}$ & Habitação & $\begin{array}{c}\text { Mobilidade } \\
\text { Urbana }\end{array}$ & $\begin{array}{l}\text { Agricultura } \\
\text { Sustentável }\end{array}$ & $\begin{array}{c}\text { Gestão } \\
\text { Ambiental }\end{array}$ & $\begin{array}{l}\text { Gestão de } \\
\text { Risco }\end{array}$ & $\begin{array}{c}\text { UAl Municípios } \\
\text { Paulistas }\end{array}$ \\
\hline Turmalina & 0,6667 & 0,0000 & 0,2000 & 0,6250 & 0,2000 & 0,3383 \\
\hline Ubarana & 0,0000 & 0,2000 & 0,4000 & 0,3750 & 0,2000 & 0,2350 \\
\hline Ubatuba & 0,6667 & 0,8000 & 0,6000 & 0,6250 & 0,4000 & 0,6183 \\
\hline Ubirajara & 0,0000 & 0,0000 & 0,0000 & 0,2500 & 0,2000 & 0,0900 \\
\hline Uchoa & 0,0000 & 0,2000 & 1,0000 & 0,2500 & 0,0000 & 0,2900 \\
\hline União Paulista & 0,0000 & 0,2000 & 0,6000 & 0,1250 & 0,0000 & 0,1850 \\
\hline Urânia & 0,0000 & 0,2000 & 0,4000 & 0,0000 & 0,0000 & 0,1200 \\
\hline Uru & 0,0000 & 0,0000 & 0,4000 & 0,1250 & 0,2000 & 0,1450 \\
\hline Urupês & 0,0000 & 0,2000 & 0,6000 & 0,2500 & 0,4000 & 0,2900 \\
\hline Valentim Gentil & 0,3333 & 0,4000 & 0,4000 & 0,2500 & 0,4000 & 0,3567 \\
\hline Valinhos & 1,0000 & 0,6000 & 0,4000 & 0,3750 & 0,2000 & 0,5150 \\
\hline Valparaíso & 1,0000 & 0,2000 & 0,8000 & 0,5000 & 0,4000 & 0,5800 \\
\hline Vargem & 0,0000 & 0,4000 & 0,4000 & 0,1250 & 0,4000 & 0,2650 \\
\hline Vargem Grande do Sul & 0,0000 & 0,4000 & 0,2000 & 0,6250 & 0,2000 & 0,2850 \\
\hline Vargem Grande Paulista & 0,3333 & 0,4000 & 0,0000 & 0,3750 & 0,4000 & 0,3017 \\
\hline Várzea Paulista & 0,6667 & 0,6000 & 0,0000 & 0,5000 & 0,6000 & 0,4733 \\
\hline Vera Cruz & 0,0000 & 0,2000 & 0,2000 & 0,3750 & 0,4000 & 0,2350 \\
\hline Vinhedo & 1,0000 & 0,6000 & 0,4000 & 0,6250 & 0,8000 & 0,6850 \\
\hline Viradouro & 0,6667 & 0,6000 & 0,0000 & 0,2500 & 0,2000 & 0,3433 \\
\hline Vista Alegre do Alto & 0,0000 & 0,2000 & 0,2000 & 0,3750 & 0,2000 & 0,1950 \\
\hline Vitória Brasil & 0,0000 & 0,4000 & 0,2000 & 0,1250 & 0,0000 & 0,1450 \\
\hline Votorantim & 1,0000 & 0,6000 & 0,0000 & 0,7500 & 0,4000 & 0,5500 \\
\hline Votuporanga & 0,6667 & 0,8000 & 0,4000 & 0,5000 & 0,6000 & 0,5933 \\
\hline Zacarias & 0,3333 & 0,2000 & 0,0000 & 0,5000 & 0,6000 & 0,3267 \\
\hline
\end{tabular}

